\title{
NBSIR 76-1059
}

\section{Intermediate Minimum Property Standards for Solar Heating and Domestic Hot Water Systems}

Solar Energy Program

Office of Housing and Building Technology

Center for Building Technology, IAT

National Bureau of Standards

Washington, D. C. 20234

April 1976

Interim Report

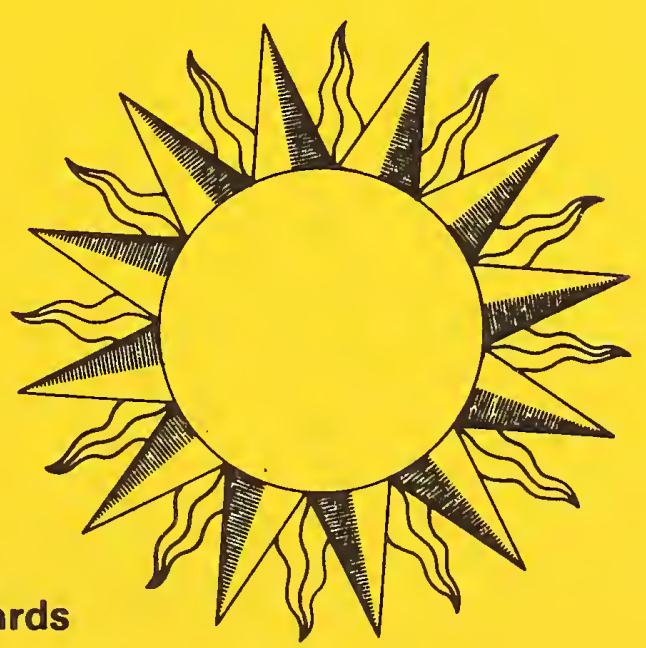

Prepared for

Department of Housing and Urban Development Office of Policy Development and Research Division of Energy, Building Technology and Standards Washington, D. C. 20410 



\section{INTERMEDIATE MINIMUM PROPERTY \\ STANDARDS FOR SOLAR HEATING AND \\ DOMESTIC HOT WATER SYSTEMS}

Solar Energy Program

Office of Housing and Building Technology

Center for Building Technology, IAT

National Bureau of Standards

Washington, D. C. 20234

April 1976

Interim Report

\section{Prepared for}

Department of Housing and Urban Development

Office of Policy Development and Research

Division of Energy, Building Technology and Standards

Washington, D. C. 20410

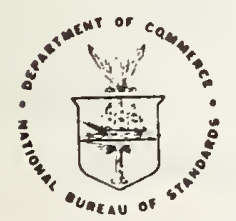

U.S. DEPARTMENT OF COMMERCE, Elliot L. Richardson, Secretery James A. Baker, III, Under Secrotary Dr. Betsy Ancker-Johnson, Assistant Secretary for Science and Technologn NATIONAL BUREAU OF STANDARDS, Emest Ambler, Acting Director 

The preparation of this interim document has been a joint effort of members of the Solar Energy Program Team at the National Bureau of Standards, Center for Building Technology. Team members include:

Office of Housing and Building Technology

Robert Dikkers

Dave Waksman

John Holton

Kenneth DeCorte

Thermal Engineering Section

Elmer Streed

James Hill

John Jenkins

Dennis Jones

Materials and Composite Section

Larry Masters

Leopold Skoda

Elizabeth Clark

Paul Brown

Building Services Section

Robert Beausoliel

Grover Sherlin.

Structures Section

William Greene

Architectural Research Section

Richard Crenshaw

Building Safety Section

Theresa Raper

Office of Building Standards and Codes Services

Robert Eisenhard

Bertram Vogel

Program for Fire Control - Construction (Center for Fire Research)

Edward Budnick

Typing, Editing and Preparation by

Mary Lou Miller

Linda Sacchet

Linda Armitage

Vicki Reider

Linda Covel]. 
Preparation of Appendix C, Illustrated Definitions, was done by the AIA Research Corporation

Invaluable critique and guidance has been given by:

Department of ilousing and Urian hevelopnient

Joseph Sherman

David Moore

W111iam Freeborne

Mervin Dizenfeld

Consultant Review Panel

W111iam Beckman

John Bowen

John Duffie

Mel Green

Michael Holtz

Alwin Newton, P.E.

Andrew Parker

Richard Rittelmann

Daniel Talbott

Gordon Tulley

Ed Wachter

Edgar Weisman
Professor, University of Wisconsin

Chairman, Standards Committee, Solar Energy Industries

Association (AMETEK Corporation)

Professor, University of Wisconsin

International Conference' of Building officials AIA Research Corporation

American Society of lieating, Refrigerating and

Air Conditioning Engineers

AIA Research Corporation

AIA, Burt, Hil1 \& Associates

National Association of Home Builders

AIA Research Corporation

International Conference of Building offictals

Falcon Construction Co., Inc. 
The "Minimum Property Standards for One and Two Family Dwellings" 4900 and the "Minimum Property Standards for Multifamily Housing" 4910 have been set out to provide a sound technical basis for the planning and design of housing under numerous programs of the Department of Housing and Urban Development (HUD). These "Intermediate Minimum Property Standards for Solar Heating and Domestic Hot Water Systems" are intended to provide a companion technical basis for the planning and design of solar heating and domestic hot water systems.

These standards have been prepared as a supplement to the MPS and consider only aspects of planning and design that are different from conventional housing by reason of the solar systems under consideration. To the greatest extent possible, they are based on current state-of-the art practice and on nationally recognized standards including the MPS and the HUD "Interim Performance Criteria for Solar Heating and Combined Heating/ Cooling Systems and Dwellings".

This document considers requirements and standards applicable tc :oth one and two family dwellings and multifamily housing and references made in the text to the MPS refer to the same section in both the "Minimum Property Standards for Dne and Two Family Dwellings" 4900.1 and the "Minimum Property Standard for Multifamily Housing" 4910.1 unless otherwise noted.

In general, the Chapters and Divisions in this document are organized to parallel the Chapters and Divisions contained in the MPS. Within Divisions, however, these standards do not follow the numbering of the MPS, but rather 1ist the solar topics sequentially. It has been found that this method allows the presentation of these new topics in a manner that is clearly related to the MPS and yet is not made cumbersome. Not all Chapters or Divisions in the MPS have topics of solar concern; for example, there are no such topics in Chapter 2, General Acceptability Criteria, nor in Division 512, Furnishings.

An example will help to illustrate the organization of this document:

Consider hail loads to be applied to solar collectors. Hail loads are not a subject in the MPS, but would be covered in Chapters 6 , Division 1, General Structural Requirements if they were. In these standards they are located in Chapter 6, Division 1, Section S-601-7. For comparision, plumbing construction is covered in Chapters 6 , Division 15, Section $615-5$ of the MPS. In these standards it is also located in Chapter 6, Division 15, but in Section S-615-12.

$\begin{array}{llr} & \text { MPS } & \text { MPS Solar Supp } \\ \text { Hail loads } & \text { none } & \mathrm{S}-601-7 \\ \text { Plumbing } & 615-5 & \mathrm{~S}-615-12\end{array}$

It has frequently been found useful to include a commentary or a particular standard. The commentaries are nok mandatory, but are intended to give further explanation and guidance to users of the standards on topics which may have special consequences in solar installations. Several appendicies are included which give additional information for assistance in use of the standards. Appendix A presents the calculation procedures for determining the thermal performance of solar heating and domestic hot water systems and Appendix C presents graphic illustrations of terms used in the standard. 
The format developed for these standards has been structured to convey information in a number of categories as follows:

S - the preflx used on all sections (for solar) to distinguish them from existant MPS section

Conventional type - to present standards applicable to one and two family dwellings and multifamily housing

\section{EULD FACF. TYPF. - TO PRESENT STANDARDS AND COMMENTARIES APPLICABLE TO MULTI/FAMILY HOUSING ONLY}

Italics - to present commentaries applicable to one and two family dwellings and multi family housing

\section{SI CONVERSION UNITS}

In view of the present accepted practice in this country for building technology, common U.S. units of measurement have been used throughout this document. In recognition of the position of the United States as a signatory to the General Conference of Weights and Measures, which gave official status to the metric SI system of units in 1960, assistance is given to the reader interested in making use of the coherent system of SI units by giving conversion factors applicable to U.S. units used in this document.

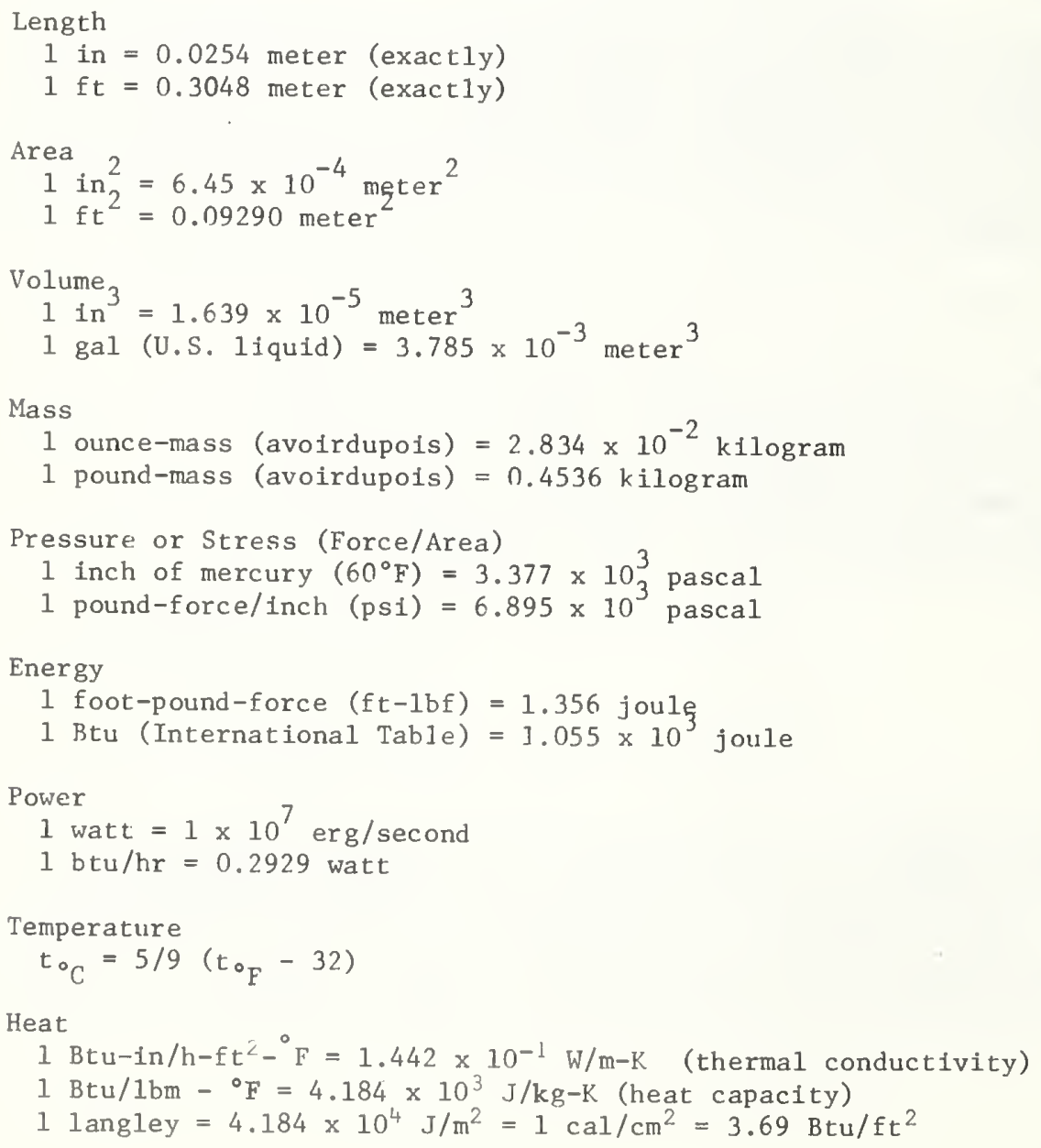


Chapter 1 General Use............................ 1-1

Chapter 2 (Not Used)............................. 2-1

Chapter 3 Site Design........................... 3-1

Chapter 4 Building Design........................ 4-1

Chapter 5 Materials............................ 5-1

Chapter 6 Construction.......................... 6-1

Appendix A Calculation Procedures for Determining the Therma1 Performance of Solar Domestic Hot Water and Space Heating Systems....................... A-1

Appendix B Materials Tables............................. B-1

Appendix C Illustrated Definitions..................... C-1

Appendix D Definitions............................. D-1

Appendix E Referenced Standards..........................

Appendix F Abbreviations.......................... F-1 

General Use

\section{APPLICATION}

These "Intermediate Minimum Property Standards for Solar Heating and Domestic Hot Water Systems" are a supplement to MPS 4900.1, "Minimum Property Standards for One and Two Family Dwellings, and I.PS 4910.1, "Minimum Property Standards for Multifamily Housing", and shall be used in conjunction with MPS 4900.1 and MPS 4910.1 Furthermore, the solar components must provide for the collection of solar energy, conversion of the solar energy to thermal energy, and distribution, storage and control of the thermal energy so obtained. Insofar as applicable, these standards apply to active and passive solar energy systems that utilize building elements, mechanical subsystems or combination thereof.

Commentary: MPS 4900.1, and MPS 4910.1 are available from HUD Regional Offices.

\section{NEW MATERIALS AND TECHNOLOGIES}

These standards are intended to encourage the use of new or innovative designs, technologies, methods or materials in solar applications. These features include designs, methods of construction, systems, subsystems, components, materials and processes which do not comply with the MPS and this document, whose acceptance cannot be determined by other provisions of this standard.

Alternatives, nonconventional or innovative designs, methods and materials shall demonstrate, however, equivalent quality to these standards in operating effectiveness, structural soundness, durability, economy of maintenance or operation, and usability.

\section{Commentary}

One basis for design, fabrication, construction and acceptance of new and innovative solar systems, subsystems, components, materials and processes is the "Interim Performance Criteria for Solar Heating and Combined Heatingl Cooling Systems and Dwellings", Jan. 1975, issued by HUD. 

SITE DESIGN

\section{S-300 GENERAL}

The provisions of this chapter are applicable to solar energy systens including heating $(\mathrm{H})$, and domestic hot water (DHW) systems. This chapter is a supplement to the Minimum Property Standards (MPS) Chapter 3.

S-301 PROPOSED SITE

S-301-1 Site Surroundings

S-301-1.1 Solar buildings and solar system components shall be located and designed in such a manner as to harmonize with the surrounding community.

Commentary: Solar system components may include elements which are Zarge and visually dominant when viewed from off-site. If not carefully designed and located, such elements can produce a detrimental effect on the overall quality of a residential area.

\section{S-303 LAND USE}

S-303-1 SOLAR EQUIPMENT LOCATION AND ARRANGFMENT

Solar buildings and site located solar equipment shall be arranged and located to relate well to:

a. The natural topography.

Commentary: The location of the solar collector should be planned to avoid pockets where frost can collect or unprotected ridges where winds can be more extreme in order to avoid heat losses due to low temperatures and high winds.

b. The climate.

Commentary: The location of the solar collector should be planned to take into account prevailing winds in order to avoid excessive heat losses due to wind and to drifting snow which impair the collection of solar energy. For specific requirements on tilt and orientation see $S-625-2.2 .2$.

c. Attractive on-site and off-site views.

Commentary: Components of the solar system may be large and could block attractive views from the building.

d. Existing and proposed site elements such as vegetation, fences, landforms and buildings.

Commentary: Proper relationship of a sclar collector to site elements can minimize the shading of the collector and reduce air flow over the collector. Location of the solar building in the northern portion of the site can help to minimize the possibility of shading solar collector surfaces by future off-site devezopment.

e. Existing and proposed circulation systems.

Commentary: Proper location of solar equipment to circulation may reduce tampering and vandalism. 
f. Existing and proposed surrounding buildings and facilities.

Commentary: The Zocation and orientation of the solar collector should. consider physical and chemical air bome waste from nearhy facilities such as incinerators and factories which might have an impact on the efficiency of the solar colzector. (See S-525-2.4)

S-303-2 SITE HLAZARDS

Special considerations must be given to assure that elements of the solar system do not create unnecessary safety hazards to users.

Commentary: Hazards which require special attention include the reflection of sunlight which creates visual distraction, the projection of sharp edges which influence the movement of people near free-standing collectors, and the proximity of solar components to recognized architectural harards such as exterior overhangs, stairs, ramps, landings, doors, etc.

S-304 LOTS, YARDS AND BUILDING SETBACK DISTANCE,

S-304-1 PROJEC.TION INTO YARD AREA

The projection of solar collectors into yards shall conform to those restrictions placed on open balconies, bay windows and uncovered porches in Section 304-2 of MPS.

S-304-2 USABLE OUTDOOR AREA

Components of the solar system shall not impinge on the requirements of Section $304-3$ of MPS.

Commentary: Reasonable outdoor open space must he maintained for liveability, service, emergency access, isolation of fire, and protection of adjacent property.

S-304-3 SNOW AND ICE

In areas which have a snow load of 20 pounds per square foot or greater, required by local codes, provisjons should be made over entrances and locations of pedestrian and vehicular ways to restrain or deflect sliding snow and ice masses which may slide off elevated solar system components.

Commentary: Solar system components may often include smooth, slippery surfaces located in elevated positions at steep angles. These eiements may heat up rapidly and lcosen masses of snow or ice which may sliae-off. Means should be provided to prevent a hazard to people or property. Methods such as deflectors, restraints, low friction materials, or design of "safe fall" areas (pedestrian or vehicular ways spaced alay from the building) should be considered.

S-309 SERVICES

S-309-1 MAINTENANCE

Solar energy components located on the site should be accessible for cleaning, adjusting, servicing, examination, replacement or repair without tresspassing on adjoining property.

Cormentary: Components should not be located unnecessarily under buizdings or roads or in other places which are difficult to reach. Storage tanks in particular are large and may need periodic replacement or inspection. 
SOLAR COLLECTORS ON ROOFS OVER 3, STORIES NUST HAVE ACCESS PROVIDED FOR CLEANING AND M:AINTENANCE,

COMMENTARY: THE USE OF PORTABLE LADDERS IS NOT CONSIDEPED TO BE ADENUATE UNDER THESE CIRCUMSTANCES.

S-311 DRAINAGE

S-311-5 DRAINAGE SWALES AND CUTTERS

Gutters shall be provided on solar collectors when the soil is of such a nature that excessive erosion or expansion will occur.

S-311-7 DOWNSPOUTS

S-311-7.1 In addition to method of disposal of 311-7.1 of the MPS, downspouts may be discharged into an acceptable non-potable water storage tank if it is part of the solar system.

Commentary: When downspouts are used as part of a solar system, it is acceptable for it to empty into a storage tank provided consideration has been given the quality of the water and its effect on the solar system. (See 525-2.3)

S-312

PLANTING DESIGN

S-312-3 NEW PLANT MATERIAL

S-312-3.9 Plant material should be selected and located to prevent the unwanted reduction of efficiency of a solar collector fron shading, sap or other by-products of plants. 

S-400 GENERAL

The provisions of this chapter are applicable to solar energy systems including heating $(\mathrm{H})$, and domestic hot water (DHW) systems. This chapter is a supplement to the Minimum Property Standards (MPS) Chapter 4.

S-401 SPACE PLANNING

S-401-1 PASSIVE SOLAR SYSTEMS

Where normal building spaces are designed to also he part of passive solar energy collection, storage, distribution or control, provisions shall be made so that this does not interfere with the intended use of these spaces.

S-401-1.1 Radiant Temperatures

The temperatures of various surfaces in a living space, used as part of a passive solar system, shall not exceed the following values:

\begin{tabular}{|c|c|}
\hline Floor & $78^{\circ}$ \\
\hline $\begin{array}{l}\text { Walls up to } 6{ }^{\prime}-8^{\prime \prime} \\
\text { Ceiling above } 6^{\prime \prime}-8\end{array}$ & $84^{\circ}$ \\
\hline
\end{tabular}

Commentary: When a living space is used as a solar collector, occupants of that space may experience discomfort from direct solar radiation, from the longiave radiation emitted by the solar heated glass or from the floor or walls of the space. To achieve the required conditions, means of control may be necessary such as shutters, draperies or louvered screens.

S-401-1.2 Draft

The movement of air through a living space used to transport solar heated air in a passive system shal1 not exceed 70 FPM measured in the occupant zone.

Commentary: See ASHRAE standard 55-74.

S-402 ACCESS AND CIRCULATION

S-402-1 GENERAL

S-402-1.1 The design and installation of the solar heating and domestic hot water systems shall not impair the normal movement of occupants of the building or emergency personnel.

COMmentary: SPECIAL CONSIDERATION SHOULD BE GIVEN TO THE EFFECT OF THE CONFIGURATION OF ROOF-MOUNTED COLLECTORS ON FIRE EXITING, FIRE FIGHTING OR EMERGENCY RESCUE。

[1] Grandjean, Etienne. 1973. Ergonomics of the Home, New York: Halsted Press

[2] Flynn, John E. and Segi], Arthur W. 1970. Architectural Interior Systems. New York: Van Nostrand Reinhold Co. 
Solar energy equipment shall be accessible for maintenance without disassembling any major structural or mechanical element. There shall be sufficient space or clearance around solar equipment based upon solar equipment sizes and potential maintenance equipment sizes to permit examination, replacement, adjusting, servictng and/or maintenance. See Section S-600-5.

Commentary: Accessibility for repair and maintenance should reflect the expected life of the equipment and the frequency of routine maintenance required. An element with a shorter maintenance cycle or life expectancy should be nore accessible than one with a long maintenance cycle or life expectancy.

S-403 LIGHT AND VENTILATION

S-403-3 VENTILATION

When attics or structural spaces are used as part of a passive solar system, attic or structural space ventilation may be omitted if other means are provided to prevent unwanted moisture build up in the building.

\section{S-405 FIRE PROTECTION}

S-405-1 GENERAL

S-405-1.1 The incorporation of the solar subsystems shall not reduce the fire resistance ratings required by Section 405 of MPS.

COMMENTARY: ROOF-MOUNTED COLLECTORS WHICH ARE AN INTEGRAL PART OF THE ROOF CONSTRUCTION MAY REDUCE THE FIRE RESISTANCE RATING OF THE ROOF BELOW ACCEPTABLE. LEVELS,

S-405-4 FIRE RESISTANCE REQUIREMENTS

Penetrations through fire-rated assemblies shall not reduce the fire resistance below the levels specifjed in Section 405 of MPS.

S-405-6 EXITS

Components of the solar subsystem shall be located in such a way that a fire in these components cannot block the primary means of occupant egress.

COMMENTARY: THE LOCATION OF SOLAR EQUIPMENT ON A ROOF COULD REDUCE THE USAEILITY OF THAT ROOF FOR ACCESS OR EGRESS,

Any solar collectors installed as an integral part of the roof assembly shall be firestopped on all sides. Firestopping material shall be wood blocking of minimum 2 in. nominal thickness or of noncombustible materlals providing equivalent protection. 
CHAPTER 5 - MATERIALS

S-500 GENERAL.................................. 5-2

S-500-1 Applicable Standards.......................... 5-2

S-500-2 Exceptions and Re-Statements.................... 5-2

S-500-3 Suitability of Alternate or Special Materials..........5-2

S-501 GENERAL REQUIREMENTS........................ 5-3

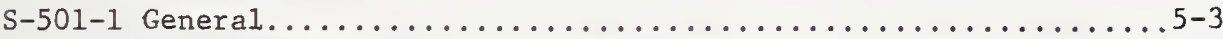

s-501-2 Labeling. ................................ $5-3$

s-501-3 Safety......................................

S-508 DOORS, WINDOWS, GLAZING PANELS................. 5-4

$S-508-7$ Hardware................................. 5-4

S-515 MECHANICAL - SOLAR POWERED EQUIPMENT................5-5

S-515-1 General Provisions..........................5-5

s-515-2 collectors................................ $5-6$

S-515-3 Energy Transport System........................ 5-20

s-515-4 Mechanical Supporting Devices..................... 5-21

s-515-5 valves................................... 5-22

S-515-6 Pumps and Compressors......................... 5-23

S-515-7 Thermal Storage Units.......................... 5-24

S-515-8 Heat Transfer Fluids......................... 5-25

s-515-9 Heat Exchangers............................ 5-27

s-515-10 Gaskets and sealants....................... 5-28

S-515-11 Insulation/Thermal and Moisture Protection...........5-29

s-515-12 Catch Basins............................... 5-30

S-515-13 Organic Coupling Hoses........................ 5-31 
MATERIALS

S-500 GENERAL

The provisions in this chapter are applicable to solar energy systems including heating $(\mathrm{H})$, and domestic hot water (DHW) systems. This chapter is a supplement to the Minimum Property Standards (MPS). Materials provisions (Chapter 5) of the MPS are applicable in addition to the items explicitly discussed in this document.

S-500-1 APPLICABLE STANDARDS

Except as modified harein, materials, equipment and installation shall be in accordance with the standards and nationally recognized model codes cited within the body of this document; the current applicable editions and titles or referenced standards and codes are contained in Appendix E. State and local codes which deviate from nationally recognized codes or standards in order to satisfy local conditions may be accepted by HUD if such deviations are identified and substantiated with satisfactory engineering data.

S-500-2 EXCEPTIONS AND RE-STATEMENTS

S-500-2.1 Exceptions

Exceptions to the cited standards are included in this document where deemed appropriate by HUD.

S-500-2.2 Re-statements

Certain requirements that are already covered in the referenced 8 tandards are re-stated in this document to emphasize the need for implementing these requirements in HUD construction.

S-500-3 SUITABILITY OF ALTERNATE OR SPECIAL MATERIALS

Alternate or special materials or products, other than those contained herein may be used when found acceptable by established HUD procedures and Division 513 of MPS and Section S-101 of this document. 


\section{S-501 GENERAI, REQUIREMENTS}

S-501-1 GENERAL

Materials installed shall be of such kind and quality as to assure that the solar energy system will provide a) adequate structural strength, b) adequate resistance to weather, moisture, corrosion and fire, c) acceptable durability and economy of maintenance and market acceptance.

\section{S-501-2 LABELING}

Mandatory labeling requirements, where applicable, are contained herein for specific materials and products. Additional labeling in accordance with the Federal Hazardous Substances Labeling Act (1960) shall be provided.

Commentary: The "Federal Hazardous Substance Labeling Act," Public Law 86-613, Tuly 12, 1960, nomally exempts parts of heating, cooling and refrigeration systems. The newness and lack of familiarity with solar equipment and materials warrants increased, readizy accessible consumer information as provided by this Act.

S-501-3 SAEETY

S-501-3.1 Protection of potable water and circulated air

No material, form of construction, fixture, appurtenance or item of equipment shall be employed that will support the growth of micro-organisms or introduce toxic substances, impurities, bacteria or chemicals into potable water and air circulation systems in quantities sufficient to cause disease or harmful physiological effects.

Commentary: This situation is of concern not only as it pertains to ducts, piping, jizters and joints but also to storage areas, such as rock beds. In addition, the growth of fungus, mold and mildew is possible when collectors are applied to a roof surface over the water tight membrane. If the collectors are in contact with the membrane or held cway from the membrane to alzow for drainage, the shaded membrare area can support the growth of mildew and other fungus in some warm, moist climates. Special design considerations should be included to avoid this problem in climates where it can occur. 
S-508 DOORS, WINDOWS, GLAZING PANELS

S-508-7 HARDWARE

S-508-7.3 Srreening

Louvered solar control insect screening for windows and doors shall have 16 mesh or equivalent in one direction.

Commentary: There are louvered solar control insect screens which have elongated openings. These vary from the traditional square openings of screens and are effective in limiting incident solar radiation as well as keeping out insects. 
S-515 MECHANICAL - SOLAR POWERED EQUIPMENT

S-515-1 GENERAL, PROVISIONS

Assemblies and the materials used in the solar subsystems shall comply with the nationally recognized codes for fire safety under all operating and nonoperating conditions. The provisions of Section S-405 of this document and MPS Section 405, FIRE PROTECTION, shall apply.

S-515-1.1 Effects of external environment

The systems for heating (H) and for domestic hot water (DHW) and their various subassemblies shall not be affected by external environmental factors to an extent that will significantly impair their function during their intended design life.

S-515-1.2 Temperature and Pressure Resistance

Components shall be capable of performing their functions for their intended design life when exposed to the temperatures and pressures that can be developed in the system under both flow and no-flow conditions.

S-515-1.3 Materials Compatibility

All materials which are joined to or in contact with other materials shall have sufficient chemical compatibility with those materials to prevent deterioration that will significantly impair their function during their intended design life. Provisions shall be made to allow for differences in the expansion of joined materials.

S-515-1.4 Airborne Pollutants

Materials exposed to airborne pollutants while in service, such as ozone, salt spray, sulfur dioxide, oxides of nitrogen and/or hydrogen chloride, shall not be affected by those pollutants to an extent that will significantly impair their function during their intended design life.

S-515-1.5 Chemical Decomposition Products

Materials shall not be affected by chemical decomposition products expelled from components under in-use conditions to an extent that will significantly impair their function during their intended design life.

S-515-1.6 Abrasive Wear

Exterior materials shall not be affected by abrasive wear caused either by cleaning or by natural factors such as wind blown sand to an extent that will significantly impair their function during their intended design life.

S-515-1.7 Soil Corrosion

Materials that are intended to be buried in soils shall not be degraded under in-use conditions to an extent that will significantly impair their function during their intended design life. 
S. 515-1.8 Corrosion by Leachable Substances

Substances that can be leached by molsture from any of the materials within the system shall not cause corrosive deterjoration of any other materials to an extent that will significantly impair their function during their intended design 1 ife.

S-515-2 COLLECTORS

S-515-2.1 General

Collectors shall perform their function for their intended design life.

Commentary: Colzector panels can be used as the roofing membrane. They can also be mounted over a roofing membrane or mounted remotely. The primary function of a roofing membrane is to prevent the entrance of water into the stmucture. When collector panels are designed to fulfill this function, leakage at joints becomes a factor of concern and must be considered in the design.

When collectors are mounted over a roofing membrane, consideration should be given to the growth of fungus, mola and mildew between the roofing membrane and the collector. Also, it is possible, due to extreme temperature differentials, to cause the formation of ice dams which could in turn back water under shingles or other roofing materials, causing rapid deterioration. This is discussed further in section S-615-2.1.4. Consideration should he given to the methods of applying non-integral collectors to roof stmuctures and to the choice of waterproofing membrane.

S-515-2.1.1 Eabeling

Collectors sha11 be labeled in accordance with 515-1.2 of the MPS. In addition, collector labels shall list total weight, cover plate materials, the types of heat transfer fluids that can or cannot be used, maximum allowable operating and no-flow temperatures, maximum allowable operating and no-flow pressures, maximum flow rates and collector efficiency as measured according to s-615-2.2.1.

S-515-2.1.2 Therma] Stabiltty

Collectors shall not have more than a $10 \%$ reduction in the intercept or a -hange in slope of more than $10 \%$ that results in decreased performance as measured according to the method in S-615-2.2.1, after being exposed to solar radiation having an average daily solar flux of $1500 \mathrm{Btu} / \mathrm{ft}^{2}$ at the tilt angle under "no-flow" conditions for 30 days. At least one four hour period during the 30 day exposure shall have a minimum solar flux of $300 \mathrm{Btu} / \mathrm{ft}^{2} / \mathrm{hr}$. Sufficient data points shall be taken before and after the 30 day exposure to verify the slope and intercept of the efficiency curve. The 30 day "no-flow" exposure must be performed on a complete collector without the transfer medium. The angle of collector exposure should be $+10^{\circ}$ of that used in service. For tracking collectors, the exposure angles shall be the same as those used in service.

Commentary: The purpose of the no-flow test is to identify, in a short period of time, potential problems with collector materials. The test will be referred to for nomerous materials in subsequent requirements. The 30 days do not necessarily have to be consecutive. 
S-515-2.1.3 Flashing

a. Flashing for collector panel supports that penetrate the primary roof membrane shall be designed to prevent the penetration of water or melting snow for the life of the roof system.

b. Flashing systems shall be designed to permit minor repairs without distrubing the roof membrane, collector supports or collector panels.

c. In general, flashing for roof penetrations shall comply with applicable Sections of $507-5$ and $507-8$ of the MPS .

Commentary: Suggested practices for flashing used on no-slope or low slope roofs and roof penetrations are provided in the National Roofing Contractors Association's "A Manual of Roofing Practice", 1970.

S-515-2.1.4 Access to Components

If routine maintenance or repair of collector components is anticipated, the collector shall be designed to permit easy access to those components.

Commentary: Some materials such as mubber hoses, joint sealants, exterior coatings, etc. may have to be replaced periodically. Also, in some geographic locations, the cover plates may have to be cleaned occasionally. If materials in the collector are likely to be replaced, repaired or maintained within the design life of the collector, it is important to provide easy access to those materials.

S-515-2.2 Cover Plates

S-515-2.2.1 Genera1

The materials used as glazing for cover plates must meet the following requirements based on materials properties as well as safety considerations. The safety requirements are made with respect to the physical location of the glazing and the exposure risk of persons nearby

Commentary: Table S-515-2.2 lists a number of materials that have been used for cover plates and properties of the materint.s.

S-515-2.2.2 Codes and Standards

Materials used as glazing for cover plates shall comply with MPS Section 508, Section S-601 of this document and applicable sections of local building codes and national standards.

S-515-2.2.3 Labeling and product Description

In addition to the labeling requirements of Section 508-8.4 of the MPS, product description shall include technical data regarding chemical composition, physical, mechanical and thermal properties such as fire resistance, flammability and flamespread, weather resistance, electrical properties, products of combustion, coefficient of expansion, transmittance, impact resistance, scratch resistance and recommended or disallowed cleaning methods.

\section{S-515-2.2.4 . Structural Requirements}

All glazing materials shall be of adequate strength and durability to withstand the loads and forces required by Section S-601 of this document. 


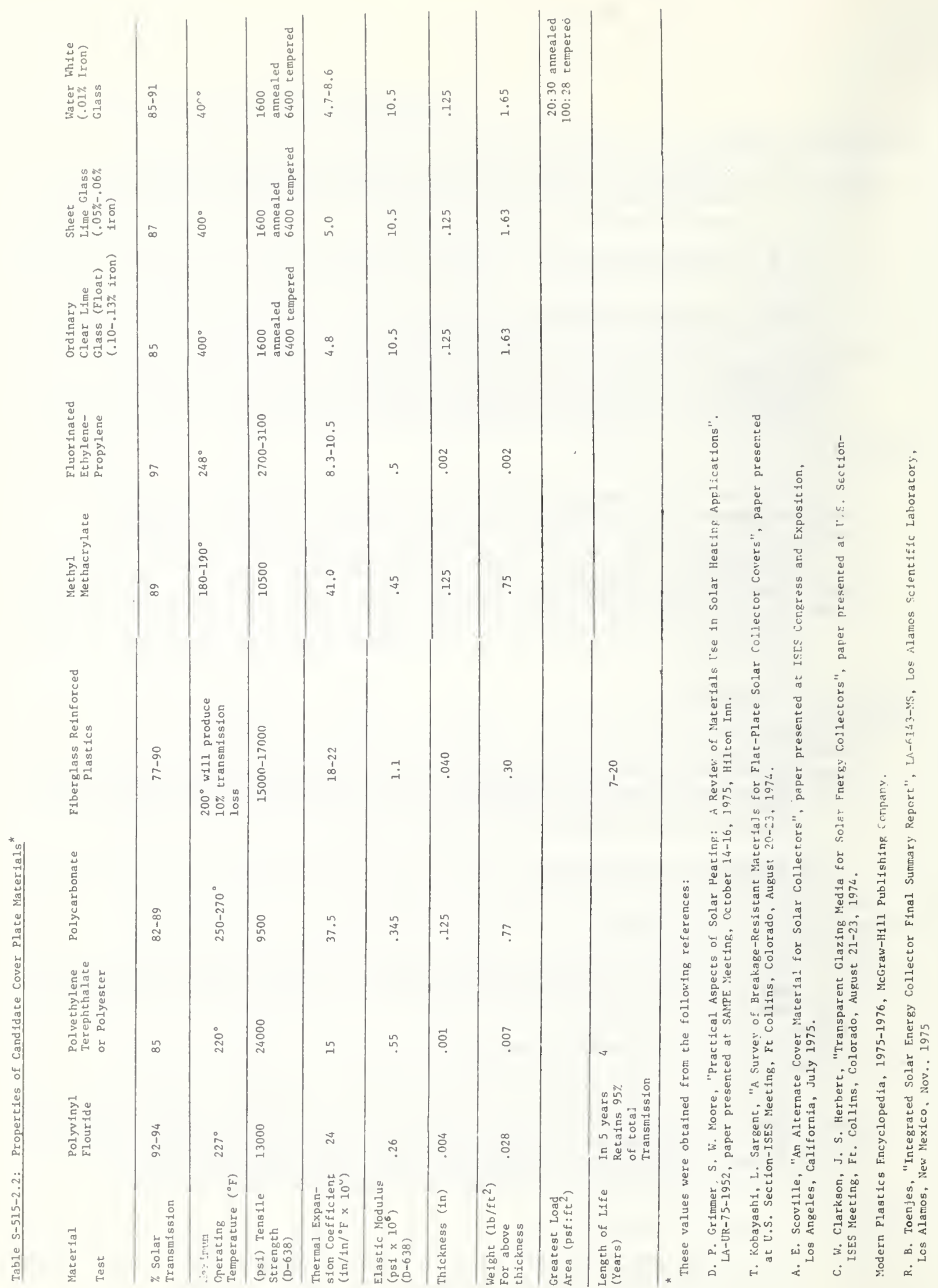


Applications include windows which act as cover plates for solar collectors, both integral with dwelling construction and freestanding components.

a. Outermost glazing near walking surface

Glazing materials exposed at ground level or at the level of a walking surface must meet the intent of the requirements for safety glazing as specified in AMTS Z97.1-1972 and MPS Section 508-8.1.

Commentary: Consumer Product Safety Commission's 16 CER, Part 1201 was published in the Federal Register on February 11,1976. 180 days after issuance of a final standard in the Federal Register, the standard will be mandatory for the safety of architectural glass. (See Cormentary under b) bel.ow,)

b. Vertically oriented outermost glazing materials in fixed panels which are installed above a rail or sill at least $3^{\prime}-6^{\prime \prime}$ above the walkway or finished floor line must meet the intent of the requirements for glazing in MPS Section 508-8.3.

Commentary: An additional consideration is that film-type glazing materials for the outermost cover plate, if unsupported, may be unacceptable if they can be deflected under load, e.g. a person's hand pushing against the glazing, may present an opportunity for exposure of the firm (and the person's hand) to hot surfaces such as the absorber plate. Also, there is a probability of exposure to impact which may result in tearing of the film.

c. Glazing materials with slopes less than $45^{\circ}$ which extend below $6^{\prime} 0^{\prime \prime}$ (from ground level) shall be safety glazed or otherwise protected against impact of falling bodies.

Commentary: This commonly refers to glazing on which children may climb or against which a passerby may fall.

d. Glazing panels which are an integral part of a roof or rack-mounted system on a roof, not routinely accessible by the occupant, shall meet the requirements of section S-601. (Annealed glass or films may be acceptable.)

$S-515-2.2 .6$

Thermal Stability

After testing as described in s-515-2.1.2, there shall be no cracking, crazing, warping, sagging or buckling of the cover plate(s) that will significantly impair its function.

S-515-2.2.7 UV Stability

Documentation shall be provided that the decrease in transmittance, as measured by ASTM E-424-71, will not significantly impair the function of the cover plate(s) during its intended design life.

$S-515-2 \cdot 2.8$

Dirt Retention

The cover plate(s) shall not collect or retain dirt to an extent that would significantly reduce its ability to transmit sunlight.

Comentary: The possible collection and retention of dirt by the cover plate and the effect of reatined dirt on collector performance may be significant. The retention of dirt may depend on the tilt angle of the collector. Rainfall and snow melt are generally sufficient 
$S-515-2 \cdot 2.9$

$S-515-2 \cdot 2 \cdot 10$

$S-515-2.2 .11$

$S-515-2 \cdot 2 \cdot 12$ to keep the collector cover plates clean. If periodic scrukbing is necessary for cleaning, the cover plates should he resistant to damage by abrasion resulting from the scrubing. If the collector is ventilated, provisions should he made for exclusion of dust hy appropriate filters.

Outgassing of Volatiles

After exposure as described in S-515-2.1.2, there shall be no visible signs of outgassing products on the cover plate surface(s) that will significantly reduce the transmittance.

Commentary: Outgassing from components inside the collector could lead to condensation on the underside of the collector cover plate(s) which may reduce the transmissivity of the cover plate(s).

Condensation

Condensation formed on the underside of the cover plate(s) shall not significantly reduce its transmittance during its design life.

Commentary: If flat plate collectors are not hermetically sealed, the likelihood of condensate forming on the underside of the cover plate(s) is quite high. Dessicants in breather tubes or breather plugs can be used to maintain a dry environment. The dessicants should ke located in such a way that they are not in contact with the collector plate.

One additional potential prollem with collectors which are not hermetically sealed is that, in industrial atmospheres, the introduction of dilutants in condensate solution may cause permanent etching of the underside of the cover plate(s) over a period of time. Such etching can permanently reduce the trarsmittance. When this possible condition exists, design considerations must be given to avoid the problem.

\section{Flamespread}

Installation of glazing or other related components of the solar system as part of the roof assembly shall not reduce the fire retardant characteristics of the roof covering below the accepted level against a fire originating outside the building in accordance with ASTM E 108-58, Methods of Fire Tests of Roof Coverings (NFPA No. 256-1970).

Glass

Where tempered glass is used, it shall meet the requirements of ANSI Z97.1-1972 and MPS, Section 508, as specified in S-515-2.2.5 of this document. Other glass cover plates shall meet the requirements for glass as specified in Federal Specification DD-G-45IC (June 15, 1972).

Commentary: Table S-515-2.2 contains solar transmittance áta and reconmended maximum continuous operating temperature for a number of types of grass.

\section{Other Materials}

Cover plate materials other than glass shall conform to the requirements of MPS, Section 513 and the intent of S-515-2.2.11. Table S-515-2.2 11sts a number of materials that have been used for cover plates. Materials 
$S-515-2.3$

$S-515-2 \cdot 3 \cdot 1$

$S-515-2 \cdot 3 \cdot 2$ shall not be used for cover plates if the maximum temperature to which they will be exposed in service under operating and non-operating conditions exceeds the maximum operating temperatures 1isted in Table S-515-2.2.

\section{Absorber Plate}

Therma1 Stability

Any deformation that occurs in the test described in S-515-2.1.2 shall not adversely affect the flow rate of the transfer medium.

\section{Erosion/Corrosion}

The absorber plate or flow conduits shall not be adversely affected by erosive wear, such as by the flow of a liquid transfer medium to an extent that will significantly impair its function during its intended design life. In lieu of other documentation, compliance with this requirement shall be demonstrated by testing with appropriate revisions of one of the following methods:

NACE TM-C2-74

NACE TM-02-70

NACE TM-01-69

ASTM D257C-73

Commentary: Appropriate revisions of the above tests should include conditions which closely simulate in-semice operation. The variables which have an important impact on the rate or erosion/corrosion are:

1) the quantity and size distribution of solids in suspension

2) the flow rate

3) the pipe diometer

4) the oxygen content of the fluid

5) the angle of the change of flow direction

6) the internal surface condition of the pipe

Compatibility With Transfer Medium

a. The absorber plate or flow conduits shall not be pitted or otherwise corroded by the heat transfer medium to an extent that will significantly impair its function during its design life. In lieu of other documentation, modifications of tests listed in Table S-515-2.3.1 shall be used to demonstrate compliance with this requirement.

Commentary: SAE Report J447a(1964), Prevention of Corrosion of Metals, provides guidance in preventing corrosion.

b. Metallic absorber plates or flow conduits in direct contact with heat transfer fluids in open systems shall be used in accordance with the acceptable conditions 1isted in Table S-515-2.3.2, where applicable. Unacceptable conditions listed in this table shall not be used. Documentation shall be provided to demonstrate that materials applications not explicitly covered in Table S-515-2.3.2 meet the intent of $\mathrm{S}-515-1.3$ and $\mathrm{S}-515-2.3 .3$

Metallic absorber plates or flow conduits in direct contact with heat transfer fluids in closed systems shall be used in accordance with the acceptable conditions 1isted in Table S-515-2.3.3 where applicable. Unacceptable conditions 1isted in this table shall not be used. Documentation sha 11 be provided to demonstrate that materials applications not explicitly covered in Table S-515-2.3.3 meet the intent of $\mathrm{S}-515-1.3$ and $\mathrm{S}-515-2.3 .3$ 
Table S-515-2.3.1: Corrosion Test Methods

Number

NACE TM-01-71

NACE TM-02-74

NACE TM-02-70

NACE TM-01-69 (1972)

ASTM D138-70

ASTM D2570-73

ASTM D2776-72
Title

Comment
Autoclave Corrosion Testing. of Metals in High Temperature Water

Dynamic Corrosion Testing of Metals in High Temperature Water

Conducting Controlled Velocity Laboratory Corrosion Tests

Laboratory Corrosion Testing of Metals for the Process Industries

Corrosion Test for Engine Antifreeze in Glassware

Simulated Corrosion Testing of Engine Coolants

Corrosivity of Water in the Absence of Heat Transfer
Modify to reflect conditions present in solar system

Modify to reflect conditions present in solar system

Modify to reflect conditions present in solar system

Describes factors to consider in corrosion testing

Modify to reflect conditions present in solar system.

Modify to reflect conditions present in solar system

Commentary: Open systeme are those ir. which air, in addition to that already in the transfer fluid initially, can be absorbed into the fluid by contact with the atmosphere. Closed systems are those in which air, in addition to that in the fluid initially cannot be atsorbed by the fluid.

In a closed system, there is no exposure of the fluid to the atmosphere except above the expansion tank, there is no entrapped air in the piping or storage systems and the expansion tank is isolated from the flow path between the colzector and storage.

Corrosion is a very complex phenomenon in which many parameters are of importance. In the case of the corrosion of metals likely to be used in the fluid contairment system parameters of importance are:

- the composition of the metals or alloys

- the composition of the water, i.e. the concentrations of salts and dissolved gases and heavy metals

- the temperature

- the flow rate because of the possibility of erosion-corrosion

- system design factors, particularly the presence of galvanic cells or differential aeration cells.

Galvanic cells result with contact between dissimilar metals while differential aeration cells are areas where a metal is in contact with the fluid which has a variable dissolved oxygen content.

Water composition is important for corrosion. It varies substantialzy from one geographic area to another. Even within a given area water composition will vary depending on its source (surface vs. well water) and the time of year. The major variables include: $p H$, gas content $\left(\mathrm{O}_{2}, \mathrm{CO}_{2}\right)$, chloride content, sulfate content, solids content lorganic matter), and conductivity. Because of this variation in water similar variations in the type and severity of corrosion may be expected. Therefore, rather than specifying an acceptable corrosion rate based on the weight loss of a test coupon alone there is value in specifying 
a maximum rate of penetration. A spec. of this type would, however, require interaction with design specifications because of minimum wall thickness to maintain adequate strength during the design life is necessary. Although the instmonentation by inich corrosion penetration (pitting) may be measured ( $x-r a y$, eddy current devices, etc.) exists, recommended practices with regard to the frequency of measurement and the points at which these measurements should be carried out require development.

Weight loss corrosion measurements are also important. While the losses in wall thicknesses may not be significant the build-up of corrosion products could be. This could result either in flow restriction or in pitting corrosion. Depending on the $\mathrm{O}_{2}$ content of the transfer medium pitting corrosion as a result of differential aeration at the pipe-deposit interface could occur. This type of attack may also result because of scale formation. Because calcium carbonate exhibits retrograde solubility, precipitation of this compound will occur in saturated room temperature water as it is warmed. In addition each time make up water is added or the system flushed and refilled additional scale will be built up. Softening of water will help to alleviate this problem and may be recommended.

\section{Chlorides}

Chlorides should be kept to a minimum since their presence in water accelerates pitting corrosion. Aside from its presence in water there are several potential sources of chloride in a solar unit:

1. Residual chloride from pickling treatment of metallic components. This may also be a source of sulfate. This is a rather unlikely source of these ions but care should be taken that the components of the system are thoroughly cleaned before assembly.

2. Chloride from the decomposition of nonmetallic components in the system.

3. Chloride from flux used in soldering or brazing components during installation.

Galvanizing

Galvanizing has long been used to protect iron or steel from corrosion. Zine is more active than iron and, when the two are in electrical contact, will corrode preferentially. Thus, the iron is cathodically protected. The rate of corrosion of zinc is much lower than that of iron, so a relatively thin coating will last for quite a long time. However, there are data indicating that at elevated temperatures of above $158^{\circ} \mathrm{F}\left(70^{\circ} \mathrm{C}\right)$, this effect is reversed and the iron corrodes rather than the zine. [1]

In addition, the corrosion rate of zinc itself increases rapidly in the temperature range between 131 and $1940 \mathrm{~F}$ (55 and $90^{\circ} \mathrm{C}$ ). Accordingly the use of galvanized steel in this temperature range is not recommended.

\section{Copper in a Recirculating System}

In "once through" systems copper pipe is usually only connected upstream from iron pipe. Residential plumbing is an excomple of this.

[1] G. Butler and H.C.K. Ison: Corrosion and its Prevention in Waters, Reinhold Publishing N.Y. 1966. 
This practice is carried out because small amounts of copper tend to go into solution. When these copper ions contact more active metals such as Fe or Al they are reduced to copper metal which subsequentiy deposits on the metal surface. When this occurs, a galvanic cell is set up and rapici corrosion initiates. The presence of a dielectric pipe joint between $C U$ and $A Z$ or Fe wit r. not alleviate this prohlem. Similar action may be expected for $A I$ in the presence of $\mathrm{Fe}$.

$p H$

The $\mathrm{pH}$ of the transfer medium witl have an important impact on corrosion rates. However, the optimu pH to achieve minimum corrosion will change with temperature. [2] Because varying temperatures occur within a solar heating system and the temperature at a given point will change with time, care must be taken to optimize the $\mathrm{pH}$.

\section{Temperature}

The temperature is an important consideration with regard to selection of containment materials. Corrosion in aqueous media generally increases rapidly with temperature until the boiling point is approached. In open systems, the corrosion rate will tend to decrease due to a sharp decrease in the solubility of oxygen in water at these temperatures. However, in a closed system, from which the dissolved oxygen cannot escape, corrosion may continue at an accelerated rate.

\section{Stress corrosion}

This could be a problem in the collector panels where high strength alloys (esp Al) are clad to higher purity Al. Residual stresses in roll bonded and blown collectors could be sufficient for stress corrosion to occur. However, stress corrosion is unlikely unless chloride is present.

$\mathrm{O}_{2}$ content of water

Generaliy corrosion will decrease with a decreasing comount of $\mathrm{O}_{2}$ in water. In a closed system, $\mathrm{O}_{2}$ wizl be depleted and in theory corrosion will cease. However, the probability of designing and constmeting a system in which there is no leakage of oxygen is uncertain. If this were possible the only other sources of oxygen would be that from decomposition of organic components and from chemicals added to elevate the boiling point of water. Corrosion inhibitor's lould not be necessary in a completely closed containment system composed of steel or copper; if the proper $\mathrm{pH}$ is maintained. In the absence of oxygen, measurable corrosion of copper and steel does not occur.

The corrosion of aluminum, however, may continue even in the absence of oxygen. Becouse aluminum is more electropositive than Cu, Fe or $\mathrm{Zn}$, an alternative cathodic process may occur. This is the reduction of water to molecular hydrogen. This reaction may be suppressed if the $\mathrm{pH}$ is maintained in the range between about 5 and 7. The presence of chlorides and more noble metals should be avoided regardiess of the oxygen content and the $\mathrm{pH}$ of the fluid since these factors accelerate pitting corrosion. Stainless steel is unacceptable for use in contact with fluids, such as water/glycol mixtures, in closed

[2] R. M. Diamant: The Prevention of Corrosion, Business Books Ltd. London 1971. 


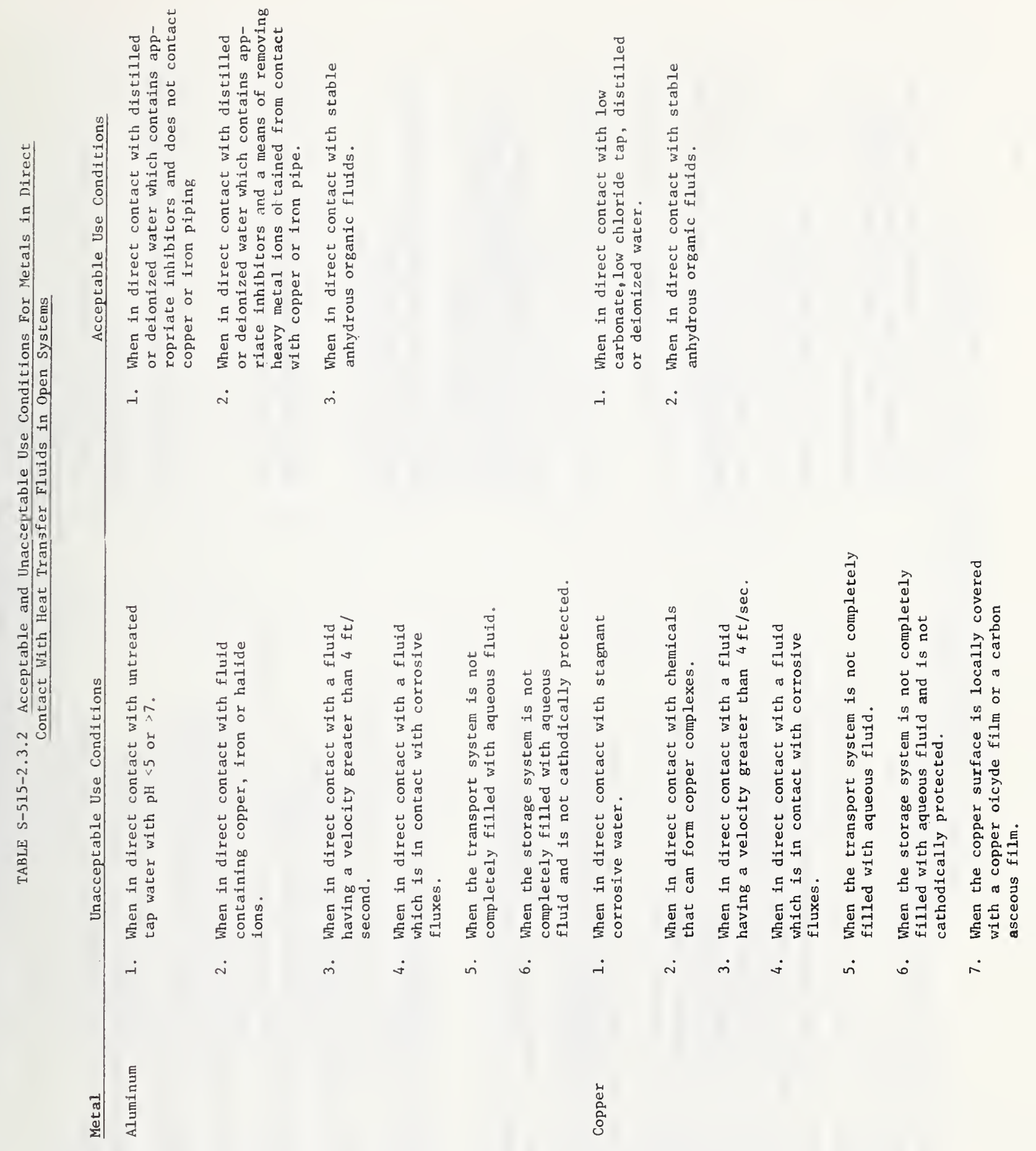



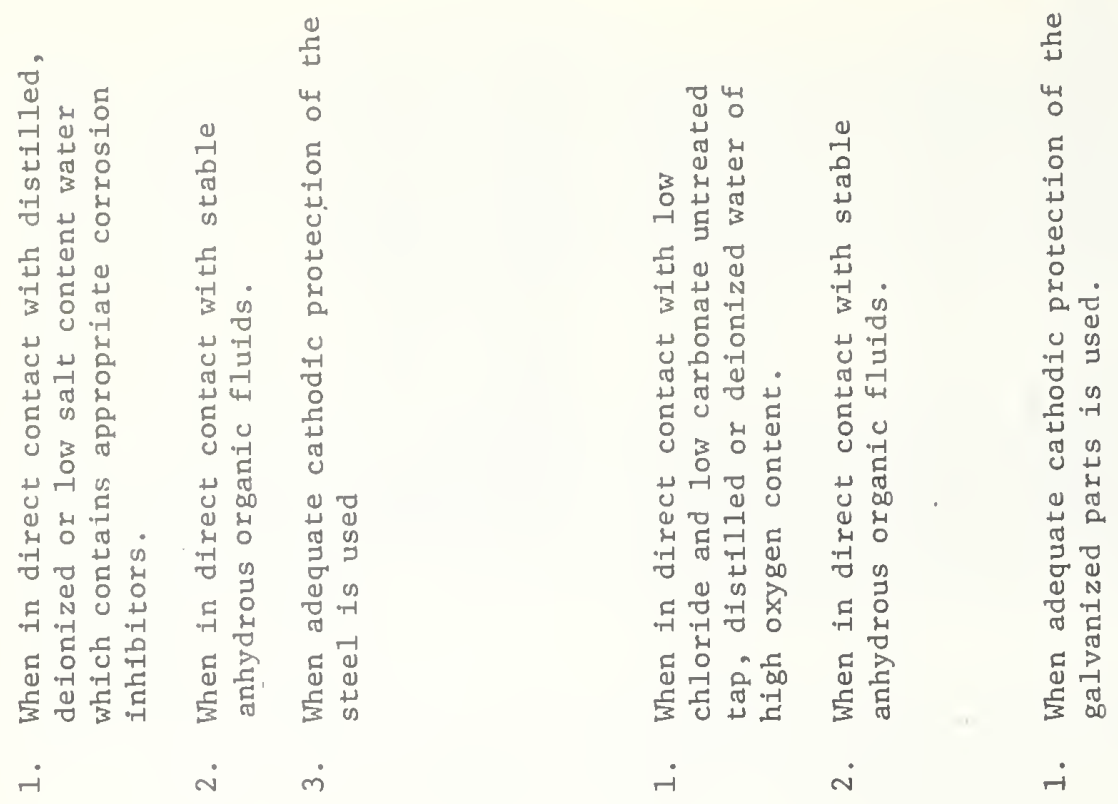

范

?

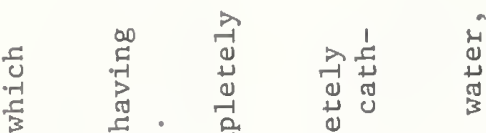

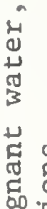

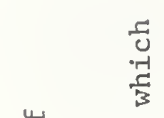

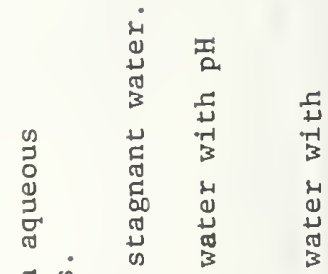

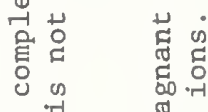

in

范

유

ह क्ष

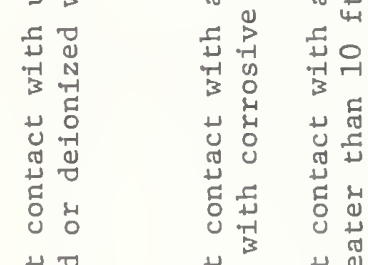

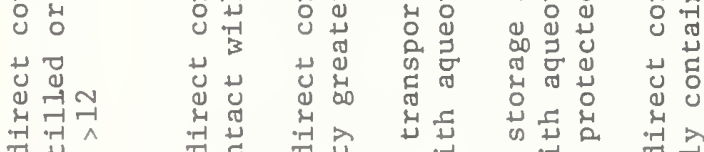

न

ज्ञ

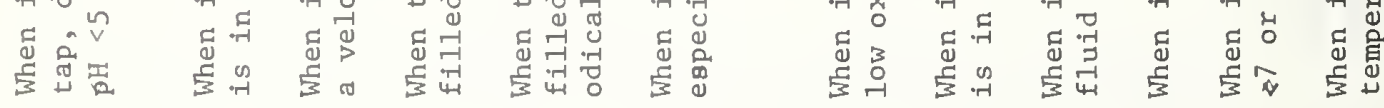

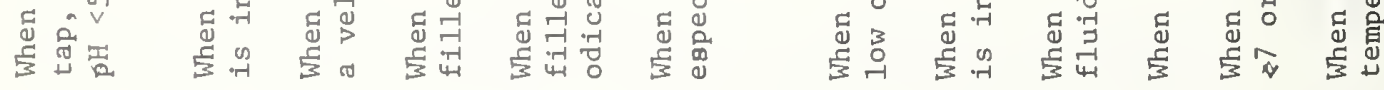

㢣

.7.

5
.
3
4
4
告
3
3

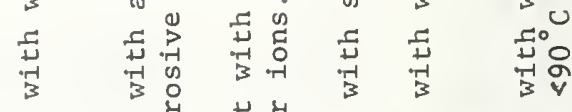

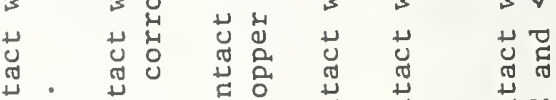

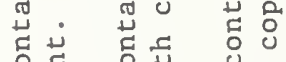

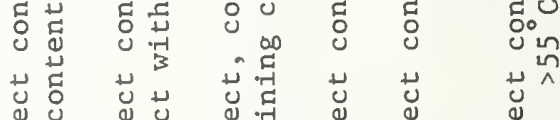

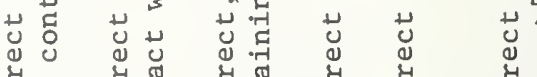

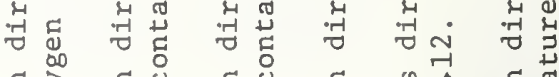

.

न द्न द व

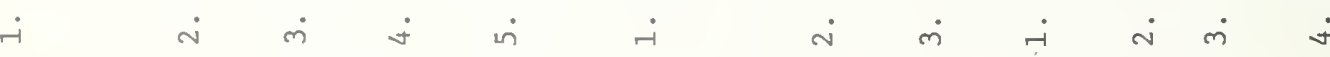

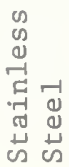

草 


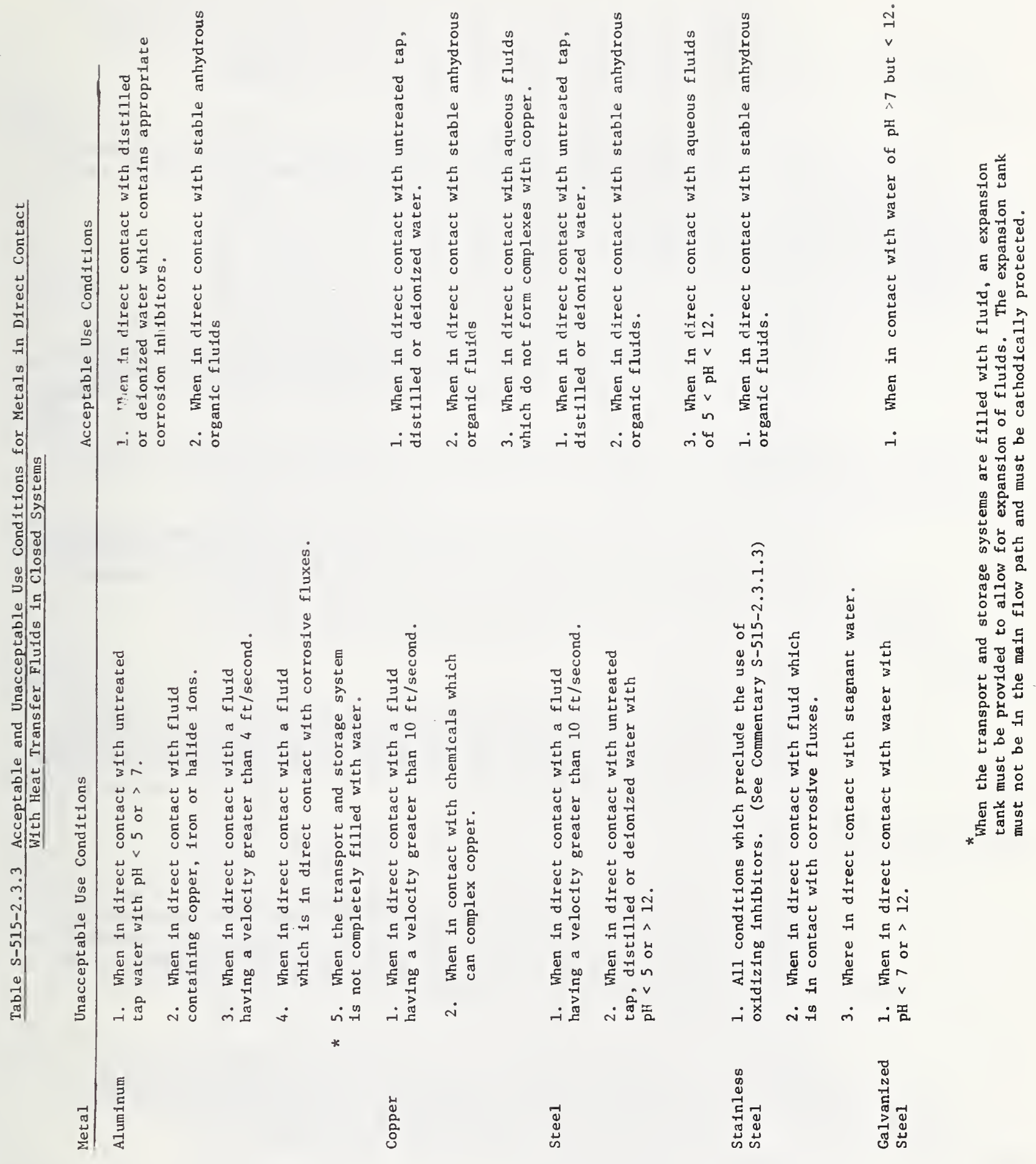




$$
S-515-2 \cdot 3 \cdot 4
$$

$S-515-2.4$

$S-515-2.4 .1$

$S-515-2 \cdot 4 \cdot 2$

$S-515-2 \cdot 4 \cdot 3$

$S-515-2 \cdot 4 \cdot 4$ systems because witer/giycol mixtumes prelukl the use of oxidizing inhifitors. In solutions with low oxygen content, stainless steel is susceptible to crevice corrosion because insuf'ficient oxygen is available to replenish the protective oxide layer once crevice corrosion starts.

\section{UV Stability}

Absorber plates shall not degrade to an extent that will significantly impair their function luring thefr design lifc when exposed to UV radiation.

\section{Absorpt1ve Coatings}

General

Absorptive coatings are generally of two types, either selective or nonselective. A nonselective coating has an absorptance to emmitance ratio near unity whereas in a selective coating, the ratio is higher. Appendix B-1 lists some characteristics of potential absorptive coatings.

Commentary: An effecient coating has a high abscrptance (a) over the solar spectrum $(.3$ to $2.0 \mathrm{um}$ ) with low emittance ( $\varepsilon$ ) to reduce thermal radiative heat losses.

For coatings applied by an electroplating process, as are many selective coatings, the substrate finish, plating geometry, bath composition, and current density may influence the properties necessary for optimum solar applications.

\section{Thermal Stability}

After exposure as described in S-515-2.1.2, there shall be no evidence of checking, cracking, blistering or flaking of the absorptive coating, that will significantly impair its function. ASTM methods D660-44 (1970), D661-44 (1975), D714-56 (1974) and D772-47 (1975) shal1 be used to evaluate the above properties.

UV Stability

Documentation shall be provided that the absorptive coating is not adversely affected by UV radiation to an extent that will significantly impair its function during its intended design life. In lieu of other documentation, the absorptive coating shall not exhibit checking, cracking, blistering or flaking after testing for 500 hours according to ASTM D 822-60 (1973).

Commentary: The above tests shatz be performed with a cover plate between the absorptive coating and the light source (if so designed) to simulate in-service conditions. The cover plate shall be of the scome type and configuration as used in an actual collector.

Moisture Stability

Documentation shall be provided that the absorptive coating is not adversely affected by molsture with which it comes in contact to an extent that will significantly impair its function during its intended design life. In lieu of other documentation, the absorptive coating shall not exhibit checking, cracking, blistering or flaking after testing for 30 days according to ASTM D 2247-68 (1973). 
Commentary: Moisture is not expected to come in contact with absorptive coating in collectors which have a dessicant.

$S-515-2 \cdot 4 \cdot 5$

S-515-2.5

$S-515-2.5 .1$

$S-515-2.5 \cdot 2$

$S-515-2.53$

S-515-2.5 4

S-515-2.6.1

$S-515-2 \cdot 6.2$

S-515-2 - 6.3

$S-515-2 \cdot 6 \cdot 4$
Compatibility With Heat Transfer Medium

When absorptive coatings are in direct contact with the heat transfer medium, documentation shall be provided to show that they are not affected by the medium to an extent that would significantly impair their function during their design lives. In lieu of other documentation, the absorptive coating shall exhibit no checking, cracking, blistering or flaking or signs of erosion after immersion in the fluid transfer medium for 100 hours at the maximum service temperature according to ASTM D 1308-57 (1973).

\section{Collector Enclosure}

Thermal Stability

After exposure as described in S-515-2.1.2, there shall be no cracking or warping of the collector enclosure materials that will significantly impair their function.

\section{UV Stability}

Documentation shall be provided that materials used in the collector enclosure do not degrade significantly over their intended lifetimes when exposed to solar radiation.

Materials

Collector enclosure materials sha11 be in accordance with applicable sections of Division 5 and 6 of the MPS.

Coating

Protective coatings, where used, shall be in accordance with Section 509-7 of the MPS.

\section{Reflective Surfaces}

Genera1

These provisions are applicable where reflective or antireflective surfaces are an inherent part of the collector design.

Thermal Stability

After exposure as in S-515-2.1.2, there shall be no cracking, crazing, delamination or change in reflectance of the reflective surfaces that will significantly impair their function.

UV Stability

Documentation shall be provided that the reflectance properties of the surfaces will not decrease by more than $10 \%$ below the design reflectance when exposed to solar radiation for the intended life of the surface.

Damage by Impact

The reflective surfaces shall not be adversely affected by impact, such as by hail, to an extent that would significantly impair their function during their design life. 
$S-515-3$

$s-31 b-3.1$

$S-515-3.1 .1$

$S-515-3.1,2$

$S-515-3 \cdot 1 \cdot 3$

$S-515-3.1 .4$

$\mathrm{S}-515-3.1 .5$

$S-515-3.1 .6$
ENERGY TRANSPORT SYSTEM

This section includes materials used to transport the heat transfer medium to a heat exchanger or storage facility and also those necessary components used to return the heat transfer medium from the heat exchanger or storage facility to the collector subsystem.

Applicable Standards for Liquid Systems

Compliance with MPS

Materials used in the transport system shall be in accordance with Sections $515-3.1,515-3.2,515-5.1,515-5.2$ and 515-6.4 of the MPS where applicable.

Other Standards

Materfals used for transporting fluids shall be shown to be in compliance with applicable standards. Examples of some standards that may be useful are given in Appendix Table $\mathrm{B}-2$.

Commentary: Most of the standards for piping shown in Appendix Table B-2 are the standards normally considered by the model plumbing codes.

Designers may use other ANSI, ASTM, or Federal Standards or Specifications that may be more appropriate to their particular design. The standards and specifications for each component of the piping system shall also be given on plans and specificaticns.

\section{Thermal Stability}

Components comprising the transport system shall not be damaged by normal thermal expansion and contraction of piping materials uitder in-use conditions. Proper pipe hangers and supports and fittings shall be used to allow normal movement of piping. See Appendix Table B-2.

Chemical and Physical Compatibility

a. Materials comprising the transport system shall have sufficient chemical and physical compatibility with organic materials in the system, such as sealants and gaskets, to which they are joined or in contact to prevent deterioration.

b. Materials comprising the piping or transport system shall have sufficient chemical and physical compatibility with the heat transfer medium to prevent corrosive wear and deterioration. (For metals, see S-515-3.1.7.)

Erosion/Corrosion

Materials comprising the transport system shall be in conformance with S-515-2.3.2.

Joints Between Dissimilar Metals

Dissimilar materials joined to form the transport system shall be electrically isolated from each other unless documentation is provided to demonstrate that the joints are sufficiently compatible to prevent corrosive wear and deterioration during their design lives. 
Commentary: Dielectric couplings used to isolate dissimilar metals which are buried in soil may be ineffective because of contact of the metals with ground water.

S-515-3.1.7 Metals

Metals used in the transport system which are in direct contact with heat transfer fluids shall be used in accordance with the acceptable conditions listed in Tables S-515-2.3.2 or S-515-2.3.3, where applicable. Unacceptable conditions listed in these tables shall not be used. Documentation shall be provided to demonstrate that material usages not covered in the tables meet the intent of S-515-1.3 and S-515-3.1.5.

S-515-3.2 Applicable Standards for Air Systems

Design of all warm air heating systems shall be in accordance with the recommendations of the ASHRAE Guide on applicable manuals of NESCA and ARI. Installation shall comply with NFPA Standards 31 and 54 and either NFPA $90 \mathrm{~A}$ or $90 \mathrm{~B}$, as applicable.

S-515-3.2.1 Size

Air distribution equipment shall be adequately sized to fulfill the heating requirements of the system.

S-515-3.2.2 Humidifiers of the central type shall be in compliance with ARI Standard 610, "Standard for Central Humidifiers (1974)."

S-515-3.2.2 Self Contained Humidifiers shall be in compliance with ARI Standard 620, "Standard for Self-Contained Humidifiers."

S-515-3.2.4 Air Filters shall conform to the requirements of UL 900 (ANSI B124.1-1971).

S-515-3.2.5 Heating supply and return air ducts in unconditioned spaces sha11 be insulated with materials or have thermal characteristics as specified in Section $515-3.1$ of MPS.

$S-515-4$

MECHANICAL SUPPORTING DEVICES

$S-515-4.1$

General

Mechanical supporting devices shall be sufficiently durable to perform their intended functions for their design lives.

S-515-4.2 Roof Mounted Collectors

When collector panels are added to an existing roof, the attachment hardware shall be fabricated of materials that will not be seriously affected by weathering for the expected design life of the roof membrane.

S-515-4.3 Remote Mounted Collectors

The materials used to support collector panels remotely located from the dwelling unit shall not be adversely affected by external environmental factors including solar radiation, temperature extremes or cycles of moisture. 


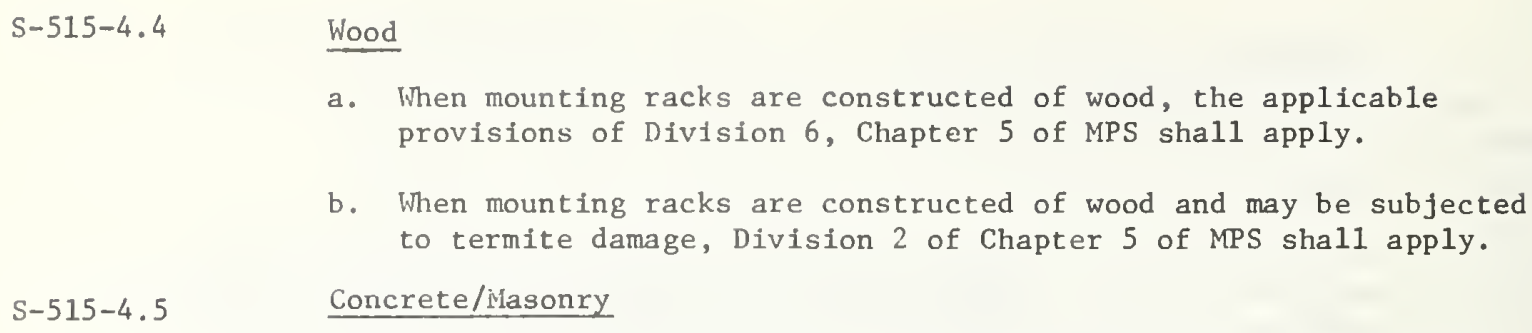

a. When mounting racks are constructed of wood, the applicable provisions of Division 6, Chapter 5 of MPS shall apply.

b. When mounting racks are constructed of wood and may be subjected to termite damage, Division 2 of Chapter 5 of MPS shall apply.

\section{S-515-4.5 Concrete/Masonry}

When concrete is used as any portion of mounting construction, the applicable provisions of Division 3, Chapter 5 of MPS shall apply. When masonry is used as any portion of mounting construction the applicable provisions of Division 4, Chapter 5 of MPS shall apply.

$S-515-4.6$

$S-515-4.7$

$S-515-4.8$

$S-515-5$

$S-515-5.1$

Metals

When metals are used as any portion of mounting rack construction the applicable provisions of Division 5, Chapter 5 of MPS shall apply.

Coatings

Coatings on wood, concrete/masonry or metals, if used, shall comply to Section $509-7$ of MPS

Y1pe and Duct Hangers

Pipe and duct hangers, used to support insulated pipes or ducts, shall be designed to avoid damaging the insulation material.

Commentary: If pipe or duct hangers are installed over the insulation material, metal surface plates should be used to avoid damadina the insulation.

VALVES

Applicable Standards

Valves shall conform to one or more of the following standards as appropriate. Valves manufactured to other standards not listed but fulfilling the requirements of a particular solar heating system design may be acceptable.

Standard for Solenoid Valves for use with volatile Refrigerants and Water (1975) -- ARI Standard 760.

Valves, Pressure, Reducing and Regulating for Installation on Domestic Water Supply Lines -- IAPMO PS15-71 [4]

Water Pressure Reducing Valves for Domestic Water Supply Systems -ASSE No. 1003, 1970.

Valves, Automatic Relief -- ANSI 21.22 - 1971. (For Water/Steam).

Valves, Cast Iron Gate, $125 \& 250 \mathrm{lb}$; Threaded and Flanged -WW-V-58a-1966.

[4] International Association of Plumbing and Mechanical officials, 5032 Alhambra Ave., Los Angeles, California 90032 
Combination Check and Relief Valves -- IAPMO TSC-8-66

Valves, Ba11 -- WW-V-35a-1965

Valves, Bronze, Angle, Check and Globe, 125 and 150 1b, Threaded and Flanged or Soldered -- WW-V-5ld-1967.

Valves, Water Heater Drain -- ASSE 1005.

Globe Tyf ${ }^{\circ}$ loglighter valves, angle Ir straight pattern -- IAPMO PS10-66

Valves, Electrically Operated (1955) -- UL 429.

Valves (125 pound Bronze Gate) (1969) -- MSS SP 37 [5]

Valves (150 pound Corrosion Resistant, Cast, Flanged) -- MSS SP 42

Valves (Butterfly) 1966 -- MSS SP67

Commentary: Standards for valves usually present pressure-temperature ratings. Appendix Table B-3 presents these ratings as an example for ball valves, Federal Specification WW-V-35a-1375. The valve standards do not consider valve sealing materials. The sealing material may not be compatible with the heat transfer fluid. The designer should consult the valve manufacturer for advice concerning appropriate valves and seals. National standards do not cover all valves useful to solar heating system design. Valves not covered by standards may be acceptable to HUD if a history of successful usage can be demonstrated by the valve manufacturer or solar heating system designer.

$S-515-6$

PINTPS ANT COMPRESSORS

$S-515-6.1$

Genera1

Pumps and compressors shall be in accordance with Section S-615-5

$S-515-6.2$

Applicable Standards

a. Centrifugal, rotary and reciprocating pumps shall be in compliance with the requirements of the Hylraulic Institute.

b. Sump pumps shall be tested, rated and labeled in conformance with the current SPMA Domestic Sump Pump Standards.

c. Heat pumps shall be in compliance with ASHRAE Standard 37-69, "Method of Testing for Unitary Air Conditioning and Heat Pump Equipment", and/or the ARI Standard 240, Standard for Unitary Heat Pump Equipment (1975).

d. Fans shall comply with the applicable standards of the AMCA or HVI and shall be tested, rated and labeled accordingly.

[5] Manufacturers Standardization Society of the Valve \& Fitting Industry, 1815 North Fort Meyer Drive, Arlington, VA 22209 
Comentary: A Hydraulic Institute Standard defines the product, material, process or procedure with reference to one or more of the following: nomenciature, composition, constmuction, dimensions, tolerances, safety, operating characteristics, performance, quality, rating, testing and service for which designed [6]

$5-515-7$

$5-515-7.1$

$S-515-7.2$

$5-515-7 \cdot 3$

$S-515-7.4$

THERMAL STORAGE UNITS

Thermal storage units are defined as any container, space or device which has the capacity to store thermal energy or transfer media (1iquid or solid) containing thermal energy for later use.

\section{General}

Thermal storage units shall be of sufficient durability to fulfill the heating storage requirements of the system for the intended design life of the storage unit.

Commentary: Storage units which are inaccessible for replacement, as defined in 615-1.5 of the MPS, should be designed to perform their function for the lifetime of the building. Routine maintenance and minor repairs is acceptable during the expected life of the unit.

Applicable Standards

Applicable standards for thermal storage units are presented in Appendix Table B-4.

\section{Contamination}

Thermal storage tank materials, including any interior protective coatings and the heat storage medium used, shall not impart toxicity, undesirable tastes, or odors to either air or water intended for human consumption.

\section{Materials Compatibility}

a. Materlals comprising the thermal storage system shall have sufficient chemical compatibility with the heat transfer medium to prevent corrosive wear and deterforation.

b. Metals used in the thermal storage system which are in direct contact with heat transfer fluids shall be in accordance with the acceptable conditions listed in Tables S-515-2.3.2 or S-515-2.3.3, where applicable. Unacceptable conditions listed in these tables shall not be used. Documentation shall be provided to demonstrate that material usages not covered in the tables meet the intent of $\mathrm{S}-515-1.3$ and $\mathrm{S}-515-7.4$ a.

[6] Hydraulic Institute, 1230 Keith Bullding, Cleveland, Ohio 44115 HYDRAULIC INSTITUTE STANDARDS FOR CENTRIFUGAL, ROTARY \& RECIPROCATING PUMPS, thirteenth edition, 1975 Library of Congress CArd No. A56-4036 
The heat trnasfer fluid is generally a gas or liquid which transports generated heat from the collector subsystem to the thermal stcrage subsystem.

S-515-8.1 General

S-515-8.1.1 Labeling

The information described in the Federal Hazardous Substances Labeling Act $(1960)$ is required for heat transfer flulds. In addition, heat transfer media must be classified and containers duly labeled with reference to NFPA 30, the Flammable and Combustible Liquids Code. Flashpoint and classification as to flammability and combustibility shall be given as indicated in the General Provisions of NFPA 30.

Labeling shall also include the following items:

- service temperature range

- viscosity over service temperature range

- freezing point

- boiling point

- specific heat

- vapor pressure over service temperature range

- materials with which it is compatible

- instructions for inspection, treatment and disposal of the fluid

S-515-8.1.2 Finction - General

The heat transfer fluid shall perform its intended functions without deleterious effects to those parts of the solar energy system with which it comes into contact. Appendix Table B-5 presents a partial listing of properties of several types of heat transfer fluids.

$S-515-8.2$

Toxic and Flammable Fluids

$5-515-8.2 .1$

Genera1

Heat transfer fluids which require special handling (e.g., toxic, flammable, corrosive, explosive, etc.) shall not be used unless the systems in which they are used are designed to avoid exposure to unnecessary or unreasonable hazards; see Sec. S-615-10.1

S-515-8.2.2 Flashpoint

The flashpoint of the heat transfer medium shall not be less than $400^{\circ} \mathrm{F}$ $\left(204^{\circ} \mathrm{C}\right)$ as determined by NFPA 321,1971 , Standard on Basic Classification of Flammable and Combustible Liquid except as provided in Section S-615-14.2.2

Commentam: The maximum temperature to which the heat transfer medium will be exposed is that achieved by the fluid in the collector during no-flow conditions.

S-515-8.2.3 Atmospheric Concentration of Toxic Materials

The concentration of the vapor of the heat transfer medium in the interior atmospheric environment shall not exceed $1 / 10$ th the threshold limit value (TLV) for that particular medium in an 8-hour period. 
Comnentary: The TLV is primarily concerned with industrial exposures. Because routine household exposure could be for much longer time periods, the 1/10th value of the TLV is recommended. TLV's are under continuous review; a list of currently adopted values is published by the American Conference of Government Industrial Hygienists.

Fluid Disposal - Biodegradability and Aquatic Quality

a. A list of the chemical components of the heat transfer medium must be provided in mg/liter. This list must include any substances which comprise more than $0.10 \%$ of the medium.

b. The organic constituents of these substances must have a five-day Biochemical Oxygen Demand (BOD), using sewage seed, of at least $70 \%$ of the theoretical oxygen demand. This test shall be in conformance with the Standard Methods for the Examination of Water and Waste Water, American Public Health Association (1971).

c. The concentration of chemical constituents must be compared with the 96 Hour LC-50* bioassay value for protection of aquatic life. This comparison is to be made in accordance with the Water Quality Criteria 1972.

Using the gallon/day capacity of the local sewage treatment plant, approximate the concentration at the treatment plant. If the dilution of the chemical constituents is $1 / 10$ th the LC-50 value or greater at the sewage treatment plant, the heat transfer medium must be diluted before emptying into a public sewer.

Commentary: Means for the disposal of heat transfer fluids are discussed in Section S-615-9 of this document. Consideration should also be given to the effect of flushing solar systems on the "Basic Design Loading" for sewage treatment, Section CS 603, HUD Handbook 4940.3, Minimum Design Standards for Community Sewage Systems. A preziminary draft of the Environmental Protection Agency's Quality Criteria for Water, October 10, 1975, is currently under review. After its publication in the Federal Register, EPA's criteria will supercede those currently cited.

Changes in the Heat Transfer Fluid

Except when such changes are allowed by the design of the system, the heat transfer fluid shall not freeze, give rise to excessive preclpitation, otherwise lose its homogeneity, boil, change $\mathrm{pH}$ or undergo changes in viscosity outside the design range when exposed to its intended service temperature and pressure range.

$5-515-8.4$

Chemical Compatibility

Heat transfer fluids designed to be used in contact with component materials shall be sufficiently chemically compatible with those materials to prevent deterioration that would impair their function during their design lives. Inhibitors, added to the transfer fluid to prevent corrosion, shall be compatible with all components in the system with which they come in contact.

Commentary: This problem is further discussed in Section S-515-2.3 of this document. Appendix Table B-6 presents a list of inhibitors which have been reported in the literature for use with various metals.

$*_{\mathrm{LC}}=$ Lethal Concentration. See definitions in Appendix D. 


$$
S-515-8.5
$$

S-515-9

S-515-9. 1

S-515-9. 2

S-515-9. 3

\section{Thermal Stability}

The heat transfer fluid shall not degrade at the maximum temperature to which it will reach in-service to an extent that would significantly impair its function during its design life.

Commentary: Wiis maximum temperature will generally be reached under "no-flow" conditions. Appendix Table B-5 includes data for a number of typical transfer fluids. Some fluids may decompose somewhat at elevated temperatures. For excmple, ethylene glycol can degrade to form organic acids. Buffers are usually included with such fluids to control the pH. It may be desirable, if fluids decompose with time, to change the fluids periodicalzy.

\section{HEAT EXCHANGERS}

Cowpliance with Standards

Heat exchangers shall be in compliance with the appropriate standards given in S-515-9.2 and S-515-9.3. Exchangers manufactured to other standards not listed but fulfilling the requirements of a particular solar heating system design may be acceptable.

Tubular Heat Exchangers

Tubular heat exchangers shall be in compliance with the appropriate requirements of TEMA.

Heating Coils

Forced circulation air-heating coils shall be in compliance with the requirements of ARI Standard 410. 
S-515-10

$S-515-10.1$

S-515-10.2

$S-515-10 \cdot 2.1$

$S-515-10.2 \cdot 2$

$S-515-10 \cdot 2 \cdot 3$
GASKETS AND SEALANTS

Applicable Standards

Caulking and sealants shall be in accordance with 507-6 of the MPS, where applicable. Gaskets which seal pressurized systems shall withstand the maximum service pressure when tested in accordance with ASTM D 1081-60 (1974).

Commentary: Since gaskets and sealants used in solar systems may not be adequately covered by existing specifications, Appendix Table B-? is included to serve as a guide in selecting specific sealing materials.

\section{Materials Performance}

Thermal Stability

Gaskets and sealants included in the test described in S-515-2.1.2 shall not exhibit cracking, loss of elasticity, outgassing, or loss of adhesion sufficient to impair their function at the completion of the test.

Commentary: A potential problem with sealants and gaskets used in collectors is that during no-flow conditions outgassing may occur with the outgassing products being deposited on the interior surface of the cover plate. Such deposits can reduce the transmittance of the cover plate.

Chemical and Physical Compatibility

a. Gaskets and sealants shall be chemically and physically compatible with the substrates to which they are joined.

Commentary: Compatibility of gaskets and sealants with substrates may be evaluated in the process of testing materials for compliance with the Federal Specifications listed in Appendix Table B-?.

b. Documentation shall be provided to show that gaskets and sealants in direct contact with the heat transfer fluid are not degraded by the fluid. In lieu of other documentation, gaskets and sealants which are in direct contact with heat transfer fluid shall not exhibit significant expansion, cracking, loss of elasticity or loss of adhesion when immersed for 100 hours in the heat transfer fluid at the maximum service temperature. ASTM F82-67(1973) Standard Recommended Practice for Fast Quality Check on Immersion For Nonmetallic Gasket Materials, shall be used as a guide in performing these tests.

UV Stability

Gaskets and sealants that are normally exposed to UV radiation in-service shall not be adversely affected by such radiation. Documentation shall be provided demonstrating that such materials are capable of withstanding exposure to sunlight for their design lives without functional impairment.

Commentary: Gaskets of ethylene propylene diene monomer (EPDM) mbber or silicone rubber may be appropriate for these applications. 
S-515-11

S-515-11.1

S-515-11.1.1

$S-515-11.1 .2$

S-515-11.2

S-515-11.2.1

INSULATION/THERMAL AND MOISTURE PROTECTION

\section{Genera1}

Materials used for insulation shall be of sufficient proven effectiveness and durability under the expected operating conditions to assure that required design conditions concerning heat losses, sound control or fire rating are attained. Insulation in contact with the ground shall not be adversely affected by soil, vermin or water. Insulating materials shall be in accordance with Section 507-3 of the MPS.

Flame Spread Classification

The flame spread classification index for all insulation materials shall not exceed the following values:

$\begin{array}{lr}\text { plastic foam } & 25 \\ \text { all other insulation material } & 150 .\end{array}$

The ASTM E84-70 flame spread test method shall be the basis for evaluating the surface burning characteristics of the residential insulation material. Where fibrous blankets with facings are to be used, the surface burning characteristics of the complete faced insulation blanket shall be measured.

Commentary: No single test is sufficient to provide a full estimate of performance of a product in a fire. Plastic foams are difficult to evaluate in ASTM E84-70. The requirement of flame spread classification of 25 maximum for these foams wilz provide as much a safety assurance as is possible with current test methods. Such a classification lor any other numerical classification) shall not be construed as the equivalent of "noncombustible." Many insulation materials, including those consisting of cellulose, plastic foam and fibrous glass (containing organic binder) are combustible materials which will bum and release heat, especially when exposed to continuous large fire sources.

\section{Flame Resistance Permanency}

Chemical retardant insulations shall retain their flame resistance throughout their service lifetime. The procedures and equipment specified in ASTM C739-73, Section 10.4, "Flame Resistance Permanency" shall be used in judging the effect of aging on the permanence of any flame retardants used during manufacture.

\section{Collector Insulation}

Genera1

Collector insulation shall be sufficiently stable at the maximum temperature to which it will be exposed in-service. Suggested upper temperature limits for several insulating materials are listed in Appendix Table B-8.

Commentamy: Organic materials found in insulation have been known to evolve from collector insulation during system operation, leaving a coating on the cover plates which impairs collector performance. Normally the insulation nearest the absorber plate is exposed to temperatures higher than insulation near other parts of the collector. It may be possible to use one type of insulation adjacent to the absorber plate and another type in areas of the collector which willnot be exposed to extreme temperatures. Fiberglass insulation with binders can be pre-heated to expel volatiles prior to use in collectors. If such pretreatment is used, the upper temperature limit becomes somewhat higher. 
Some plastic focm insulations are available with various encapsulated gases. Those using freon can cause severe outgassing problems while those insulations blown with $\mathrm{CO}_{2}$ could be acceptable.

$S-515-11.2 .2$

$5-515-11.3$

$5-515-11.4$

$S-515-11.5$

$5-515-11.6$

$S-515-12$

$S-515-12.1$

$S-515-12.2$

$S-515-12.3$
Thermal Stability

After exposure as described in S-515-2.1.2, there shall be no swelling or other dimensional changes in the collector insulation that will significantly affect the collector performance. In addition, the insulation shall not, during operating or non-operating periods, give off volatile materials that could affect the performance of components of the solar energized system or the safety of the dwelling occupants.

\section{Pipe or Duct Insulation}

Pipe or duct insulation shall be sufficiently stable at the maximum temperature to which it will be exposed in-service. Suggested upper temperature limits for several insulating materials are listed in Appendix Table B-8.

Storage Subsystem Insulation

If insulation whose thermal properties are affected by water is used, the insulation shall be protected in accordance with S-515-11.5 and S-515-11.6 of this document.

Waterproofing and Dampproofing

Materials used for waterproofing shall be in accordance with Section 507-1 of the MPS.

\section{Vapor Protection}

Materials used for vapor barriers shall be in acccordance with Section 507-2 of the MPS.

\section{CATCH BASINS}

General

Catch basins shall be of adequate size and construction to fulfill their intended functions.

Materials Compatibility

Catch basin materials which are jointed to or in contact with other materials shall have sufficient chemical and physical compatibility with those materials to prevent deterioration.

\section{Coating}

The catch basin coating, when used, shall not be significantly deteriorated during its design life by weathering or by the transfer medium with which it comes in contact. 
S- 515-13

$S-515-13.1$

$S-515-13.2$

$S-515-13.2 .1$

$S-515-13.2 .2$

$S-515-13 \cdot 2 \cdot 3$

$S-515-13 \cdot 2 \cdot 4$
ORGANIC COUPLING HOSES

\section{Genera1}

Organic coupling hoses shall be of proven effectiveness and durability under the expected operating and exposure conditions.

Materials Performance

\section{Thermal Stability}

Organic coupling hoses included in the test described in S-515-2.1.2 shall not exhibit cracking, loss of elasticity, or embrittlement at the completion of the test that will significantly impair their function.

Commentary: The selection of coupling hoses and clamps is quite critical. Many faizures have been noted due to the clamping of hoses with screw or spring-type clamps, exposing the hose to high temperatures which tend to vulcanize the area beneath the clamp, causing it to lose resiliency and begin to leak. Further tightening of the clamps will temporarily stop leakage but further vulcanizing will occur with the end result being a hard non-resilient ring under the clamp which can no Zonger be tightened to prevent leakage. Silicone mibber hose is one of the few materials which have been tested and tend to maintain their resiliency with no tendency to take a thermal set. The silicone mibber hoses, however, tend to be so pliable that screw-type clamps with perforated bands should not be used as it is possible to extmude the material through the perforations in the band. If this material is used, smooth band clomps should be utilized.

\section{UV Stability}

Organic coupling hoses which are exposed in service to UV radiation shall not be adversely affected by the radiation. In lieu of other documentation, organic coupling hoses shall not exhibit significant cracking, loss of elasticity or embrittlement after 500 hours exposure as described in ASTM D750-68 (1974).

Compatibility with Heat Transfer Fluid

Documentation shall be provided to demonstrate that organic coupling hoses which are in direct contact with heat transfer fluids are not significantly degraded by the fluids. In lieu of other documentation, the hoses shall not exhibit cracking, loss of elasticity or embrittlement that will significantly impair their function when tested for 100 hours at the maximum service temperature according to ASTM F82-67(1973).

Commentamy: SAE Standard J20e (1974) covers coolant system hoses for automobiles. For solar systems using glycol fluids, this SAE Standard may be applicable for demonstrating compliance with S-515-13.2.3. It is expected, however, that hoses in solar systems will be exposed to more strenuous conditions than automobile hoses.

Compatibility with Piping Materials

Organic coupling hoses which are used to join piping shall be compatible with the piping. 
Documentation shall be provided to demonstrate that organic coupling hoses which are exposed in-service to the environment are not significantly degraded by ozone in the air. In lieu of other documentation, the hoses shall exhibit no cracking or loss of elasticity that will significantly impair their function when tested for 100 hours to an ozone atmosphere of $50+5 \mathrm{pphm} /$ volume at $23^{\circ} \mathrm{C}$ according to ASTM DI149-64(1970). 
CHAPTER 6 CONSTRUCTION

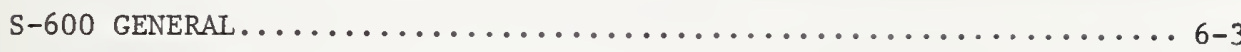

s-600-1 Labeling...................................... 6.

S-600-2 Alternate Construction........................... 6-3

S-600-3 Installation, Operation, and Maintenance Manual..........6-3

S-600-4 Replacement Parts.............................. 6-4

S-600-5 Maintainability of Systems and subsystems.............6 6-4

S-600-6 Safety and Health Requirements................... 6-4

S-601 GENERAL STRUCTURAL REQUIREMENTS..................... 6-6

s-601-1 General. ...................................6-6

s-601-2 Design Dead Loads.............................6-6

S-601-3 Design Live Loads............................6-6

s-601-4 Wind Loads..................................6-6

S-601-5 snow Loads.................................. 6.

s-601-6 Seismic Loads................................6-8

s-601-7 Hail Loads.................................. 6-9

S-601-8 Maintenance Loads............................. 6-15

s-601-9 Thermal Distortion........................... 6-15

s-601-10 Collector Cover Plates.........................6-15

S-601-11 Connections of Collector Frames and/or Other
Support Structures..................... $6 \ldots \ldots$

s-601-12 storage Tanks...............................6-16

S-601-13 Dynamic Loads............................... 6-16

S-604 MASONRY...................................... 6-17

s-604-1 General..................................... 6-17

S-607 THERMAL AND MOISTURE PROTECTION...................... 6-18

S-607-3 Building Insulation for Passive Solar Systems..........6-18

S-615 MECHANICAL..................................... 6-19

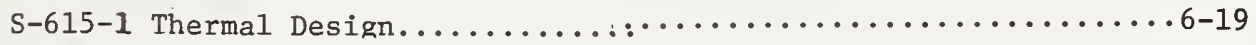

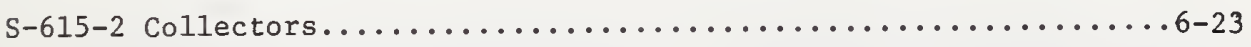


S-615-3 Mechanical Supporting Devices.................... 6-27

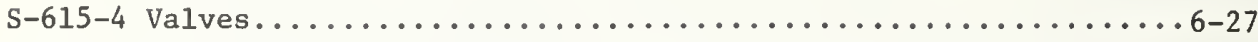

S-615-5 Pumps and Compressors............................ 6-27

S-615-6 Mechanfcal Vibration Isolation................. 6-27

S-615-7 Thermal storage............................. 6-28

S-615-8 Heat Transfer Fluids......................... 6-30

S-615-9 Waste Disposal.............................6. 30

S-615-10 Plumbing................................

S-615-11 Auxiliary Energy System...................... 6-35

S-615-12 Heat Exchangers................................. 34

S-615-13 Air Distribution........................... 6-36

S-615-14 Controls and Instrumentation.......................... 37

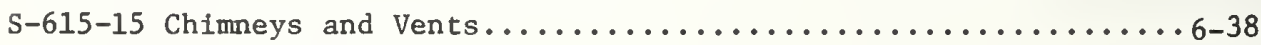

S-615-16 Mechanical Ventilation...................... 6-38 


\section{CONSTRUCTION}

$S-600$

$S-600-1$

$S-600-2$

$S-600-3$

S-600-3.1 Installation Instructions

The provisions of this chapter are applicable to solar energy systems including heating $(\mathrm{H})$ and domestic hot water (DHW) systems. This chapter is a supplement to the Minimum Property Standards (MPS). Building construction provisions (Chapter 6 ) of the MPS are applicable in addition to the items explicitly discussed in this document.

\section{LABELIRT}

Solar heating (H) and/or domestic hot water (DHW) systems, equipment and hazardous substances shall be labeled or given clear indication of their input and output, operating temperatures, pressures, flow and filled weight as appropriate.

\section{ALTERNATE CONSTRUCTION}

Alternate or special methods of construction other than those contained herein, may be used when found acceptable by established HUD procedures and Section S-101 of this document.

\section{INSTALLATION OPERATION AND MAINTENANCE MANUAL}

A manual shall be provided for the installation, operation and maintenance of the $\mathrm{H}$ and/or DHW systems.

\section{Commentary}

It is suggested that each manufacturer of a subsystem should provide installation, operating and maintenance manuals for each subsystem he provides, and that he show typical systems using his and other subsystems to complete the whole. The installer, who is responsible for the complete installation and therefore for the complete system should assemble all the manuals from the subsystem manufacturers into a complete manual pertinent to the system. He should add any other information needed for an understanding of the system and its functioning. Control sequences are determined almost entirely in the field and should be described for the specific installation.

The manual shall include physical, functional and procedural instructions describing how the subassemblies of the $\mathrm{H}$ and/or DHW systems are to be installed.

These instructions shall include descriptions of both interconnection and connections with the dwelling and site.

\section{S-600-3.2 Maintenance and Oderation Instructions}

The manual shall completely describe the $\mathrm{H}$ and/or DHW systems, their breakdown into subsystems, their relationship to external systems and elements, their performance characteristics, and their required parts and procedures for meeting specified capabilities.

The manual shall list all parts of the systems, by subsystem, describing as necessary for clear understanding of operation, maintenance, repair and replacement, such characteristics as shapes, dimensions, materials, 
weights, functions, and performance characteristics. The manual shall include a tabulation of those specific performance requirements which are dependent upon specific maintenance procedures. The maintenance procedures including ordinary, preventive and minor repairs, shall be cross-referenced for all subsystems and organized into a maintenance cycle. The manual shall fully describe operating procedures for all parts of the system including those required for implementation of specified planned changes in mode of operation.

\section{S-600-3.3 Maintenance Plan}

The manual shall include a comprehensive plan for maintaining the specified performance of the $\mathrm{H}$ and/or DHW systems for their design service lives.

The plan shall include all the necessary ordinary maintenance, preventive maintenance and minor repair work, and projections for equipment replacement, and should include important pressure, temperature and flow information as checkpoints throughout the system to assist in troubleshooting.

\section{S-600-4 REPLACEMENT PARTS}

Parts, components, special tools and test equipment required for service, repair or replacement shall be commercially available or available from the system or subsystem manufacturer or supplier.

\section{Commentary}

This criterion is intended to preclude long periods of system down-time due to the need for the repair or replacement of parts.

\section{S-600-5 MAINTAINABILITY OF SYSTEMS AND SUBSYSTEMS}

The $\mathrm{H}$ and DHW systems and subsystems shall be capable of being serviced with a minimum amount of special equipment by a trained service technician using a maintenance manual and common tools.

\section{COMMENTARY}

ON LARGER COLLECTOR INSTALLATIONS IT MAY BE DESIRABLE TO MAKE PROVISIONS FOR SUPPLYING ELECTRICAL POWER AND WATER FOR MAINTENANCE PURPOSES,

\section{S-600-6 SAFETY AND HEALTH REQUTREMENTS \\ S-600-6.1 General}

Materials or construction used in the installation of solar systems shall be in accordance with the fire protection provisions of Section 405-7 of MPS.

\section{S-600-6.2 Penetrations Through Fire Rated Assemblies}

Penetrations through fire-rated assemblies as a result of the solar subsystems shall not reduce the fire resistance below the levels specified in Section 405 of MPS.

\section{S-600-6.3 Protection From Heated Components}

The surface temperature of any accessible surfaces, exposed pipes and/or ducts must be less than $150^{\circ} \mathrm{F}$. Evidence shall be provided that no hazard exists from such exposure. 


\section{S-600-6.4 System Component Clearances}

Any system components installed within a confined area or as an integral part of a structural assembly of the building which can be expected to operate under elevated temperatures shall be installed in accordance with NFPA No. 89M-71, Clearances for Heat Producing Appliances.

S-600-6.5 Protection Against Over-Pressure and Over-Temperature

The total system shall be protected against excessive pressures and temperatures. Pressures shall be limited as specified in S-615.14.2.

\section{S-600-6.6 Personal Safety}

Where access for service or cleaning of solar subsystems requires a person to balance on a narrow or (steeply) sloping surface, provisions shall be made for securing a life-line, guard-rail or other personal protective device.

S-600-6.7 Frowth of Fungi, Mold or Mildew

Components and materials used in the $H$ and DHW systems shall not promote the growth of fungi, mold or mildew in accordance with applicable codes, the test specification of Section 10, UL 181-74 and MPS, Appendix D, Section E.

S-600-6.8 Protection Against Vermin or Rodents

Solar energy systems (including piping, fixtures, appliances and other equipment) should not contribute to the entry or growth of vermin or rodents. Maintenance of physical barriers, minimization of concealed spaces conducive to harboring vermin or rodents, provisions of access for cleaning shall be in accordance with applicable codes such as Section 2.13 of the National Standard Plumbing Code.

S-600-6.9 Protection of Potable Water Supply

The design and installation of the complete system and its individual components shall be completed in such a manner as to provide complete protection of the potable water supply. Such installations shall be in accordance with Chapter 10 of the National Standard Plumbing Code and other applicable codes (see Sec. S-615-10) 
$S-601$

S-601-1

$S-601-2$

$S-601-3$

$S-601-3.1$

$S-601-4.1$

\section{GENERAL}

This section contains those supplemental requirements to Chapter 6 of MPS needed to cover solar systems which utilize conventional structural materials (materials covered by the current MPS edition). Unless specifically modified herein, the requirements of MPS Chapter 6, apply in addition to the supplemental requirements in this section.

Al1 structural design for solar systems and their mounting structures shall be based on generally accepted engineering practice. All loading shall be in accordance with ANSI A58.1 except as shown otherwise in this document or MPS.

\section{DESIGN DEAD LOADS}

In calculating the dead loads for solar systems, the weights of the transfer fluid in the collector, fluid in storage tank, and fluid in other subsystems and components shall be included.

\section{DESIGN LIVE LOADS}

Roof Mounted Solar Systems

Design live roof loads prescribed in Table 6-1.2 of MPS 4900.1 shall not be required for flat plate collector panels that are mounted on roofs that do not form an integral part of the roof if adequate access is provided for service and maintenance personnel. For flat plate collectors which form an integral part of the roof, the design live roof loads listed in Table 6-1.2 sha11 be required.

\section{Commentary}

The design live loads contained in Table 6-1.2 of MPS 4900.1 constitute minimum loading requirements needed primarily for human safety. The roof will need to be reparied from time to time; therefore, it must support the workman making the repairs, regardless of the wind and snow loading requirements. This is not the case for accessible roof-mounted collectors; they do not need to support workmen when being repaired. Hence, they need only to sustain the required environmental loading (wind, snow and hail).

\section{WIND LOADS}

\section{Flat Plate Collectors Mounted on Roofs and Walls}

Wind loads on flat plate solar collectors shall be those specified for roofs and walls in section $601-6$ of the MPS or as modifled in paragraphs $\mathrm{S}-601-4.1 .1, .2, .3$, and .4 below.

S-601.4.1.1 Flat plate collectors that are mounted with their cover plates and back surfaces flush wth the surface of the roof shall be subjected to the wind loads that would have been imposed on those areas of the roof covered by the collectors.

S-601-4.1.2 Flat plate collectors mounted at an angle or parallel to the 
surface of the roof on open racks can have an uplift load caused by the impingement of wind on the underside of the collector. This wind load is in addition to the equivalent roof area wind loads to which the collectors shall be subjected, and shall be determined by utilizing accepted engineering procedures which may include wind tunnel testing. Equivalent roof area wind loads are those wind loads that would have been applied to the areas of the roof occupied by the collectors. Equivalent roof area wind loads shall be applied to the outer cover plate of the collectors.

S-601-4.1.3 In calculating design wind loads for flat plate collectors mounted on roofs, the internal pressure coefficients, $C_{p i}$, listed in Table 11, ANSI A58.1 shall be neglected. (See Commentary)

S-601-4.1.4 Wind loads on flat plate collectors mounted at an angle to a vertical wall shall be the same as those required for equivalent roof eave area as stipulated in section 6.5.3.2.4 of ANSI A58.1. Wind loads on flat plate collectors mounted parallel to, or integral with vertical walls shall be the same as those required for exterior walls.

\section{S-601-4.2 Concentrating Solar Collectors}

Wind loading on concentrating solar collectors snall de deterwiud usiug the results of accepted engineering prccerures or physical simulation, which may include wind tunnel testing.

S-601-4.3 Roof Wind Loads

Roof loading due to wind effects on flat plate collector and concentrating collector support structures and/or enclosures must be included not only in the design of the roof support framing, but also in the design of all structural elements influenced by these loads.

\section{S-601-4.4 Ground Mounted Collectors}

Wind loading on ground-mounted flat plate collectors and their support structures shall be determined in the same manner as that for roof-mounted flat plate collectors. Where flat plate collectors are mounted on open racks, equivalent roof area wind loads shall be those given for nonenclosed structures as given in section 6.6, ANSI A58.1, taking into account local terrain characteristics.

\section{S-601-4.5 Exposed Storage Tanks}

Wind loads on exposed storage tanks shall be determined in accordance with ANSI A58.1.

\section{Commentary}

Paragraph 4.1.3 It is assumed that no uplift pressure is exerted on the underside of a collector except as indicated in paragraph 4.1 .2 above. However, in calculating the overall roof loading, internal pressure in the dwelling must be considered in the usual manner.

\section{S-601-5 SNOW LOADS}

S-601-5.1 Flat Plate Solar Collectors Mounted on Roofs and Walls

Snow loads acting on flat plate solar collectors or caused by their installation shall be those required for roofs as specified in 
Section 601-5 of MPS or as modified in paragraphs S-601-5.1.1, .2, and .3 below

S-601-5.1.1 Flat plate collectors that are mounted with their cover plates and back surfaces parallel to the surface of a roof, and those that are mounted at an angle to the surface of a roof, on open or closed racks in a saw-tooth arrangement shall be designed to support the snow loads that would otherwise have been imposed on areas of the roof covered by the collectors. Where collectors are mounted with their cover plates forming steep slopes, shedding of snow from the collector may cause snow to accumulate at the base of the collector or other hazardous conditions which must be considered in the design of the roof.

S-601-5.1.2 Flat plate collectors mounted at an angle to the surface of a wall, and supported by the wall, shall be designed to support the same snow loads as an equivalent roof eave area.

S-601-5.1.3 Consideration shall be given to the potential local accumlation of snow under flat plate collectors.

\section{S-601-5.2 Roof Loading}

S-601-5.2.1 A single or multiple saw-tooth array of collectors may cause severe drifting between rack mounted collectors (and under open racks) in addition to the snow load on the cover plates. These unusual snow loads must be determined on the basis of local snow conditions.

S-601-5.2.2 Snow loads on concentrating solar collectors shall be determined by accepted engineering procedures.

S-601-6 SEISMIC LOADS

S-601-6.1 Genera1

Selsmic design requirements for the mechanical and electrical components of solar energy systems are covered in this section. Architectural and structural components shall be designed in accord with MPS Sec. 601-9. The requirements of this section shall apply to the erection, installation, relocation, or replacement of, or addition to, any mechanical or electrical component of, ? sriar system. If elements of the solar energy system are attached to any existing structural element, or if parts of any existing structural element are modified or replaced with parts different in size and weight, the element, as well as Its connections to the building shall be re-designed to comply with the seismic design requirements of Section 601-9 of MPS.

\section{S-601-6.2 Design Provisions}

S-601-6.2.1 Mechanical or electrical components of a solar system are subjected to seismic forces generated by their mass and may also be influenced by interaction with elements of the structural system. The design of all connections between the mechanical or electrical components and the structural frame shall allow for anticipated movements of the structure. The details of the connections shall be made a part of the design documents. 
Selsmic Forces. Mechanical and electrical components of solar energy systems and their connections shall be designed to resist the seismic forces stipulated hereafter in accordance with Section 2314 of the Uniform Building Code, as adopted and revised in October 1975, which provides the following equation. [1]

$$
\mathrm{F}_{\mathrm{p}}=\mathrm{ZC}_{\mathrm{p}} \mathrm{SW}_{\mathrm{p}}
$$

Where

$\mathrm{F}_{\mathrm{p}}=$ Force on the part or component and in the direction under consideration

$\mathrm{Z}=$ Numerical coefficient related to the seismicity of the region as shown in Figures $S-601.1, a, b, c$, and $d$. The values of $Z$ for the respective zones are listed below:

$\begin{array}{lll}\text { Zone } & 0 & Z=0 \text { (no damage) } \\ \text { Zone } & 1 & Z=3 / 16 \\ \text { Zone } 2 & Z=3 / 8 \\ \text { Zone } 3 & Z=3 / 4 \\ \text { Zone } 4 & Z=1\end{array}$

$S$ = Numerical coefficient for site structure resonance. When the characteristic site resonance is not established in accordance with Section 2314 of UBC the value of S shall be taken as 1.5 .

$\mathrm{C}_{\mathrm{p}}=$ Numerical coefficient specified in Table S-601.2

$\mathrm{W}_{\mathrm{p}}=$ The weight of the part or component, including the weight of contents in accordance with Section S-601.2

S-601-7 HAIL LOADS

The cover plates of solar collectors shall be designed to resist, without failure, the vertical impact of a single hailstone of the magnitude stipulated below falling at its terminal velocity.

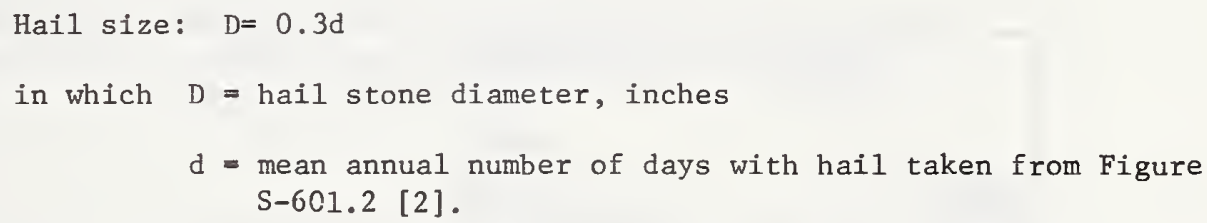

Terminal velocities for various hail sizes are given in Table S-601.3. [3]. Compliance with this provision shall be based on documented past hail loading performance or testing using the procedures described in NBS Building Science Series BSS 23 [4] or analytical procedures acceptable to HUD.

[1] The design provisions in this paragraph have been extracted from the business meeting reports of the International Conference of Building Officials (UBC). These provisions contain the approved code changes which will appear in the 1976 UBC.

[2] Baldwin, J. L., Climates of the United States, U.S. Dept. of Commerce, Washington, D.C. (1973).

[3] Mathey, R. C., Hail Resistance Tests of Aluminum Skin Honeycomb Pane1s for the Relocatable Lewis Building, Phase II, NBS Report 10 193, National Bureau of Standards, Washington, D. C. (1970).

[4] Greenfield, H., Hail Resistance of Roofing Products, Building Science Series 23, National Bureau of Standards, Washington, D.C. (August 1969). 


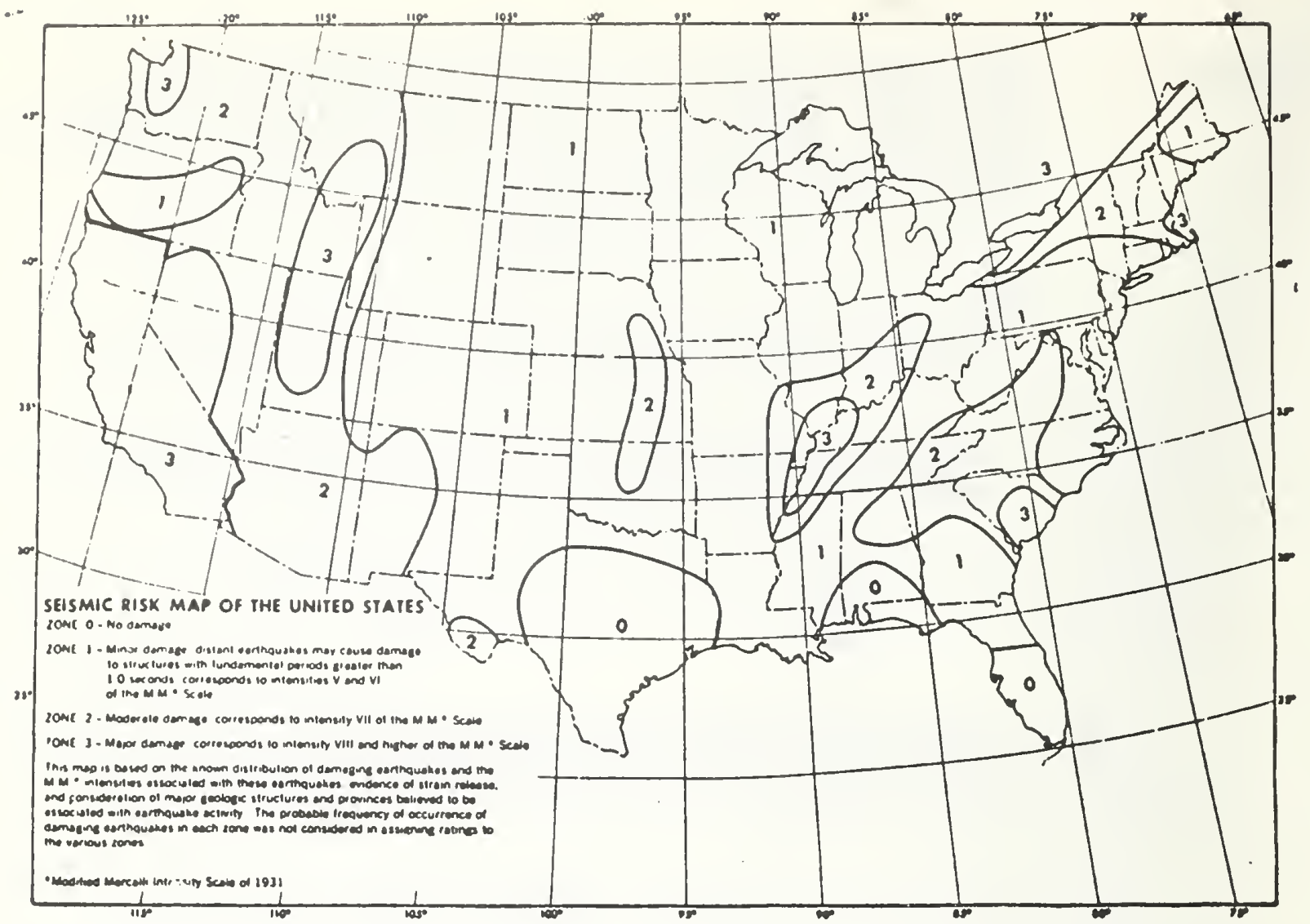

Figure S-601.1a Seismic zone map of Continental United States. (Zone 4 is shown in figures $S-601.1 b$ and $S-601.1 c$ )

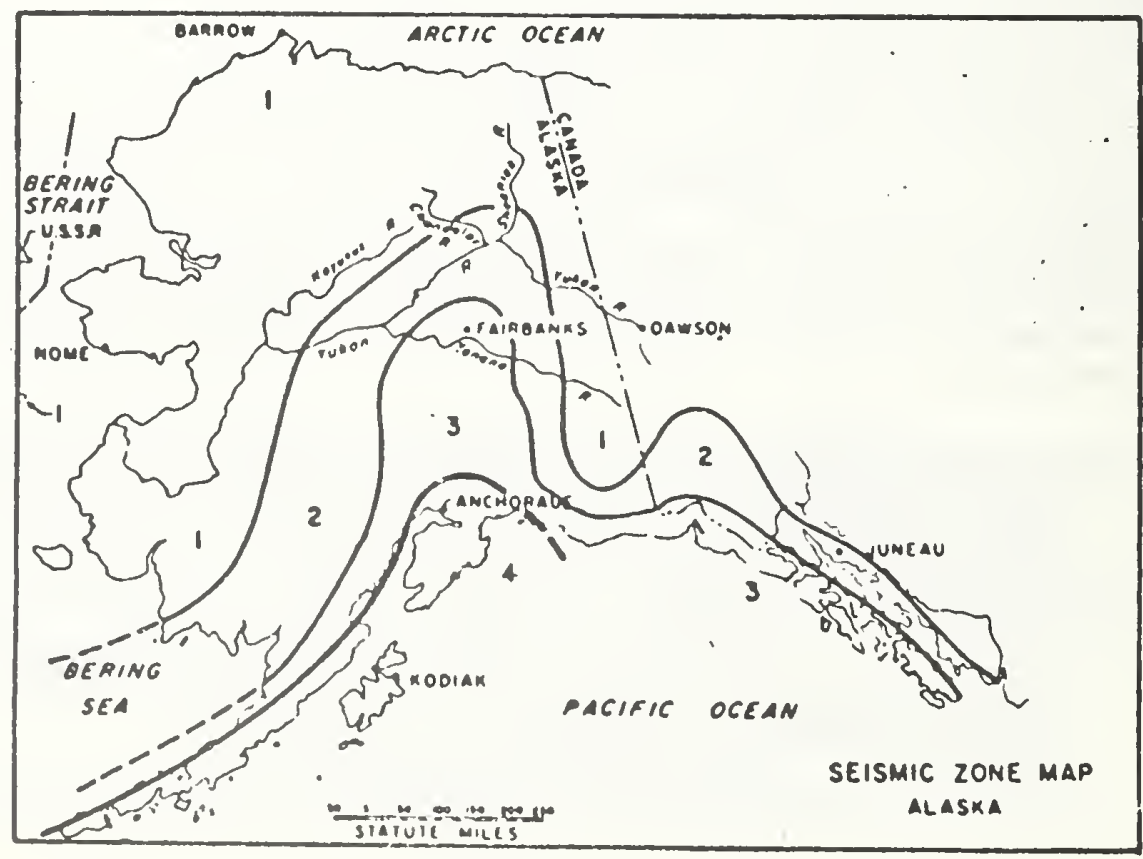

Figure S-601.1b Seismic zone map of Alaska. 


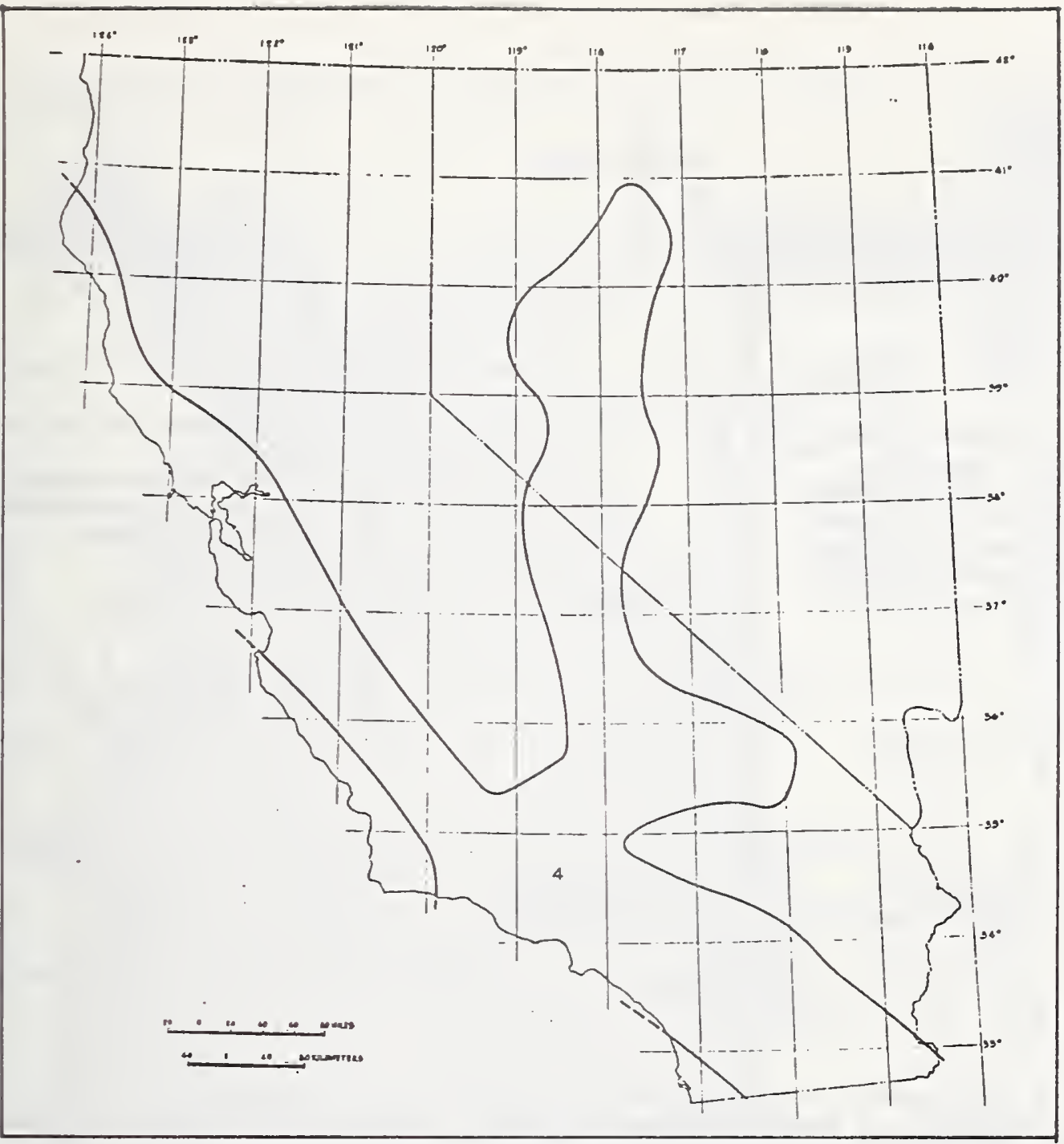

Figure S-601.1c Seismic map of zone 4 in Continental United States.

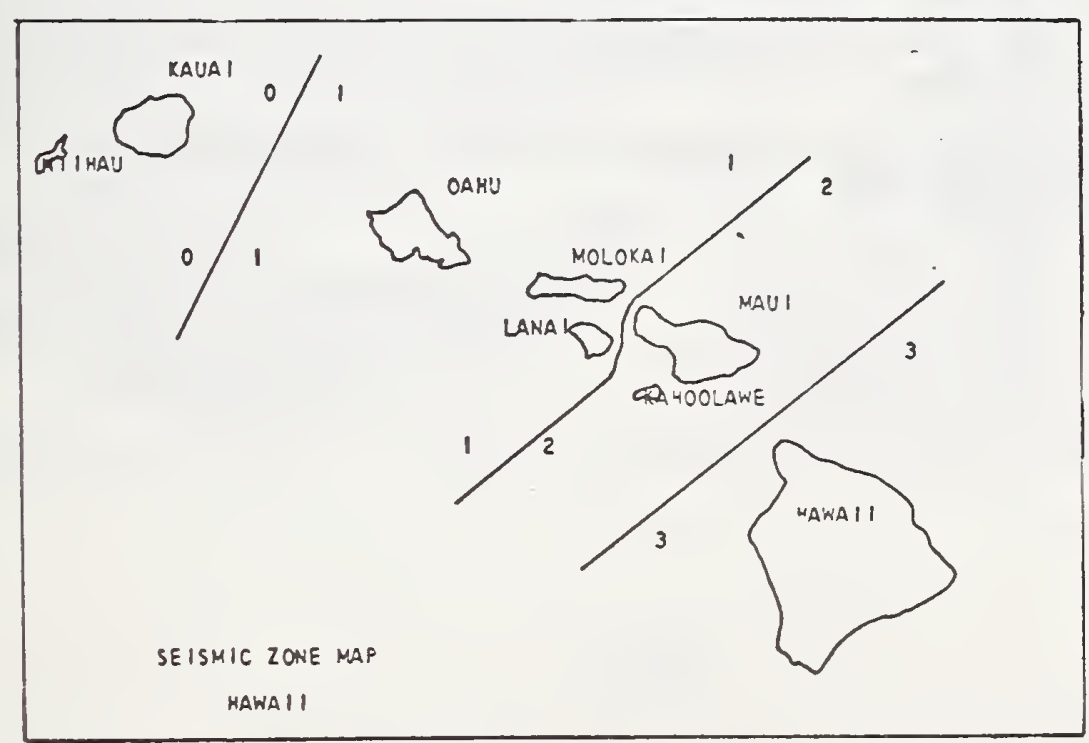

Figure S-601.1d Seismic zone map of the Hawaiian Islands. 
TABLE S-601.2

\begin{tabular}{|c|c|c|}
\hline Part of System & $\begin{array}{l}\text { Direction of } \\
\text { Force }\end{array}$ & Value of $\mathrm{C}_{\mathrm{p}} \frac{1 /}{2 /}$ \\
\hline $\begin{array}{l}\text { Storage tanks, pressure vessels } \\
\text { boilers, furnaces, absorption } \\
\text { air conditioners, other equipment } \\
\text { using combustible or high temper- } \\
\text { ature energy sources, electrical } \\
\text { motors and motor control devices, } \\
\text { storage tanks, heat exchangers, } \\
\text { pressure vessels }\end{array}$ & $\begin{array}{l}\text { any } \\
\text { direction }\end{array}$ & $\begin{array}{l}0.12 \text { when resting on } \\
\text { ground } \\
0.20 \text { when connected to, } \\
\text { or housed, elsewhere } \\
\text { in the building. }\end{array}$ \\
\hline $\begin{array}{l}\text { Flat plate and concentrating } \\
\text { solar collectors }\end{array}$ & $\begin{array}{l}\text { any } \\
\text { direction }\end{array}$ & 0.20 \\
\hline $\begin{array}{l}\text { Tranfer liquid pipes larger } \\
\text { than } 21 / 2 \text { in. in diameter }\end{array}$ & $\begin{array}{c}\text { any horizontal } \\
\text { direction }\end{array}$ & 0.12 \\
\hline
\end{tabular}

1/ For flexible and flexibly mounted equipment and machinery, appropriate values of $\mathrm{C}$ shall be determined by a properly documented dynamic analysis, or by dynamic testifhg, using appropriate excitation spectra approved by HUD. Consideration shall be given to both the dynamic properties of the equipment and machinery and to the building or structure in which it is placed.

2) WHEN LOCATED IN THE IIPPER PORTION OF ANY BUILDING WHERE THE $\|$ N $/$ D FATIO IS $5: 1$ OR GREATER THE CP VALUE SHALL BE INCREASED BY $50 \%$

WHERE $H_{N}=$ HEIGHT IN FT, OF THE PART OF THE SYSTEM ABOVE THE BASE LEVEL OF THE BUILDING

$D=$ THE DIMENSION OF THE STRUCTURE. IN FEET IN A DIRECTION PARALLEL TO THE APPLIED FORCE 


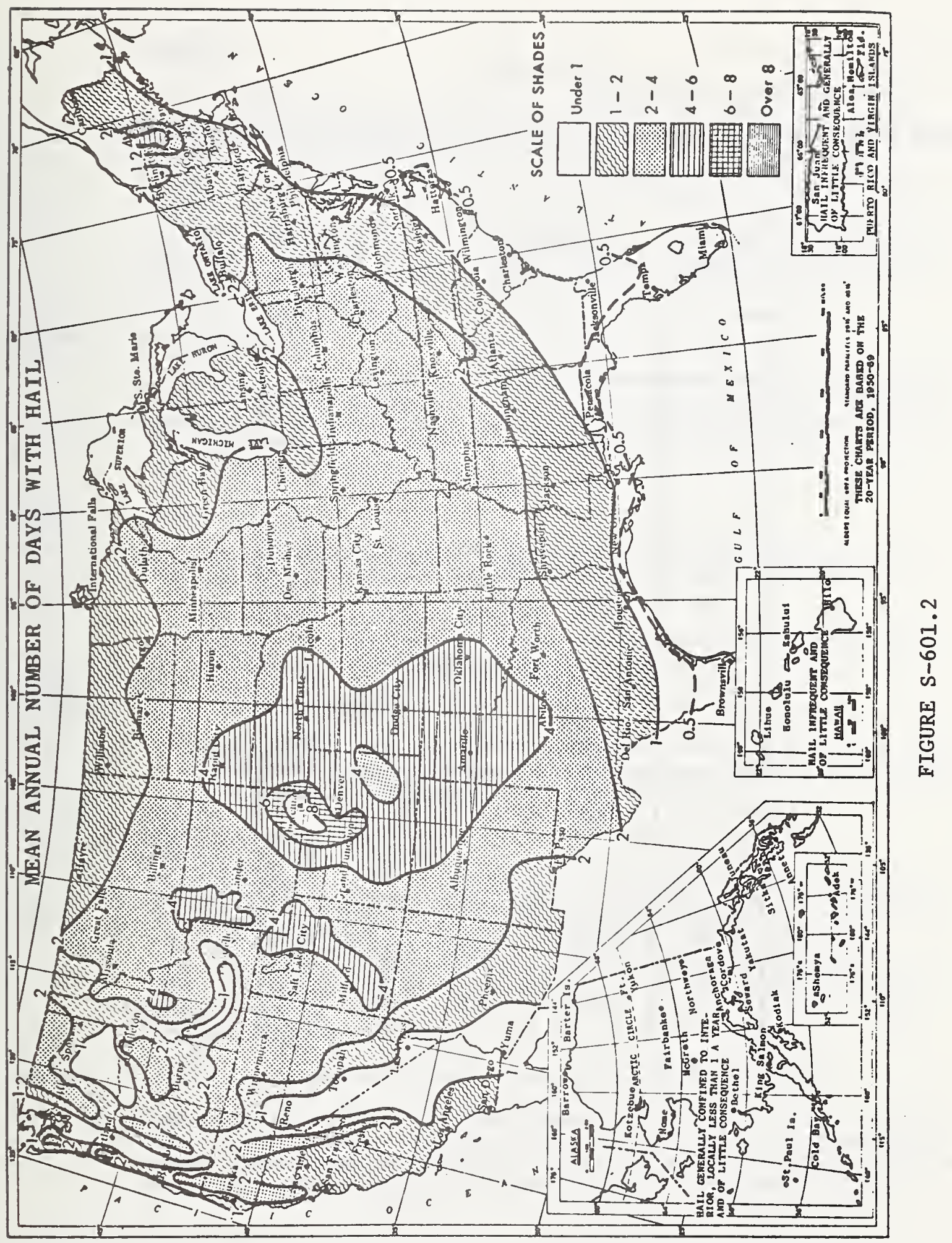


TABLE $S-601.3$

Values of weight and terminal velocity in free fall computed for smooth ice spheres.

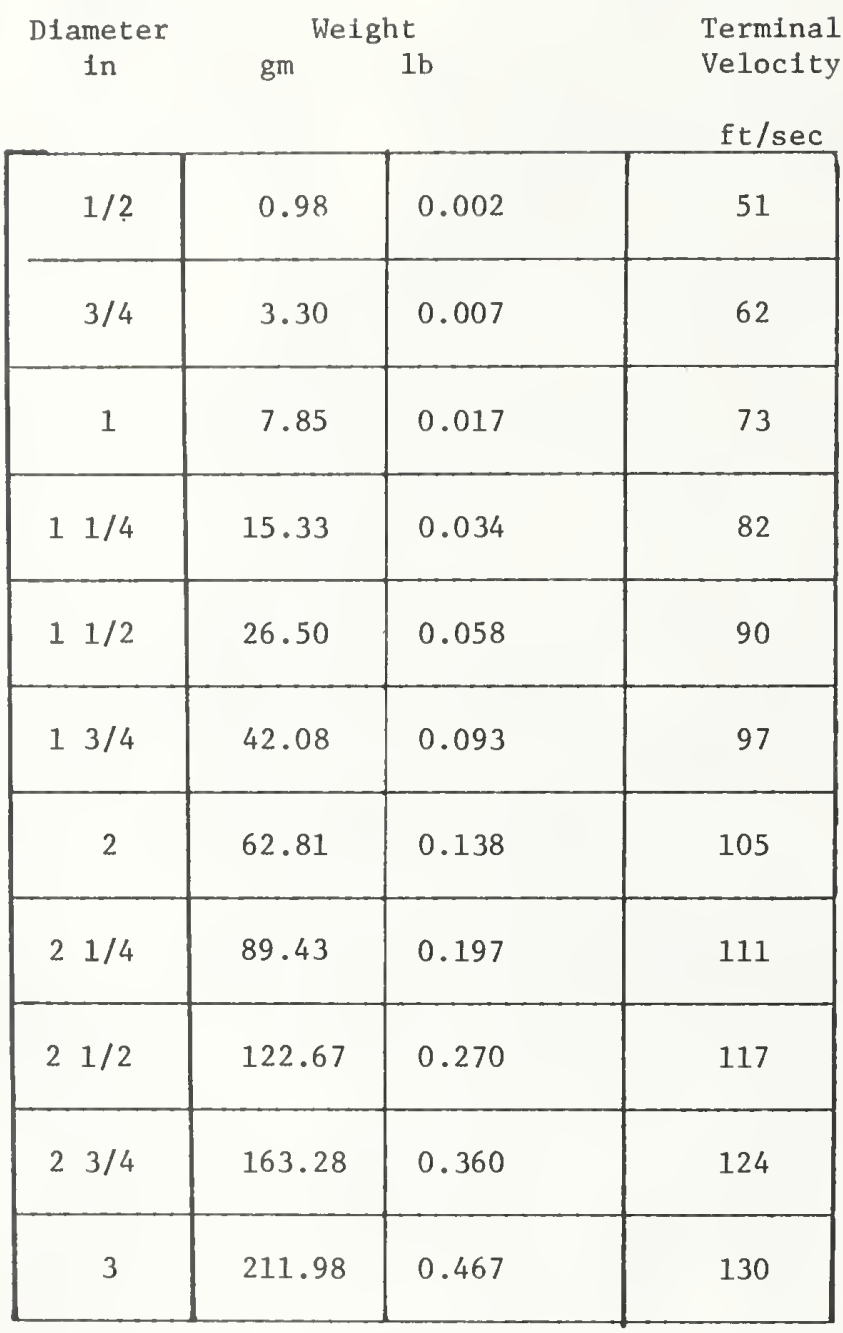


The correlation of hail size with mean annual number of days with hail was determined using data relating the probability of occurrence of hail particle size to the number of days with hail (tabulated in Ref. [1]), and limited statistical information relating the local area covered by a hailstorm, and the regional area for which statistical data is compiled. The hail size indicated has a $5 \%$ probability of being exceeded in any one year (estimated 20 year recurrence interval). The hail requirements in this section are based on available information which does not contain physical test data. Therefore, local hailstone loading performance should be considered in implementing the requirements of this section.

$S-601-8$

\section{MAINTENANCE LOADS}

Al1 components of the solar energy systems which must support maintenance personnel shall be designed to resist a single concentrated load of $250 \mathrm{lbs}$. distributed over a $4 \mathrm{sq}$. in. area, acting on the installed component in the most critical locations. Special allowance shall also be made for heavy maintenance equipment, if used.

S-601-9 THEKMAL DISTORTION

(1) Thermal distortion of the mechanical or structural components of the solar system during operation and periods of stagnation shall not cause deterioration of the system's performance.

(2) Thermal distortion of the solar system shall not cause distress to the system or the supporting dwelling structure.

\section{S-601-10 COLLECTOR COVER PLATES}

(1) Deflection or local distress of cover plates resulting from the maximum design loading shall not impair the functioning of the unit. This shall be demonstrated by analysis or physical simulation.

Commentary

Since wind can come from any direction, there will be maximum pressure (inward) loading for units mounted on the windward side of an installation and maximum suction (outward) loading for those mounted on the leeward side (unless shielding is provided). Depending on the installation, suction loading can, and often does, exceed pressure loading; hence, cover plate retainers must be adecuately designed to prevent them from being separated from the collector frome or induce failure of the cover plate by suction Zoading.

\section{S-601-11 CONNECTIONS OF COLLECTOR FRAMES AND/OR OTHER SUPPORT STRUCTURES}

When collector frames and/or other support structures are mounted on walls, roofs, or other weather resistant surfaces, distortion of the frame from imposed loading shall not cause penetrations or separations of these surfaces such that moisture leaks occur through the weather resistant surfaces.

[1] Storm Data, U.S. Dept. of Commerce, National Oceanic and Atmosphere Administration, Environmental Data Service (monthly periodical) 
S-601-12.1 Design and Fabrication

Storage tanks shall be designed and fabricated to standards embodying principles recognized as good engineering design and fabrication practices for the materials used. These standards shall be approved by HUD.

\section{S-601-12.2 Testing}

Each liquid storage tank shall be tested by the manufacturer or the installation contractor to prove that leakage does not occur. The test pressure shall be 1.5 times the maximum design pressure for pressures less than 15 psi; however, these pressures shall not be less than 5 psi. For tanks designed for pressures greater than 15 psi, the proof test pressures sha11 be approved by HUD.

Storage tanks designed to contain dry heat storage material need not be leak tested unless a safety hazard can result from a storage tank failure.

S-601-12.3 Environmental and Vehicular Loading

In addition to the design, fabrication and test requirements, for storage tanks stipulated in the preceeding paragraphs of this section, the following loading requirements shall be included in the design of storage tanks.

S-601-12.3.1 Above Ground

Unsheltered storage tanks shall be designed to resist loads resulting from, snow, wind, hail, and siesmic loading. Sheltered (completely enclosed) tanks need only be designed to resist seismic loading.

S-601-12.3.1 Underground

Underground tanks shall be designed to resist soll and hydrostatic loads and foundation loads transmitted to them; and they shall be anchored to prevent flotation resulting from flooding or high ground water level when the tanks are empty. For sites subject to commercial traffic or heavy truck traffic, the wheel loads specified in AASHO H20-44 shall be used with no impact. For areas subject to other vehicular or human traffic, the pertinant loads stipulated in the MPS, section $601-4.3$ sha11 be used.

\section{Commentary}

The criterion specifies the level of vehicular traffic for which buried components should be designed in cases where heavy vehicular traffic is anticipated to occur in service for purposes of access. The H20-44 truck is considered to be representative of load levels associated with heavy vehicles such as trucks for repair, maintenance, moving, and delivery of fuel.

S-601-13 DYNAMIC LOADS

Dynamic Loads resulting from sun tracking solar collectors or other moving equipment shall be taken in to account in the design of the dwelling frame. 


\section{S-604 MASONRY}

S-604-1 GENERAL

S-604-1.1 Termination Height of Masonry Chimneys

Termination height of masonry chimneys shall be in accordance with NFPA 211.

Commentary

The presence of solar equipment may introduce building components that are elevated above the roof surface more than is usually required, thus producing wind distmbance at a higher level. The standard of NFPA 211 provides for proper clearance and separation. 
S-607 THERMAL AND MOISTURE PROTECTION

S-607-3 BUILDING INSULATION FOR PASSIVE SOLAR SYSTEMS

S-607-3.1 Insulation Values

Insulation values may vary where they can be shown to improve the overall energy balance of the building.

Commentary

Section 607-3 of MPS was originally written to conserve energy or minimize the U-value of the exterior enclosure. For some solar systems it may be desirable to vary the U-value in order to collect useful energy and prevent it from escaping or, at least, to provide a compromise U-value between the collection and loss of useful energy. An example might be a shuttered window which has single glazing. When the shutters are open the window collects energy and its U-value can be Zower than those stated in 607-3. When the shutters are closed the window conserves energy and the U-value would fall at or higher than those stated in 607-3.

S-607-3.2 Areas of Application

Materials used for thermal insulation may be applied in residential housing to the following areas: walls, roofs, ceilings, floors, pipes, ducts, vessels and equipment exposed to the external environment.

Exposed plastic foam (untreated or fire-retardant treated) and non-fireretardant treated cellulosic loose-fill insulation shall not be permitted in habitable areas. These materials should be protected by a layer of gypsum board of $1 / 2$ inch thickness or greater, or an equivalent fire barrier.

Installed insulation and vapor barrier shall not make contact with recessed light fixtures, motors, fans, blowers, heaters, flues, and chimneys. Thermal insulation should not be installed within 24 inches of the top or within 3 inches of the side of a recessed electrical fixture enclosure, wiring compartment or ballast unless labeled for the purpose. To retain loose-fill insulation from making contact with other energy-dissipating objects, a minimum of 2 inches of air space should be provided and assured by the use of blocking.

\section{Cominentary}

Although a degree of material combustibility is allowed, the intent is to allow insulating materials which are not more combustible (or flammable) than existing constmction and insulation materials, and to preclude any increased fire hazard due to the retention of heat from energy-dissipating objects.

In areas where occupants are likely to be engaged in normal activities, the insulation should perform its intended function without the increased risk of ignition, rapid flame spread, and heat and smoke generation. Insulation in concealed spaces may be a praticular fire problem due to its susceptibilty to smouldering and its inaccessibility for firefighting. 
S-615 MECHANICAL

S-615-1 THERMAL DESIGN

S-615-1.1 Genera1

The solar system shall be capable of collecting and converting solar energy into thermal energy. Solar thermal energy shall be used, in combination with a conventional auxiliary energy source and other components such as thermal storage or heat pumps to augment the system effectiveness to meet the standards and requirements for space heating and domestic hot water set forth in Section 615 of MPS.

\section{Commentary}

Solar systems for residential applications generally are capable of storing and providing thermal energy to meet at least one design winter 24 hour heating load.

\section{S-615-1.2 Back-up}

The solar energy system thermal energy contribution shall be backed up 100 per cent with a thermal energy subsystem utilizing a conventional energy source or a back-up system which will provide the same degree of reliability and performance as a conventional system.

\section{Commentary}

The uncertainty in the availability of solar energy during inclement weather requires complete back-up of the solar system to meet comfort and hot water standards.

\section{S-615-1.3 System Capacity - Space Heating}

S-615-1.3.1 Auxiliary Energy Subsystem

Heat load requirements used to determine the size of the auxiliary energy subsystems shall be calculated in accordance with the procedures and $971 / 2 \%$ design temperatures described in Section $615-3.1$ of MPS

\section{Commentary}

Uncertainties of \pm 10 percent or more in the calculated heating load are tolerated in sizing the auxiliary energy subsystem. Thermai load programs should reflect the energy conserving features of the building construction and operation such as insulation, thermal windows, actual indoor temperatures and night-time set-back.

\section{S-615-1.3.2 Solar Energy System}

a. The solar energy system size sha11 be based upon month1y average heat loads determined by a degree-day method using average monthly design temperature and conditions as the maximum analytical time interval. Hourly or daily simulation times may be used if detailed local solar radiation is available. Calculations of building heat loss for use 
in sizing solar energy subsystem shall be performed for the full heating season using a method at least as sophisticated as described in Appendix $\Lambda$.

\section{Commentary}

Since the methods of calculating heat losses and heat gain specified in 615-3.1 and 615-4.2 of the MPS may not be detailed enough to predict the performance of the heating and cooling systems for buildings using passive solar sustems other approved methods may be used for making calculations for passive solar buildings. An example of the considerations and level of detailed analysis are presented in ASHRAE Standard 90-75 Energy Conservation in New Building Design.

b. The solar energy contribution shall be determined as a percentage of the dwelling average annual space heating energy requirements. Analytical simulations or correlations based upon simulations combining the bullding heating load, solar system performance and climatic conditions shall be utilized to predict the average monthly and annual energy contribution to be provided by solar energy, auxillary energy and electrical operating energy as illustrated in Appendix A.

\section{Commentary}

Parcometric studies have shown that a solar energy contribution of between 30 to $70 \%$ for an active system is generally optimum when cost benefits have been considered. Passive systems may contribute from 5 to 100\% depending upon the relationship between the demand/buizding/climate.

S-615-1.4 System Capacity - Domestic Hot Water Heating

S-615-1.4.1 Auxiliary Energy Subsystem

The auxiliary energy domestic hot water heating system shall meet the minimum requirements for storage, draw and recovery shown in Tables 615-2 or 615-3 of MPS.

\section{S-615-1.4.2 Solar Energy System}

a. Determination of the average annual energy requirements for solar hot water heating applications shall be based on average monthly conditions as the maximum analytical simulation time interval to compare solar system performance with the load.

b. A minimum daily usage of $50 \mathrm{gal}$. of hot water from domestic use and 75 gal. when automatic cycle washers are included shall be used for design purposes. 
The design shall allow for the higher requirement where the potential increase in use exists.

c. An average hot water temperature of $140^{\circ} \mathrm{F}$ and an average source water temperature of $50^{\circ} \mathrm{F}$ shall be used for design purposes, if local temperatures are unknown.

\section{Commentary}

Tap temperatures as lov as $120^{\circ} \mathrm{F}$ may be local option however lower storage temperatures are usually combined with larger storage to provide equivalent inermal capacity. Local source water temperature can vary from 45 to $75^{\circ} \mathrm{F}$ with climate region and season.

d. The solar energy contribution shall be determined as a percentage of the dwelling average annual DHW energy requirements. Analytical simulations or correlations based upon simulations including the load, solar system performance and climatic conditions shall be utilized to predict the average monthly and annual energy contribution to be provided by solar energy and auxiliary energy as illustrated in Appendix A.

Commentary

Parametric studies have shown that a solar energy contribution of between 50 and $80 \%$ of the DHW load is generally optimum when cost benefits have been considered.

S-615-1.5 System Capacity - Combined Space and Domestic Hot Water Heating Systems

a. The solar energy contribution shall be determined as a percentage of the combined dwelling average annual space heating and average annual DHW energy requirements. Analytical simulations or correlations based upon simulations combining the space and DHW loads, solar system performance and climatic conditions shall be utilized to predict the average monthly and annual energy contributions to be provided by solar energy, electrical operation energy and auxiliary energy as illustrated in Appendix A.

S-615-1.6 Environmental Conditions - Integral Passive Systems

Where normal building spaces are designed to be part of a solar energy collection, storage, distribution or control system, indoor design conditions can vary as long as they do not interfere with the normal use of a space.

S-615-1.6.1 Design Air Temperature for Passive System

The air temperature in hall and storage areas can be designed for fluctuation from $57^{\circ} \mathrm{F}$ to $83^{\circ} \mathrm{F}[1]$. Other areas can be designed for fluctuation from $62^{\circ} \mathrm{F}$ to $78^{\circ} \mathrm{F}$ [1] provided there are provisions for bringing the air temperature up to design conditions required in section 6-15-3.16 of MPS when the space is in use.

[1] Grandjean, Ftienne, 1973 Ergonometrics of the Home, New York, Halstead Press. 
The operation of a passive system is usually dependent upon natural convective or radiative heat transfer processes which are in turm dependent upon temperature gradients. Therefore the temperature differences of at least $4^{\circ} \mathrm{F}$ to $6^{\circ} \mathrm{F}$ are required in a completely passive system.

S-615-1.7 Protection Against Blockage of Fluld Flow

The entire heat transport system shall be protected to prevent contamination by foreign substances that could impair the flow and quality of the heat transfer fluid beyond acceptable limits.

Commentary

The heat transfer fluid passages in solar collectors and some heat exchangers may have small cross sections in which blockage by dirt, scale, pieces of gasket material, pieces of packing or other foreign matter in the heat transfer fluid could occur.

\section{S-615-1.8 SYSTEM SHITTMIN!}

THE SHUTDOWN OF THE HEATING OR DOMESTIC HOT WATER SYSTEM IN ONE UNIT OF A MULTI-FAMILY DWELLING SHALL NOT INTERFERE WITH THE FUNCTION OF THESE SYSTEMS IN ANY OTHER UNIT,

\section{COMMENTARY}

THIS IS TO PERMIT THE SHUTDOMN OF ERUIPMENT IN AN INDIVIDUAL DWELLING UNIT FOR REPAIRS WITHOUT IMPAIRING THE OPERATION OF THE EQUIPMENT IN OTHER DWELLING UNITS THAT ARE CONNECTED TO THE SAME CENTRAL SYSTEM. 


\section{S-615-2.1 General Provisions}

S-615-2.1.1 Design Flow Rates

When an array of solar collectors is connected by manifolds, provision shall be incorporated in the manifolds and/or collectors to maintain the design flow rate through each collector.

Commentamy

An available method of balaneing air and liquid HVAC equipment is described in the National Standards for Field Measurement and Instmumentation: Total System Balance, Vol. 1, 110. 81266 (Associated Air Balance Council 2146 Sunset Blvd., Los Angeles, California 90026). The method describes procedures and measurements, but does not establish standard balance values.

S-615-2.1.2 Tilt and Orientation

The collector shall be installed in a mount capable of maintaining tilt and orientation to. within \pm 10 degrees of design conditions.

\section{Commentary}

A collector tilt angle equal to the latitude plus 20 to 25 degrees from the horizontal is generally used to provide maximm collection during the winter season for space heating applications. However, deviations of + io degrees from this value, when using conventional flat plate collectors, will have little effect as illustrated in Eigure S-6I5.4 which shows, for a particulor excmple, the effect on annual performance of variations of tilt angles for a collector facing south.

Conventional flat plate collector orientation should be such that the effective aperature generally faces south. However, deviations to the east or west by up to $20^{\circ}$ may not result in a significant decrease in incident radiation as indicated by the exomple of the infiuence of air collector orientation on the solar fraction of total load shoun in Figure S-615.5.

A fixed collector tilt angle equal to the latitude or latitude + 25 degrees for domestic hot water applications is typically used to favor winter heating requirements. This angle will tend to maximize the year-round performance of domestic hot water heaters. The orientation of concentrator type collectors is a function of the collector acceptance angle design and may require tracking within specific limits.

\section{S-615-2.1.3 Shadowing}

Shadowing of collectors shall be considered during the design so that shadowing by trees or other obstructions do not exceed design limits.

\section{Commentary}

On east and west exposures during the entire year, and on south exposures during the winter, and solar altitude may be low enough to cause direct shading and a resultant loss in collection capability. 


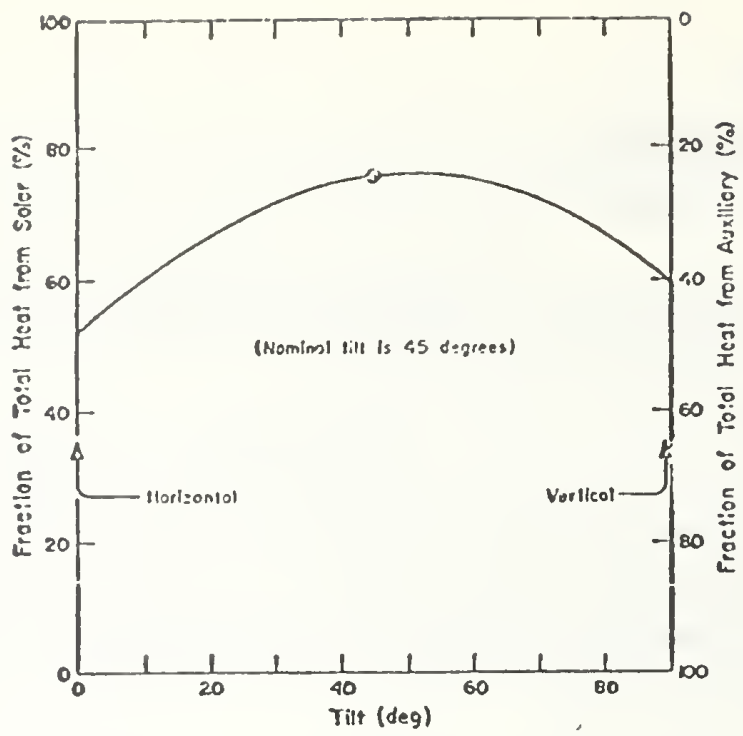

Figure S-615.4 An example of the effect of Collector Tilt for a particular System/C1imate Combination.*

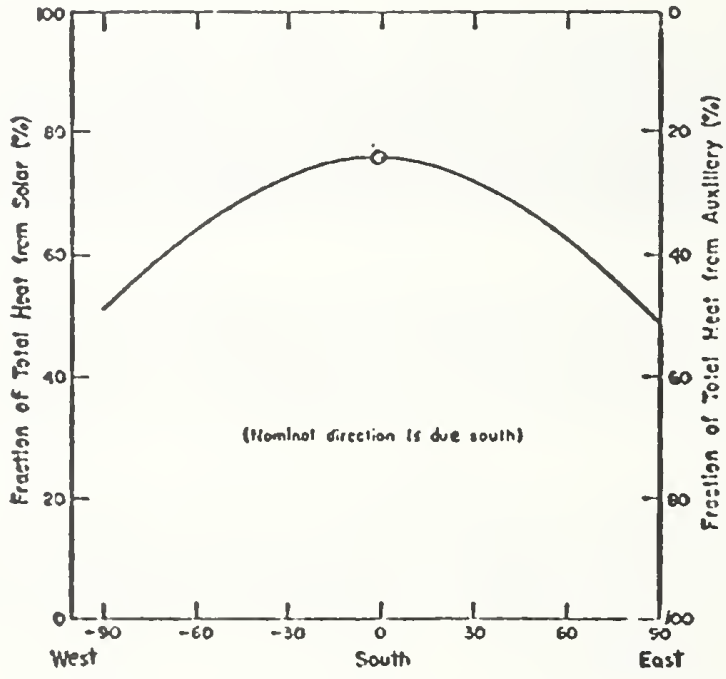

Figure S-615.5 An example of the effect of Collector Orientation $\left(45^{\circ} \mathrm{Tilt}\right)$ for a particular Collector/Climate Combination.*

* Balcomb, J.D., J.C. Hedstrom, B.T. Rogers, "Design Considerations of Air Cooled/ Collector Rock-Bin Storage Solar Heating Systems," presented at the 1975 ISES Congress, Los Angeles, California, 1 Aug. 1975. 
S-615-2.1.4 Ice Dams and Snow Build Up

The design of solar buildings and systems shall provide for the possibility of formation of ice dams and snow build up.

\section{Commentary}

In very cold climates, water flowing off a warm collector may freeze on cold surfaces immediately below it (such as exposed eves), thereby forming an ice dam which can cause water to back up under roofing or into the the collector itself. This may be moderated by methods such as elimination of the cold surface or provision of an impervious surface such as continuous flashing. Snow sliding off a collector may pile up at the bottom and cover part of the collector. This would have a tendency to reduce the efficiency of the collector and increase the possibility of thermal breakage of glass in the collector. This may be moderated by methods such as the provision of space below the collector for snow pile up or by the installation of heating cables.

\section{S-615-2.1.5 Mud Splash}

The design of solar buildings and systems shall minimize the possibility of mud splash on collector surfaces.

\section{Commentary}

Water muning off collectors located close to the ground can cause mud splashing to coat portions of the collector and reduce its efficiency. Remedies to this include: easy access for cleaning, position of collectors elevated sufficiently to avoid splashing, or provisions of gutters or splash free material at the base of the collector.

\section{S-615-2.1.6 Protection Against Maximum Temperature and Pressure}

Collectors shall not be damaged or adversely affected by maximum temperature and pressure that could occur during periods when heat transfer fluid is not flowing.

\section{Commentary}

Temperatures in excess of $300^{\circ} \mathrm{F}$ would probably occur within flat plate collectors that are not cooled by heat transfer fluid. Such conditions could occur during normal shut down, loss of fluid flow resulting from pump or fan failure, system blockage, or loss of electric power.

The designer should either assure that the materials used in the collector can withstand the maximum temperatures and pressures or provide temperature and pressure relief from thermal cyling or shock.

\section{S-615-2.2 Collector Therma1 Performance}

\section{S-615-2.2.1 Genera1}

This section is intended to cover subsystem, component and integral collectors which can be flat plate, concentrating, reflector aided, fixed or tracking types. 
This type collector can be characterized as a subsystem or component for an active solar system requiring the use of powered mechanical equipment to move the heat transfer fluid (11quid or gas) through the collector. The collector thermal performance shall be based upon the slope-intercept method of expressing efficiency for the range of operating conditions including solar power density, heat transfer fluid temperature, ambient temperature, wind, solar radiation incident angle, and flow rates, to be used in the design.

Commentary

The collector performance characteristics can be measured using the National Bureau of Standards proposed test method (NBSIR 74-635) for rating solar collectors or any other method demonstrated to have an overall limit-of-error of less than $+5 \%$. This method provides sufficient efficiency versus operating condition datā to constmet a curve normalized for insolation and temperature difference between ambient and heat transfer fluid temperature. Curves for typical flat black and selestive coated absorber panels with one and two covers are shown in Appendix A for air and water collectors. Collectors with other geometric, optical or thermal characteristics may require additional tests to fully describe their thermal performance for ali environmental and operating conditions. The operating electrical power is recorded and reported during all tests.

b. Combined Collectors and Storage Devices

This type of combined component system can be characterized as a system with integral construction and operation of the components such that the solar radiation collection and storage phenomena cannot be measured separately in terms of flow rate and temperature changes. The system thermal performance is determined by the short term ( 1 to 3 days) collection and storage of thermal energy obtained from solar radiation and the amount of useful energy delivered to the load from storage for part and full load conditions. Experimental performance data, in terms of heat collected and stored or delivered to load, shall be provided for the design conditions including solar power density, heat transfer fluid temperature, ambient temperature, wind, solar radiation incident angle, and flow rates. The daily and average test period electrical operating requirements are reported with system performance.

\section{Commentary}

Although a consensus test method to rate and evaluate these systems does not exist, the efficiency in terms of converting incident solar energy into useful thermal energy can be measured and reported as a function of the specified operating conditions.

\section{c. Integral Collector, Storage and Building (Passive)}

An integral collector system can be characterized as one in which the collector and storage components are an integral part of the building in a passive solar system. Auxiliary energy may be used for control purposes but heating is generally achieved by natural heat transfer phenomena. Roof ponds, modified walls, roof sections with sky lights, or similar applications where solar energy is used to supply a significant fraction of the building heating requirements, are examples of passive collectors. The thermal performance of an integral collector system can be obtained from a detailed simulation analysis of the climate, building thermal properties and occupancy thermal influence. 
A more detailed simulation of solar heating, building thermal capacitance and thermal energy control must be included in the traditional building load determination programs for the design and evaluation of an integral solar system. Experimental evaluation of the system performance includes measurement of the climatic conditions, auxiliary energy use and comfort level for sufficient periods to account for building thermal capacitance effects

(minimum of 7 days) and, preferably, monthly or seasonal averages are obtained.

S-615-3 MECHANICAL SUPPORTING DEVICES

S-615-3.1 Pipe Hangers and Supports

Pipe hangers and supports shall be installed in accordance with the prevailing model plumbing code having jurisdiction in the area.

\section{S-615-4 VALVES}

Gate valves or similar valves that open to nearly full pipe bore shall be used for shut off valves. Globe or similar valves shall be used for flow control.

S-615-5 PUMPS \& COMPRESSORS

S-615-5.1 Applicable Standards

a. Pumps shall be installed in accordance with the requirements of the Hydraulic Institute.*

b. Pump motors shall conform to appropriate NEMA Standards such as NEMA Standard M G1-18.615.

c. All moving machinery shall be protected and guarded to comply with the current safety standards of ANSI B15.1 if such machinery is exposed to other than maintenance personnel.

S-615-6 MECHANICAL VIBRATION ISOLATION

S-615-6.1 Genera1 Requirements

All operating mechanical equipment shall be isolated by suitable piping connections and where necessary by isolation pads or foundations to prevent transmission of noise or vibration. The dwelling shall be free of objectionable sound as required in HUD circular 1390.2, Noise Abatement and Control.

Equipment conforming to other sound level criteria referenced in these standards shall also be acceptable.

*Hydraulic Institute Standards for Centrifugal, Rotary and Reciprocating Pumps, Thirteenth Edition, 1975. The Hydraulic Institute, 1230 Keith Building, Cleveland, 0hio 44115. 
S-615-7.1 Thermal Storage Requirements

S-615-7.1.1 General Provisions

This section applies to sensible and latent heat type thermal energy storage devices using gas or liquid as the heat transfer fluid and liquid or solid as the heat storage medium. The storage medium can be contained in a separate enclosure, stored at more than one temperature, or can be a part of the building structure. Some typical storage subsystem arrangements aie shown in Appendix C.

Commentary: The interaction between storage temperature and collector operating efficiency must be considered in the location and operation of the auxiliary energy source. Auxiliary energy supplied to the storage medium directly can result in decreased system efficiency. Designs which enhance normal storage temperature gradients and control the heat transfer fluid mixing, which use electrical "peak shaving" power or which use solar assisted heat pumps may influence storage temperature or operation.

\section{S-615-7.1.2 Space Heating}

The thermal energy storage capacity for space heating shall not be less than 500 Btu per square foot of solar collector area for a component (active) system. The thermal energy storage capacity for space heating shall be not less than 1000 Btu per square foot of collector area for an integral (passive) system.

Commentary: The relationship between the load fraction supplied by solar energy to the storage capacity for liquid and air applications is presented in Appendix A. The storage heat capacity for integral (passive) systems is a function of the thermai coupling between storage and the load but, because of usual lower storage temperatures, a larger heat capacity is desired.

S-615-7.1.3 Domestic Hot Water Heating

The solar thermal energy storage for preheating domestic hot water shall have a volume capacity not less than the number of gallons shown in Tables 6-15.2 or $6-15.3$ of MPS.

Commentary: Although it is possible to design a hot water storage container with large temperature gradients permitting the auxiliary energy source to be incomprated in the same container, it is preferred to add the auxiliary energy after the water has been removed from the solar heated container.

S-615-7.1.4 Combined Space and Domestic Hot Water Heating

The thermal energy storage capacity for a solar energy system providing thermal energy for both space and domestic hot water shall not be less than 500 Btu per square foot of solar collector area.

S-615-7.1.5 Therma1 Energy Loss

The thermal energy loss from storage containers shall not exceed 10 percent of the maximum operating thermal energy capacity over a 24 hour winter design day. 
Commentary: Calculations of the thermal loss from tanks, piping, and valves can be performed using average fluid and combient temperatures and thermal insulation conductivity values with procedures described in the ASHRAE Handbook of Fundomentals. In addition to energy loss, consideration of the heat contribution to occupied spaces can result in more insulation.

S-615-7.1.6 Tank Drainage

Each tank shall be provided with means of emptying the liquid. Each tank located above grade or floor level shall be provided with a valved pipe at its lowest point to permit emptying the tank. Each buried tank shall have provisions for utilizing a pump or siphon or other means to allow emptying.

S-615-7.1.7 Vacıum Relief

The solar system, including collectors, pipes, tanks, and heat exchangers shall be designed with vacuum relief valves or otherwise protected against possible collapse.

Commentary: System components may be subjected to collapse if heating system leakage were to occur or if the system were drained without venting.

S-615-7.1.8 Tank Filling

Tanks of large capacity should have an indicator or other means for determining that the tank is full. Tanks should have overflows with outlets located so that spillage will not run into the building structure or damage the premises. Tanks that do not contain potable water but require make up water from the potable water system shall be filled by way of an air gap or other means acceptable to the administrative authority having jurisdiction. 
S-615-8.1 Toxic and/or Flammable Media

S-615-8.1.1 Genera1

Requirements for handling non-potable heat transfer fluids are discussed in sections S-615-9, Waste Disposal; S-615-10, Plumbing; and S-615-12, Heat Exchangers, of this document.

S-615-8.1.2 Detection of Toxic and Flammable Fluids

If nonpotable heat transfer fluids are used, means sha11 be provided for the detection of leaks and the warning of occupants when leaks occur.

Commentary: These substances shall be treated in a manner similar to air conditioning condensates, refrigerants (Chapter 14, ASHRAE Handbook of Eundamentals), and gases (NFPA 54) when providing for tell-tale indicators. For instance, antifreeze agents, such as ethylene glycol, should be treated with non-toxic dyes which distinguish them clearly. Furthermore, if any such materials are to be stored on the premises, they should be stored in containers which are labeled in accordance with the Hazardous Substances Labeling Act and are protected from easy opening by children, e.g., childproof zids. Safe storage locations should be provided.

S-615-9 WASTE DISPOSAL

S-615-9.1 Catchment

Systems utilizing other than air or potable water as a heat transfer fluid shall provide for the catchment and/or harmless removal of these fluids from vents, drains or re-charge points. Potable water shall be discharged to suitable drainage systems connected to the building or site drains. See MPS Section 615-9.

S-615-9.2 Provision of containment for discharge treatment of hazardous media

Adequately sized and protected recepticles sha11 be provided when liquids requiring special handling are used in order to collect and store the overflow from pressure relief valves, liquids drained from the system when it is being serviced, potential leakage, and accidental drainage. Provisions of MPS Section 615-4.4 shall be applied.

Commentam: When a toxic heat transfer medium is used (see Section S-5158.2.4), a catch basin must be provided. It must be sufficiently large to accept dilution as required by MPS Section 515-9 before disposal. If the diluted medium is biodegradable through conventional sewage treatment, the diluted medium is to be flushed into the sanitary sewer system (not the storm sewer system). 
$S-615-10$

PLUMBING

$S-615-10.1$

Handling of Nonpotable Substances

Potable water supply shall be protected against contamination in accordance with the prevailing model plumbing code having jurisdiction in the area.

S-615-10.1.1 Separation of Circulation Loops

Subsystems requiring the circulation of nonpotable heat transfer fluids shall be separated from the domestic (potable) water system so that contamination of the domestic water will not occur.

S-615-10.1.2 Identification of Nonpotable and Potable Water

In buildings where dual fluid systems, one potable water and the other non-potable fluid, are installed each system may be identified either by color marking or metal tags as required in ANSI Al3.1-1956 [1] or other appropriate method as may be approved by the Administrative Authority. Such identification may not be required in all cases.

S-615-10.1.3 Backflow Prevention

Backflow of nonpotable heat transfer fluids into the potable water system shall be prevented in a manner approved by the Administrative Authority.

Commentary: The use of air gaps and/or mechanical backflow preventers are two possible solutions to this problem. The following are some recognized standards that may be acceptable to the administrative authority: Complete titles are given in Appendix $F$.

$\begin{array}{ll}\text { Air gaps } & \text { ANSI-A112.1.2 } \\ \text { Backflow preventers - } & \text { ECCCHR Chapter } 10 \\ & \text { IAPMO PS 31-74 } \\ & \text { AWWA C506-69 } \\ & \text { A.S.S.E. } 1011 \\ & \text { A.S.S.E. } 1012 \\ & \text { A.S.S.E. } 1013 \\ & \text { A.S.S.E. } 1015 \\ & \text { A.S.S.E. } 1020 \\ & \text { ANSI-A112.1.1 }\end{array}$

S-615-10.2 Pipe Sizing

Pipe sizing shall be in accordance with recognized methods.

Commentary: Piping system design guidance is given in Model Plumbing Codes, the Hydraulic Institute's Pipe Friction Manual - 1967, and in handbooks such as "Handbook of Hydraulics" by King and Brater. [2]

[1] Scheme for the Identification of Piping Systems, ANSI Al3.1 - 1956.

[2] Handbook of Hydraulics for the Solution of Hydrostatic and Fluid-Flow Problems, by Horcace Williams King and Ernest F. Brater (McGraw-Hill Book Company) 5 th ed. 1962 . 
System designs incorporating automatic drainage of heat transfer fluid to storage to prevent freezing of the fluid in solar collectors shall not be constructed of materials which corrode in the presence of air or shall be suitably protected. Liquid systems shall be designed so that complete isolation and drainage of all system components, piping, or storage tanks can take place in a reasonable length of time for maintenance purposes. See S-615-7.1.6, Tank Drainage.

Commentary: One means of preventing corrosion during system drainage would be by introducing an inert gas such as nitrogen.

\section{S-615-10.4 Protection from Scalding}

All domestic hot water systems shall be equipped with means of limiting temperature as required in MPS section 615-6.

\section{S-615-10.5 Provision of Valves and Fittings}

S-615.10.5.1 Shutoffs

A11 domestic water heaters and water heating systems shall be valved to provide shutoff from the cold water supply systems.

S-615-10.5.2 Water Hammer Arresters

When a liquid is used as the transfer fluid in a solar energy system and quick-closing valves are employed in the design, the piping system shall be able to control or withstand potential "water hammer". Water hammer arresters shall be in compliance with local codes

S-615-10.5.3 Air Bleeds

When liquid heat transfer fluids are used in solar heating systems, the systems shall be provided with suitable means for air removal from high points in the piping system.

S-615-10.5.4 System Flushing

To facilitate solar heating system maintenance and repair, systems employing liquids shall be capable of being conveniently filled and drained. Suitable connections shall be provided for flushing (cleaning) the system. All piping shall be pitched to drain completely. 
Adequate provisions for the thermal expansion of solar heat transfer and storage liquids that would occur over the service temperature range shall be incorporated into the solar heating system design.

Expansion tanks shall be sized in accordance with the recommendations of ASHRAE Guide and Data Book.

S-615-10.7 Leak Testing

Those portions of heating systems which contain liquid heat transfer fluids and are not directly connected to the potable water supply shall not leak when pressures of not less than 1-1/2 times their design pressure are imposed for a minimum of 15 minutes [1]. The pressure shall be gradually applied and sustained for a sufficient length of time to permit examination of all pipe joints for leakage. Those portions of the system using domestic hot water shall not leak when tested in accordance with the code having jurisdiction in the area where the system is used. In areas having no building code, a nationally recognized model code shall be used [1].

Conmentary: A hydrostatic test pressure of 1-1/2 times design pressure is considered a standard test pressure. [2]. For most applications, clear water is used. The temperature of the water should be no lower than that of the ambient atmosphere. Otherwise, sweating will result and proper examination will be difficult. In environments where freezing may occur, antifreeze or hydrocarbons may be added to keep the water from freezing. Bleeder valves or petcocks should be provided at the highest point or points in the system to permit venting of all air in the piping during the filling operation [2]. Automatic vents must be protected from freezing.

S-015-10.8 Discharge of Liquids

Relief valves shall be piped to discharge to locations acceptable to the administrative authority having jurisdiction.

10-615-10.9 Location of Exposed Piping

Piping and equipment shall be located so as not to interfere with normal operation of windows, doors, or, other exit openings and so as to prevent damage to piping, equipment, or injury to persons.

\section{S-615-10.10 Underground Piping}

Undergound water service piping shall be installed in accordance with the provisions of Section $615-5.3$ of MPS. Underground heat distribution piping shall be installed in accordance with Section 615-3.5 (k) of MPS.

S-615-10.11 Treatment of Water

When make-up water is of such a quality that excessive corrosion is known to exist, a suitable water treatment system as recommended by the Water Conditioning Foundation shall be provided.

[1] The BOCA Basic Plumbing Code, Southern Standard Plumbing Code, and the Uniform Plumbing Code.

[2] Piping Handbook, Remo C. King and Sabin Crocker, McGraw-Hill Book Company, 5th Edition. 
Provisions for the dumping of thermal energy may be required when the energy demand is less than the collected useful energy.

Commentary: For systems in which it is not practical to shut the coliection system down, excess thermal energy can be disposed of by dumping to the extemal environment.

\section{S-615-11 AUXILIARY ENERGY SYSTEMS \\ S-615-11.1 Applicable Standards}

a. Domestic water heaters shall comply with the following appropriate standards:
Oil . . . . . . . . UL-732

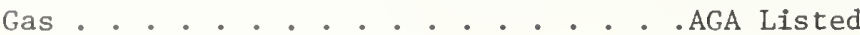
Electric .......... . . UL-174

b. Heating systems shall comply with the following appropriate standards:

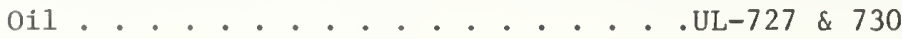
Gas ......................... LG Listed
Electric . . . . . . . . UL-573, NFPA-70

Boiler (Steam \& Water)

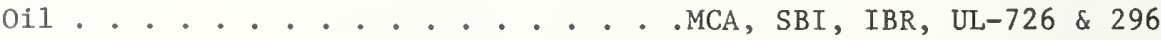

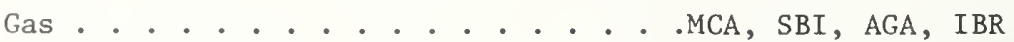

Electric . . . . . . . . . SBI, UL-174

Radiation

Baseboard ............ IBR Rated

Finned Tube ............. . IBR Rated

Electric ............ . . UL-1042, NESCA

Fue1 Tanks . . . . . . . . . UL-58

c. Heat pumps shall be installed in compliance with the requirements of ANSI B9. 1 - 1971, "Safety Code for Mechanical Refrigeration" (ASHRAE) and ARI Standard 260, "Standard for Application, Installation, and Servicing of Unitary Systems" (1967). 


\section{S-615-12.1 Sizing}

a. A heat exchanger when used in conjunction with the solar collector and storage shall be sized such that the effectiveness in transferring heat from the collector to storage is not less than 0.70 . The heat exchanger effectiveness is expressed by:

$$
\varepsilon_{c}=\left(\dot{m} c_{p}\right)_{s}\left(t_{1}-t\right) /\left(\dot{m} c_{p}\right)_{\min }\left(t_{0}-t\right)
$$

where

$$
\begin{aligned}
& \left(\dot{\mathrm{m}} \mathrm{c}_{\mathrm{p}}\right)_{\text {min }}=\text { the minimum capacitance rate of }\left(\dot{\mathrm{m}} \mathrm{c}_{\mathrm{p}}\right) \text { collector } \\
& \left(\dot{\mathrm{m}} \mathrm{c}_{\mathrm{p}}\right)_{\mathrm{s}}=\text { flow circuit } \\
t \quad= & \text { storage temperature }\left({ }^{\circ} \mathrm{F}\right) \\
\mathrm{t}_{0}= & \text { collector outlet temperature }\left({ }^{\circ} \mathrm{F}\right) \\
\mathrm{t}_{1}= & \text { collector inlet temperature }\left({ }^{\circ} \mathrm{F}\right) \\
\varepsilon_{\mathrm{c}}= & \text { effectiveness of the collector }- \text { storage heat exchangers } \\
\dot{\mathrm{m}}= & \text { flow rate of the working fluid }(1 \mathrm{bm} / \mathrm{min}) \\
c_{\mathrm{p}}= & \text { fluid capacitance (Btu/1bm } \left.-{ }^{\circ} \mathrm{F}\right)
\end{aligned}
$$

b. The load heat exchanger heat transfer rate shall be selected such that the ratio of the heat exchanger effectiveness times the minimum capacitance rate to the total heating load is between a value of 1 and 5 . This dimensionless parameter and relationship is expressed by:

$$
1 \leq \frac{\varepsilon_{\mathrm{L}}\left(\text { in } c_{\mathrm{P}}\right) \min }{\mathrm{UA}} \leq 3
$$

where

$$
\begin{aligned}
& \varepsilon_{\mathrm{L}}=\text { Effectiveness of load heat exchanger } \\
& \mathrm{UA}=\text { Building heat loss factor (Btu/Day }{ }^{\circ} \mathrm{F} \text { ) }
\end{aligned}
$$

Commentary: Diagrams of the typical Zocation and performance of heat exchangers are presented in Appendix $A$ and $C$. Calculation methods for heat exchanger performance are described in the ASHRAE Handbook of Fundamentals.

\section{S-615-12.2 Handling of Nonpotable Fluids}

When nonpotable fluid is used in a solar energy system to transfer heat to domestic (potable) hot water, the design of the heat exchanger shall prevent diffusion or mixing of the toxic fluid into the potable water should a leak occur in the heat exchanger. The system should be designed so that a leak is readily apparent. 
S-615-13.1 Applicable Standards

Design of all warm air heating systems shall be in accordance with applicable recommendations of the ASHRAE GUIDE, manuals of NESCA and ARI. Installation shall comply with NFPA standards $90 \mathrm{~B}, 31$ and 54.

Commentary: Duct work should be designed for the shortest practical run and elbows should he kept to a minimum. Constrictions should be avoided.

\section{S-615-13.2 Dust and Dirt Prevention}

Duct and fan systems shall be protected against accumulation of deposits of of dust or dirt that could reduce flow and efficiency in addition to creating a potential health hazard when admitted into occupied spaces. Air filters are required on the outlet side of rockbed storage systems.

Cormentary: The gravel used for rockbed storage with air systems is selected for size and freedom from dirt and dust. Therefore, smooth and washed material combined with the use of filtered air is desirable to provide a maintenance free clean distribution system. Fan grilles should be removable or hinged to permit access to the fan and motor for cleaning, servicing, replacement, or repair. 


\section{S-615-14 CONTROLS AND INSTRUMENTATION \\ S-615-14.1 Fail-Safe Controls}

The control subsystem shall be designed so that in the event of a power failure, or a failure of any of the components in the subsystem, the temperatures and/or pressures developed in the $\mathrm{H}$ and DHW systems will not be damaging to any of the components of the systems and the building or present a danger to the occupants. The safety devices shall meet the requirements of Section 515-6.4 of MPS and be demonstrated to be adequately safe and protected for the intended application.

S-615-14.2.1 Automatic Pressure and Temperature Relief Valves for Nonflammable or. Noncombustible Fluids

Adequately sized pressure and/or temperature relief valves, such as in MPS Section 615-6.2, shall be provided in those parts of the energy transport subsystem containing pressurized fluids.

Relief valves shall drain to locations acceptable to the local administrative code authority.

Commentary: Precautions must be taken to assure that heat transfer solutions do not discharge on asphalt base roofing materials or other type of roofing or other locations which may be hazardous, cause structural damage, building finish discoloration, or damage to shrubs and Zawns.

S-615-14.2.2 Automatic Pressure and Temperature Relief Valves for Flammable or Combustible Fluids

The fluid transfer system shall include a pressure relief valve. The valve and its discharge system shall not permit fluid dischrage directly into the occupancy. It is recommended that a holding tank be included in the system for collection of discharge. The pressure relief valve shall be designed based on maximum temperature criteria for abnormal operating conditions such as no-flow. ( $\triangle \mathrm{P}$ must be limited to comply with temperature criteria.)

The fluid transfer system shall include a temperature relief valve. It shall prevent further increase in temperature and provide discharge in the same manner as the pressure relief valve.

Maximum fluid temperature at which temperature relief valve shall operate:

a) $100^{\circ} \mathrm{F}$ below flashpoint of fluid, flash point to be determined in accordance with NFPA 321, 1971, Standard on Basic Classification of Flammable and Combustible Liquids.

b) $400^{\circ} \mathrm{F}$

Local alarm shall be required to indicate a failure of the fluid transfer system (e.g., leakage, pump failure) or activation of relief valves. Alarms shall be installed in accordance with NFPA 26, Supervision of Valves, and NFPA 72A.

\section{S-615-14.3 Identification and Location of Controls}

Main shutoff valves and switches shall be considered comparable to electrical service panels and be conspicuously marked and placed in an easily accessible location in accordance with Section 240.24 of NFPA 70, and MPS, Section 616 . 
S-615-14.4 Indirect Water Heaters

Indirect domestic water heater installations shall include operating controls for the heat source, of the type recommended by the boiler manufacturer. The installation shall be made in accordance with the boiler manufacturer's instructions.

615-14.5 Efficient Operation

A differential thermostat shall be utilized to control operation of the collector heat transfer fluid pump.

Commentamy: The collector operation is limited to conditions when the heat transfer fluid temperature in the collector is areater than in storage or for load requirements, a start-up $\Delta T$ of $10^{\circ} \mathrm{F}$ and shutdown $\Delta T$ of $3^{\circ} \mathrm{F}$ are commonly used.

\section{S-615-15 CHIMNEYS AND VENTS}

S-615-15.1 Termination height of chimneys and vents

Termination height of chimneys and vents shall be in accordance with NFPA 211.

Commentary: The presence of solar equipment may introduce buizding components that are elevated above the roof surface, thus producing wind disturbance at a higher level. The standards of NEPA $22 \mathrm{z}$ wiZl provide for proper clearance and separation.

S-615-16 MECHANICAL VENTILATION

S-615-16.1 Air Discharge Openings

Air discharge openings through roofs or exterior walls shall not be located such that their exhaust will cause the deposition of grease, lint, condensation or other deleterious materials on solar optical components. 
APPENDIX A

Calculation Procedures for Determining the Thermal Performance of Solar Space Heating and Domestic Hot Water Systems 



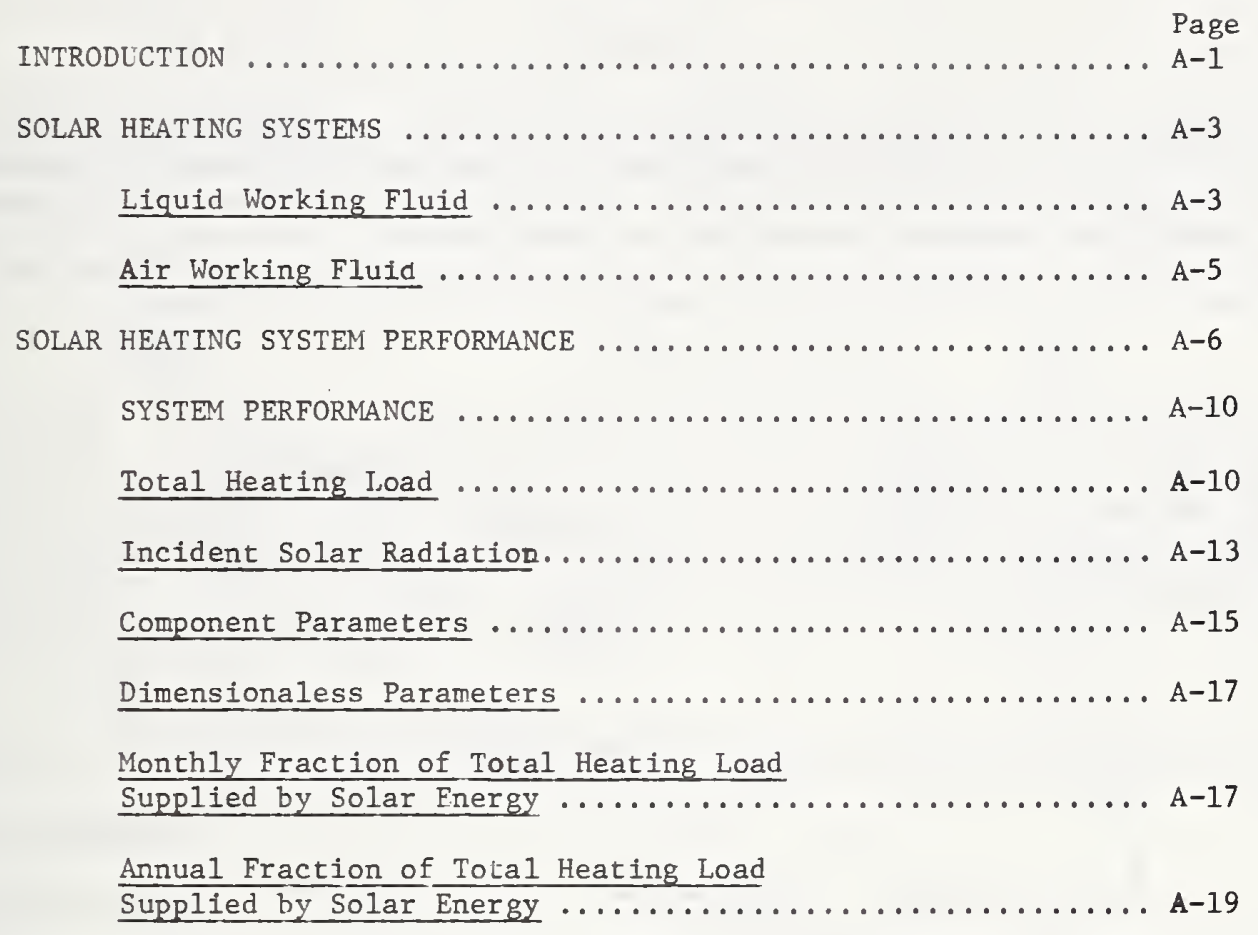




\section{INTRODUCTION}

The performance of any solar heating system is directly related to the amount of solar radiation available, the outside air temperature, the heated space thermal characteristics, and the solar heating system characteristics. One type of a simplified solar heating system and energy flow diagram is shown in the figure below.

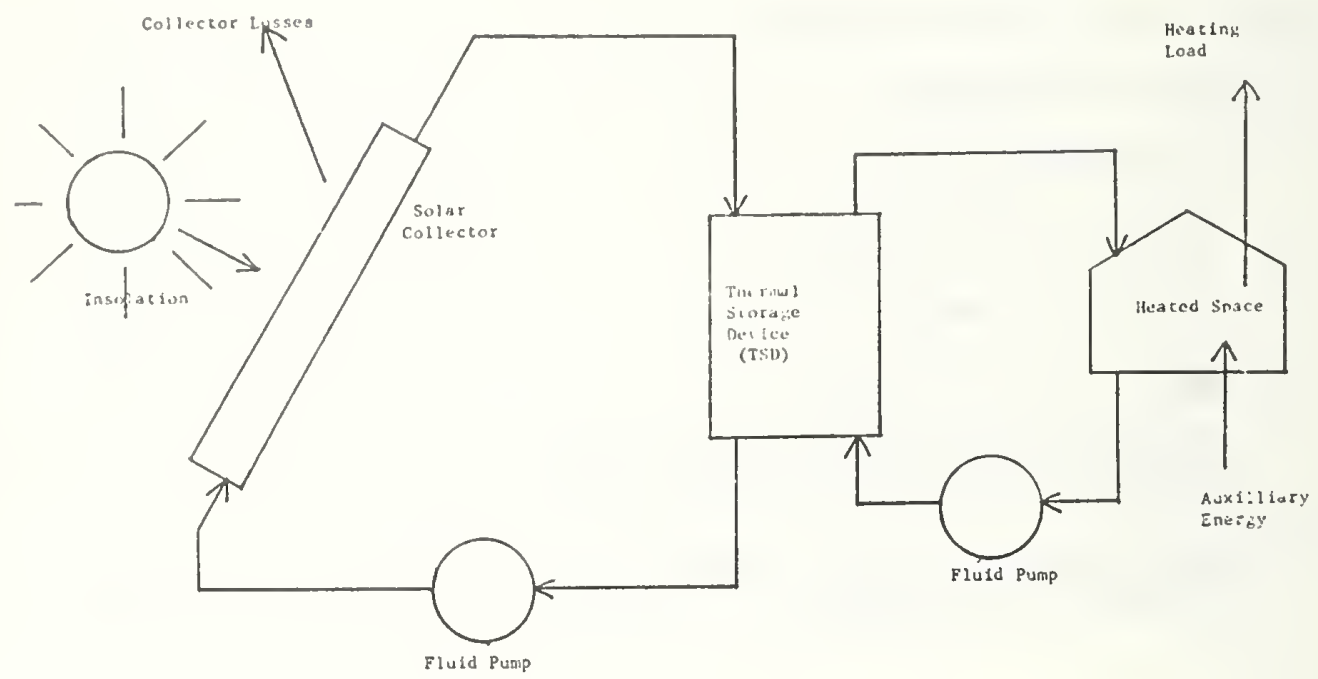

Figure A-1

The goal in a solar heating system is to convert the absorbed solar radiation on the collector into useful energy for keeping the heated space at a comfortable temperature with reduced usage of conventional energy. The challenge is to do it in a way that is economically competitive with conventional forms of heating.

Starting on the left side of the figure, solar energy falls on the solar collector. Some energy is lost from the collector due to reflection from the collector and heat transfer to the ambient. The amount of energy actually collected by a solar collector is termed useful energy and is directly proportional to the collector area.

Useful energy is transferred to the thermal storage device (TSD) by a working fluid. The TSD is necessary due to the intermittent nature of solar energy and is characterized by the TSD heat capacity.

Energy from the TSD to the heated space is transferred as needed to meet the heating load. If the TSD cannot meet the heating load, auxiliary energy from a conventional source is necessary. Heat exchangers and pumping systems must be properly sized to meet energy flow requirements.

Prediction of performance of solar heating systems is difficult due to the unpredictable nature of weather and the mathematically complex relationships between the system components.

The procedure for estimating performance of a solar heating system used in this document was developed by Klein, Beckman, and Duffie of the University of Wisconsin. Their approach was to use a detailed hour by hour computer simulation for several typical solar heating systems covering a wide range of system parameters and at several locations in order to develop a generalized performance chart (f-chart) to predict long-term system performance. 
Although differences were found between the simulated and estimated performance using the generalized chart for specific monthly periods, the correlation was found to be quite satisfactory in most cases for predicting year-long performance, as shown in Fig. A-3. It should be emphasized, however, that the generalized performance chart is not intended to provide an accurate estimate of system performance for any particular month, but rather for the long-term. The difference between the simulated and estimated yearly performance of systems in different locations were also found to be small. The standard error in the fraction of load to be met by solar predicted for four different cjties was 0.014 , an error judged to be substantially lower than the errors inherent in the simulation model and the recorded data.

The procedure has been checked using the data obtained from existing solar heating systems and the difference between estimated and actual performance is small. For example, for M.I.T. Solar House IV, the difference between actual performance and estimated performance over two complete heating seasons was about eight percent.

There are some limitations on the use of this procedure. The procedure was developed for a liquid system as shown in Figure A-2 Figure A-2 is typical of most active solar heating systems using a liquid as the heat transfer fluid. The procedure has been applied to air systems with fairly good results; however, a study of the applicability of the procedure for air systems has not been released. The procedure does not apply to passive systems or active systems that are not general1y configured like Figure A-2. These other systems must be analyzed in some other manner. The procedure cannot be used for systems in latitudes farther north than sixty degrees.

The procedure is intended for use by architects and engineers to evaluate long-term performance of most solar heating systems using a simple desk calculator or slide rule.

\section{Solar Heating Systems}

\section{Liquid Working Fluid}

A typical solar heating system that utilizes liquid as an energy transport medium is shown in the figure below.

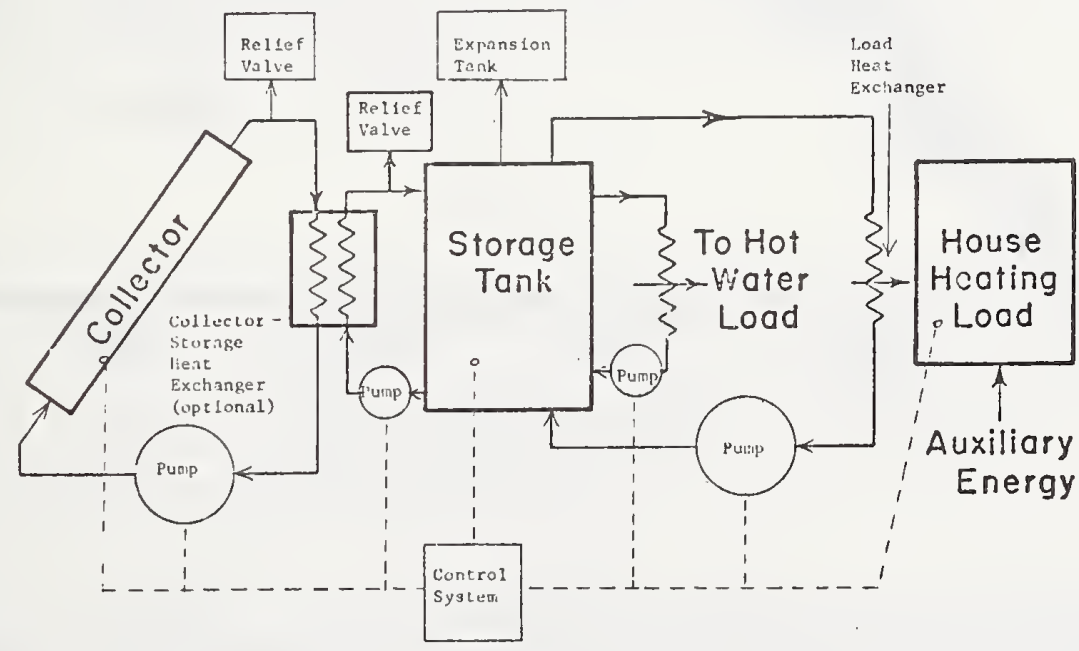

Figure A-2

As can be seen, the liquid system uses an insulated liquid thermal storage tank and heat exchanger in appropriate fluid loops to transfer energy. 


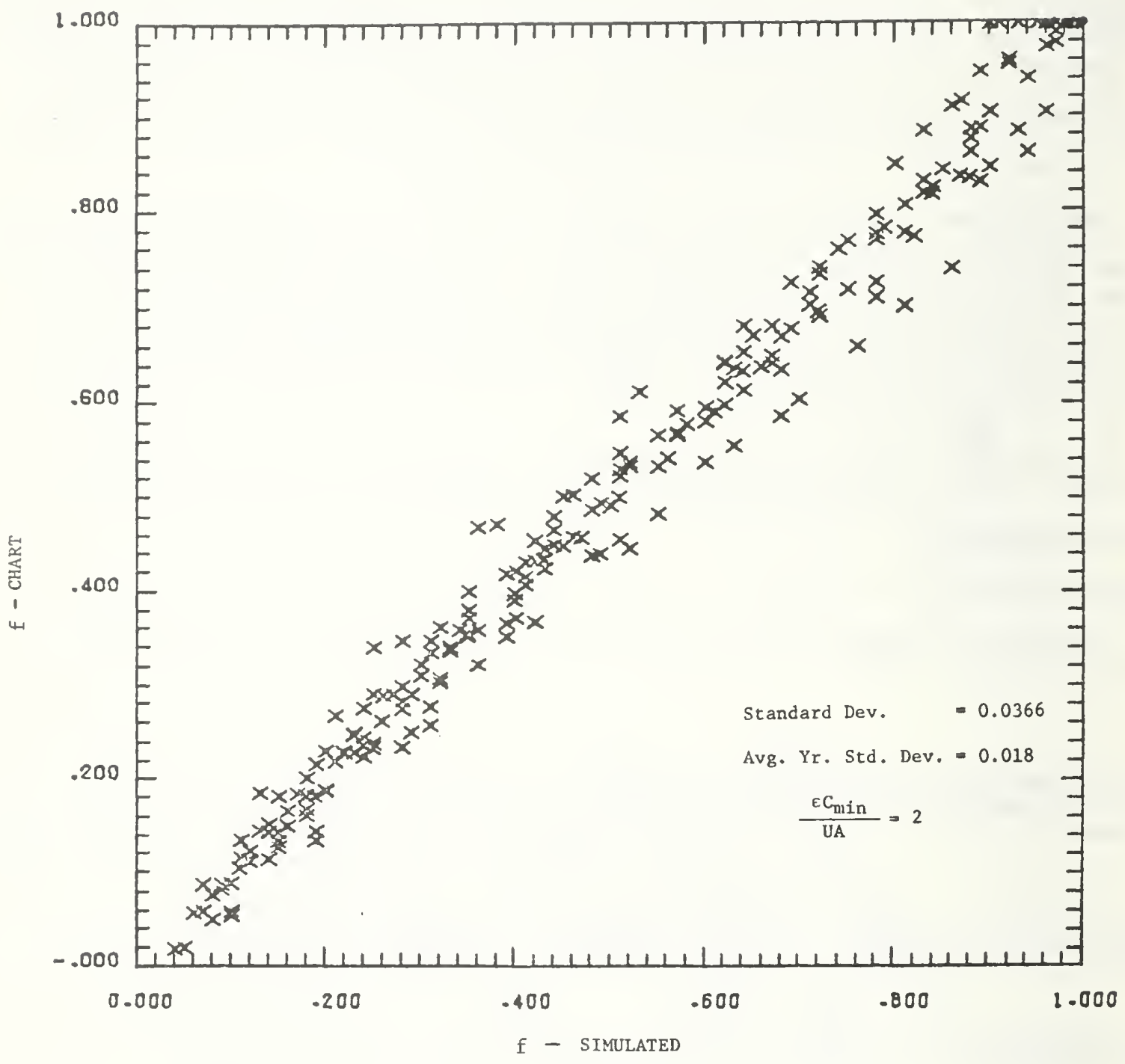

Figure A-3 Comparison of system performance between $\mathrm{f}$ - chart and detailed simulation 
Liquid systems are very flexible in that all components are independently connected to the storage tank.

Liquid systems must be protected against corrosion, freezing, and over pressurizing; but have the advantage over air systems of significantly more compact piping and storage. Overall performance of a liquid system is comparable to that of an air system.

\section{Air Working Fluid}

A typical solar heating system that utilizes air as the energy transporting medium is shown in the figure below.

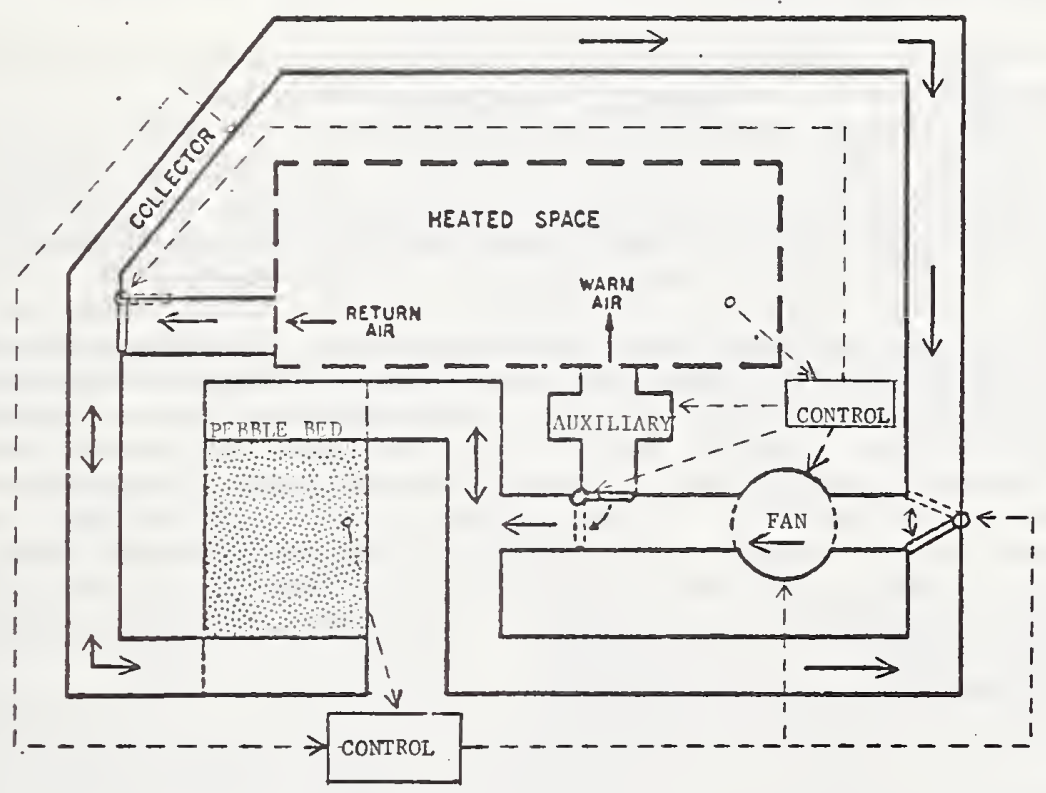

Figure A-4

As can be seen, in addition to the air-cooled collector, an air system is generally characterized by the absence of heat exchangers and the use of a pebble bed thermal storage device.

By use of the thermostatically controlled dampers, four basic modes of operation are possible using a single fan; direct space heating from the collector, space heating from the pebble bed storage unit, charging of the pebble bed storage unit from the collector, and space heating using the auxiliary energy source.

Air systems in general do not have corrosion, freezing, or over-heating problems. Aircooled collectors generally run at lower efficiencies than liquid colled collectors, but the absence of heat exchangers and the characteristics of pebble bed storage units make up for this difference in performance. Air systems generally require more power to operate than do liquid systems, but power requirements in a properly designed system are small when compared to the solar energy gained. 
General

a) The following procedure allows the estimation of long-term solar heating system performance applicable for combined space heating and domestic hot water systems. The method is also applicable to air heating systems. The system evaluation procedure is not intended to provide an accurate prediction of system performance for any particular month, but rather for the long-term average.

b) The evaluation of system heating performance is applicable for systems schematically identical to Figure 1 or similar simplified models. The following assumptions were made in developing the procedure:

1) Thermal storage is contained within the heated structure and all storage heat losses are considered to supplement the space heating load.

2) Auxiliary heat sources are provided to supply energy for both the space and water heating when the energy in storage is depleted. The auxiliary energy source is connected such that it does not heat the thermal storage unit directly. The rate of use of auxiliary energy is such that it provides just enough energy to supplement the solar heating system in meeting the heating load.

3) For heating systems utilizing a liquid heat transfer fluid, a heat exchanger can be used between the collector and the storage tank. When an anti-freeze solution is circulated through the collector to avoid the problems of freezing and corrosion, the use of a heat exchanger in conjunction with water storage may be more economical than using the anti-freeze solution as the energy storage medium.

4) The heat transfer fluid is circulated through the collector whenever a positive energy gain can be achieved. During periods of low radiation (when the energy gain becomes zero or negative), the collector pump or blower is turned off.

5) For the space heating load determination it was found that an energy per degree day model was adequate. But in general, any procedure that accurately predicts the building thermal load is acceptable.

6) The average domestic hot water demand as a function of the time of day and family size was established in the development of the procedure, but in general is highly dependent upon the habits of the occupants. However, it has been determined that the actual time distribution of the water heating load will have only a small effect upon the long-term performance for solar heating systems combining domestic hot water and space heating.

7) Since in most instances flat plate collectors are utilized for heating buildings, the collector component parameters are only valid for modeling flat plate collectors. Concentrating collectors or evacuated tubular collectors cannot be incorporated into the solar heating system evaluation as it is presently written in this Appendix.

8) The system evaluation procedure as outlined in this Appendix can only accurately predict system performance for systems using south facing collector arrays. Cases of different collector orientations must be analyzed using a different procedure.

c) The fluid mass flow rate through the collectors may vary considerably for different systems. The collector efficiency curve used as part of this evaluation procedure shall have been generated for the collector flow rate used in the system under consideration.

d) To eliminate reductions in system performance resulting from an undersized load heat exchanger, the ratio of the capacitance rate in the heat exchanger to the heating load (as given in equation [1]) should be greater than or equal to 1 . Additionally, for most considerations the ratio should be less than five. Cases involving a factor outside this range may be evaluated by using a correction factor ( $\mathrm{K}_{1}$ ) for correcting the fraction of the total heating supplied by solar. The method for utilizing the correction factor will be described later in the procedure. The ratio of capacitance rate in the heat exchanger to the heating load is given by: 


$$
1 \leq \frac{E}{\mathrm{~L}\left(\dot{m} c_{p}\right) \min }<5
$$

$$
\begin{aligned}
\text { where } \varepsilon_{\mathrm{L}} & =\text { effectiveness of the load heat exchanger } \\
& =\frac{\text { actual heat transfer }}{\text { maximum possible heat transfer }} \\
\left(\dot{m}_{\mathrm{p}}\right) \text { min } & =\text { minimum fluid capacitance rate }\left(\frac{\mathrm{Btu}}{\mathrm{h}^{\circ} \mathrm{F}}\right)
\end{aligned}
$$

flowing across the load heat exchanger.

$$
\begin{aligned}
\mathrm{UA} & =\text { building load heat loss factor } \\
& =\frac{\text { Design Heat Loss Rate }}{\text { Design Temperature Difference }}\left(\frac{\mathrm{Btu}}{\mathrm{h}^{\circ} \mathrm{F}}\right)
\end{aligned}
$$

The water to air or air to water load heat exchanger effectiveness ( $\varepsilon_{L}$ ) is easily calculated from methods given in the ASHRAE Handbook of Fundamentals or from data supplied by the manufacturer of the heat exchanger.

e) In the evaluation procedure, an example problem has been included for a system using a liquid as the transfer fluid. Notes are included within the example whenever a different calculation step would be required in evaluating a system using air.

f) The system evaluation procedure consists basically of six steps:

1) Calculate the monthly total heating load (L).

2) Calculate the monthly incident solar radiation on the collector array (S).

3) Determine the component parameters; i.e., collector area, effectiveness of heat exchangers, storage capacity, etc.

4) Knowing 1,2 , and 3 calculate two dimensionless parameters ( $D_{1}$, $D_{2}$ ) for each month.

5) Using $\mathrm{D}_{1}$ and $\mathrm{D}_{2}$ for each month, calculate the monthly fraction of the heating load supplied by solar energy. (f)

6) With the monthly loads and monthly functions supplied by solar, calculate (F annual) the annual fraction of the heating load supplied by solar energy. 
Nomenclature

$A_{c}-$ Collector aperture area $\left(\mathrm{ft}^{2}\right)$

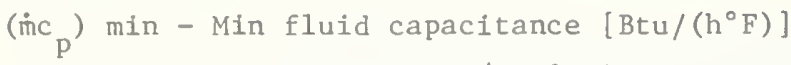

$c_{p}$ - Fluid capacitance [Btu/(16 $\left.\left.{ }^{\circ} \mathrm{F}\right)\right]$

$\mathrm{D}_{1}, \mathrm{D}_{2}$ - Dimensionless parameters

$\Delta t_{d}$ - Temperature difference for building design temperature conditions ( $\left.{ }^{\circ} \mathrm{F}\right)$

$\Delta t$ - Total number of hours in a particular month (h)

$E_{C}-$ Effectiveness of the collector-storage heat exchanger

$\varepsilon_{L}$ - Effectiveness of the load heat exchanger

$\theta$ - Collector tilt $\left({ }^{\circ}\right)$

E - Solar energy supplied for a particular month (Btu/Month)

$\mathrm{E}_{\text {Total }}$ - Solar energy supplied for an entire year (Btu/Year)

f - Monthly fraction of total heating load supplied by solar energy

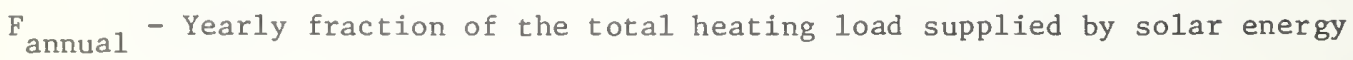

$\mathrm{F}_{\mathrm{R}}$ - Collector heat removal factor

$\mathrm{F}_{\mathrm{R}}^{\prime}$ ' - Combined form of the collector heat exchanger effectiveness ( $\varepsilon_{c}$ ) and the collector heat removal factor $\left(F_{\mathrm{R}}\right)$

$\gamma$ - Solar collector azimuth angle (For Due South $=180^{\circ}$ )

$\overline{\mathrm{I}}_{\mathrm{H}}$ - Monthly average of the daily radiation incident on a horizontal surface $\left[\mathrm{Btu} /\left(\mathrm{Day} \cdot \mathrm{ft}^{2}\right)\right]$

$\overline{\mathrm{I}}_{\mathrm{T}}$ - Monthly average of the daily radiation incident on a tilted surface [Btu/(Day•ft ${ }^{2}$ )]

$\overline{\mathrm{K}}_{t}$ - Ratio of the monthly averages of the daily radiation on a horizontal surface to the extraterrestrial radiation on a horizontal surface

$\mathrm{K}_{1}$ - Correction factor to correct $\mathrm{f}$ for various storage capacities other than $15 \mathrm{Btu} /\left({ }^{\circ} \mathrm{F} \cdot \mathrm{ft}{ }^{2}\right)$

$\mathrm{K}_{2}$ - Correction factor to correct for $\varepsilon_{\mathrm{L}}\left(\dot{\mathrm{m}}_{\mathrm{p}}\right) \mathrm{min} / \mathrm{UA}$ other than 2

L - Total heating and hot water load for a particular month (Btu/Month)

$\mathrm{L}_{\text {Total }}$ - Total heating and hot water load for an entire year (Btu/Year)

$\mathrm{m}$ - Mass of domestic hot water used for a particular month (1b)

$\dot{\mathrm{m}}$ - Flow rate of the working fluid either air or liquid (1b/hr)

M - Mass of thermal storage (1b)

$\mathrm{N}$ - Number of days in a particular month

$\emptyset$ - Latitude

$Q_{S}$ - Space heating load for a particular month (Btu/Month)

$Q_{w}$ - Domestic hot water heating load for a particular month (Btu/Month)

$\mathrm{q}_{\mathrm{d}}$ - Building design rate of sensible heat loss (Btu/h)

$\overrightarrow{\mathrm{R}}$ - Ratio of the monthly average-daily radiation on a tilted surface to that on a horizontal surface

S - Monthly incident solar radiation on a tilted surface [Btu/(month. $\left.\mathrm{ft}^{2}\right)$ ]

$\overline{\mathrm{t}}_{\mathrm{a}}$ - Monthly average ambient air temperature $\left({ }^{\circ} \mathrm{F}\right)$

$t_{S}$ - Temperature of domestic hot water supply $\left({ }^{\circ} \mathrm{F}\right)$

$t_{m}$ - Temperature of water main supply $\left({ }^{\circ} \mathrm{F}\right)$

$\mathrm{t}_{\text {ref }}-$ Reference temperature, $212^{\circ} \mathrm{F}$

$\Delta$ time - total number of hours in each month 
Nomenclature (cont'd)

$\overline{\tau \alpha}$ - Average transmissivity-absorptivity product for design purposes

$(\tau \alpha)_{n}$ - Transmissivity-absorptivity product at normal incidence

$\mathrm{U}_{\mathrm{L}}-$ Collector heat loss factor $\left[\mathrm{Btu} /\left(\mathrm{h} \cdot{ }^{\circ} \mathrm{F} \cdot \mathrm{ft}^{2}\right)\right]$

UA - Building heat loss factor $\left[\mathrm{Btu} /\left(\mathrm{h} \cdot{ }^{\circ} \mathrm{F}\right)\right.$

\section{References Cited}

1. Klein, S. A., Beckman, W. A., and J. A. Duffie, "Design Procedure for Solar Heating Systems," presented at the 1975 International Solar Energy Congress, UCLA, Los Angeles, California, July 1975.

2. B. Y. H. Liu, R. C. Jordan, "Availability of Solar Energy for Flat-Plate Solar Heat Collectors," Low Temperature Engineering Application of Solar Energy, ASHRAE, New York, 1967. 

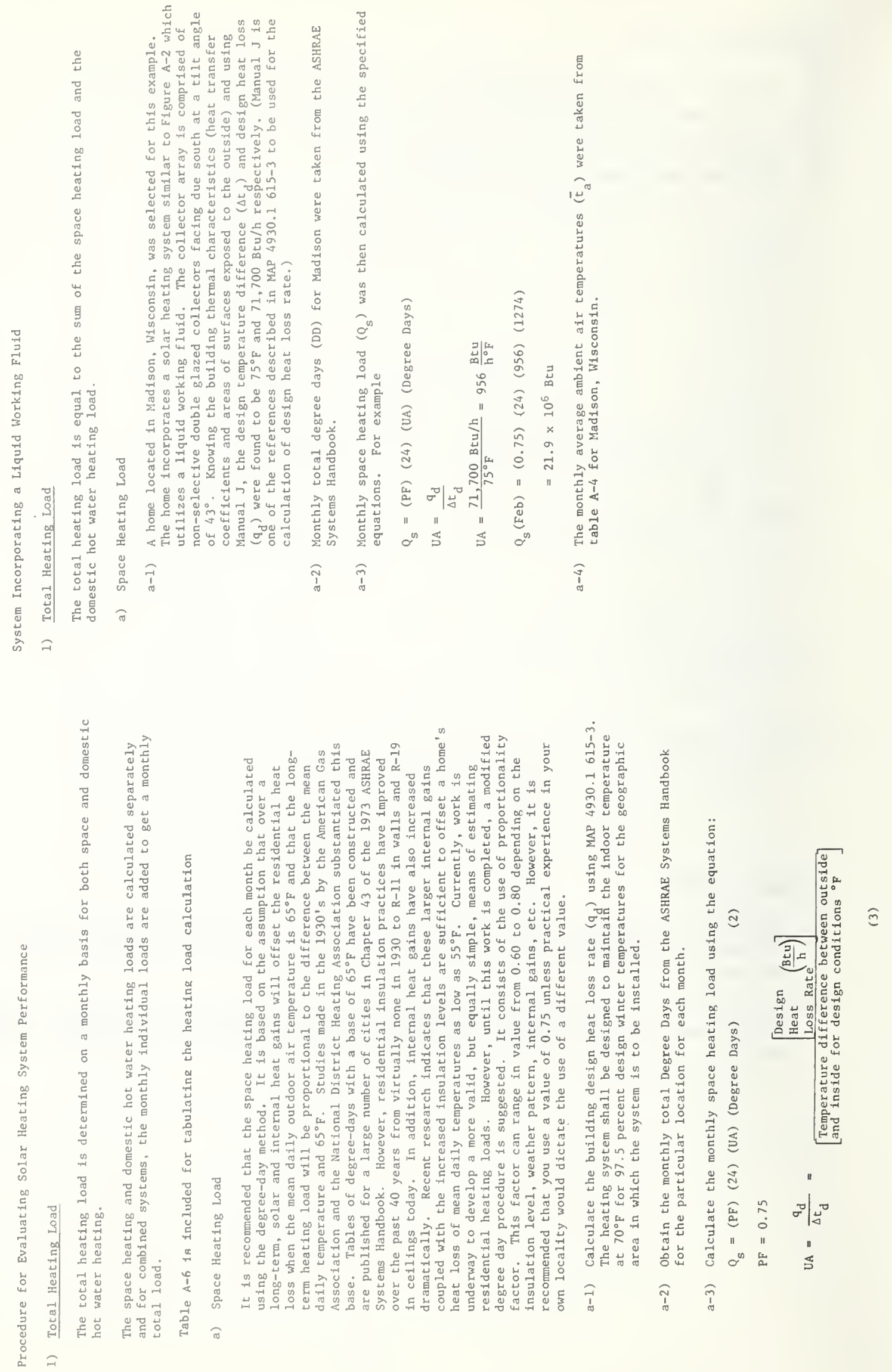

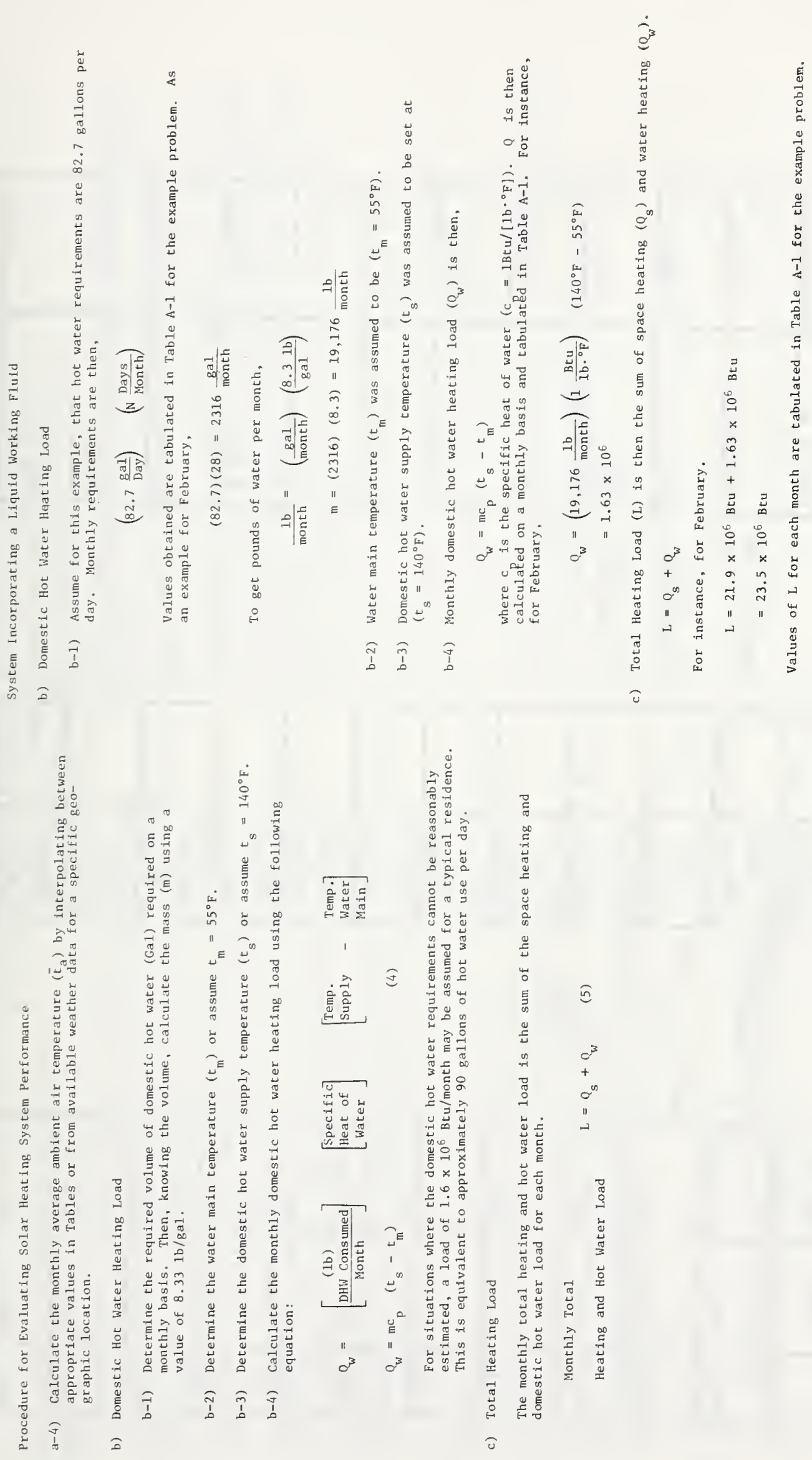


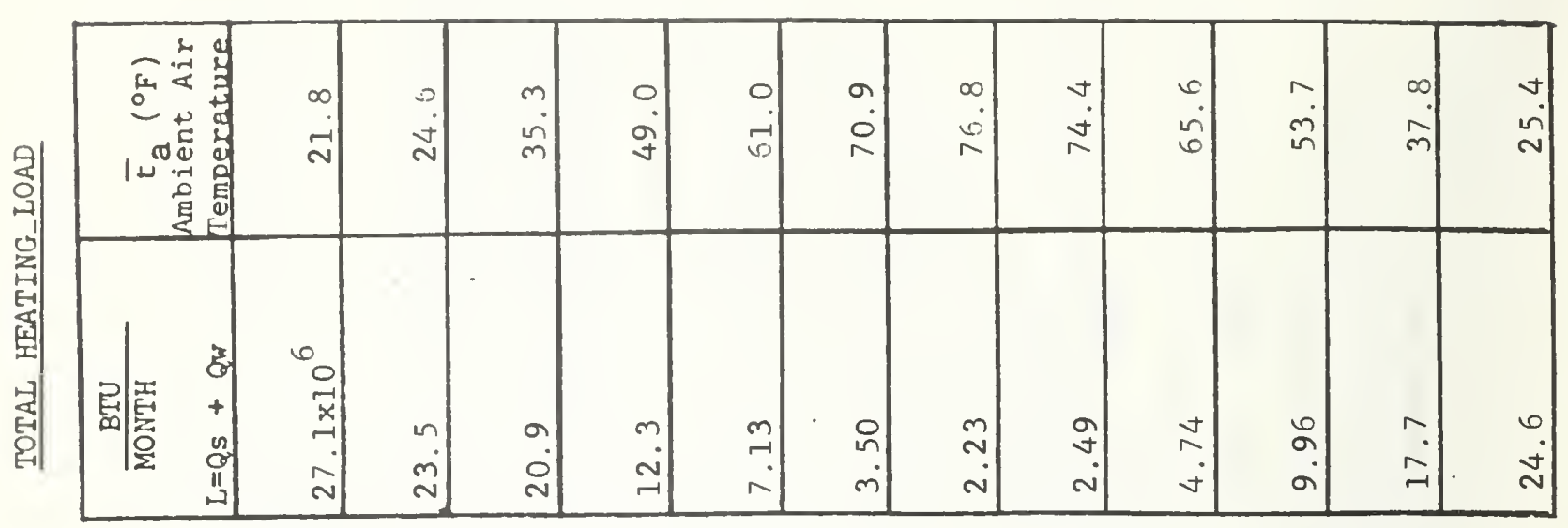

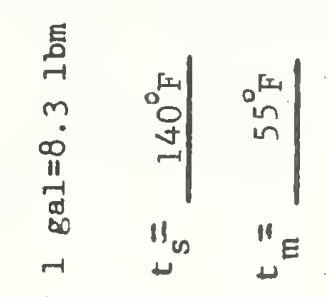

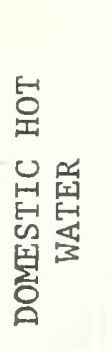

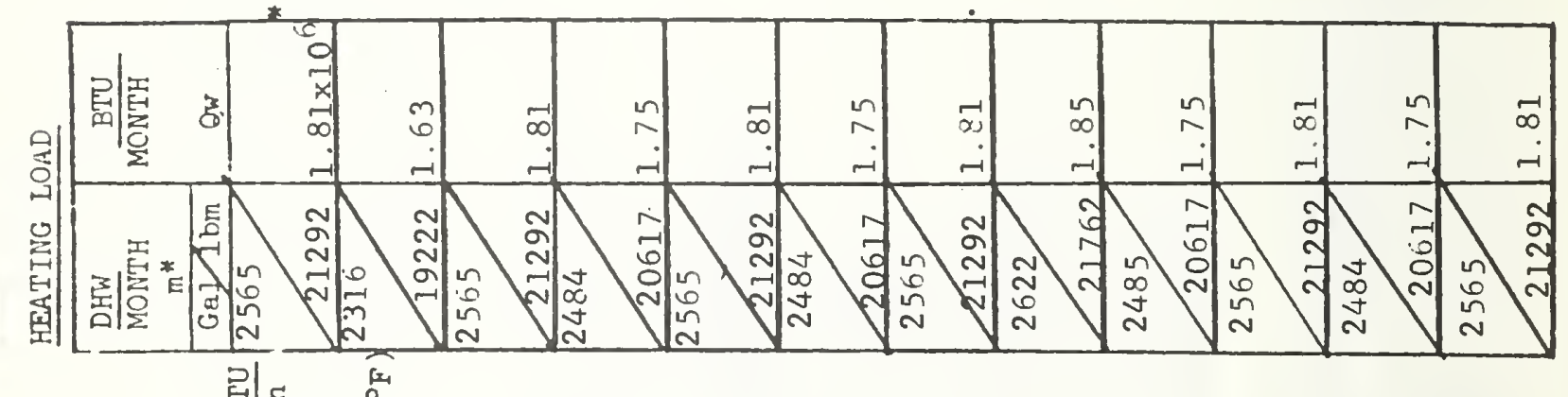

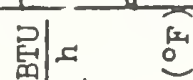

일 n

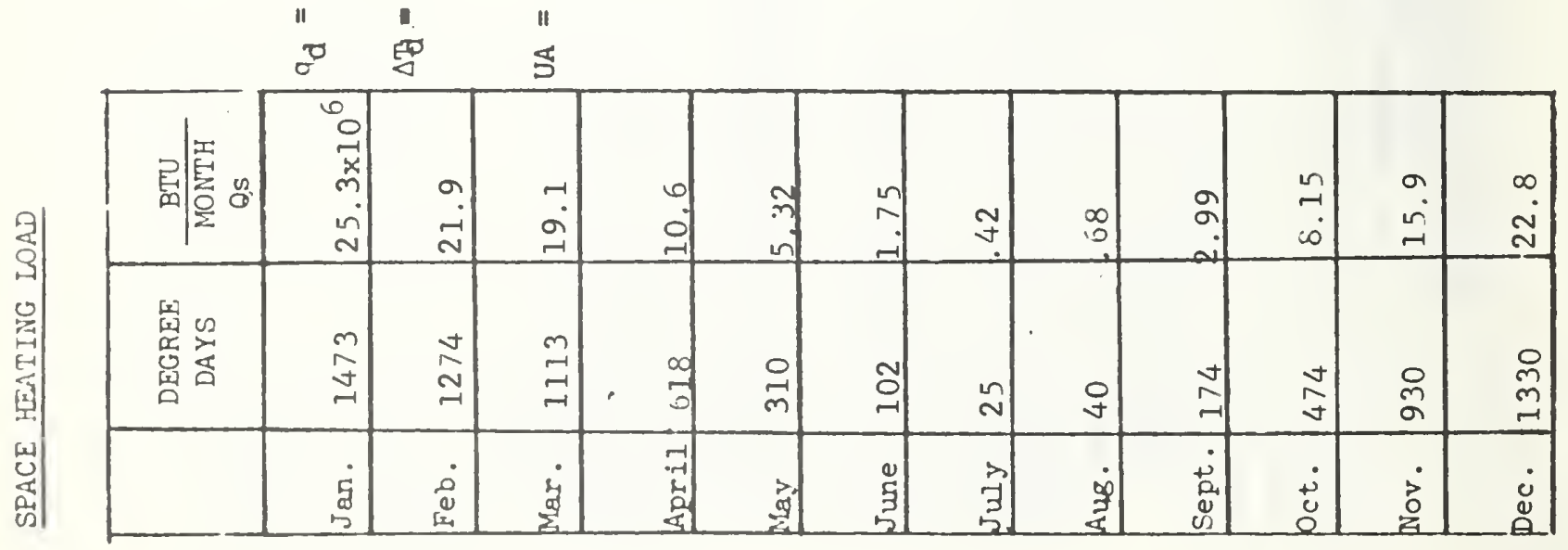



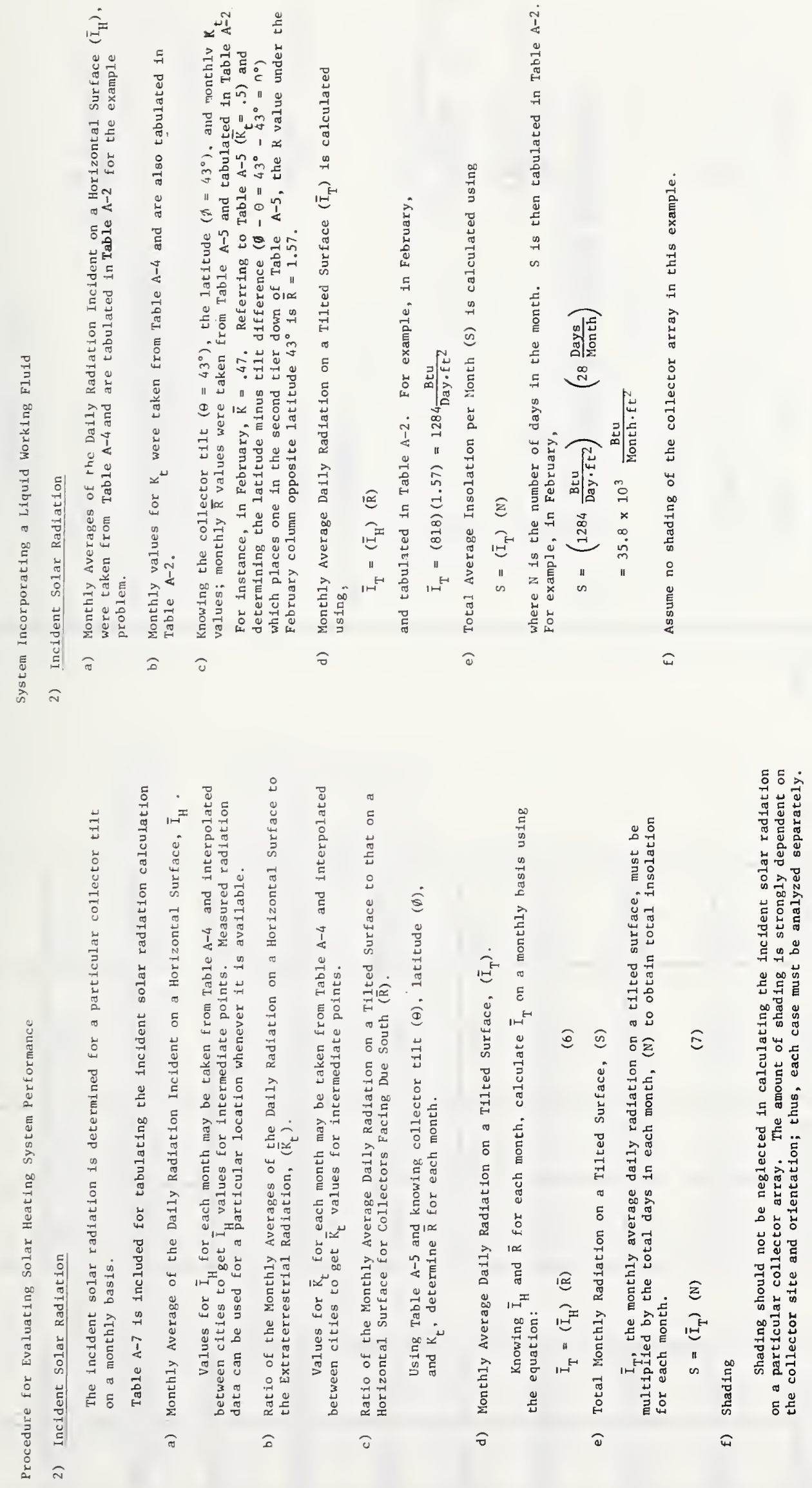

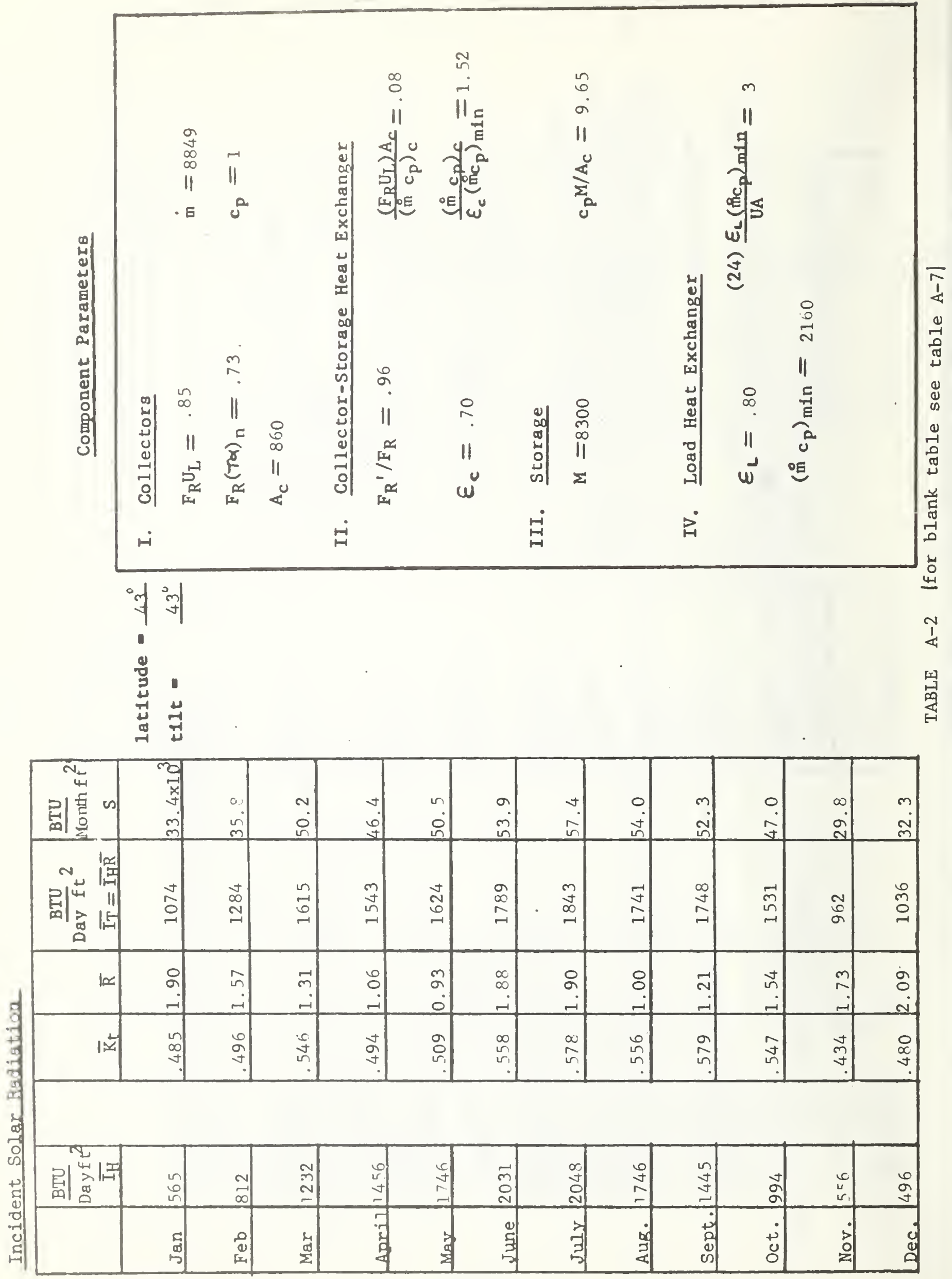

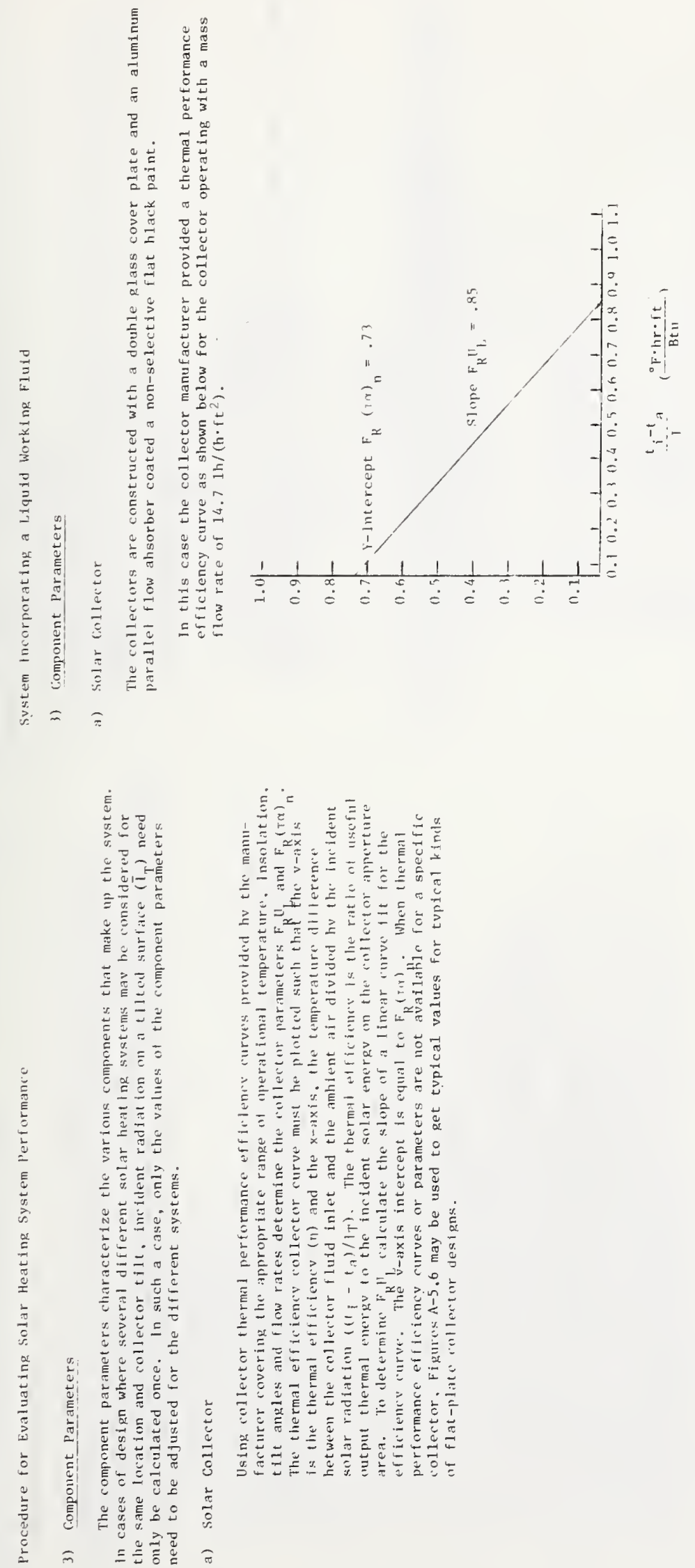

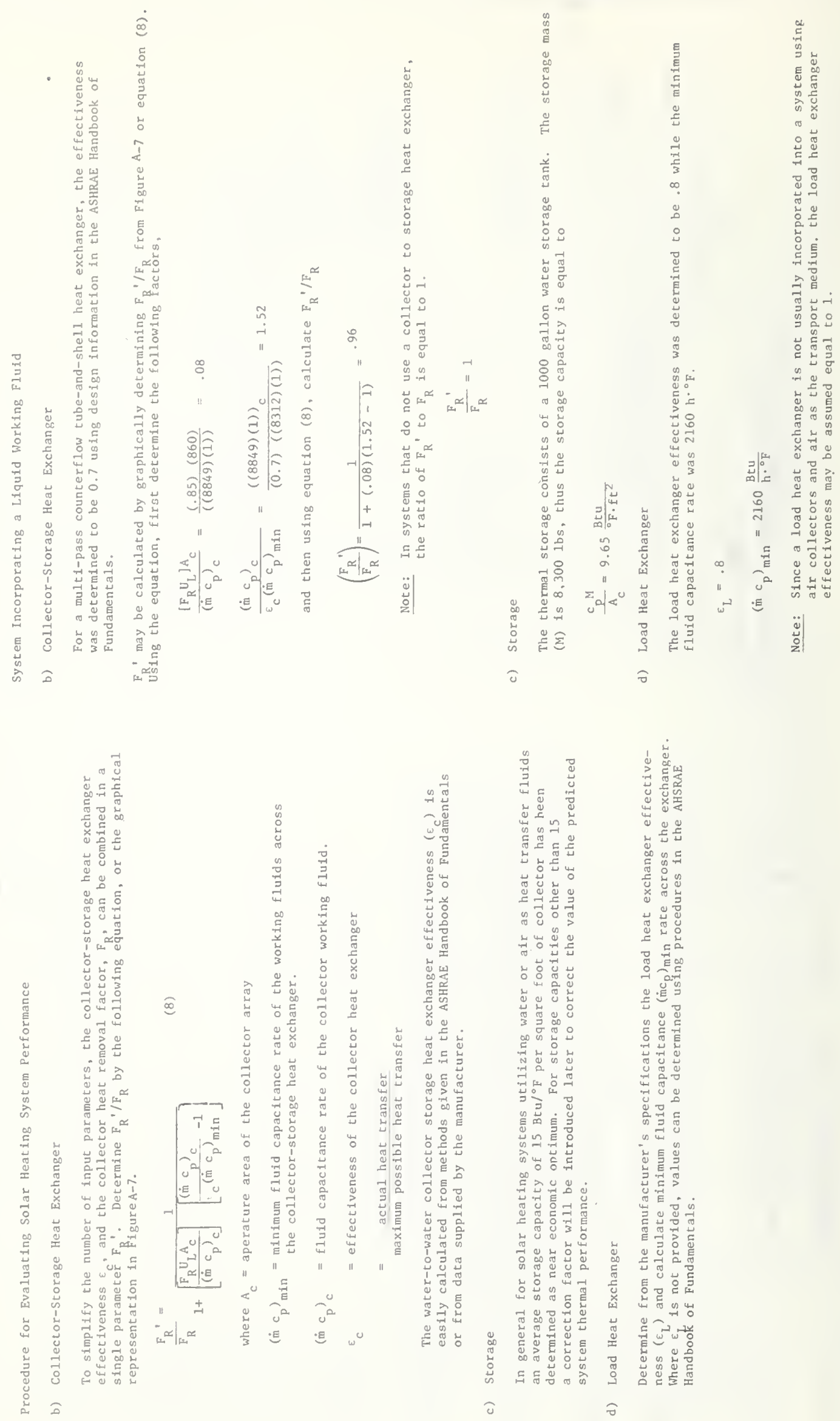

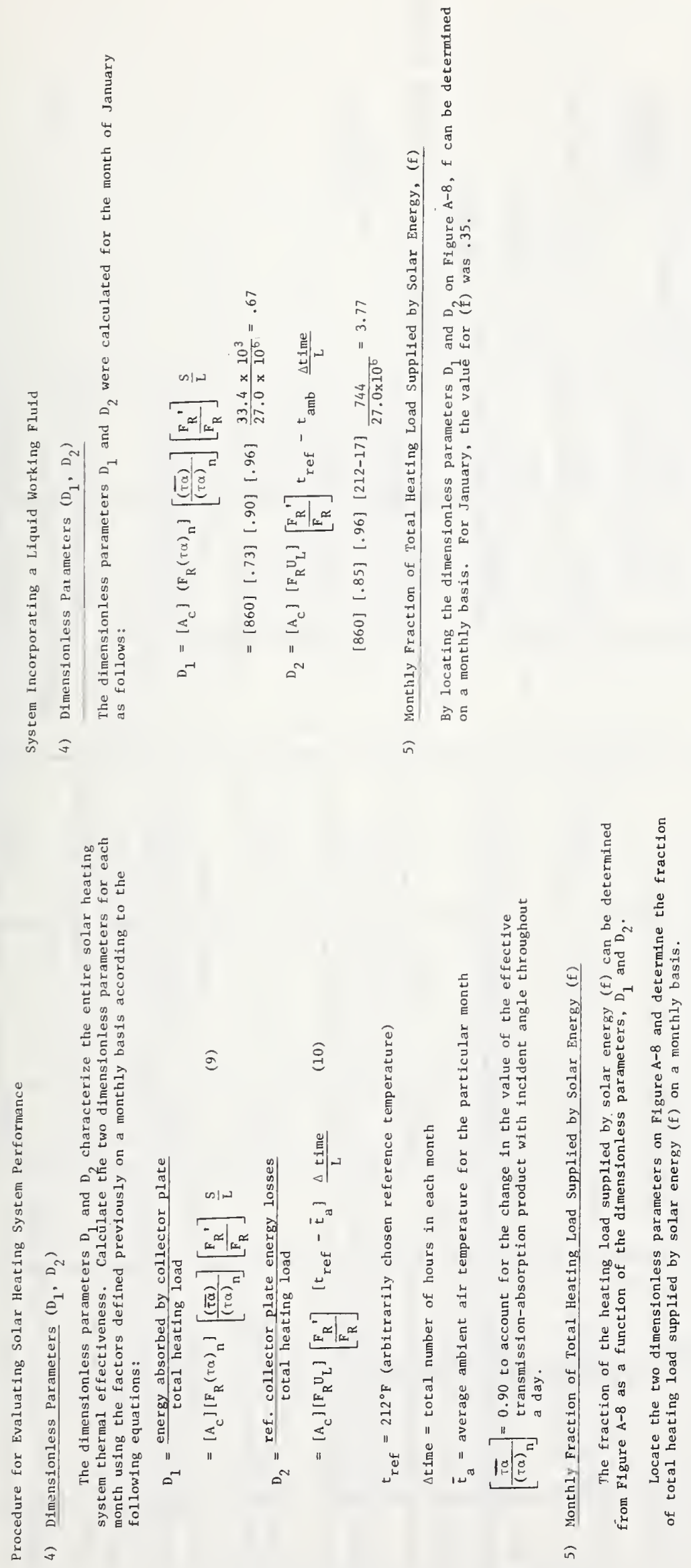

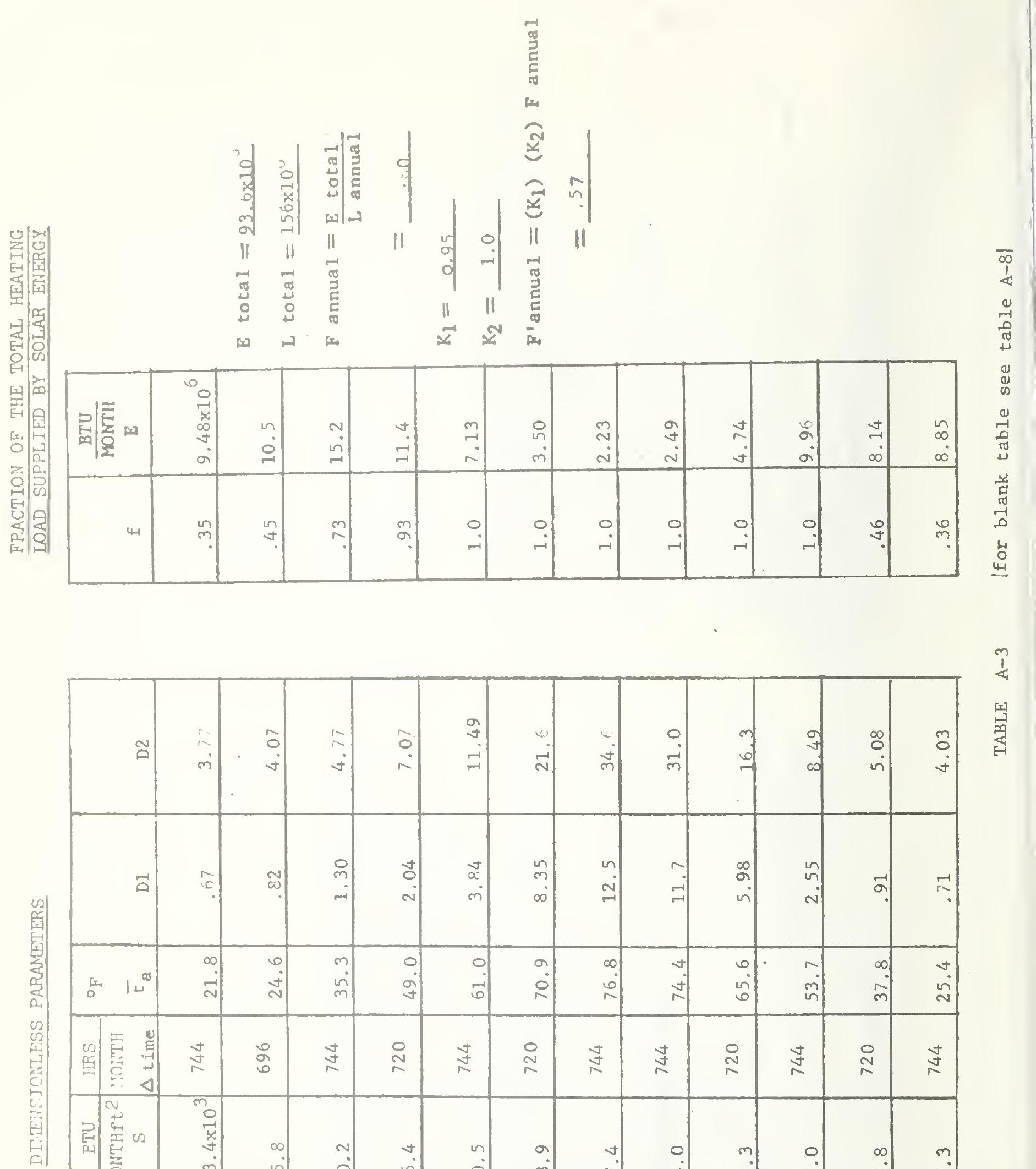

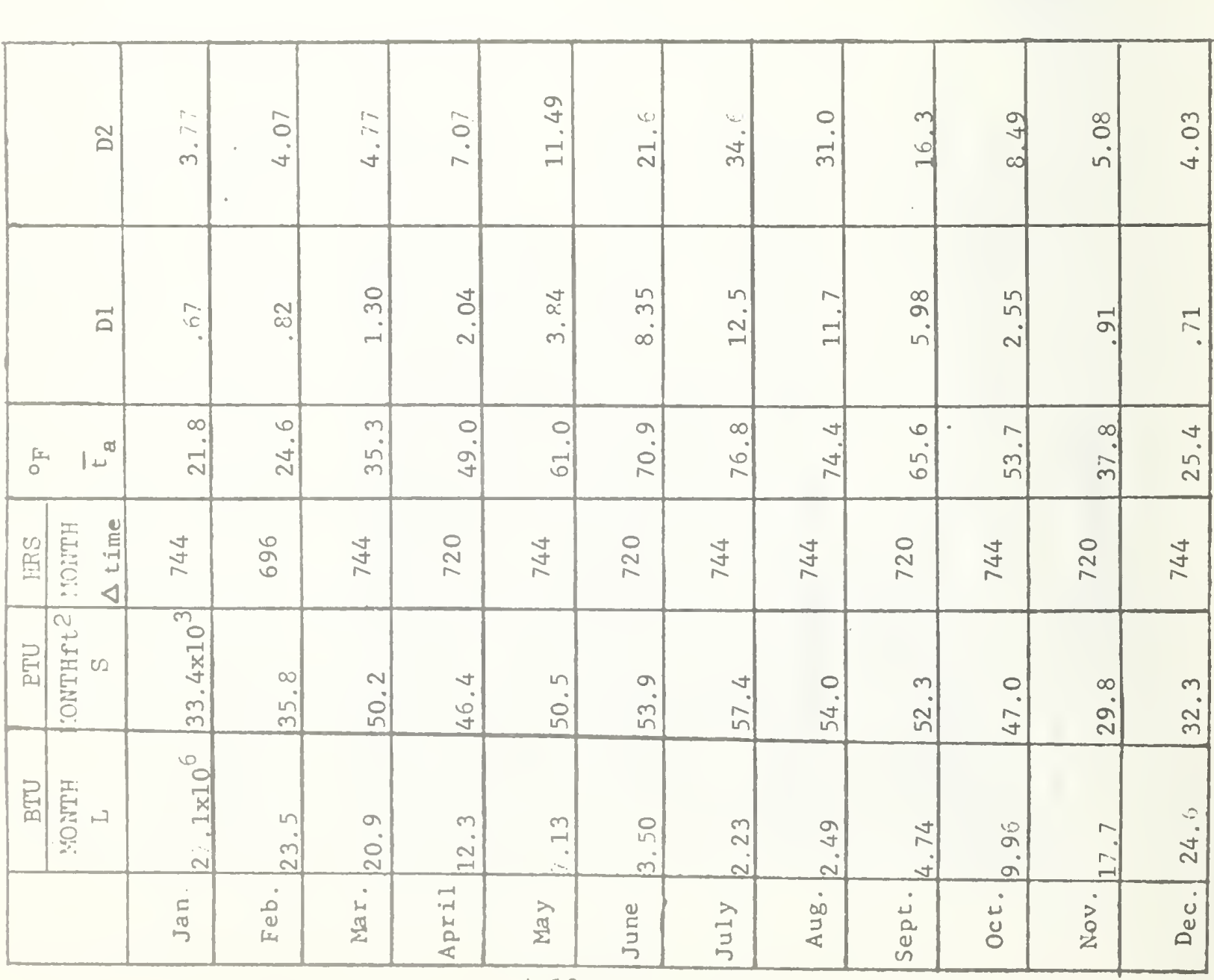



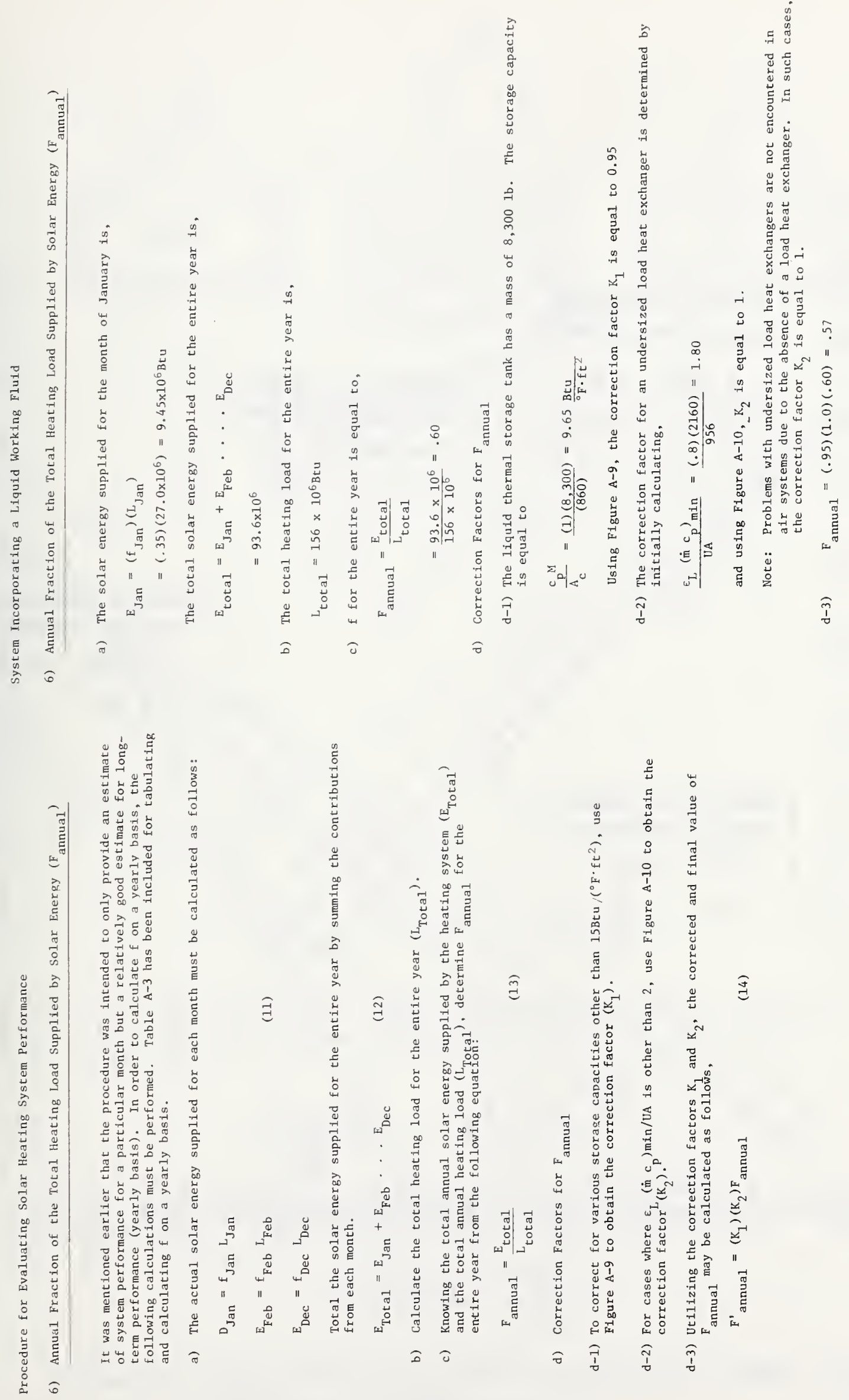


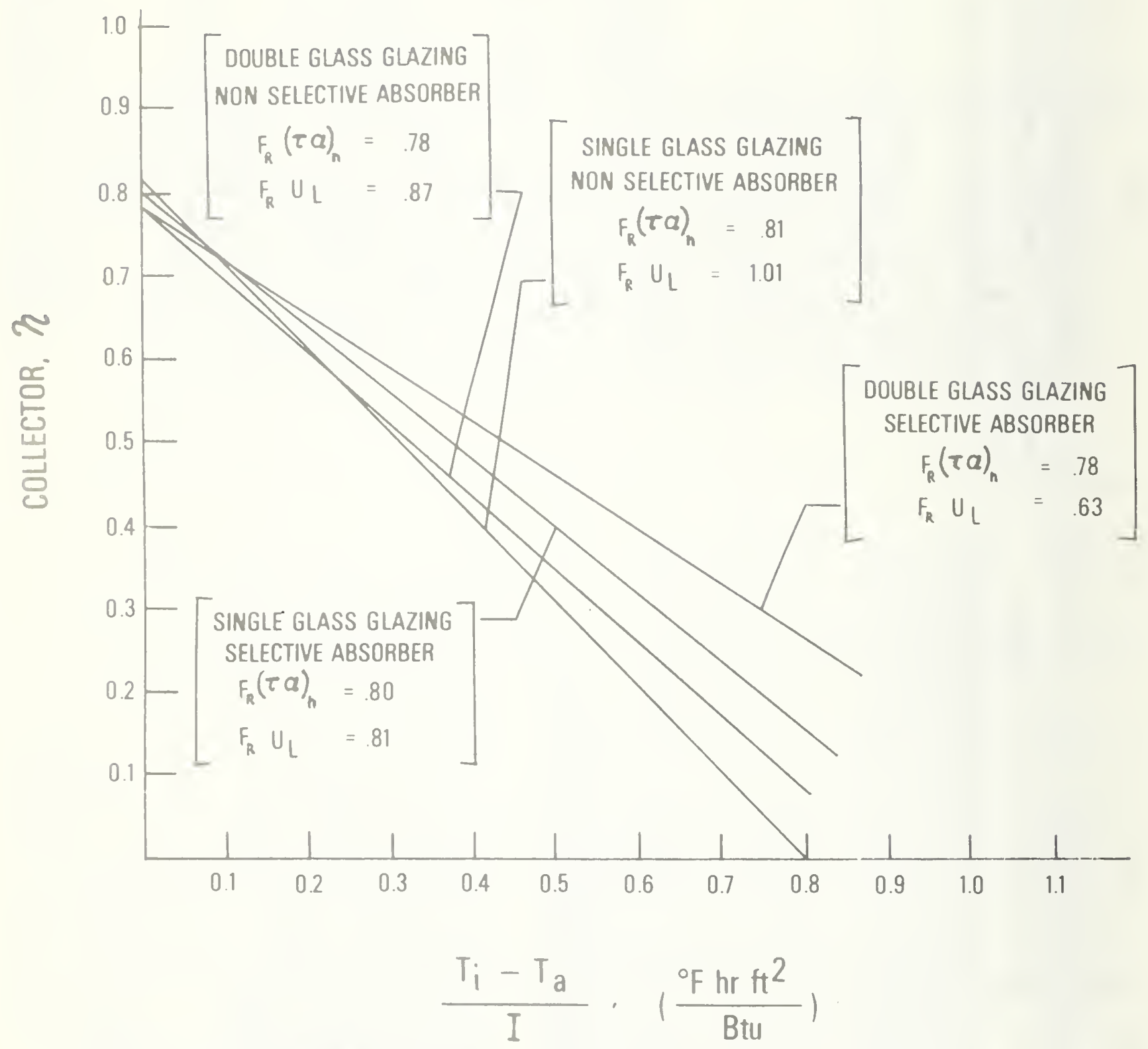

Figure A-5 Thermal Efficlency Curves for Typlcal Flat Plate Collectors using a Liquid Working Fluid 


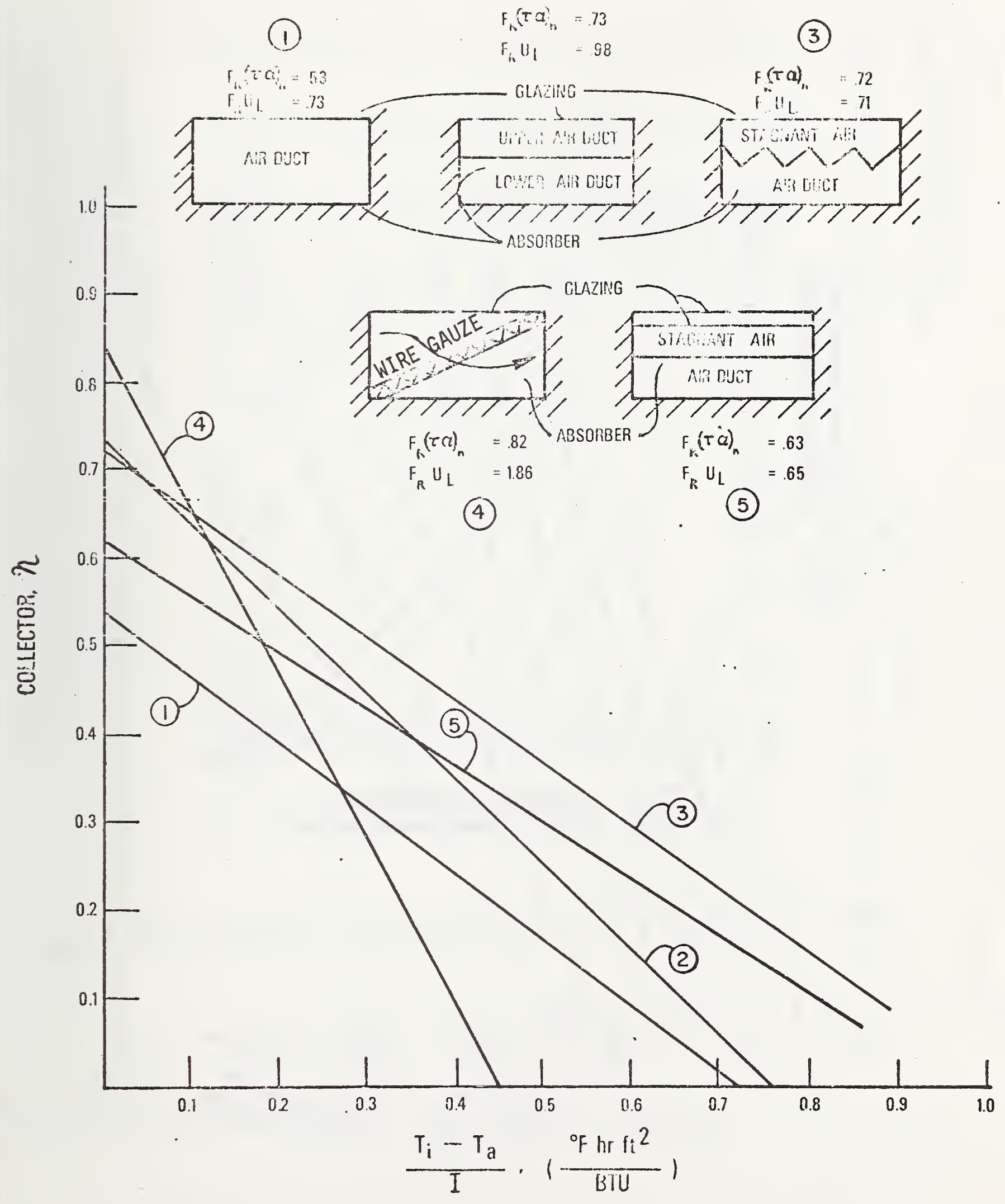

Figure A-6 Thermal Efficiency Curves for Typical Flat Plate Collectors Using Air as a Working Fluid 


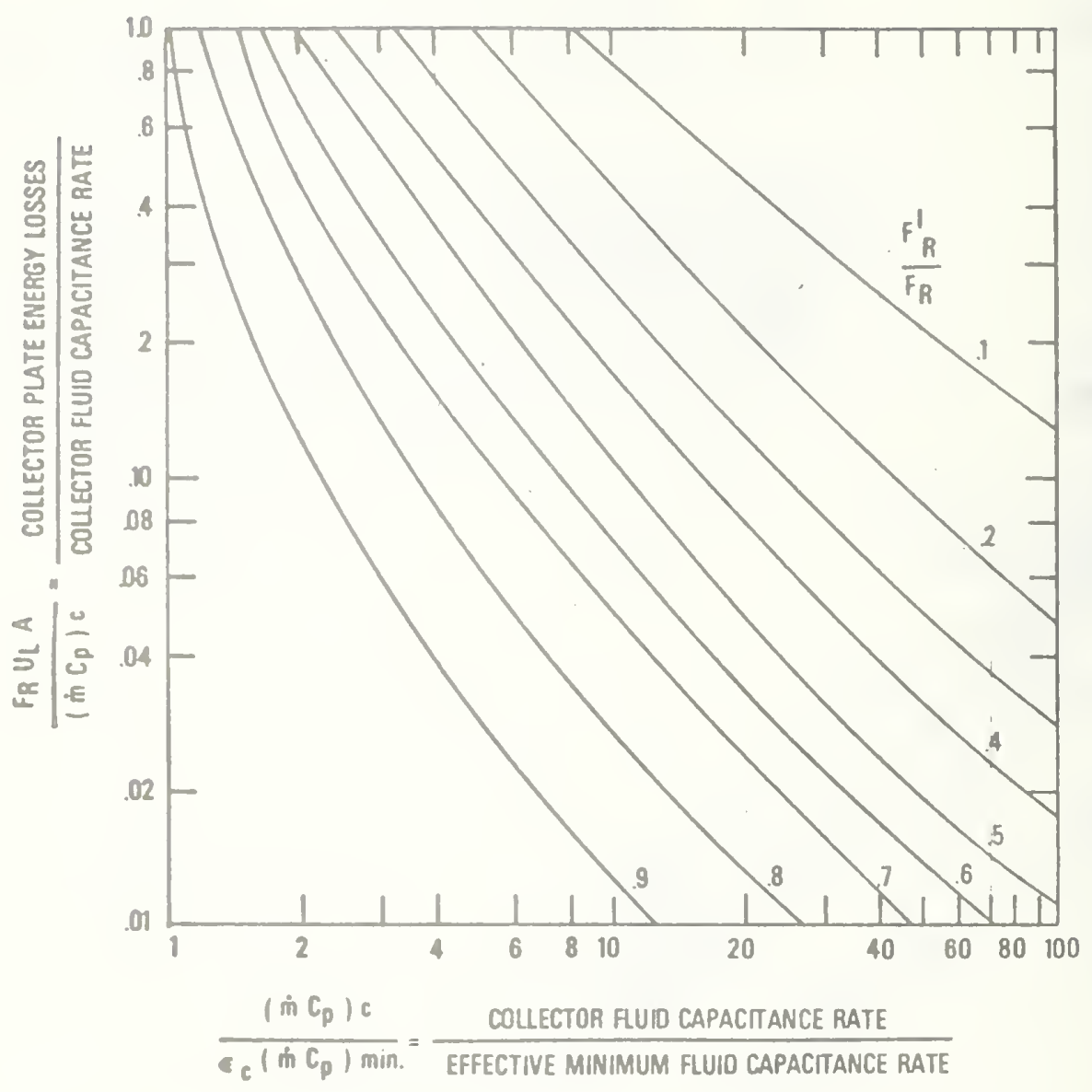

Figure A-7 $F_{R}{ }^{1 / F_{R}}$ as a function of $F_{R} U_{L} A /\left(\dot{\dot{m}} C_{p}\right)_{C}$ and $\left(\dot{m} C_{p}\right)_{C} / \varepsilon_{L}\left(\dot{m} E_{\dot{p}}\right)$ min 


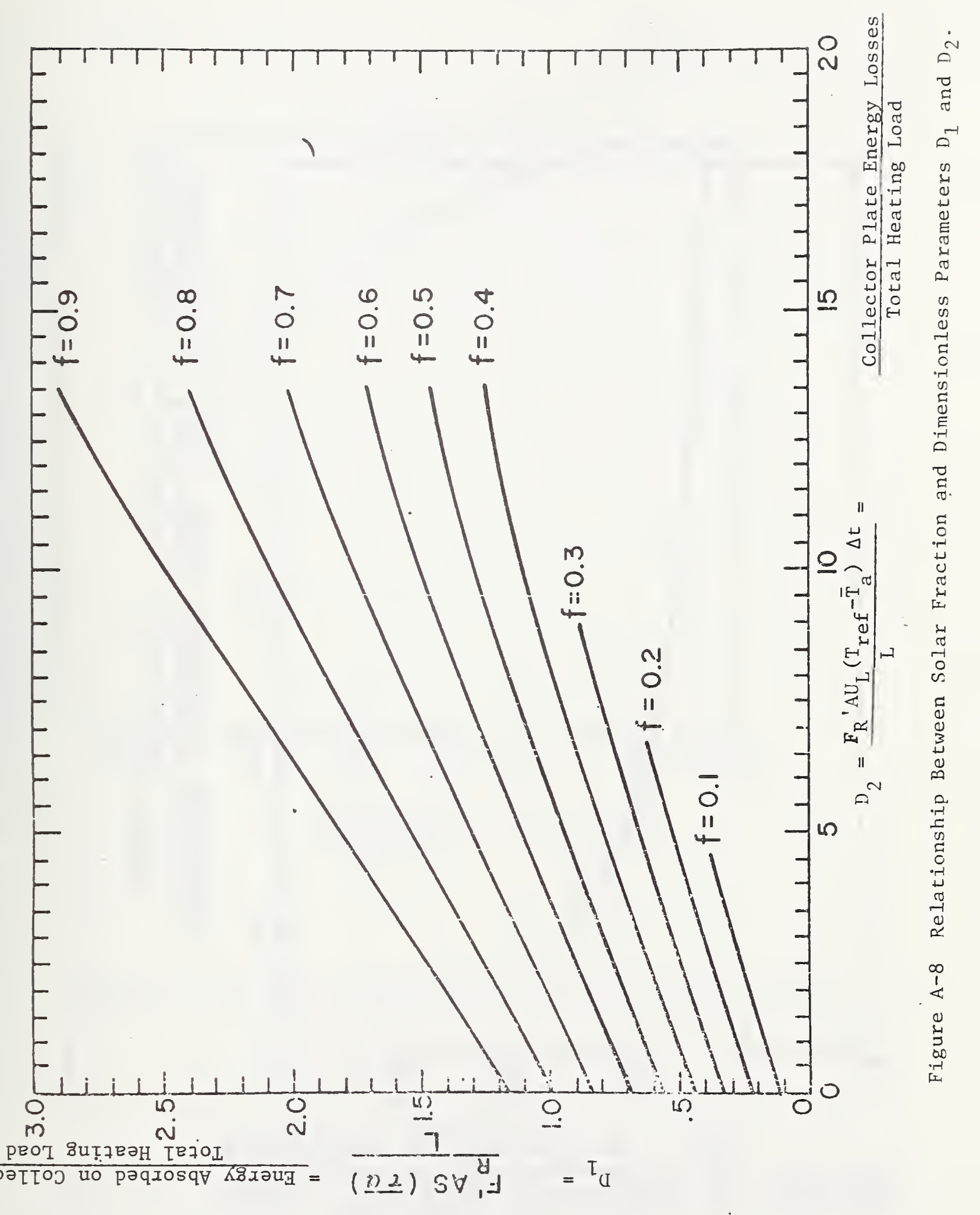




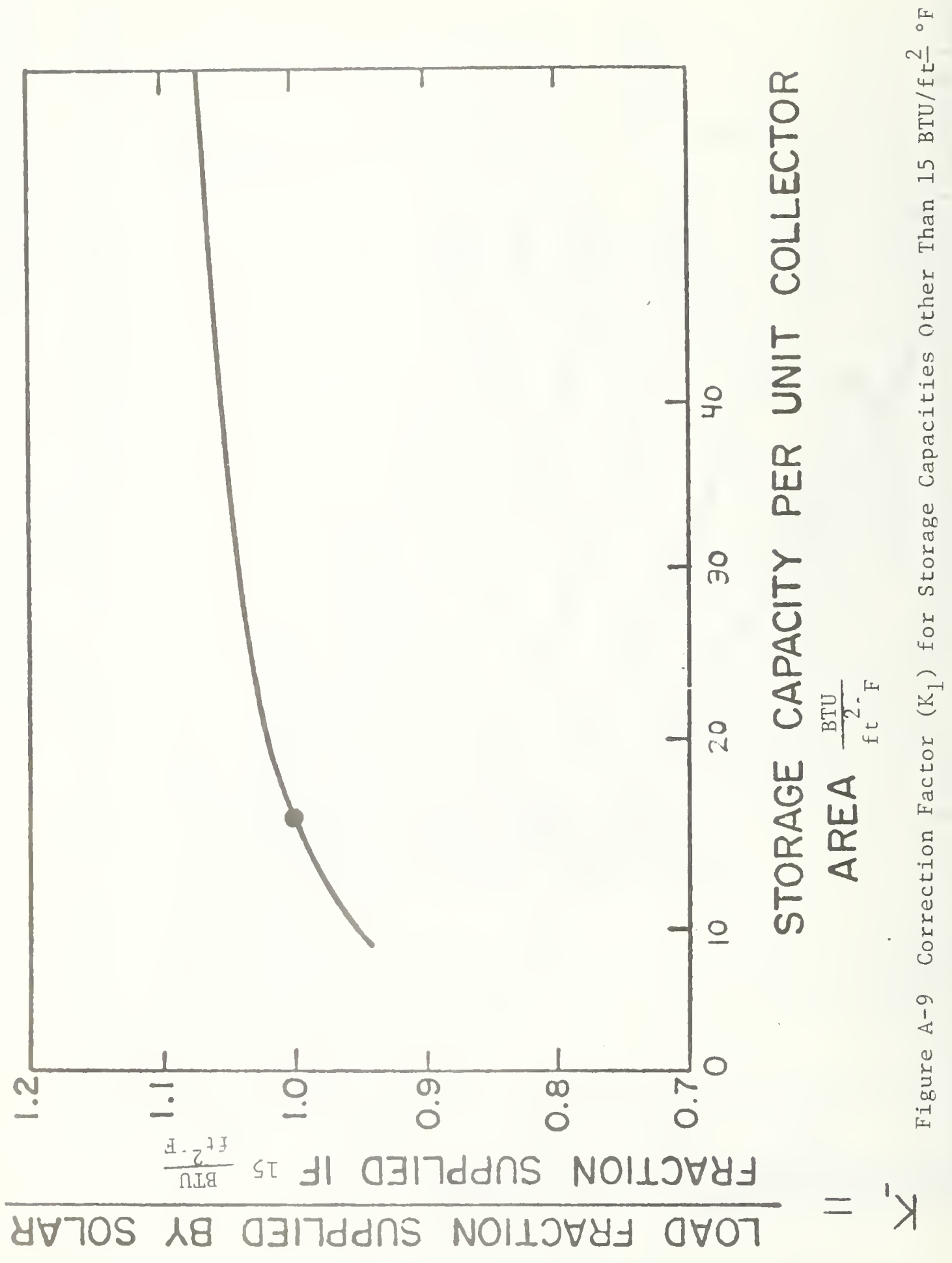




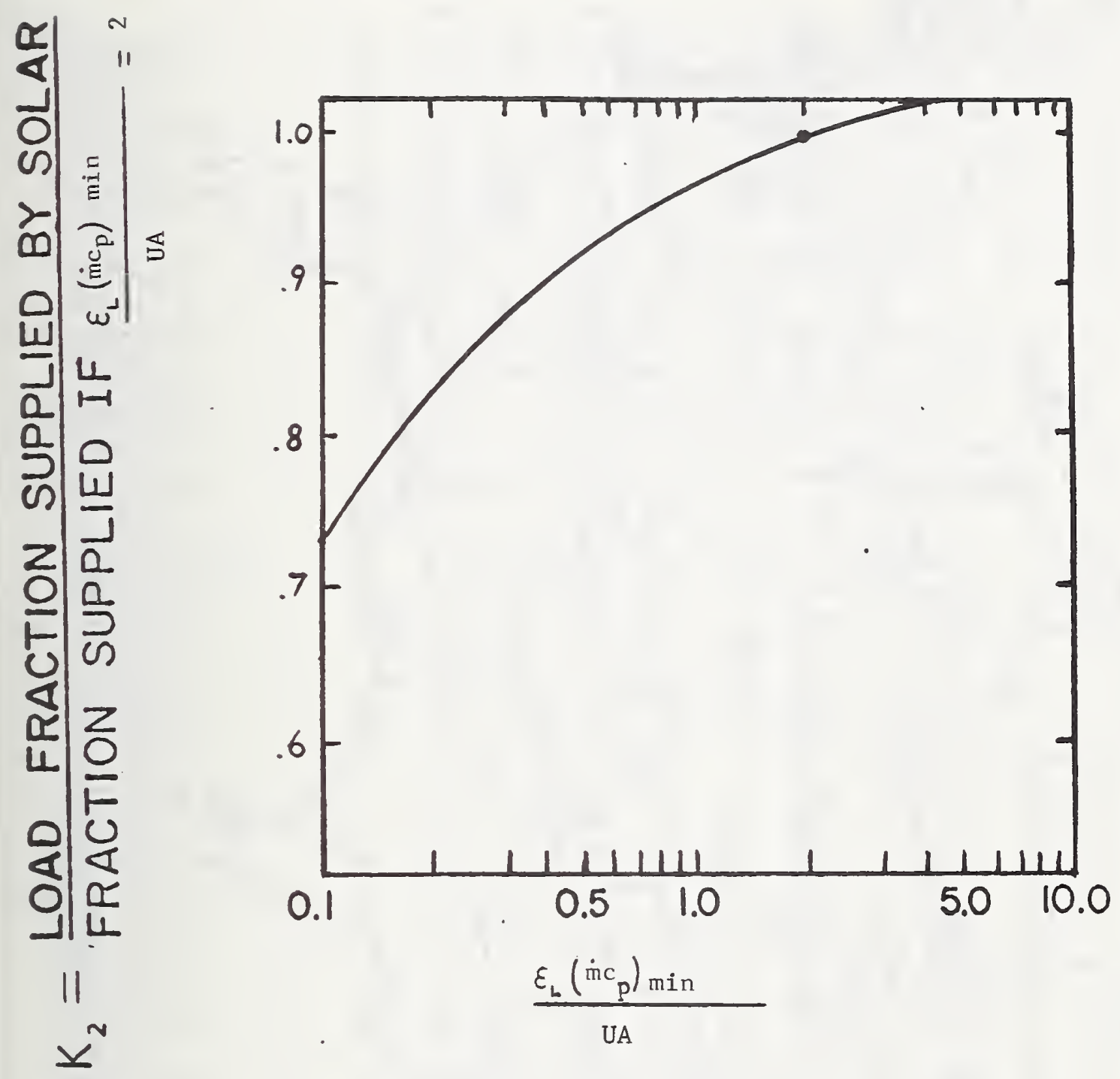

Figure A-10 Correction Factor $\left(\mathrm{K}_{2}\right)$ for Various Values of $\varepsilon_{\mathrm{L}}\left(\dot{m}_{\mathrm{p}}\right)_{\mathrm{min}}$ /UA 


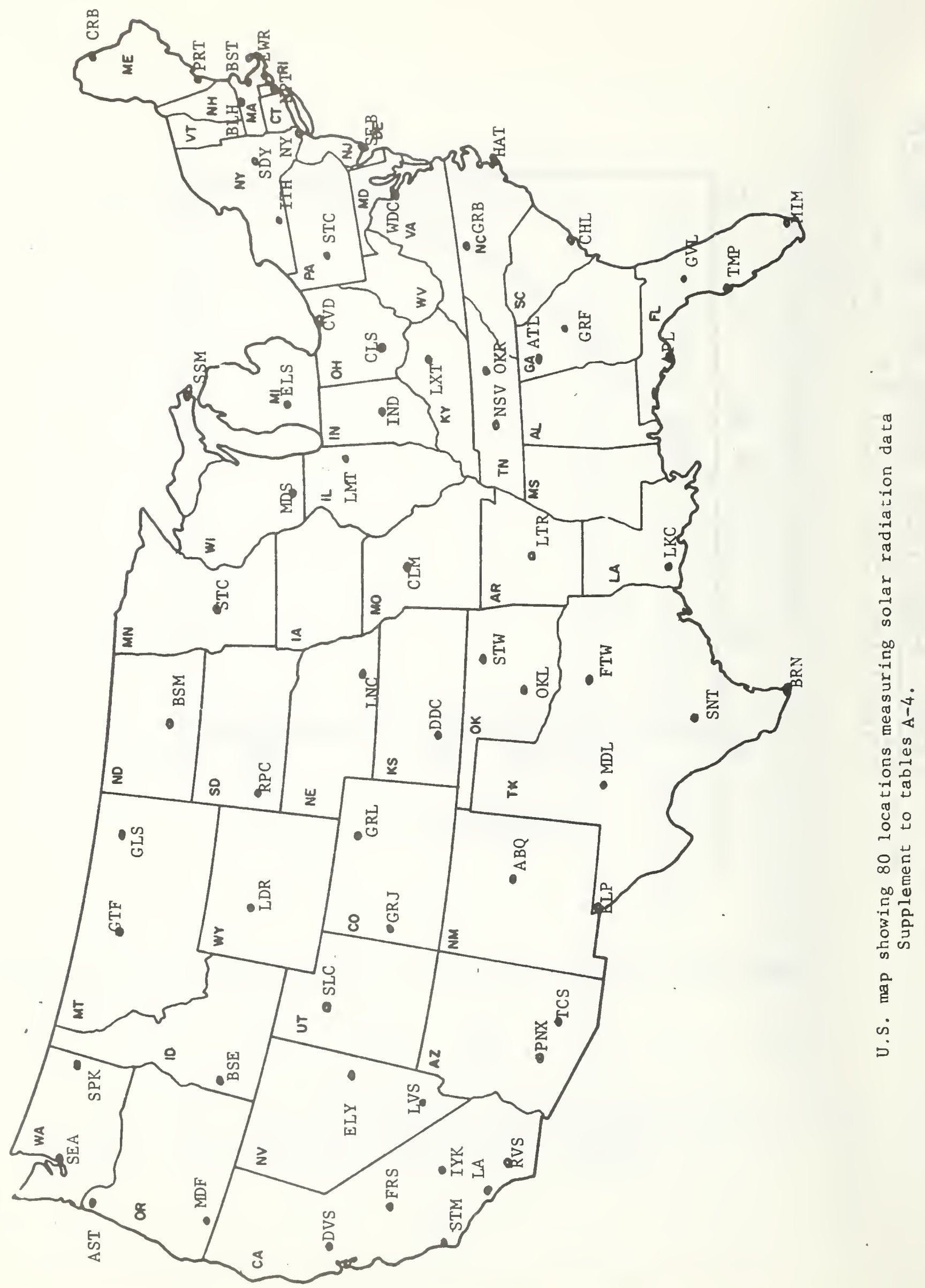


Table A-4

Radiation and Other Data for 80 Locations in the United States ${ }^{2}$

(F $F=$ Monthly average dally total radiation on a horizontal surface, Btu/day- $\mathrm{ft}^{2} ; \mathrm{K}_{\mathrm{t}}=$ the fraction of the extra terrestrial radiation transmitted through the atmosphere; $t_{a}=$ amblent temperature, deg $F$.)

Albuquerque, N.M. . . . . . .

Lat. $35^{\circ} 03^{\prime} \mathrm{N} \ldots \ldots \ldots \ldots$

Annette Is., Alaska. . . . . .

Lat. $55^{\circ} 02^{\prime} \mathrm{N}, \ldots \ldots \ldots$.

El. $110 \mathrm{ft} \ldots \ldots \ldots \ldots$

Apalachicola, Florida .....

Lat. $29^{\circ} 45^{\prime} \mathrm{N} \ldots \ldots \ldots \ldots$

E1. $35 \mathrm{ft} \ldots \ldots \ldots \ldots$

Astoria, Oregon. . . . . . .

Lat. $46^{\circ} 12^{\prime} \mathrm{N} \ldots \ldots \ldots \ldots$

E1. $8 \mathrm{ft} \ldots \ldots \ldots \ldots \ldots$

Atlanla, Georgia ........

Lat. $33^{\circ} 39^{\prime} \mathrm{N} \ldots \ldots \ldots \ldots$

Barrow, Alaska. . . . . . .

Lat. $71^{\circ} 20^{\prime} \mathrm{N} \ldots \ldots \ldots \ldots$

El. $22 \mathrm{ft} \ldots \ldots \ldots \ldots \ldots$

Belhel, Alaska. . . . . . . .

Lat. $60^{\circ} 47^{\prime} \mathrm{N} \ldots \ldots \ldots \ldots$

El. $125 \mathrm{ft} \ldots \ldots \ldots \ldots$

Bismarck, North Dakota . . .
Lat. $46^{\circ} 47$ ' . . . . . .

Lat. 1660 ft $\ldots \ldots \ldots \ldots \ldots$

Blue Hill, Mass........

Lat. $42^{\circ} 13^{\prime} \mathrm{N} \ldots \ldots \ldots \ldots$

Boise, Idaho . . . . . . .

Lat. $43^{\circ} 34^{\prime} \mathrm{N}$

El. $2844 \mathrm{ft} \ldots \ldots \ldots \ldots$.

Boston, Mass.

Lat. $42^{\circ} 22$ ' . . . . . . .

El. $29 \mathrm{ft} \ldots \ldots \ldots \ldots$.

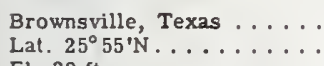

El. $20 \mathrm{ft} \ldots \ldots \ldots \ldots \ldots$

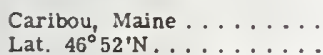

Lat. $46^{\circ} 52 \mathrm{~N} \ldots \ldots \ldots \ldots$

Charleston, s.c. .......

Lat. $32^{\circ} 54^{\prime} \mathrm{N} \ldots \ldots \ldots \ldots$

El. $46 \mathrm{ft} \ldots \ldots \ldots \ldots$

Cleveland, Ohio . . . . . .
Lat. $41^{\circ} 24$ '..$\ldots \ldots$

Ll. $805 \mathrm{ft} \ldots \ldots \ldots \ldots \ldots$

Columbia, Mo .........

Lat. $38^{\circ} 58^{\prime} \mathrm{N} \ldots \ldots \ldots \ldots$.

El. $785 \mathrm{ft} \ldots \ldots \ldots \ldots$

Columbus, Ohio........

Lat. $40^{\circ} 00^{\prime} \mathrm{N} \ldots \ldots \ldots \ldots$

El. $833 \mathrm{ft} \ldots \ldots \ldots \ldots$

Davis, Calif...........

Lat. $38^{\circ} 33^{\circ} \mathrm{N} \ldots \ldots \ldots \ldots$

El. $51 \mathrm{ft} \ldots \ldots \ldots \ldots$.

Dodge City, Kan. . . . . . .

Lat. $37^{\circ} 46^{\prime} \mathrm{N} \ldots \ldots \ldots \ldots$

East Lansing, Michigan ...

Lat. $42^{\circ} 44^{\prime} \mathrm{N}$. . . . . . . .

El. $856 \mathrm{ft} \ldots \ldots \ldots \ldots$

East Wareham, Mass .....

Lat. $41^{\circ} 46^{\prime} \mathrm{N} \ldots \ldots \ldots \ldots$
$\overline{I_{H}}$
$\bar{K}$
$\bar{t}_{a}$
$\frac{T_{H}}{T_{H}}$
$\frac{\bar{t}_{a}^{t}}{t}$

Jan

Feb

Mar

Apr

May Jun

Jul Aug

Sep

Oct Nov Dec

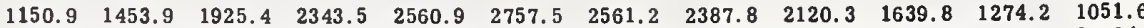

$\begin{array}{llllllllllll}236.2 & 428.4 & 883.4 & 1357.2 & 1634.7 & 1638.7 & 1632.1 & 1269.4 & 962 & 454.6 & 220.3 & 152\end{array}$

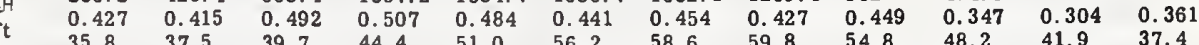

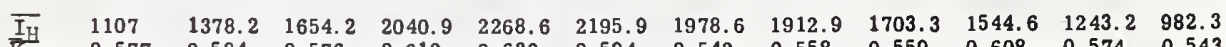

$\begin{array}{lllllllllllll}\bar{R}_{\mathrm{K}} & 0.577 & 0.584 & 0.576 & 0.612 & 0.630 & 0.594 & 0.542 & 0.558 & 0.559 & 0.608 & 0.574 & 0.543\end{array}$

$\begin{array}{lllllllllllll}\mathrm{t}_{\mathrm{a}} & 57.3 & 59.0 & 62.9 & 69.5 & 76.4 & 81.8 & 83.1 & 83.1 & 80.6 & 73.2 & 63.7 & 58.55\end{array}$

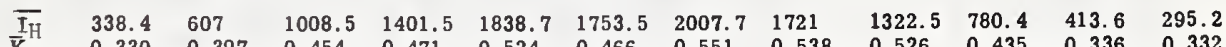

$\begin{array}{lllllllllllll}\overline{\mathrm{K}} & 0.330 & 0.397 & 0.454 & 0.471 & 0.524 & 0.466 & 0.551 & 0.538 & 0.526 & 0.435 & 0.336 & 0.332 \\ \overline{\mathrm{t}} & 0.31 & & 0.35 & \end{array}$

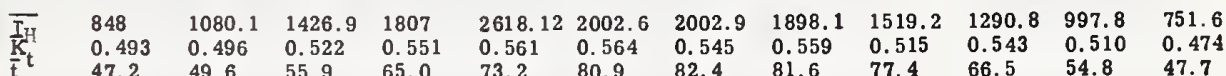

$\begin{array}{llllllllllll}47.2 & 49.6 & 55.9 & 65.0 & 73.2 & 80.9 & 82.4 & 81.6 & 77.4 & 66.5 & 54.8 & 47.7\end{array}$

$\begin{array}{llllllllllll}\bar{I}_{\mathrm{H}} & 13.3 & 143.2 & 713.3 & 1491.5 & 1883 & 2055.3 & 1602.2 & 953.5 & 428.4 & 152.4 & 22.9\end{array}$

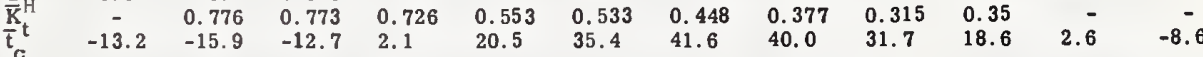

$\begin{array}{lllllllllllll}\overline{\mathrm{I}_{\mathrm{H}}} & 142.4 & 404.8 & 1052.4 & 1662.3 & 1711.8 & 1698.1 & 1401.8 & 938.7 & 755 & 430.6 & 164.9 & 83\end{array}$

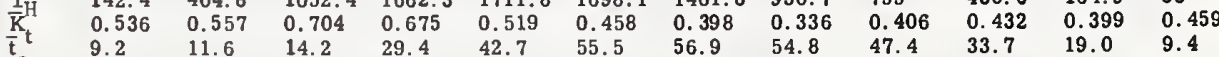

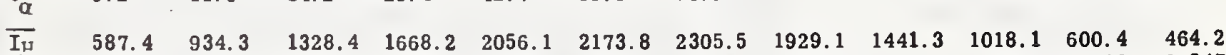

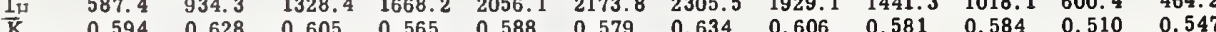

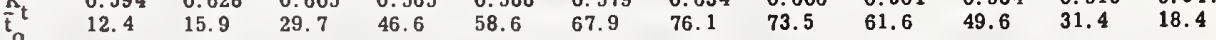

$\begin{array}{lllllllllllll}\overline{I_{H}} & 555.3 & 797 & 1143.9 & 1438 & 1776.4 & 1943.9 & 1881.5 & 1622.1 & 1314 & 941 & 592.2 & 482.3 \\ \overline{\mathrm{V}} & 0.45 & 0.458 & 0.477 & 0.464 & 0.501 & 0.516 & 0.513 & 0.495 & 0.492 & 0.472 & 0.406 & 0.436\end{array}$

$\begin{array}{lllllllllllll}\mathrm{K} & \\ \mathrm{t} & 0.445 & 0.458 & 0.477 & 0.464 & 0.501 & 0.516 & \mathbf{0 . 5 1 3} & \mathbf{0 . 4 9 5} & \mathbf{0 . 4 9 2} & \mathbf{0 . 4 7 2} & 0.406 & 0.436 \\ \mathrm{a} & 28.3 & 28.3 & 36.9 & 46.9 & 58.5 & 67.2 & \mathbf{7 2 . 3} & \mathbf{7 0 . 6} & \mathbf{6 4 . 2} & \mathbf{5 4 . 1} & 43.3 & 31.5\end{array}$

$\begin{array}{lllllllllllll}\overline{I_{\mathrm{K}}} & 518.8 & 884.9 & 1280.4 & 1814.4 & 2189.3 & 2376.7 & 2500.3 & 2149.4 & 1717.7 & 1128.4 & 678.6 & 456.8 \\ \overline{\mathrm{K}} & 0.446 & 0.533 & 0.548 & 0.594 & 0.619 & 0.631 & 0.684 & 0.660 & 0.656 & 0.588 & 0.494 & 0.442\end{array}$

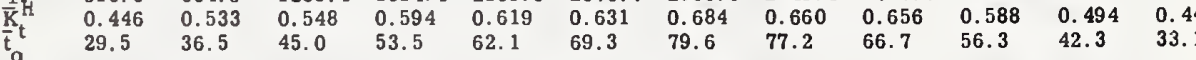

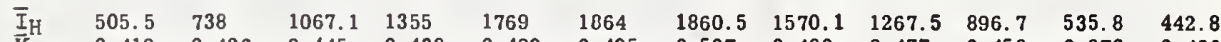

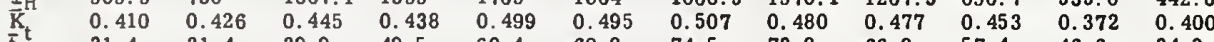

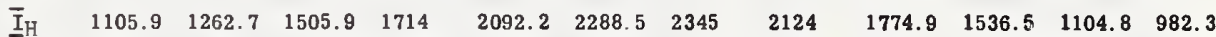

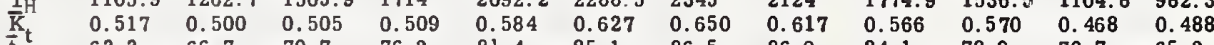

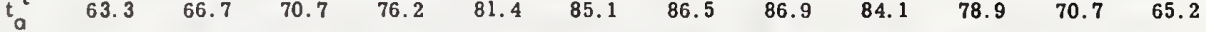

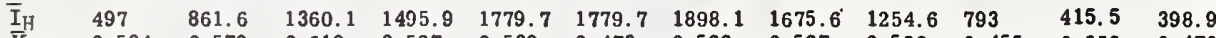

$\begin{array}{lllllllllllll}\overrightarrow{\mathrm{K}} & 0.504 & 0.579 & 0.619 & 0.507 & 0.509 & 0.473 & 0.522 & 0.527 & 0.506 & 0.455 & 0.352 & 0.470\end{array}$

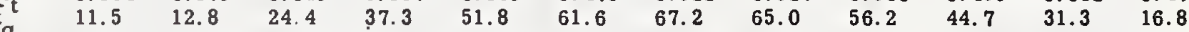

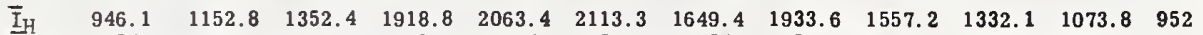

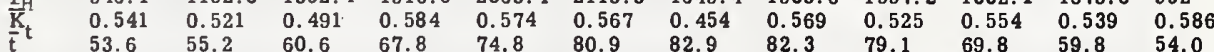

$\begin{array}{llllllllllllll}\overline{\mathrm{I}} & & 466.8 & 681.9 & 1207 & 1443.9 & 1928.4 & 2102.6 & 2094.4 & 1840.6 & 1410.3 & 997 & 526.6 & 427.3\end{array}$

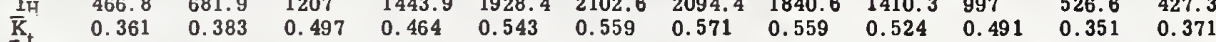

$\begin{array}{lllllllllllll}\mathrm{t}_{\mathrm{a}} & 30.8 & 30.9 & 39.4 & 50.2 & 62.4 & 72.7 & 77.0 & 75.1 & 68.5 & 57.4 & 44.0 & 32.8\end{array}$

$\begin{array}{lllllllllllll}\overline{\mathrm{I}}_{\mathrm{H}} & 651.3 & 941.3 & 1315.8 & 1631.3 & 1999.6 & 2129.1 & 2148.7 & 1953.1 & 1689.6 & 1202.6 & 839.5 & 590.4\end{array}$

$\begin{array}{lllllllllllll}\overline{\mathrm{K}}_{\mathrm{t}} & 0.458 & 0.492 & 0.520 & 0.514 & 0.559 & 0.566 & 0.585 & 0.588 & 0.606 & 0.562 & 0.510 & 0.457\end{array}$

$\begin{array}{lllllllllllll}\overline{\mathrm{I}}_{\mathrm{H}} & 486.3 & 746.5 & 1112.5 & 1480.8 & 1839.1 & (2111) & 2041.3 & 1572.7 & 1189.3 & 919.5 & 479 & 430.2\end{array}$

$\begin{array}{llllllllllllll}\overrightarrow{\mathrm{K}} & 0.356 & 0.401 & 0.447 & 0.470 & 0.515 & (0.561) & 0.555 & 0.475 & 0.433 & 0.441 & 0.302 & 0.351\end{array}$

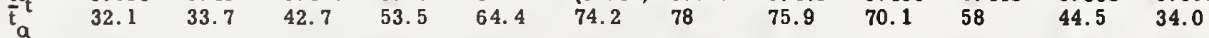

$\begin{array}{lllllllllllll}\overline{\mathrm{I}}_{\mathrm{H}} & 599.2 & 945 & 1504 & 1959 & 2368.6 & 2619.2 & 2565.6 & 2287.8 & 1856.8 & 1288.5 & 795.6 & 550.5\end{array}$

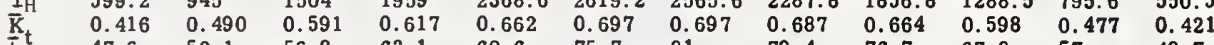

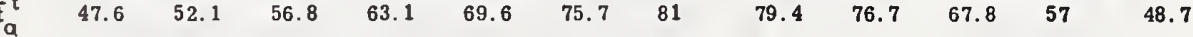

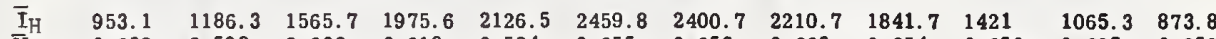

$\begin{array}{lllllllllllll}\overline{\mathrm{K}}_{\mathrm{K}} & 0.639 & 0.598 & 0.606 & 0.618 & 0.594 & 0.655 & 0.652 & 0.663 & 0.654 & 0.650 & 0.625 & 0.652\end{array}$

$\begin{array}{lllllllllllll}\mathrm{l}_{\mathrm{a}} & 33.8 & 38.7 & 46.5 & 57.7 & 66.7 & \mathbf{7 7 . 2} & \mathbf{8 3 . 8} & \mathbf{8 2 . 4} & \mathbf{7 3 . 7} & 61.7 & 46.5 & 36.8 \\ \overline{\mathrm{I}}_{\mathrm{H}} & 425.8 & 739.1 & 1086 & 1249.8 & 1732.8 & 1914 & 1884.5 & 1627.7 & 1303.3 & 891.5 & 473.1 & 379.7\end{array}$

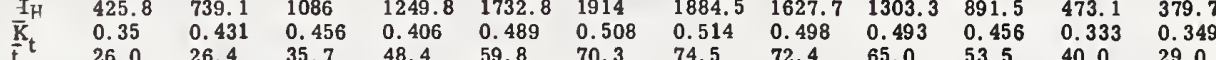

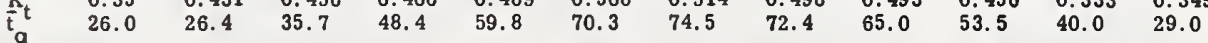

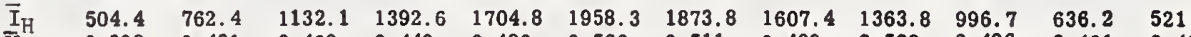

$\begin{array}{lllllllllllll}\overline{\mathrm{K}}_{\mathrm{H}} & 0.398 & 0.431 & 0.469 & 0.449 & 0.480 & 0.520 & 0.511 & 0.489 & 0.508 & 0.486 & 0.431 & 0.461 \\ \overline{\mathrm{t}}_{\mathrm{\alpha}} & 32.2 & 31.6 & 39.0 & 48.3 & 58.9 & 67.5 & 74.1 & 72.8 & 65.9 & 56 & 46 & 34.8\end{array}$ 
Edmonton, Alberta. ...... Lat. $53^{\circ} 35^{\prime} \mathrm{N} \ldots \ldots \ldots \ldots$

E1. $2219 \pi \ldots \ldots \ldots \ldots$.

El Paso, Texas . . . . . . .

Lat. $31^{\circ} 48^{\prime} \mathrm{N}$.

El. $3916 \mathrm{ft}$

Ely, Nevada .........

Lat. $39^{\circ} 17 \mathrm{~N} . \ldots \ldots \ldots$

El. 6262 ft .........

Fairbanks, Alaska ......

Lat. $64^{\circ} 49^{\prime} \mathrm{N} \ldots \ldots \ldots$

Fort Worth, Texas......

Lat. $32^{\circ} 50^{\prime} \mathrm{N}$

El. $544 \mathrm{ft}$

Fresno, Calif...........

Lat. $36^{\circ} 46^{\prime} \mathrm{N} \ldots \ldots \ldots$

El. $331 \mathrm{ft} \ldots \ldots \ldots \ldots$

Gainesville, Fla........

Lat. $29^{\circ} 39^{\prime} \mathrm{N} \ldots \ldots \ldots \ldots$

E1. $165 \mathrm{ft} \ldots \ldots \ldots \ldots \ldots$.

Glasgow, Mont. ........

Lat. $48^{\circ} 13^{\prime} \mathrm{N} \ldots . . .$.

El. 2277 ft ........

Grand Junction, Colo .....

Lat. $39^{\circ} 07$ ' $\ldots . \ldots \ldots$. .

El. $4843 \mathrm{ft} \ldots \ldots \ldots \ldots$.

Grand Lake, Colo. . . . . . .

Lat. $40^{\circ} 15^{\prime} \mathrm{N} \ldots \ldots \ldots \ldots$

El. $8389 \mathrm{ft} \ldots \ldots \ldots \ldots$

Great Falls, Mont ......

Lat. $47^{\circ} 29^{\prime} \mathrm{N} \ldots \ldots \ldots \ldots$. .

El. $3664 \mathrm{ft} \ldots \ldots \ldots \ldots$.

Greensboro, N. C. . . . . .

Lat. $36^{\circ} 05$ 'N . . . . . . .

El. $891 \mathrm{ft} \ldots \ldots \ldots \ldots$

Griffin, Georgia. . . . . . . .

Lat. $33^{\circ} 15^{\prime} \mathrm{N} \ldots \ldots \ldots \ldots$

El. $980 \mathrm{ft} \ldots \ldots \ldots \ldots$.

Hatteras, N. C. . . . . .

Lat. $35^{\circ} 13^{\prime} \mathrm{N} \ldots \ldots \ldots \ldots$

El. $7 \mathrm{ft} . \ldots \ldots \ldots \ldots$. . .

Indianapolis, Ind . . . . .

Lat. $39^{\circ} 44^{\prime} \mathrm{N} \ldots \ldots \ldots \ldots$

E. $793 \mathrm{ft} \ldots \ldots \ldots \ldots$

Inyokern, Calif . . . . . .

Lat. $35^{\circ} 39^{\prime} \mathrm{N} \ldots \ldots \ldots \ldots$

El. $2440 \mathrm{ft} \ldots \ldots \ldots \ldots$

Ithaca, N. Y. . . . . . . .

Lat. $42^{\circ} 27 \mathrm{~N} \ldots$

El. 950 it .........

Lake Charles, La ......

Lat. $30^{\circ} 13$ 'N . . . . . . .

El. $12 \mathrm{ft} \ldots \ldots \ldots \ldots$.

Lander, wyo.........

Lat. $42^{\circ} 48^{\prime} \mathrm{N} \ldots \ldots \ldots \ldots$

El. 5370 it $\ldots \ldots \ldots \ldots$

Las Vegas, Nev........

Lat. $36^{\circ} 05$ 'N.............

El. 2162 it $\ldots \ldots \ldots \ldots$.

Lemont, Illinols........

Lat. $41^{\circ} 40^{\prime} \mathrm{N} \ldots \ldots \ldots \ldots$. . .

El. $595 \mathrm{ft} \ldots \ldots \ldots \ldots$

Lexington, $\mathrm{Ky} \ldots \ldots \ldots \ldots$
Lat. $38^{\circ} 02{ }^{\prime} \mathrm{N} . \ldots \ldots \ldots$

Lat. $38^{\circ} 02 \mathrm{~N} \ldots \ldots \ldots \ldots$

\section{Feb}

Mar

Apr

May

Jun

Jul Aug

$\begin{array}{llllllllllll}331.7 & 652.4 & 1165.3 & 1541.7 & 1900.4 & 1914.4 & 1964.9 & 1528 & 1113.3 & 704.4 & 413.6 & 245 \\ 0.529 & 0.585 & 0.624 & 0.564 & 0.558 & 0.514 & 0.549 & 0.506 & 0.506 & 0.504 & 0.510 & 0.492 \\ 10.4 & 14 & 26.3 & 42.9 & 55.4 & 61.3 & 66.6 & 63.2 & 54.2 & 44.1 & 26.7 & 14.0\end{array}$

$\overline{\mathrm{I}}_{\mathrm{H}}$

$1247.6 \quad 1612.9$

273

54.2

26. 7

$\begin{array}{llllllllllll}0.686 & 0.714 & 0.730 & 0.741 & 0.743 & 0.733 & 0.652 & 0.669 & 0.693 & 0.695 & 0.647 & 0.626\end{array}$

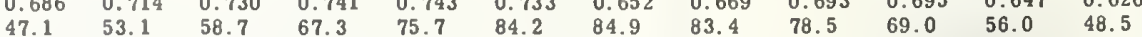

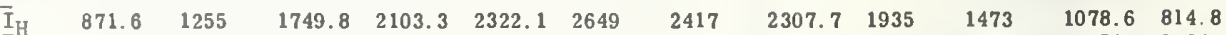

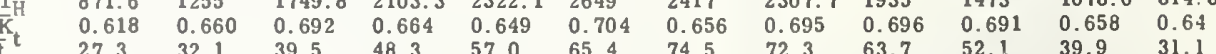

$\begin{array}{lllllllllllll}a & 27.3 & 32.1 & 39.5 & 48.3 & 57.0 & 65.4 & 74.5 & 72.3 & 63.7 & 52.1 & 39.9 & 31.1 \\ \bar{I}_{H} & 66 & 283.4 & 860.5 & 1481.2 & 1806.2 & 1970.8 & 1702.9 & 1247.6 & 699.6 & 323.6 & 104.1 & 20.3\end{array}$

$\begin{array}{lllllllllllll}\mathrm{K}_{\mathrm{K}} & 6.639 & 283.4 & 860.5 & 1481.2 & 1806.2 & 1970.8 & 1702.9 & 1247.6 & 699.6 & 323.6 & 104.1 & 20.3 \\ \mathrm{t} & 0.556 & 0.674 & 0.647 & 0.546 & 0.529 & 0.485 & 0.463 & 0.419 & 0.416 & 0.47 & 0.458\end{array}$

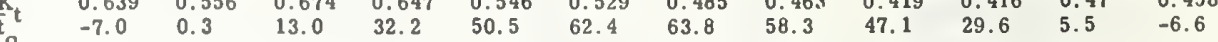

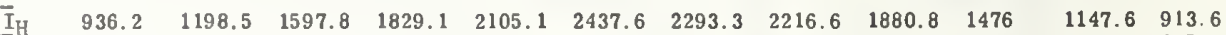

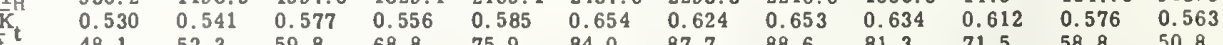

$\begin{array}{lllllllllllll}\text { a } & 48.1 & 52.3 & 59.8 & 68.8 & 75.9 & 84.0 & 87.7 & 88.6 & 81.3 & 71.5 & 58.8 & 50.8 \\ \bar{I}_{H} & 712.9 & 1116.6 & 1652.8 & 2049.4 & 2409.2 & 2641.7 & 2512.2 & 2300.7 & 1897.8 & 1415.5 & 906.6 & 616.6\end{array}$

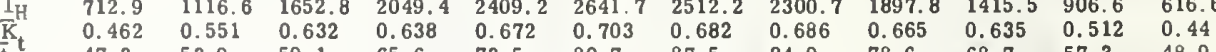

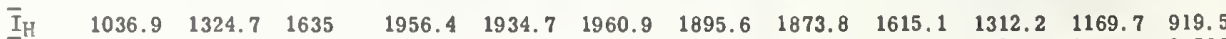

$\begin{array}{lllllllllllll}\overline{\mathrm{I}}_{\mathrm{H}} & 572.7 & 965.7 & 1437.6 & 1741.3 & 2127.3 & 2261.6 & 2414.7 & 1984.5 & 1531 & 997 & 574.9 & 428.4 \\ \mathrm{Z}_{\mathrm{K}} & 0.621 & 0.678 & 0.672 & 0.597 & 0.611 & 0.602 & 0.666 & 0.630 & 0.629 & 0.593 & 0.516 & 0.548\end{array}$

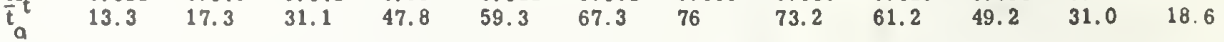

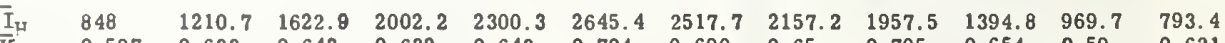

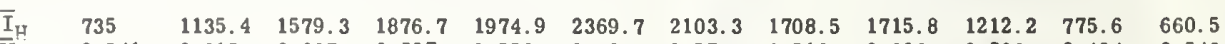

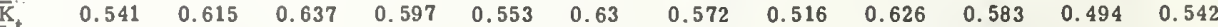

$\begin{array}{lllllllllllll}\mathrm{t}_{\mathrm{a}} & 18.5 & 23.1 & 28.5 & 39.1 & 48.7 & 56.6 & 62.8 & 61.5 & 55.5 & 45.2 & 30.3 & 22.6 \\ \overline{\mathrm{I}}_{\mathrm{H}} & 524 & 869.4 & 1369.7 & 1621.4 & 1970.8 & 2179.3 & 2383 & 1986.3 & 1536.5 & 984.9 & 575.3 & 420.7\end{array}$

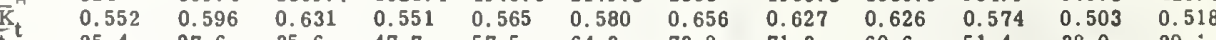

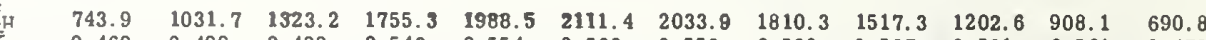

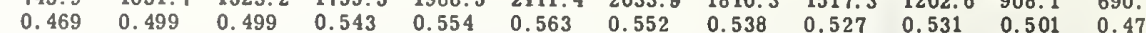

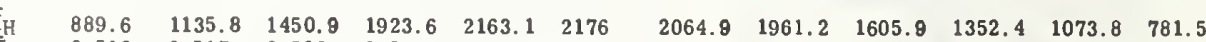

$\begin{array}{llllllllllll}0.513 & 0.517 & 0.528 & 0.586 & 0.601 & 0.583 & 0.562 & 0.578 & 0.543 & 0.565 & 0.545 & 0.487\end{array}$

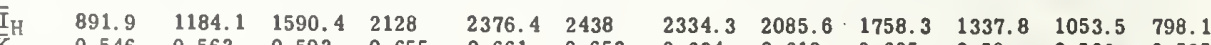

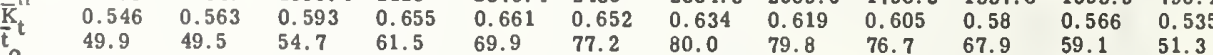

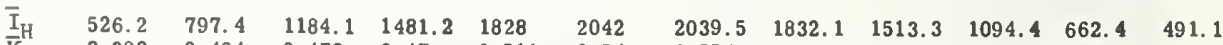

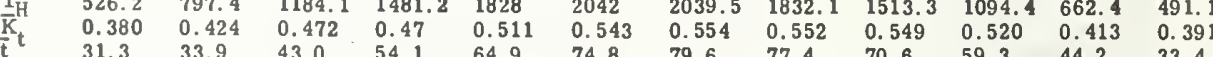

$\begin{array}{llllllllllll}\text { a } & & & & & & \end{array}$

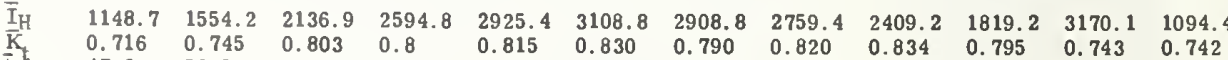

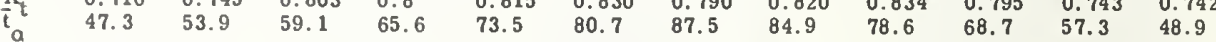

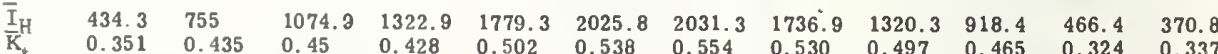

$\begin{array}{lllllllllllll}\overline{\mathrm{K}} & 0.351 & 0.435 & 0.45 & 0.428 & 0.502 & 0.538 & 0.554 & 0.530 & 0.497 & 0.465 & 0.324 & 0.337 \\ \overline{\mathrm{t}} & 27.2 & 26.5 & 36 & 48.4 & 59.6 & 68.9 & 73.9 & 71.9 & 64.2 & 53.6 & 41.5 & 29.6\end{array}$

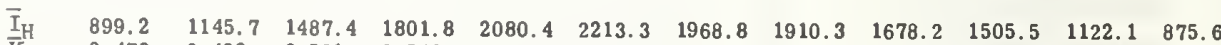

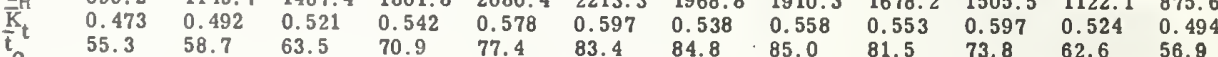

$\begin{array}{llllllllllllll}\mathrm{I}_{\mathrm{H}} & 786.3 & 1146.1 & 1638 & 1988.5 & 2114 & 2492.2 & 2438.4 & 2120.8 & 1712.9 & 1301.8 & 837.3 & 694.8\end{array}$

$\begin{array}{lllllllllllll}\mathrm{K}_{\mathrm{t}} & 0.65 & 0.672 & 0.691 & 0.647 & 0.597 & 0.662 & 0.665 & 0.649 & 0.647 & 0.668 & 0.589 & 0.643\end{array}$

$\begin{array}{lllllllllllll}\mathrm{a} & 20.2 & 26.3 & 34.7 & 45.5 & 56.0 & 65.4 & 74.6 & 72.5 & 61.4 & 48.3 & 33.4 & 23.8 \\ \overrightarrow{\mathrm{I}}_{\mathrm{H}} & 1035.8 & 1438 & 1926.5 & 2322.8 & 2629.5 & 2799.2 & 2524 & 2342 & 2062 & 1602.6 & 1190 & 964.2\end{array}$

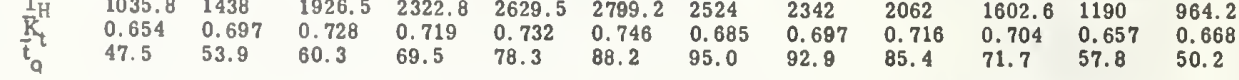

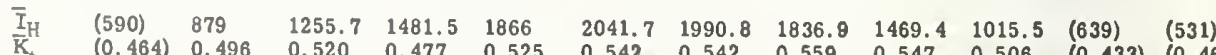

$\begin{array}{lllllllllllll} & \\ \overline{\mathrm{K}}_{\mathrm{t}} & (0.464) & 0.496 & 0.520 & 0.477 & 0.525 & 0.542 & 0.542 & 0.559 & 0.547 & 0.506 & (0.433) & (0.467) \\ \mathrm{a} & 28.9 & 30.3 & 39.5 & 49.7 & 59.2 & 70.8 & 75.6 & 74.3 & 67.2 & 57.6 & \mathbf{4 3 . 0} & 30.6\end{array}$

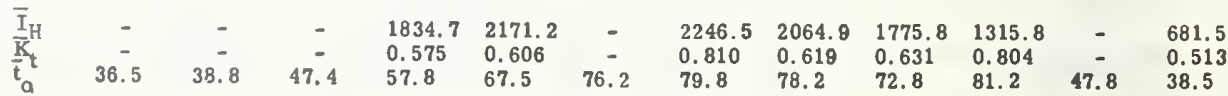


Lincoln, Neb. . . . . . . . .

Lat. $40^{\circ} 51^{\prime} \mathrm{N} \ldots \ldots \ldots \ldots$

E]. $1189 \mathrm{ft} \ldots \ldots \ldots \ldots$

Little Rock, Ark .......

Lat. $34^{\circ} 44^{\prime} \mathrm{N} \ldots \ldots \ldots \ldots$

El. $265 \mathrm{ft} \ldots \ldots \ldots \ldots$. .

Los Angeles, Calif. (WBAS).

Lat. $33^{\circ} 56^{\prime} \mathrm{N} \ldots \ldots \ldots \ldots$

El. $99 \mathrm{ft} \ldots \ldots \ldots \ldots$.

Los Angeles, Calif. (WBO).

Lat. $34^{\circ} 03^{\prime} \mathrm{N} \ldots \ldots \ldots \ldots$

El. $99 \mathrm{ft} . \cdots$

Madison, wis ........

Lat. $43^{\circ} 08^{\prime} \mathrm{N} \ldots \ldots \ldots \ldots$

El. $866 \mathrm{ft} \ldots \ldots \ldots \ldots$

Matanuska, Alaska...... .

Lat. $61^{\circ} 30^{\circ} \mathrm{N} \ldots \ldots \ldots \ldots$

Medford, Oregon H. . . . . .

Lat. $42^{\circ} 23^{\prime} \mathrm{N} . . . \ldots \ldots$.

E1. $1329 \mathrm{ft} \ldots \ldots \ldots \ldots$

Miami, Florida........

Lat. $25^{\circ} 47^{\prime} \mathrm{N} \ldots \ldots \ldots \ldots$

El. $9 \mathrm{ft} . \ldots \ldots \ldots \ldots$

Midland, Texas........

Lat. $31^{\circ} 56{ }^{\prime} \mathrm{N} \ldots \ldots \ldots \ldots$

El. $2854 \mathrm{ft} \ldots \ldots \ldots \ldots$

Nashville, Tenn.......

Lat. $36^{\circ} 07^{\prime} \mathrm{N} \ldots \ldots \ldots \ldots$. .

El. $605 \mathrm{ft} \ldots \ldots \ldots \ldots$.

New Port, R.1. . . . . .

Lat. $41^{\circ} 29^{\prime} \mathrm{N} \ldots \ldots \ldots \ldots$

El. $60 \mathrm{ft} \ldots \ldots \ldots \ldots$.

New York, N. Y. ......

Lat. $40^{\circ} 46^{\prime} \mathrm{N} \ldots \ldots \ldots \ldots$

El. $52 \mathrm{ft} \ldots \ldots \ldots \ldots \ldots$

Oak Ridge, Tenn .......

Lat. $36^{\circ} 01$ ' $\ldots \ldots \ldots \ldots$

Oklahoma City, Oklahoma..

Lat. $35^{\circ} 24$ ' $\ldots \ldots \ldots \ldots \ldots$

Ottawa, Ontario........

Lat. $45^{\circ} 20^{\prime} \mathrm{N} \ldots \ldots \ldots \ldots$

E1. $339 \mathrm{ft} \ldots \ldots \ldots \ldots$

Phoenix, Ariz .........

Lat. $33^{\circ} 26^{\prime} \mathrm{N} \ldots \ldots \ldots \ldots$

El. $1112 \mathrm{ft} \ldots \ldots \ldots \ldots$

Portland, Maine. . . . . . .

Lat. $43^{\circ} 3 g^{\prime} \mathrm{N} \ldots \ldots \ldots \ldots$

El. $63 \mathrm{ft} \ldots \ldots \ldots \ldots$. . .

Rapld City, S.D........

Lat. $44^{\circ} 09^{\prime}$. . . . . . . . .

El. 3218 it .....................

Riverside, Callf .......

Lat. $33^{\circ} 57^{\prime} \mathrm{N} . \ldots \ldots \ldots$

El. $1020 \mathrm{ft} \ldots \ldots \ldots \ldots$

St. Cloud, Minn. . . . . . .

Lat. $45^{\circ} 35^{\prime} \mathrm{N} \ldots \ldots \ldots$. . .

El. $1034 \mathrm{ft} \ldots \ldots \ldots \ldots$

Salt Lake City, Utah. .....

Lat. $40^{\circ} 46^{\prime} \mathrm{N} . \ldots . . .$.

E1. $4227 \mathrm{ft} \ldots \ldots \ldots \ldots$

San Antonio, Tex.......

Lat. $29^{\circ} 32$ ' . . . . . . .

E1. $794 \mathrm{ft} \ldots \ldots \ldots \ldots \ldots$
011.4

502.6

$\begin{array}{lll}1543.5 & 1215.8 & 773.4\end{array}$

643.2

$\begin{array}{llllllllllll}704.4 & 974.2 & 1335.8 & 1669.4 & 1960.1 & 2091.5 & 2081.2 & 1938.7 & 1640.8 & 1282.6 & 913.8 & 701.1\end{array}$ $\begin{array}{llllllllllll}44.6 & 48.5 & 56.0 & 65.8 & 73.1 & 76.7 & 85.1 & 84.6 & 78.3 & 67.9 & 54.7 & 46.7\end{array}$

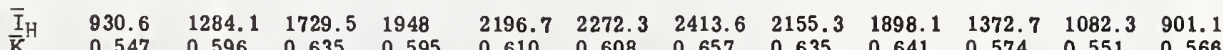

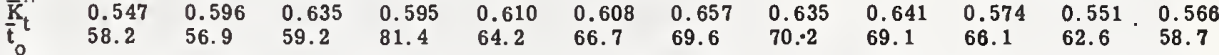

$\overline{\mathrm{I}}_{\mathrm{H}} \quad \begin{array}{llllllllllll}911.8 & 1223.6 & 1640.9 & 1866.8 & 2061.2 & 2259 & 2428.4 & 2198.9 & 1891.5 & 1362.3 & 1053.1 & 877.8\end{array}$

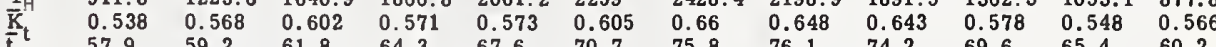

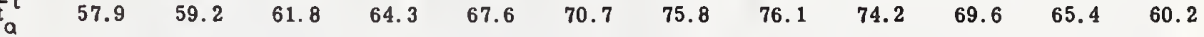

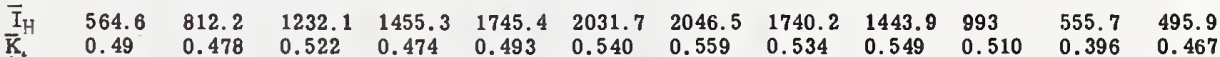
$\begin{array}{lllllllllllll}\mathrm{t}_{\mathrm{t}} & 21.8 & 24.6 & 35.3 & 49.0 & 61.0 & \mathbf{7 0 . 9} & \mathbf{7 6 . 8} & \mathbf{7 4 . 4} & \mathbf{6 5 . 6} & \mathbf{5 3 . 7} & \mathbf{3 7 . 8} & \mathbf{2 5 . 4}\end{array}$

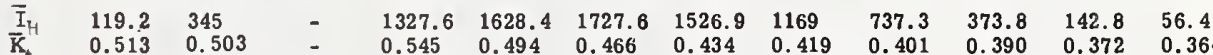

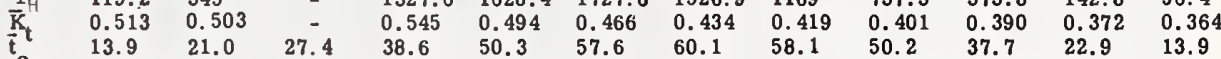
$\begin{array}{lllllllllllll}\overline{\mathrm{I}}_{\mathrm{H}} & 435.4 & 804.4 & 1259.8 & 1807.4 & 2216.2 & 2440.5 & 2607.4 & 2261.6 & 1672.3 & 1043.5 & 558.7 & 346.5\end{array}$

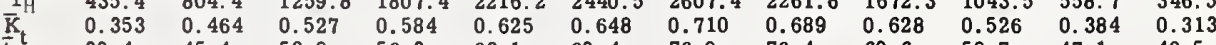
$\begin{array}{llllllllllllll}\overline{\mathrm{I}}_{\mathrm{H}} & 1292.2 & 1554.6 & 1828.8 & 2020.6 & 2068.6 & 1991.5 & 1992.6 & 1890.8 & 1646.8 & 1436.5 & 1321 & 1183.4\end{array}$

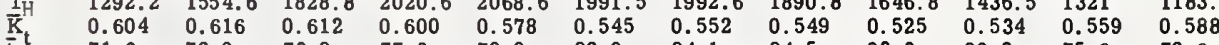

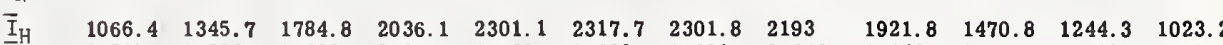

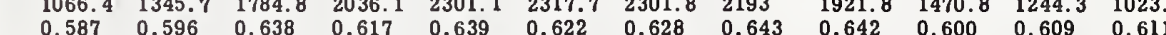

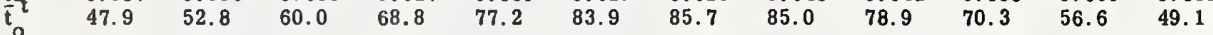

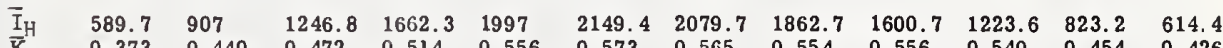

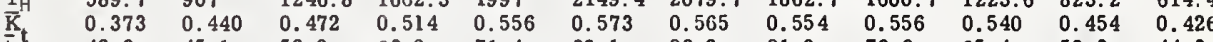
$\begin{array}{lllllllllllll}\text { a } & 42.6 & 45.1 & 52.9 & 63.0 & 71.4 & 80.1 & 83.2 & 81.9 & 76.6 & 65.4 & 52.3 & 44.3\end{array}$ $\begin{array}{lllllllllllll}\overline{\mathrm{I}}_{\mathrm{H}} & 565.7 & 856.4 & 1231.7 & 1484.8 & 1849 & 2019.2 & 1942.8 & 1687.1 & 1411.4 & 1035.4 & 656.1 & 527.7 \\ \overline{\mathrm{K}}_{\mathrm{H}} & 0.438 & 0.482 & 0.507 & 0.477 & 0.520 & 0.536 & 0.529 & 0.513 & 0.524 & 0.512 & 0.44 & 0.460 \\ \mathrm{t}_{\mathrm{t}} & 29.5 & 32.0 & 39.6 & 48.2 & 58.6 & 67.0 & 73.2 & 72.3 & 66.7 & 56.2 & 46.5 & 34.4\end{array}$

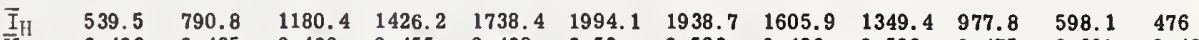

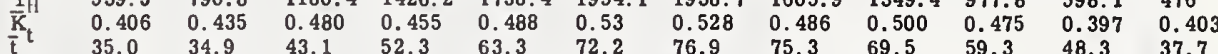
$\begin{array}{llllllllllllll}\overline{\mathrm{I}}_{\eta} & 604 & 895.9 & 1241.7 & 1689.6 & 1942.8 & 2066.4 & 1972.3 & 1795.6 & 1559.8 & 1194.8 & 796.3 & 610\end{array}$

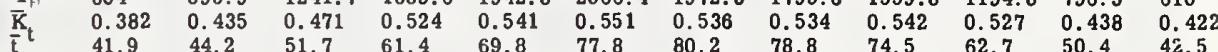

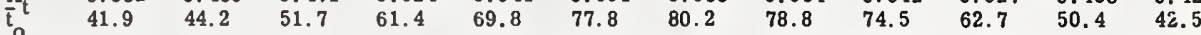

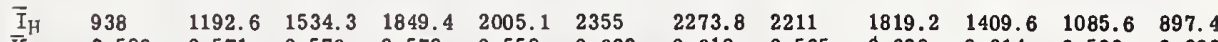

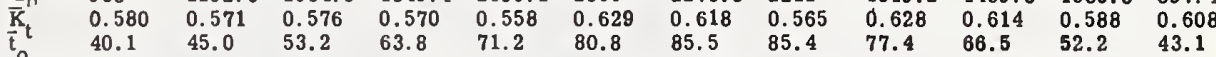
$\begin{array}{lllllllllllll}\overline{\mathrm{I}}_{\mathrm{H}} & 539.1 & 852.4 & 1250.5 & 1506.6 & 1857.2 & 2084.5 & 2045.4 & 1752.4 & 1328.6 & 826.9 & 458.7 & 408.5\end{array}$

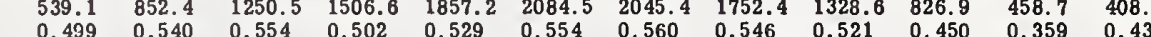
$\begin{array}{lllllllllllll}\mathrm{t}_{\mathrm{a}} & 14.6 & 15.6 & 27.7 & 43.3 & 57.5 & 67.5 & 71.9 & 69.8 & 61.5 & 48.9 & 35 & 19.6\end{array}$

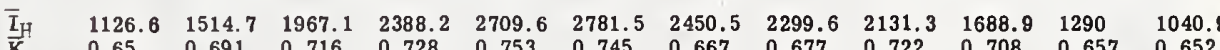
$\begin{array}{lllllllllllll}\mathrm{K} & 0.65 & 0.691 & 0.716 & 0.728 & 0.753 & 0.745 & 0.667 & \mathbf{0 . 6 7 7} & 0.722 & 0.708 & 0.657 & 0.652 \\ \mathrm{t} & 54.2 & 58.8 & 64.7 & \mathbf{7 2 . 2} & \mathbf{8 0 . 8} & \mathbf{8 9 . 2} & \mathbf{9 4 . 6} & \mathbf{9 2 . 5} & \mathbf{8 7 . 4} & \mathbf{7 5 . 8} & 63.6 & 56.7\end{array}$

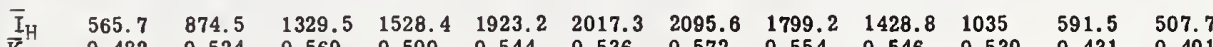

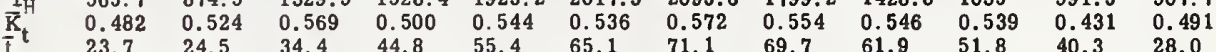
$\begin{array}{lllllllllllll}\text { a } & 23.7 & 24.5 & 34.4 & 44.8 & 55.4 & 65.1 & 71.1 & 69.7 & 61.9 & 51.8 & 40.3 & 28.0 \\ \bar{I}_{\mu} & 687.8 & 1032.5 & 1503.7 & 1807 & 2028 & 2193.7 & 2235.8 & 2019.9 & 1628 & 1179.3 & 763.1 & 590.4\end{array}$

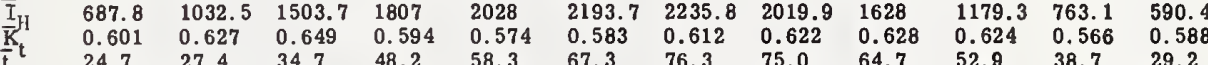

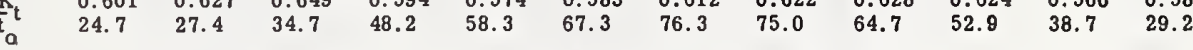

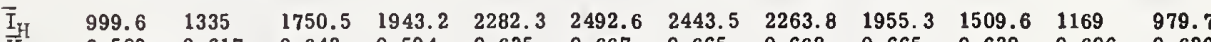

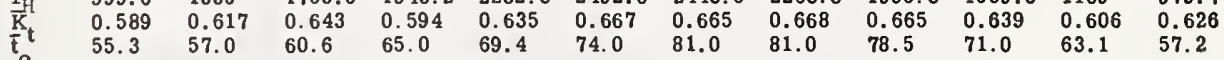
$\begin{array}{lllllllllllll}\bar{I}_{1} & 632.8 & 976.7 & 1383 & 1598.1 & 1859.4 & 2003.3 & 2087.8 & 1828.4 & 1369.4 & 890.4 & 545.4 & 463.1\end{array}$

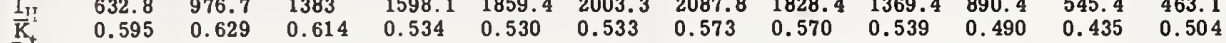
$\begin{array}{lllllcccccccc}\mathrm{a} & 13.6 & 16.9 & 29.8 & 46.2 & 58.8 & 68.5 & 74.4 & 71.9 & 62.5 & 50.2 & 32.1 & 18.3 \\ \overline{\mathrm{I}}_{\mathrm{H}} & 622.1 & 986 & 1301.1 & 1813.3 & - & - & - & - & 1689.3 & 1250.2 & - & 552.8\end{array}$

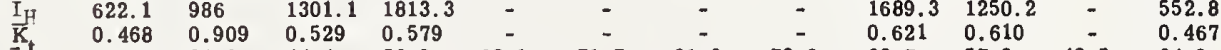

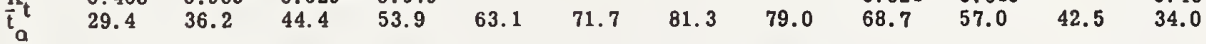

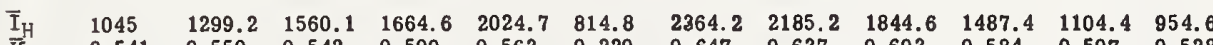

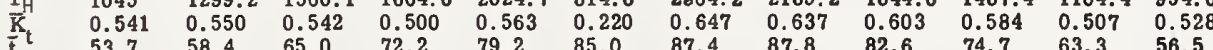
$\begin{array}{llllllllllll}53.7 & 58.4 & 65.0 & 72.2 & 79.2 & 85.0 & 87.4 & 87.8 & 82.6 & 74.7 & 63.3 & 56.5\end{array}$ 
Santa Marla, Calls..... Lat. $34^{\circ} 54$ 'N .......... E1. 238 It . . . . . . . .

Sault Ste. Marle, Michigan Lat. $46^{\circ} 28 ' \mathrm{~N}$. . . . . . . . ต. 724 It.$\cdots \cdot$

Sayville, N. Y . . . . . . Lat. $40^{\circ} 30^{\prime} \mathrm{N} \ldots \ldots \ldots \ldots$ El. $20 \mathrm{ft} \ldots \ldots \ldots \ldots$. . .

Schenectady, N. Y. . . . . . . Lat. $42^{\circ} 50^{\circ} \mathrm{N} \ldots \ldots \ldots \ldots$ El. 217 It . . . . . . . .

Seattle, Wash ........ Lat. $47^{\circ} 27$ ' $\ldots \ldots \ldots \ldots$ El. $386 \mathrm{ft} \ldots \ldots \ldots \ldots$

Scattle, Wash ........

Lat. $47^{\circ} 36^{\prime} \mathrm{N} \ldots \ldots \ldots \ldots$

El. $14 \mathrm{ft} \ldots \ldots \ldots \ldots \ldots$

Seabrook, N.J. . . . . . .

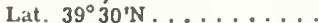

El. $100 \mathrm{ft} \ldots \ldots \ldots \ldots$.

Spokane, Wash........

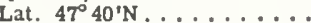

El. $1968 \mathrm{ft} \ldots \ldots \ldots \ldots$

State College, Pa.......

Lat. $40^{\circ} 48^{\prime} \mathrm{N} \ldots \ldots \ldots \ldots$

E1. $1175 \mathrm{ft} \ldots \ldots \ldots \ldots$

Stillwater, Okla........

Lat, $36^{\circ} 09^{\prime} \mathrm{N} \ldots \ldots \ldots \ldots$

El. $910 \mathrm{ft} \ldots \ldots \ldots \ldots$. .

Tampa, Fla..........

Lat. $27^{\circ} 55^{\prime} \mathrm{N} \ldots \ldots \ldots \ldots$

El. 11 ft .

Toronto, Ontario .......

Lat. $43^{\circ} 41^{\prime} \mathrm{N} \ldots \ldots \ldots \ldots$. .

El. 379 ft . . . . . . .

Tucson, Arizona ........

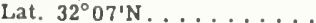

El. 2556 ft $\ldots \ldots \ldots \ldots$

Upton, N. Y . . . . . . . .

Lat. $40^{\circ} 52 \mathrm{~N} \ldots \ldots \ldots \ldots$

El. 75 ft . . . . . . . .

Washington, D. C. (WBCO). .

Lat. $38^{\circ} 51^{\prime} \mathrm{N}, \ldots \ldots \ldots \ldots$

E1. $64 \mathrm{ft} \ldots \ldots \ldots \ldots \ldots$

Winnipeg, Man. . . . . . .

Lat. $49^{\circ} 54^{\prime} \mathrm{N} \ldots \ldots \ldots$.

E1. $786 \mathrm{ft} \ldots \ldots \ldots \ldots$

\begin{tabular}{|c|c|c|c|c|c|c|c|c|c|c|c|}
\hline Jan & Feb & Mar & Apr & May & Jun & Jul & Aug & Sep & Oct & Nov & Dec \\
\hline 983.6 & 1296.3 & $\begin{array}{l}1805.9 \\
0.671^{1}\end{array}$ & $\begin{array}{l}2067.9 \\
0.636\end{array}$ & $\begin{array}{l}2375.6 \\
0.861\end{array}$ & $\begin{array}{l}2599.6 \\
0.695\end{array}$ & $\begin{array}{l}2540.6 \\
0.690\end{array}$ & $\begin{array}{l}2293.3 \\
0.678\end{array}$ & $\begin{array}{l}1965.7 \\
0.674^{7}\end{array}$ & $\begin{array}{l}1568.4 \\
0.676\end{array}$ & 1169 & 43.8 \\
\hline 54.1 & $\begin{array}{l}0.613 \\
55.3\end{array}$ & $\begin{array}{l}5.671 \\
57.6\end{array}$ & $\begin{array}{l}0.636 \\
59.5\end{array}$ & 61.2 & $\begin{array}{l}0.695 \\
63.5\end{array}$ & $\begin{array}{l}0.690 \\
65.3\end{array}$ & $\begin{array}{l}0.676 \\
65.7\end{array}$ & $\begin{array}{l}0.674 \\
65.9\end{array}$ & $\begin{array}{l}0.676 \\
64.1\end{array}$ & $\begin{array}{l}0.624 \\
60.8\end{array}$ & $\begin{array}{l}0.627 \\
56.1\end{array}$ \\
\hline 488.6 & 843.9 & 1336.5 & 1559.4 & 1962.3 & 2064.2 & 2149.4 & 1767.9 & 1207 & 809.2 & 392.2 & 359.8 \\
\hline $\begin{array}{l}0.490 \\
16.3\end{array}$ & $\begin{array}{l}0.560 \\
16.2\end{array}$ & $\begin{array}{l}0.606 \\
25.6\end{array}$ & $\begin{array}{l}0.526 \\
39.5\end{array}$ & $\begin{array}{l}0.560 \\
52.1\end{array}$ & $\begin{array}{l}0.549 \\
61.6\end{array}$ & $\begin{array}{l}0.590 \\
67.3\end{array}$ & 0.554 & $\begin{array}{l}0.481 \\
57.9\end{array}$ & 0. & $\begin{array}{l}0.323 \\
33.4\end{array}$ & 0.408 \\
\hline & & & & & & & & & & & \\
\hline $\begin{array}{l}602.8 \\
0.453\end{array}$ & $\begin{array}{l}938.2 \\
0.511\end{array}$ & $\begin{array}{l}1259.4 \\
0.510\end{array}$ & 1560.5 & $\begin{array}{l}1857.2 \\
0.522\end{array}$ & 2123 & $\begin{array}{l}2040.9 \\
0.555\end{array}$ & $\begin{array}{l}1734.7 \\
0.525\end{array}$ & $\begin{array}{l}1446.6 \\
0.530\end{array}$ & $\begin{array}{l}1087 \\
0.52\end{array}$ & $\begin{array}{l}697.8 \\
0.450\end{array}$ & $\begin{array}{l}533.9 \\
0.447\end{array}$ \\
\hline 35 & 34.9 & 43.1 & 52.3 & 63.3 & 72.2 & 76.9 & 75.3 & 69.5 & 59.3 & 48.3 & $\begin{array}{l}0.447 \\
37.7\end{array}$ \\
\hline 488.2 & 753.5 & 1026.6 & 1272.3 & 1553.1 & 1687.8 & 1662.3 & 1494.6 & 1124.7 & 820.6 & 438.2 & 356.8 \\
\hline 0.408 & 0.441 & 0.433 & 0.413 & 0.438 & 0.448 & 0.454 & 0.458 & 0.428 & 0. & 0. & 0.331 \\
\hline 24.7 & 24.6 & 34.9 & 48.3 & 61.7 & 70.8 & 76.9 & 73.7 & 64.6 & 53.1 & 40.1 & 28.0 \\
\hline 282.6 & 520 & 992.2 & 1507 & 1881.5 & 190 & 2110.7 & 1688.5 & 1211.6 & 702.2 & 386.3 & 239.5 \\
\hline 0.296 & 0.355 & 0.456 & 0.510 & 0.538 & 0.508 & 0.581 & 0.533 & 0.492 & 0.407 & 0.336 & 0.292 \\
\hline 42.1 & 45.0 & 48.9 & 54.1 & 59.8 & 64. & 68.4 & 67. & 63.3 & 56.3 & 48.4 & 44.4 \\
\hline & 471.6 & 917 & 137 & 166 & 172 & $18 \mathrm{C}$ & 16 & 112 & 6 & 32 & 218.1 \\
\hline 0.266 & 0.324 & 0.423 & 0.4 & 0.477 & 0.459 & 0. & 0.511 & 0.459 & 0.372 & & 0.269 \\
\hline 38.9 & 42.9 & 46.9 & 51.9 & 58. & 62.8 & 67.2 & 66.7 & 61.6 & 54.0 & 45.7 & 41.5 \\
\hline 591.9 & 854.2 & 1195.6 & 1518.8 & 1800.7 & 1964.6 & 1949.8 & 171 & 144 & 10 & 721.8 & 522.5 \\
\hline 0.426 & 0.453 & 0.476 & 0.48 & 0.5 & 0.5 & 0. & 0.517 & 0. & 0. & 0.449 & 0.416 \\
\hline 39.5 & 37.8 & 43.9 & 54.7 & 64.9 & 74. & 79. & 77. & 69.7 & 61.2 & 48.5 & 39.3 \\
\hline 448 & 837 & 120 & 186 & 210 & 2226 & 2479.7 & 20 & 15 & & & 279 \\
\hline 0.478 & 0.579 & 0.556 & 0.6 & 0.6 & 0.5 & 0.6 & 0.656 & 0.616 & 0.494 & 0.428 & 0.345 \\
\hline & 31.7 & 40.5 & 49.2 & 57. & 64.6 & 73.4 & 71.7 & 62.7 & 51.5 & 37.4 & 30.5 \\
\hline 501.8 & 749. & 1108.6 & 39 & 1754.8 & 202 & 196 & 165 & 1336.1 & 10 & 580.1 & 443.9 \\
\hline 0.3 & 0.41 & 0.45 & 0.4 & 0.4 & 0.5 & 0. & 0. & 0 & 0. & & 0.376 \\
\hline 31. & 31. & 39.8 & 51.3 & 63. & 71. & 75. & 73. & 66.1 & 55. & 43.2 & 32.6 \\
\hline 763 & 108 & 46 & 702.6 & 187 & 23 & 22 & 20 & 17 & 13 & & \\
\hline 0.4 & 0.527 & 0.5 & 0.5 & 0.5 & 0.5 & 0. & 0.607 & 0.599 & 0.581 & 0.548 & 0.544 \\
\hline 41.2 & 45.6 & 53.8 & 64.2 & 71. & 81.1 & 85.9 & 85. & 77.5 & 67.6 & 52.6 & 43.9 \\
\hline 1223.6 & 1461.2 & 1771.9 & 01 & 222 & 5 & 19 & 184 & 1687.8 & $14 S$ & 1328.4 & 1119.5 \\
\hline 0.60 & 0.60 & $0.6 \mathrm{c}$ & 0.6 & 0.6 & 0.58 & 0.5 & 0.5 & & & & 0.589 \\
\hline 64.2 & 85.7 & 68.8 & 74.3 & 79.4 & 83.0 & 84.0 & 84. & 82. & 77. 2 & 69.6 & 65.5 \\
\hline $\begin{array}{l}451.3 \\
0.388\end{array}$ & $\begin{array}{r}674.5 \\
0.406\end{array}$ & 1088.9 & 1388.2 & 1785.2 & 1941.7 & 1968.8 & 1622.5 & 1284.1 & 835 & & 352.8 \\
\hline 26.5 & 26.0 & $\begin{array}{l}0.467 \\
34.2\end{array}$ & $\begin{array}{l}0.455 \\
46.3\end{array}$ & $\begin{array}{l}0.506 \\
58\end{array}$ & $\begin{array}{l}0.516 \\
88.4\end{array}$ & $\begin{array}{l}0.539 \\
73.8\end{array}$ & $\begin{array}{l}0.500 \\
71.8\end{array}$ & $\begin{array}{l}0.493 \\
64.3\end{array}$ & 0.438 & $\begin{array}{l}0 . \\
40\end{array}$ & $\begin{array}{l}0.346 \\
30.2\end{array}$ \\
\hline 1171.9 & 1453 & - & & - & 60 & & 17 & & & & \\
\hline 0.64 & 0.646 & - & 0.73 & - & & 0.625 & 0.640 & $\begin{array}{l}2122.5 \\
0.710\end{array}$ & 1640.9 & 1322.1 & \\
\hline 53. & & 62.3 & 69.7 & 78.0 & 87.0 & 90. & 0 & $\begin{array}{l}0.710 \\
84.0\end{array}$ & $\begin{array}{l}0.672 \\
73.9\end{array}$ & $\begin{array}{l}0.650 \\
62.5\end{array}$ & $\begin{array}{l}0.679 \\
56.1\end{array}$ \\
\hline 583 & 8 & 1280 & 1609.9 & 89 & 215 & 204 & $1789.6^{\circ}$ & 1472.7 & 1102.8 & & \\
\hline$?$ & 0. & 0.52 & 0.51 & 0.53 & 0.574 & .5 & & 0.5 & 0.538 & 0.448 & 0.467 \\
\hline & 34.9 & 43.1 & 52. & 63.3 & 72.2 & 76.9 & 75.3 & 69.5 & 59.3 & 48. & 37.7 \\
\hline 632.4 & 901.5 & 1255 & 1600.4 & 346.8 & 2080.8 & & 1712.2 & 14 & 108 & & 594.1 \\
\hline $\begin{array}{l}0.445 \\
38.4\end{array}$ & $\begin{array}{l}0.470 \\
39.6\end{array}$ & $\begin{array}{l}0.496 \\
48.1\end{array}$ & & 0.516 & 0.553 & 0.524 & 0.516 & 0.5 & 05 & & 460 \\
\hline & & & & 67. & & $\cdots$ & 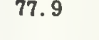 & 2.6 & 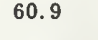 & 00.2 & 40.2 \\
\hline $\begin{array}{l}488.2 \\
0.601\end{array}$ & $\begin{array}{l}835.4 \\
0.636\end{array}$ & $\begin{array}{l}1354.2 \\
0.661\end{array}$ & $\begin{array}{l}1641.3 \\
0.574\end{array}$ & 1904 & 1962 & 212 & 176 & & & & \\
\hline 3. & 7. & 21.3 & 40.9 & $\begin{array}{l}0.550 \\
55.8\end{array}$ & $\begin{array}{l}0.524 \\
65.3\end{array}$ & $\begin{array}{l}0.587 \\
71.9\end{array}$ & $\begin{array}{l}0.567 \\
69.4\end{array}$ & $\begin{array}{l}0.504 \\
58.6\end{array}$ & $\begin{array}{l}0.482 \\
45.6\end{array}$ & $\begin{array}{l}0.436 \\
25.2\end{array}$ & $\begin{array}{l}0.503 \\
10.1\end{array}$ \\
\hline
\end{tabular}




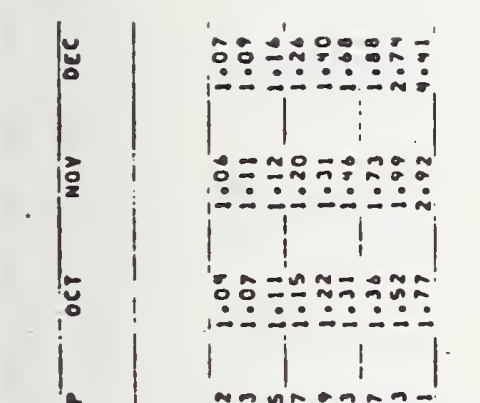

年

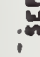

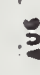

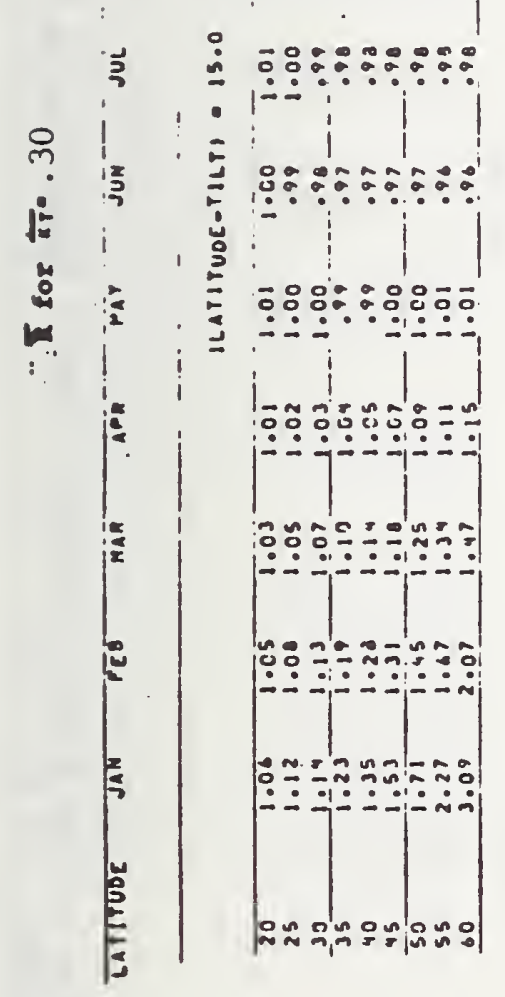

\section{1}

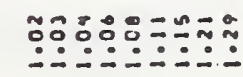

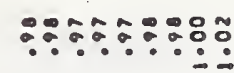

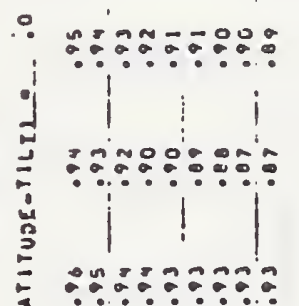

$\therefore \therefore: 3: 23: 3$

|

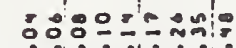

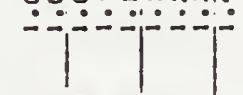

으ำกำกำ

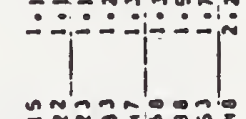

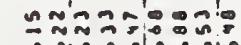

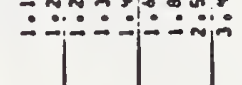

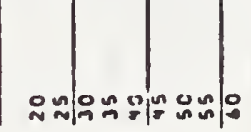

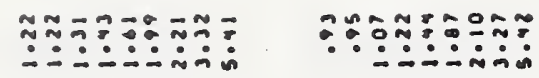

1

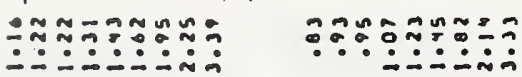

.

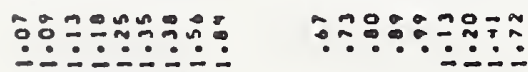

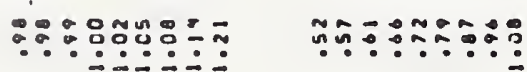

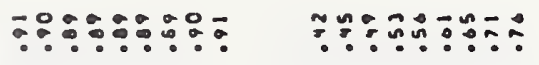

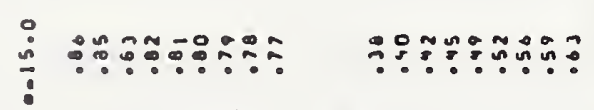

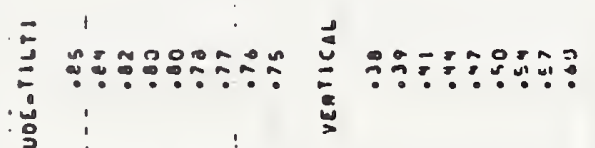

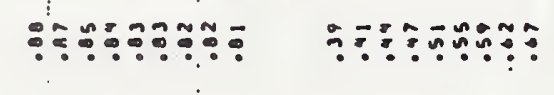

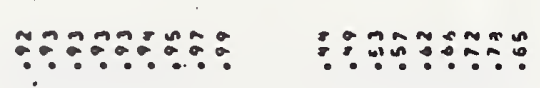

i

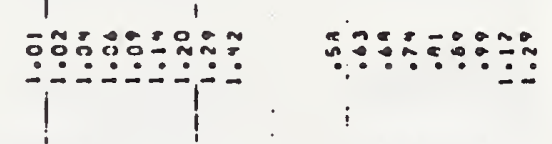

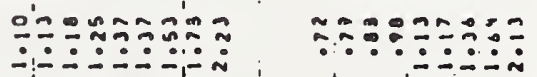

!

| 


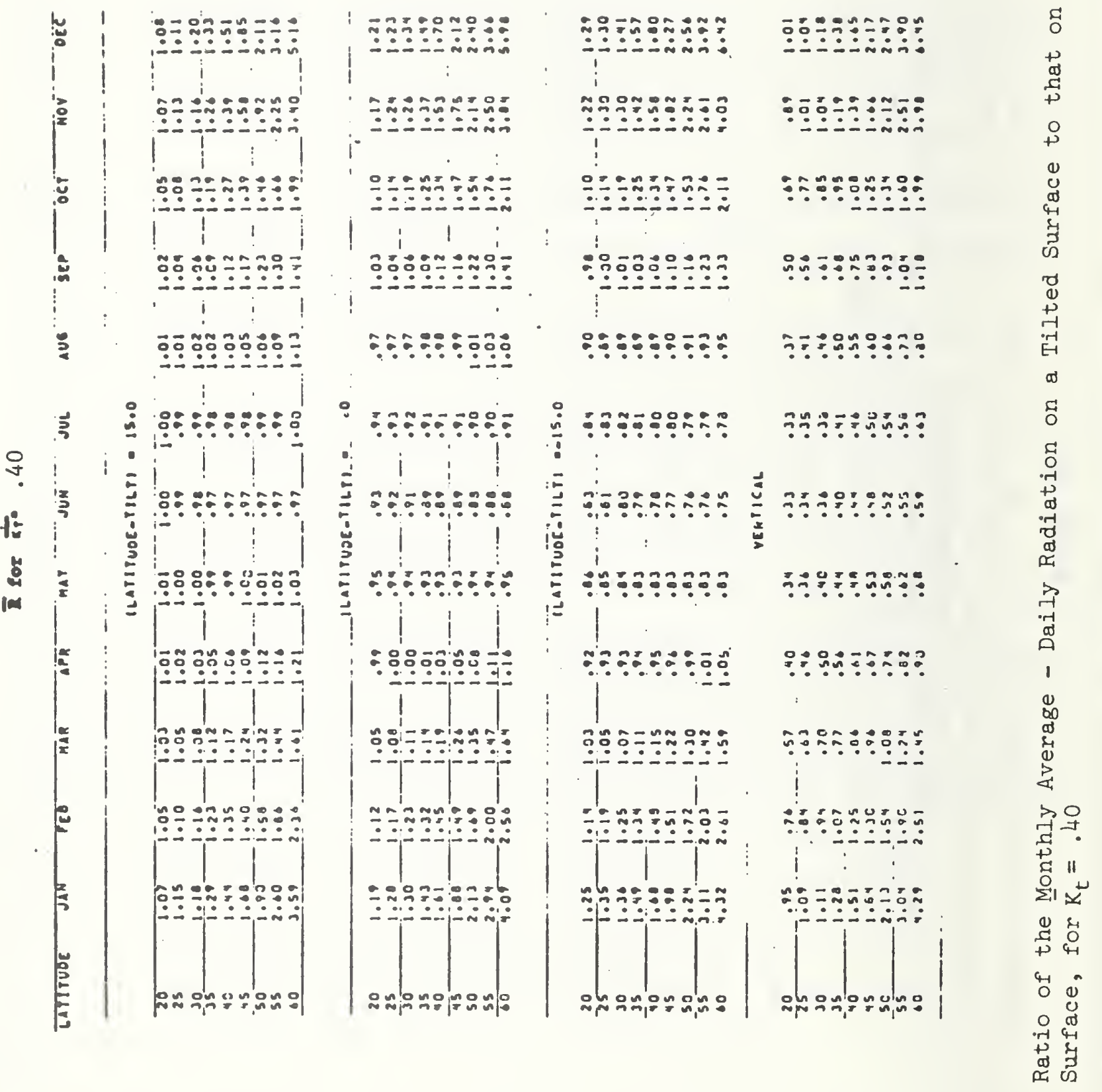


le $\quad$ le

i 1

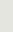

일

:

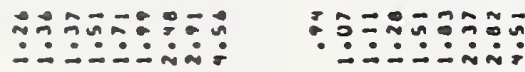

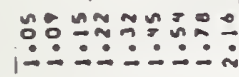

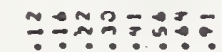

-

⿷匚

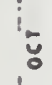

1 1 1

$\vdots$

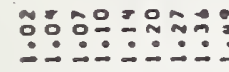

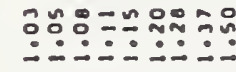

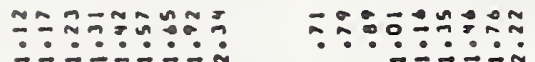

兽

క

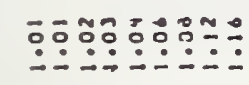

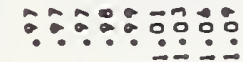

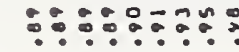

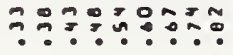

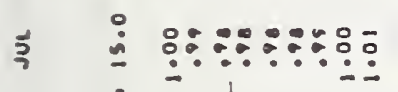

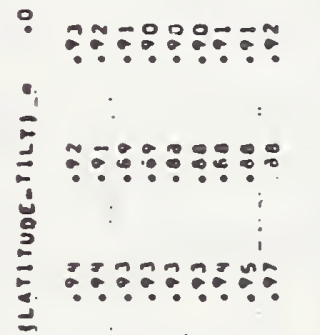

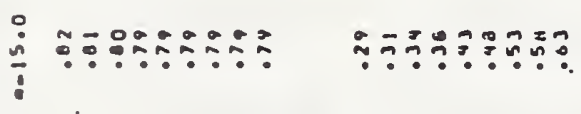

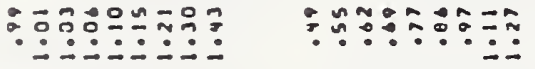

赵

in

ว

1

若

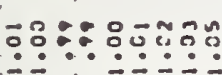

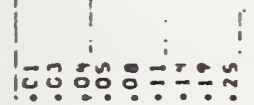

i

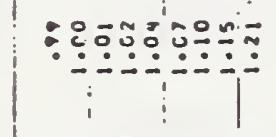

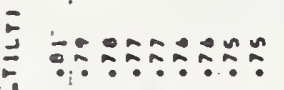

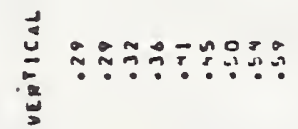

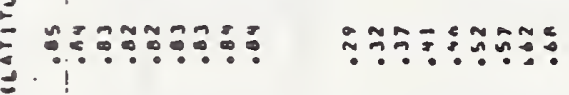

$+$

\%

थี

D
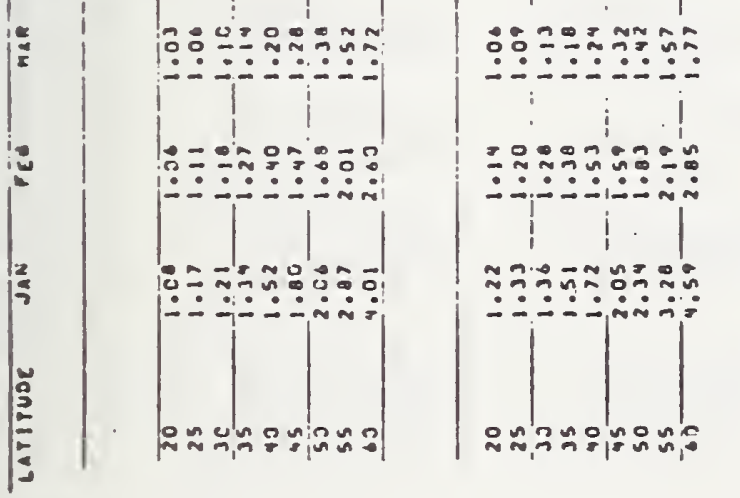

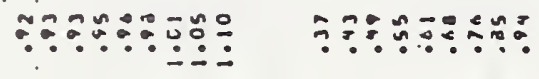

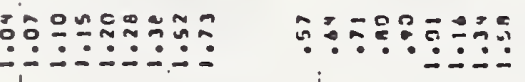

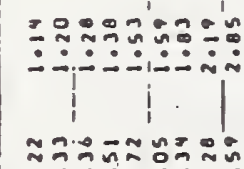

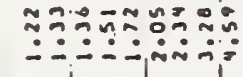

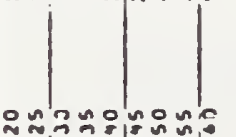

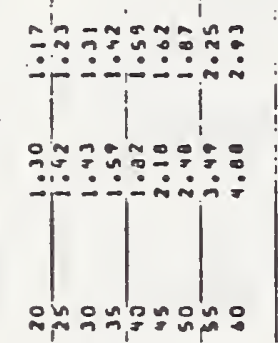

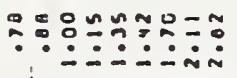

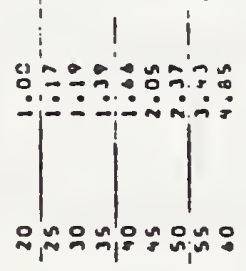

$\infty$

동

ㄷำ

苛

नु

空

1

๑0

\&

安

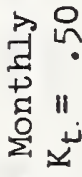

究

$4-1$

0 ๘

- $\rightarrow$

क्ष 


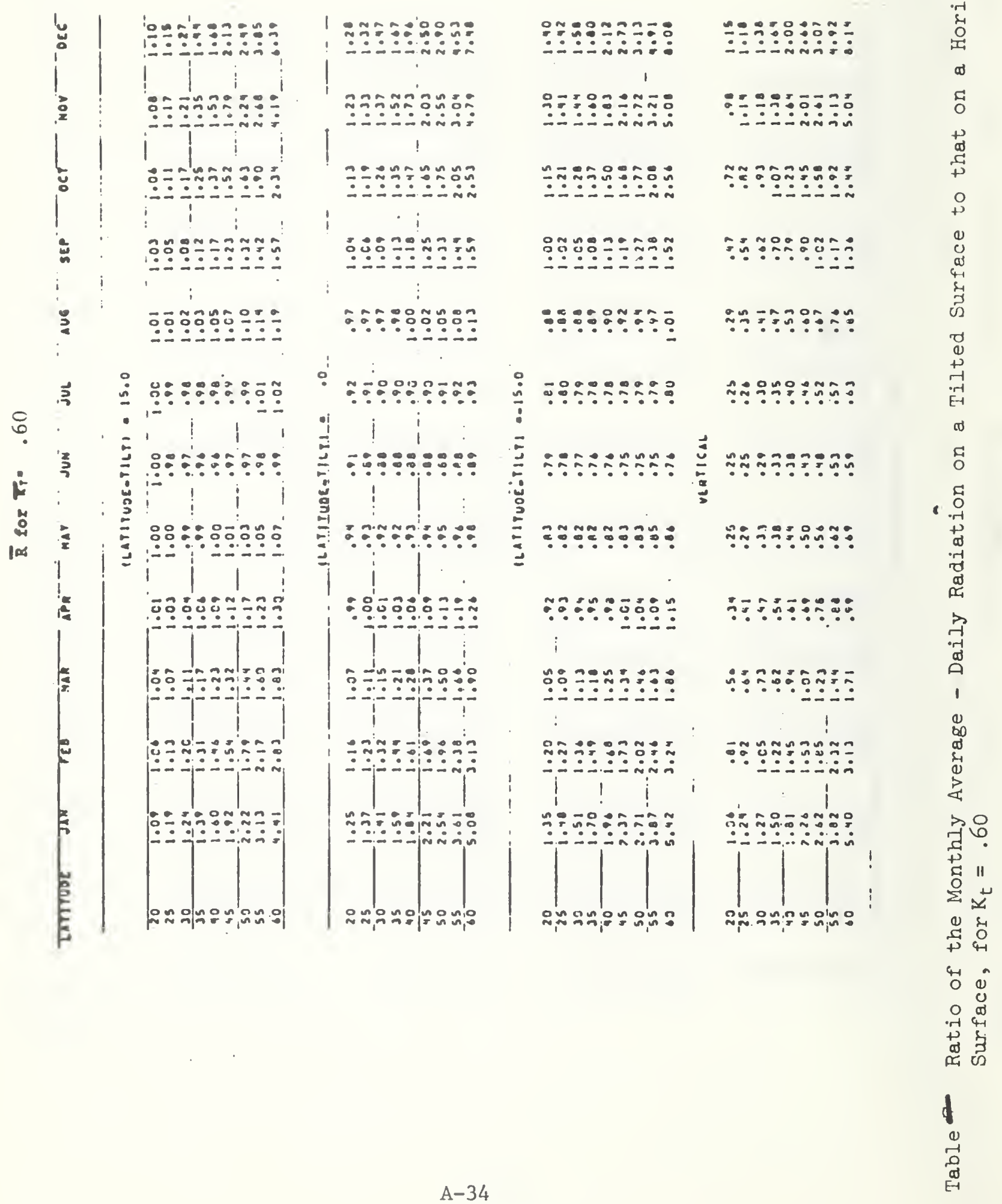




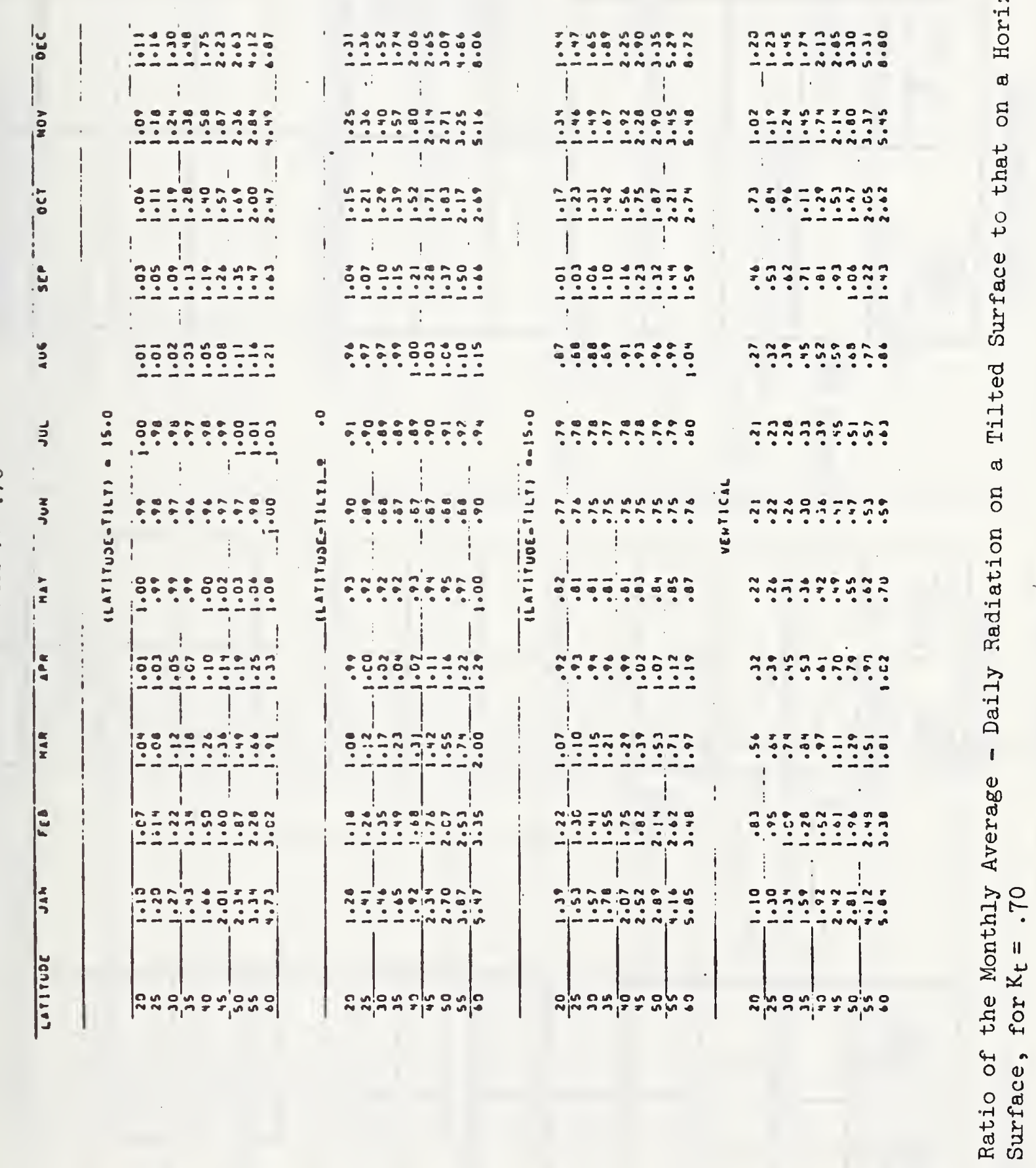



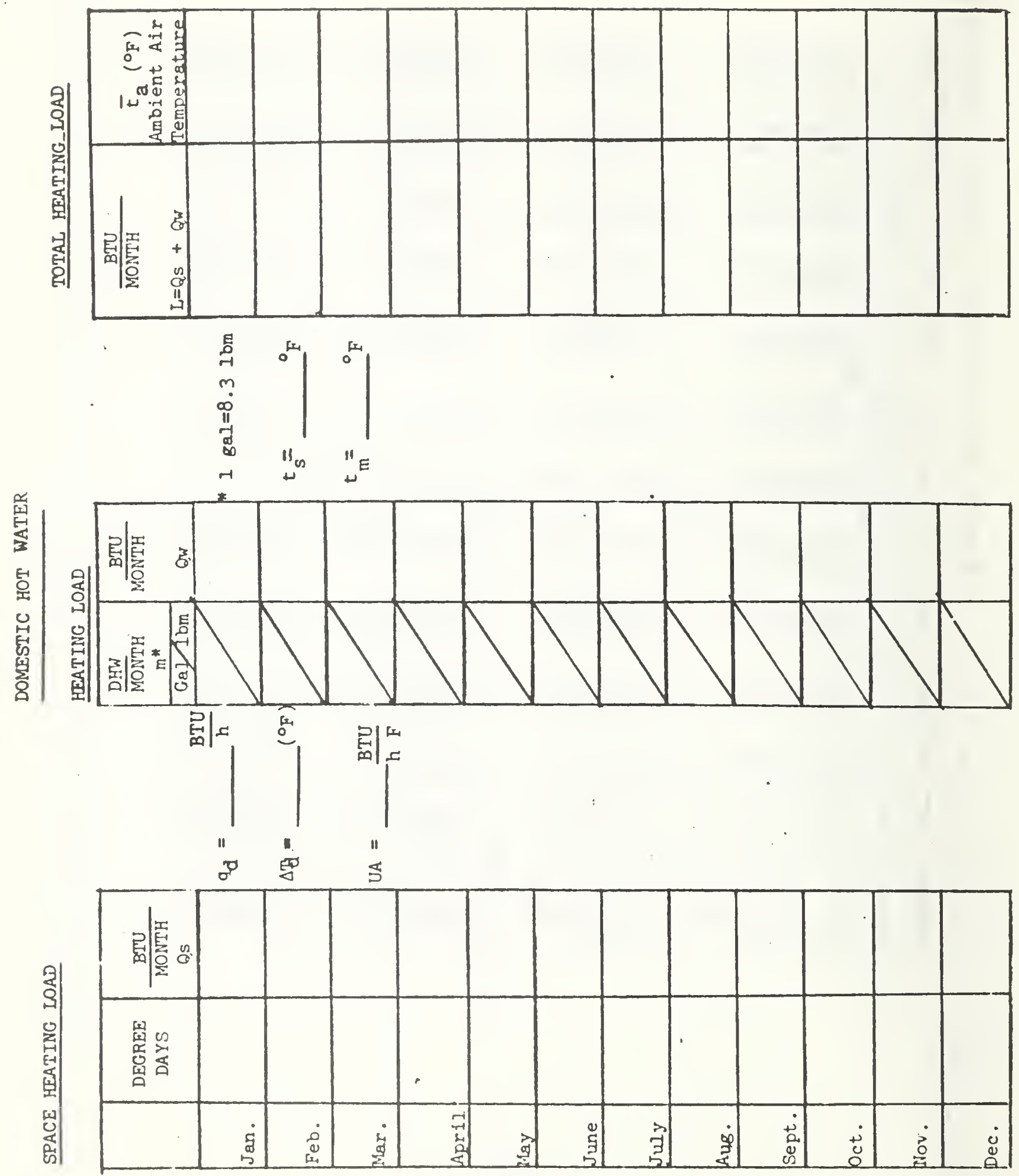

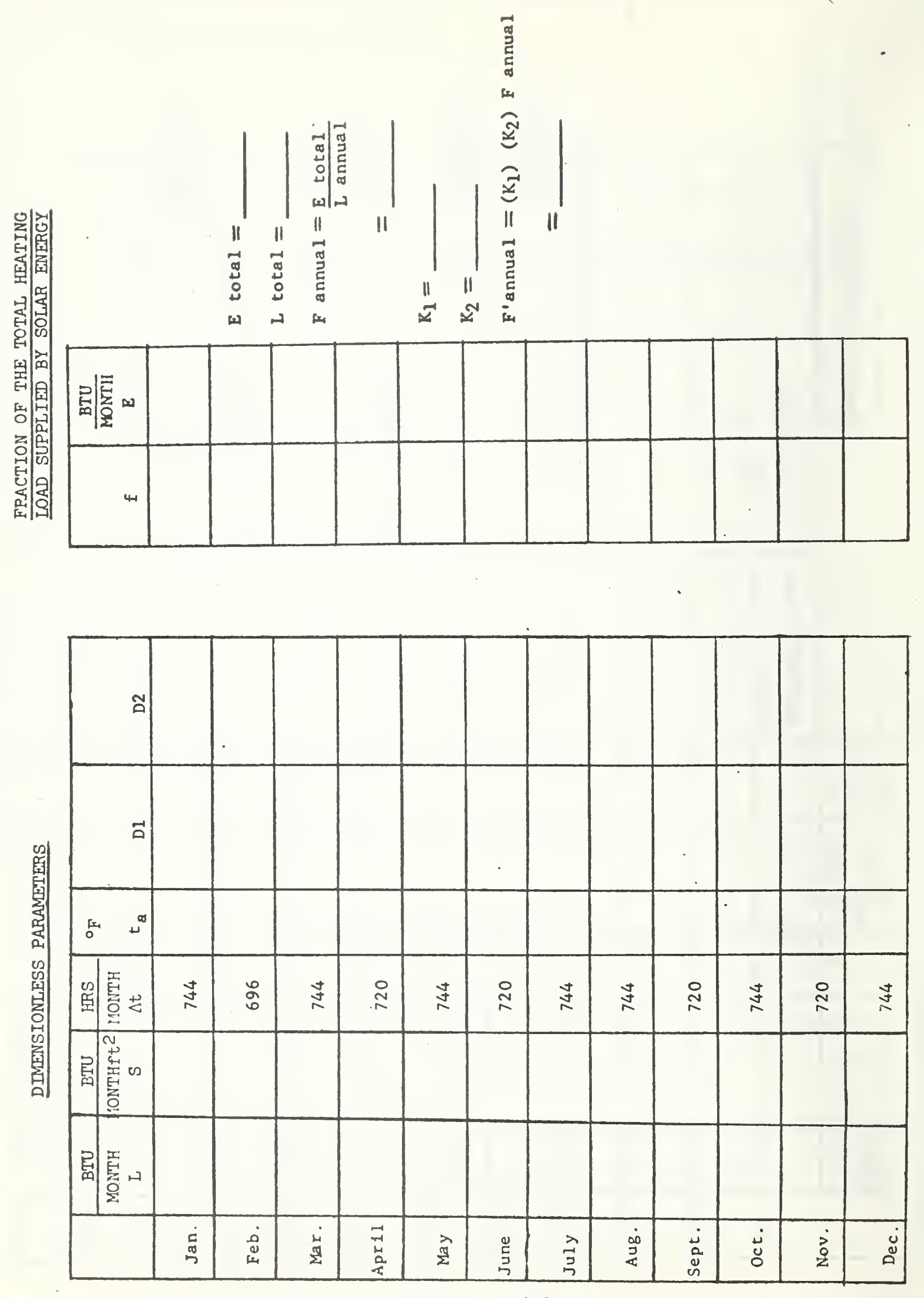


\section{APPENDIX B}

MATERIALS TABLES 

Appendix Table B-1: Characteristics of Absorptive Coatings

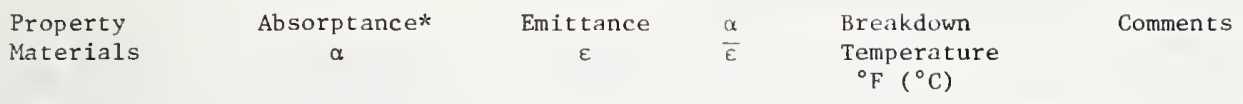

\begin{tabular}{|c|c|c|c|c|c|}
\hline Black Chrome & $.87-.93$ & .1 & $\sim 9$ & & \\
\hline Alkyd Enamel & .9 & .9 & 1 & & $\begin{array}{l}\text { Durability Limited at High } \\
\text { Temperatures }\end{array}$ \\
\hline $\begin{array}{l}\text { Black Acrylic } \\
\text { Paint }\end{array}$ & $.92-.97$ & $.84-.90$ & 21 & & \\
\hline $\begin{array}{l}\text { Black Inorganic } \\
\text { Paint }\end{array}$ & $.89-.96$ & $.86-.93$ & $\sim 1$ & & \\
\hline $\begin{array}{l}\text { Black Silicone } \\
\text { Paint }\end{array}$ & $.86-.94$ & $.83-.89$ & $\sim 1$ & & Silicone Binder \\
\hline $\begin{array}{l}\mathrm{PbS} / \text { Silicone } \\
\text { Paint }\end{array}$ & .94 & .4 & 2.5 & $662(350)$ & $\begin{array}{l}\text { Has a High Emittance for } \\
\text { Thicknesses }>10 \mu \mathrm{m}\end{array}$ \\
\hline $\begin{array}{l}\text { Flat Black } \\
\text { Paint }\end{array}$ & $.95-.98$ & $.89-.97$ & $\sim 1$ & & \\
\hline Ceramic Ename1 & .9 & .5 & 1.8 & & Stable at High Temperatures \\
\hline Black Zinc & .9 & .1 & 9 & & \\
\hline $\begin{array}{l}\text { Copper Oxide } \\
\text { over Aluminum }\end{array}$ & .93 & .11 & 8.5 & $392(200)$ & \\
\hline $\begin{array}{l}\text { Black Copper } \\
\text { over Copper }\end{array}$ & $.85-.90$ & $.08-.12$ & $7-11$ & $842(450)$ & Pastinates with Moisture \\
\hline $\begin{array}{l}\text { Black Chrome } \\
\text { over Nickel }\end{array}$ & $.92-.94$ & $.07-.12$ & $8-13$ & $842(450)$ & Stable at High Temperatures \\
\hline $\begin{array}{l}\text { Black Nickel } \\
\text { over Nickel }\end{array}$ & .93 & .06 & 15 & $842(450)$ & $\begin{array}{l}\text { May be Influenced by Moisture } \\
\text { at Elevated Temperatures }\end{array}$ \\
\hline $\begin{array}{l}\text { Ni-Zn-S over } \\
\text { Nickel }\end{array}$ & .96 & .97 & 14 & $536(280)$ & \\
\hline $\begin{array}{l}\text { Black Iron } \\
\text { over Steel }\end{array}$ & .90 & .10 & 9 & & \\
\hline
\end{tabular}

*Dependent on thickness and vehicle to binder ratio.

G. E. McDonald, "Survey of Coatings for Solar Collectors", NASA TMX-71730, paper presented at Workshop on Solar Collectors for Heating and Cooling of Buildings, November 21-23, 1974, New York City.

G. E. McDonald, "Variation of Solar-Selective Properties of Black Chrome with Plating Time", NASA TMX-71731, May 1975.

S. W. Moore, J. D. Balcomb, J. C. Hedstrom, "Design and Testing of a Structurally Integrated Steel Solar Collector Unit Based on Expanded Flat Metal Plates", LA-UR-74-1093, paper presented at U. S. Section-ISES Meeting, Ft. Collins, Colorado, August 19-23, 1974.

D. P. Grimmer, S. W. Moore, "Practical Aspects of Solar Heating: A Review of Materials Use in Solar Heating Applications", paper presented at SAMPE Meeting, October 14-16, 1975, Hilton Inn.

R. B. Toenjes, "Integrated Solar Energy Collector Final Summary Report". LA-6143-MS, Los Alamos Scientific Laboratory, Los Alamos, New Mexico, November 1975.

G. L. Merrill, "Solar Heating Proof-of-Concept Experiment for a Public School Building", Honeywell Inc., Minneapolis, Minnesota National Science Foundation Contract No. C-870.

D. L. Kirkpatrick, "Solar Collector Design and Performance Experience", for the Grover Cleveland School, Boston, Massachusetts, paper presented at Workshop on Solar Collectors for Heating and Conling of Buildings, November 21-23, 1974, New York City. 
Ferrous pipe \& fittings

Steel pipe, black and hot dipped zinccoated (galvanized) welded and seamless for ordinary use

Steel pipe welded and seamless

Standard Specification for seamless and welded carbon, ferritic, and austenitic alloy steel heat exchanger tubes with integral fins

Nipples, Pipe, threaded

Pipe fittings: (bushings, locknuts and plugs) Iron, steel and aluminum (threaded) 125-150 1bs.

Malleable-iron threaded fittings, 150 and 300 lbs.

Unions, pipe, steel or malleable iron; threaded connection, 150 1bs, and 250 lbs.

\section{Nonferrous metallic pipe and fittings}

Copper pipe, seamless

Copper plpe, threadless

Copper tube, seamless

Copper tube, seamless, for

refrigeration and general use

Copper water tube seamless

General requirements for wrought seamless copper and copper alloy tube

Seamless brass tube

Seamless red brass plpe

Copper and copper alloy seamless

condenser tubes and ferrule stock

Copper-alloy condenser tube plates

U-bend seamless copper and copper

alloy heat exchanger and condenser tubes

Copper and copper alloy seamless condenser and heat exchanger tubes with integral fins

Bronze flanges and flanged fittings,

150 and 300 lbs.

H26.1-1973
H26.2-1973
H23.3-1973
H23.5-1974
H23.1-1973
H23.4-1973
H36.1-1973
H27.1-1973
H23.14-1973
---
B16.18-1972
B16.26-1967
B16.23-1969
B16.24-1971

Cast-bronze fittings for flared

copper tubes

Cast-bronze solder joint dralnage

fittings-DMV

Cast bronze solder joint pressure

fittings
B 36-55-1966

WW-P-406D-1973 WW-P-406D-1-1974

$\begin{array}{ll}\text { B125.2-1972 } & \text { A120-73 } \\ \text { B125.1-1972 } & \text { A53-73 }\end{array}$

A498-68

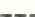

B16.3-1971

B42-75

B302-74a

B74-74b

B280-75

B88-75

B251-75

B136-74

B43-75

B111-75

B171-75

B 395-74b

B359-75

WW-P-377d-1962

ASME SB42

WW-N-351b-1967 WW-N-351b [1]-1970

WW-P-471B-1970

WW-P-521F-1968

WW-U-531D

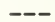

WW-T-775a-1962

WW-T-799D-1971

WW-T-791A-1971

WW-P-351a-1963
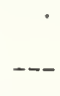

ASME SB171

ASME SB395

ASME SB359

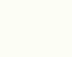


Cast bronze threaded fittings,

125 and 250 lbs.

Copper tube fittings, solder ends

Unions, brass or bronze, threaded pipe connections and solder-joint tube connections

Unions, pipe, bronze or naval brass, threaded pipe connection 250 1bs.

Copper-silicon alloy seamless pipe and tube

Wrought copper and bronze solder-joint pressure fitting

Wrought copper and wrought copper alloy solder-joint drainage fittings

Aluminum-alloy seamless pipe and seamless extruded tube

Aluminum-alloy drawn seamless tubes

Aluminum-alloy drawn seamless tubes for condensers and heat exchangers

Aluminum-alloy drawn tubes for general purpose application

Aluminum-alloy extruded round coiled tubes for general purpose application

Aluminum-alloy seamless round condenser and heat exchanger tubes with integral fins

Wrought aluminum and aluminum alloy welding fittings

P1pe hangers and supports

Pipe hangers and supports, materials, design and manufacture

Pipe hangers and supports, selection and application

Polybutylene (PB) plastic hot-water distribution systems $\left(180^{\circ} \mathrm{F}\right.$ Max.)

Plastic hot-water distribution systems: chlorinated poly (vinyl chloride) (CPVC) for water service $\left(180^{\circ} \mathrm{F}\right.$ Max.)

Cold water service, clamps, hose, low pressure

Standard methods of testing rubber hose

Insulation sleeving, thermal, pipe covering (cellular glass)

Insulation sleeving, thermal (pipe and tube covering)

Standard method of test for sealability of gasket materials

Standard method of test for fluid resistance of gasket materials

\begin{tabular}{|c|c|}
\hline B16.15-1971 & -- \\
\hline--- & --- \\
\hline--- & -- \\
\hline-- & --- \\
\hline H26. 3-1973 & В $315-75$ \\
\hline B16. 22-1973 & --- \\
\hline B16. 29-1973 & -- \\
\hline $\mathrm{H} 38.7$ & B241 \\
\hline H 38.7 & B310-74a \\
\hline H38.6-1974 & B234-73 \\
\hline H38.17-1974 & B483-73 \\
\hline Н $38.18-1974$ & B491-73 \\
\hline H $38-1974$ & B404-73 \\
\hline
\end{tabular}

H38. 19-1974

B $361-73$

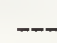

WW-H-171D-1970

MSS SP-58-1975

MSS SP-69-1966

D3309-74

D2846-73

NSF $14-1965$

WW-C-440B (2)

D380-75

$\mathrm{J} 2.5$

$--$

HH-1-175113A

HH-1-1751/GEN

2193.1-1970

F $37-68$

F146-72
W-P-460b-1967

$-460 \mathrm{~b}-1-1972$

$-T-725 a-1973$

W-U-516B

-U-516a-1967

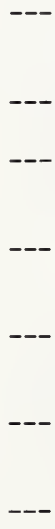


Appendix Table B-2: continued

Description

Low velocity duct construction standard

High velocity duct construction standards

Fibrous glass duct construction standards

Pressure sensitive tape standards for

fibrous glass duct

Duct liner application standard

Fire damper guide
ANSI

ASTM

Federa

Specifications

$--$

SMACNA

SMACNA

SMACNA

SMACNA

SMACNA

SMACNA 
Appendix Table B-3: Temperature and Pressure Ratings for Ball Valves $\underline{1 /}$

\begin{tabular}{|c|c|c|c|c|c|}
\hline \multirow{2}{*}{$\begin{array}{c}\text { Size } \\
\text { (inches) }\end{array}$} & \multirow{2}{*}{$\begin{array}{c}\text { Temperature, } \\
{ }^{\circ} \mathrm{F}\end{array}$} & \multicolumn{4}{|c|}{ Materials (Pressure in psi) } \\
\hline & & Bronze & Iron & Carbon Stee1 & Alloy Steel \\
\hline \multirow[t]{3}{*}{$1 / 2$} & -20 to 100 & 200 and 400 & & 1000 & 1000 \\
\hline & 150 & 400 & & 850 & 850 \\
\hline & 200 & 150 and 400 & & 700 & 700 \\
\hline \multirow[t]{3}{*}{ TO } & 250 & $15 \underline{2} /$ and 400 & & 500 & 500 \\
\hline & 300 & 300 & & 300 & 300 \\
\hline & 325 & 200 & & 200 & 200 \\
\hline \multirow[t]{3}{*}{$3 / 4$} & 353 & 125 & & 125 & 125 \\
\hline & 375 & 90 & & 90 & 90 \\
\hline & 400 & 60 & & 60 & 60 \\
\hline \multirow[t]{3}{*}{1} & -20 to 100 & 400 & & 720 & 720 \\
\hline & 150 & 400 & & 710 & 710 \\
\hline & 200 & 400 & & 700 & 700 \\
\hline \multirow[t]{2}{*}{ TO } & 250 & 400 & & 500 & 500 \\
\hline & 300 & 300 & & 300 & 300 \\
\hline \multirow[t]{4}{*}{2} & 325 & 200 & & 200 & 200 \\
\hline & 353 & 125 & & 125 & 125 \\
\hline & 375 & 90 & & 90 & 90 \\
\hline & 400 & 60 & & 60 & 60 \\
\hline \multirow[t]{2}{*}{$2-1 / 2$} & -20 to 100 & & 220 & 275 & 275 \\
\hline & 150 & & 205 & 255 & 255 \\
\hline T0 & 200 & & 190 & 240 & 240 \\
\hline 12 & 250 & & 180 & 225 & 225 \\
\hline
\end{tabular}

$1 /$ These ratings for ball valves, presented in Federal Specification WW-V-35a-1975, are intended for guidance and are not intended to be restrictive. Valves should not be used for pressures and temperatures exceeding the manufacturer's rating.

2/ 15 pounds saturated steam temperature. 
Appendix Table B-4: Thermal Storage Unit Containers-1/

\begin{tabular}{|c|c|c|c|c|c|c|c|c|c|c|}
\hline \multirow{2}{*}{$\begin{array}{l}\text { Container } \\
\text { Material }\end{array}$} & \multicolumn{2}{|c|}{ Usage } & \multicolumn{2}{|c|}{$\begin{array}{l}\text { Transfer } \\
\text { Media }\end{array}$} & \multicolumn{2}{|c|}{$\begin{array}{l}\text { Pressure } \\
\text { Conditions }\end{array}$} & \multirow{2}{*}{$\begin{array}{l}\text { Recommended } \underline{3} / \\
\text { Container } \\
\text { Standard } \\
\text { Compliance }\end{array}$} & \multicolumn{2}{|c|}{$\begin{array}{l}\text { Protective } \\
\text { Coating }\end{array}$} & \multirow{2}{*}{$\begin{array}{l}\text { Recommended } \\
\text { Coating } \\
\text { Standard } \\
\text { Compliance }\end{array}$} \\
\hline & Ground & Ground & Air & Liquid & $\mathrm{High}$ & Low & & Ext. & $\frac{8}{\text { Int. }}$ & \\
\hline Aluminum & $\mathrm{X}$ & $\mathrm{X}$ & $\mathrm{X}$ & $\mathrm{X}$ & $\mathrm{x}$ & $\mathrm{x}$ & $\begin{array}{l}\text { ANSI B96.1 } \\
1973\end{array}$ & - & - & - \\
\hline Concrete & $\mathrm{X}$ & $\mathrm{X}$ & $\mathrm{X}$ & $\mathrm{x}$ & $x$ & $\mathrm{X}$ & $\begin{array}{l}\text { IPM PSI } \\
(1966)\end{array}$ & $\mathrm{X}$ & $\mathrm{x}$ & $\begin{array}{l}\text { Ext. MPS } \\
609.7 .4 \text { Int. } \\
\text { TTP-95A(3) } \\
27 \text { May } 66\end{array}$ \\
\hline Earth & & $\mathrm{x}$ & $\mathrm{X}$ & & & $\mathrm{x}$ & $\begin{array}{l}\text { Vapor Barrier } \\
\text { Materials as } \\
\text { per ASTM E154.68 }\end{array}$ & $\begin{array}{l}\text { Vapor } \\
\text { Cover } 1 \\
\text { Solids }\end{array}$ & $\begin{array}{l}\text { Barrier } \\
\text { Ing of } \\
\text { s Required }\end{array}$ & MPS 507.2 .2 \\
\hline $\begin{array}{l}\text { Fiber Rein. } \\
\text { Polyester }\end{array}$ & $\mathrm{X}$ & $\mathrm{X}$ & $\mathrm{X}$ & $x$ & & $\mathrm{x}$ & $\begin{array}{l}\text { MIL-T-52777 } \\
21 \text { Feb } 1974\end{array}$ & - & - & - \\
\hline Stee1 & $\mathrm{X}$ & $\mathrm{X}$ & $\mathrm{X}$ & $\mathrm{X}$ & $\mathrm{x}$ & $\mathrm{X}$ & $\begin{array}{l}\text { AWWA D-100 } \\
(1967)\end{array}$ & $\mathrm{X}$ & $\mathrm{X}$ & $\begin{array}{l}\text { Ext. MPS } \\
609.7 .34 / \\
\text { Ext. \& Int. } \\
\text { AWWA D102 } \\
(1964)\end{array}$ \\
\hline Wood & $\mathrm{x}$ & & & $x$ & & $\mathrm{x}$ & NFO 8 (1965) & - & - & - \\
\hline
\end{tabular}

1/ Thermal Storage Unit - any container, space, or device which has the capacity to store transfer media (liquid or solid) containing thermal energy for later use.

$2 /$ Low pressure systems are those subjected to atmospheric pressure only, i.e. vented.

3/ When applicable, ASME Boiler and Pressure Vessel Code, Section VIII may be used.

4f In lieu of interior galvanized, glass-lined or stone-lined tanks. 


\begin{tabular}{|c|c|c|c|c|c|c|}
\hline & Water & $\begin{array}{l}85 \% \text { Ethylene } \\
\text { G1ycol/Water }\end{array}$ & $\begin{array}{l}50 \% \text { Propylene } \\
\text { Glycol/Water }\end{array}$ & $\begin{array}{l}\text { Silicone } \\
\text { Fluid }\end{array}$ & $\begin{array}{l}\text { Alkylated } \\
\text { Phenol }\end{array}$ & $\begin{array}{l}\text { Paraffinic } \\
\text { Oil }\end{array}$ \\
\hline $\begin{array}{l}\text { Freezing Point, } \\
{ }^{\circ} \mathrm{F}\left({ }^{\circ} \mathrm{C}\right)\end{array}$ & $32(0)$ & $-33(-36)$ & $-28(-33)$ & $-58(-50)$ & $-100(-73)$ & -- \\
\hline $\begin{array}{l}\text { Boiling Point, } \\
{ }^{\circ} \mathrm{F}\left({ }^{\circ} \mathrm{C}\right) \text { (at atm. } \\
\text { pressure) }\end{array}$ & $212(100)$ & $265(130)$ & -- & None & $358(181)$ & $700(371)$ \\
\hline Fluid Stability & $\begin{array}{l}\text { Requires } \mathrm{pH} \\
\text { or inhibitor } \\
\text { monitoring }\end{array}$ & $\begin{array}{l}\text { Requires } \mathrm{pH} \\
\text { or inhibitor } \\
\text { monitoring }\end{array}$ & $\begin{array}{l}\text { Requires } \mathrm{pH} \\
\text { or inhibitor } \\
\text { monitoring }\end{array}$ & Good & $\begin{array}{l}\text { Good to } \\
575^{\circ} \mathrm{F}\end{array}$ & Good \\
\hline $\begin{array}{l}\text { Flash Point, } \\
{ }^{\circ} \mathrm{F}\left({ }^{\circ} \mathrm{C}\right)\end{array}$ & None & None & $600(315)$ & $600(315)$ & 145 (63) & $455(235)$ \\
\hline $\begin{array}{c}\text { Specific Heat } \\
\left(73^{\circ} \mathrm{F}\right) \\
\left(\mathrm{BTU} / 1 \mathrm{~b} /{ }^{\circ} \mathrm{F}\right)\end{array}$ & 1.0 & 0.65 & 0.85 & $0.34-0.48$ & 0.42 & 0.46 \\
\hline $\begin{array}{l}\text { Viscosity } \\
\left(\text { cstk at } 77^{\circ} \mathrm{F}\right)\end{array}$ & 0.9 & 21 & 5 & $5-50000$ & 1 & -- \\
\hline Toxicity & None & Low & Low & Low & Moderate & -- \\
\hline
\end{tabular}


Calcium Hydroxide

Chromates

Molecularly Dehydrated Phosphates and Chromates

Molecularly Dehydrated Phosphates and Ferro Cyanides

Molecularly Dehydrated Phosphates and Organics

Molecularly Dehydrated Phosphates and Silicates

Hexameta, Phosphates, $\mathrm{Na} \& \mathrm{Ca}$

Sodium Benzoate

Sodium Hexametaphosphate

Sodium Hydroxide

Sodium Nitrate

Sodium Septa

Sodium Silicate

Sodium Sulfite

Tetraphosphoglucosate
$\mathrm{Fe}, \mathrm{Zn}, \mathrm{Cu}$, Brass

$\mathrm{Fe}, \mathrm{Zn}, \mathrm{Cu}$, Brass

Fe, $\mathrm{Zn}, \mathrm{Cu}$, Brass

$\mathrm{Fe}, \mathrm{Zn}, \mathrm{Cu}$

Fe, $\mathrm{Zn}, \mathrm{Cu}$, Brass

$\mathrm{Fe}, \mathrm{Zn}, \mathrm{Cu}$, Brass

$\mathrm{Fe}, \mathrm{Zn}, \mathrm{Cu}, \mathrm{Al}$, Brass

$\mathrm{Fe}$

Fe, $\mathrm{Zn}, \mathrm{Cu}, \mathrm{Pb}$, Brass

Fe, Zn, Cu, Brass

Fe, $\mathrm{Zn}, \mathrm{Cu}, \mathrm{Al}$, Brass

$\mathrm{Fe}, \mathrm{Zn}, \mathrm{Cu}, \mathrm{Al}$, Brass

$\mathrm{Fe}, \mathrm{Zn}, \mathrm{Cu}$, Brass

A11 Metals

$\mathrm{Fe}, \mathrm{Zn}, \mathrm{Cu}, \mathrm{Al}$, Brass
Corrosion Causes \& Prevention, 2nd Edition, 361-366

Ind. \& Engr. Chem. Vol. 41, No. $11,2376-2382$ (1949): 011 \& Gas J., Vol. 47, No. 37, 83-87 (1949) Jan. 13.

$0 i 1$ \& Gas J., Vol. 49, No. 43, 52-62 (1951) March 1: Ind. \& Engr. Chem., Vol. 44, No. 8, 1770-1774 (1952); Corrosion, Vol. 6, No. $10,331-340$ (1947) nct.

Oil \& Gas J., Vol. 49, No. 43, 52-62 (1951) March 1 .

$0 i 1$ \& Gas J., Vol. 49, No. 43, 52-62 (1951) March 1; Ind. \& Engr. Chem., Vol. 30, No. 12 $1356-1361$

Corrosion, Vol. 8, No. 12, 402-406 (1952) Dec.

Ind. \& Engr. Chem., Vol. 37, No. $8,724-735$ (1945) Aug.

Journal Soc. Chem. Indus. (Br.), Vo1. 66, 137; Chem. \& Ind. (Br.), Vol. 53, 1194 (1951)

Corrosion, Vol. 8, No. 11, 381-390 (1952) Nov; Ind. \& Engr. Chem., Vol. 32, No. 12, 1572-1579 (1938) Dec.

Ind. \& Engr. Chem., Vol. 37, No. 8, 724-735 (1945) Aug.

Journal Electrochemical Soc. Vol. 93, 63 (1948); Ind. \& Engr. Chem., Vol. 35, 358 (1943).

Ind. \& Engr. Chem., Vol. 37 , No. $8,724-735$ (1948) Aug.

Ind. \& Engr. Chem., Vol. 30, No. 3, 348-351 (1938) March; Ind. \& Engr. Chem., Vo1. 44, No. $8,1765-1769$ (1952) Aug.

Petro. Processing, Vol. 7, No. 5, 620-622 (1952) May; J. Amer. Water Works Assoc., 39 (1121) (1947).

Ind. \& Engr. Chem., Vol. 37, No. 8, 724-735 (1945) Aug. 


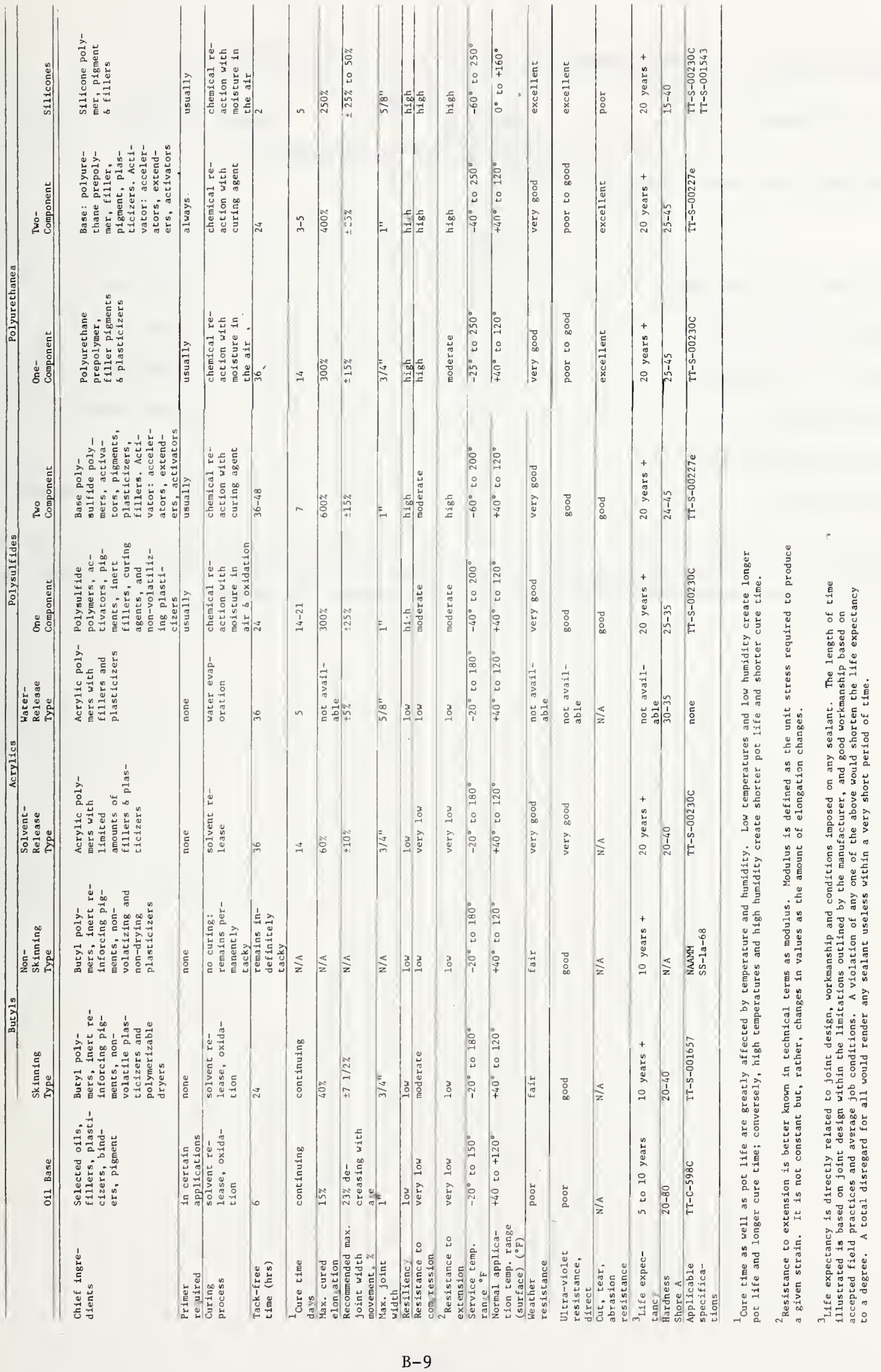


Appendix Table B̈-8: Upper Temperature Limits for Insulation Materials*

\begin{tabular}{|c|c|c|}
\hline Insulation Materials & $\begin{array}{l}\text { Density } \\
\left(1 \mathrm{~b} / \mathrm{ft}^{3}\right)\end{array}$ & $\begin{array}{l}\text { Upper Temperature Limits } \\
{ }^{\circ} \mathrm{F}\left({ }^{\circ} \mathrm{C}\right)\end{array}$ \\
\hline Fiberglass with Organic Binder & $\begin{array}{l}0.6 \\
1.0 \\
1.5 \\
3.0\end{array}$ & $\begin{array}{ll}350 & (177) \\
350 & (177) \\
350 & (177) \\
350 & (177)\end{array}$ \\
\hline Fiberglass with Low Binder & 1.5 & $850(454)$ \\
\hline Ceramic Fiber Blanket & 3.0 & $2300(1260)$ \\
\hline Mineral Fiber Blanket & 10.0 & $1200(649)$ \\
\hline Calcium Silicate & 13.0 & $1200(649)$ \\
\hline Urea-Formaldehyde Foam & 0.7 & $210(99)$ \\
\hline Ureathane Foam & $2-4$ & $250-400(121-204)$ \\
\hline
\end{tabular}

*Table from "Integrated Solar Energy Collector Final Summary Report", Robert B. Teonjes, LA-6143-MS, Los Alamos Scientiflc Laboratory, Los Alamos, New Mexico, November 1975. 
APPENDIX C

ILLUSTRATED DEFINITIONS 


\section{Table of Contents}

SOLAR HEATING AND DOMESTIC HOT WA'TER SYSTEMS: A FUNCTIONAL DESCRIPTION

$3-1$

SOLAR HEATING AND DOMESTIC HO'T WATER SYSTEMS:

$\mathrm{C}-3$

AN OPERATIONAL DESCRIPTION

$\mathrm{c}-6$

BASICS OF SOLAR ENERGY UTILIZATION

SOLAR HEATING AND DOMESTIC HOT WA'PER SYSTEMS:

$\mathrm{C}-13$

ACTIVE SYSTEMS

C -19

SOLAR HEATING AND DOMES'TIC HOT WATER SYSTEMS:

PASSIVE SYSTEMS

SOLAR HEATING AND DOMESTIC HO'T WATER SYSTEMS:

COMPONENT DESCRIPTION 



\section{Solar Heating and Domestic Hot Water Systems: A Functional Description}

The basic function of a solar heating and domestic hot water system is the collection and conversion of solar radiation into usable energy. This is accomplished--in general terms-in the following manner. Solar radiation is absorbed by a collector, placed in storage as required, with or without the use of a transport medium, and distributed to point of use. The performance of each operation is maintained by automatic or manual controls. An auxiliary energy system is usually available for operation, both to supplement the output provided by the solar system and to provide for the total energy demand should the solar system become inoperable.

The conversion of solar radiation to thermal energy and the use of this energy to meet all or part of a dwelling's heating and domestic hot water requirements has been the primary application of solar energy in buildings.

The parts of a solar system--collector, storage, distribution, transport, controls and auxiliary energy-may vary widely in design, operation, and performance. They may, in fact, be one and the same element (a south-facing masonry wall can be seen as a collector, although a relatively inefficient one, which stores and then radiates or "distributes" heat directly to the building interior). They may also be arranged in numerous combinations dependent on function, component compatibility, climatic conditions, required performance, site characteristics, and architectural requirements.

Of the numerous concepts presently being developed for the collection of solar radiation, the relatively simple flat-plate collector has found the widest application. It consists of an absorbing plate, usually made of metal painted black to increase absorption of the sun's heat. This plate is insulated on its underside and covered with a transparent cover sheet to trap heat within the collector and reduce convection losses from the absorber. The captured heat is removed from the absorber by means of a working fluid, generally air or water. The fluid is heated as it passes through or near the absorbing plate. The heated working fluid is then transported to points of use or to storage depending on energy demand.

Storage of thermal energy is necessary because there will be an energy demand during the evening or on sunless days when collection is not occurring. Heat is stored when the energy delivered by the sun and captured by the collector exceeds the demand at the point of use. The storage element may be as simple as a masonry floor that stores and then re-radiates captured heat, or relatively complex such as latent heat storage. In some cases, heat from the collector is transferred to storage by means of a heat exchanger (primarily in systems with a liquid working fluid). In other cases, transfer is made by direct contact of the working fluid with the storage medium (i.e., heated air passing through a rock pile).

The distribution component receives energy from the collector or storage and dispenses it at points of consumption. Comfort heat usually is distributed in the form of warm air or warm water within a building.

The controls of a solar system perform the sensing, evaluation and response functions required to operate the system in the desired mode. For example, when heat is needed for hot water or space heat, the controls cause the hot working fluid to be delivered to whatever system is being used, perform its function and distribute the energy to the point of use.

An auxiliary energy system provides a supply of energy during periods of extremely severe weather or extended cloudy weather. The auxiliary system, using conventional fuels such as oil, gas or electricity, provides the required heat until solar energy is available again.

The organization of components into solar heating and domestic hot water systems has led to two general characterizations of solar systems: active and passive. The terms active and passive solar systems have not yet developed universally accepted meanings. However, each classification possesses characteristics that are distinctively different from each other. These differences significantly influence solar dwelling and system design.

An active solar system can be characterized as one in which energy-in addition to solar-is used for the transfer of thermal energy. This additional energy, generated on or off the site, is required for pumps, blowers, or other heat transfer medium moving devices for system 
operation. Generally, the collection, storage, and distribution of thermal energy is achieved by moving a transfer medium throughout the system with the assistance of pumping power.

A passive solar system, on the other hand, can be characterized as one where solar energy alone is used for the transfer of thermal energy. Energy other than solar is not required for pumps, blowers, or other heat transfer inedium moving devices for system operation. The major component in a passive solar system generally utilizes some form of therinal capacitance, where heat is collected, stored, and distributed to the building without additional pumping power. Collection, storage, and distribution is achieved by natural heat transfer phenomena employing convection, radiation, conduction, and evaporation in conjunction with the use of thermal capacitance as a heat flow control mechanisin. 


\section{Solar Heating and Domestic Hot Water Systems: An Operational Description}

Solar Systems may be designed to operate in a number of different ways depending on function, required performance, cliınatic conditions, component and system design, and architectural requirements. Usually, however, solar systems are

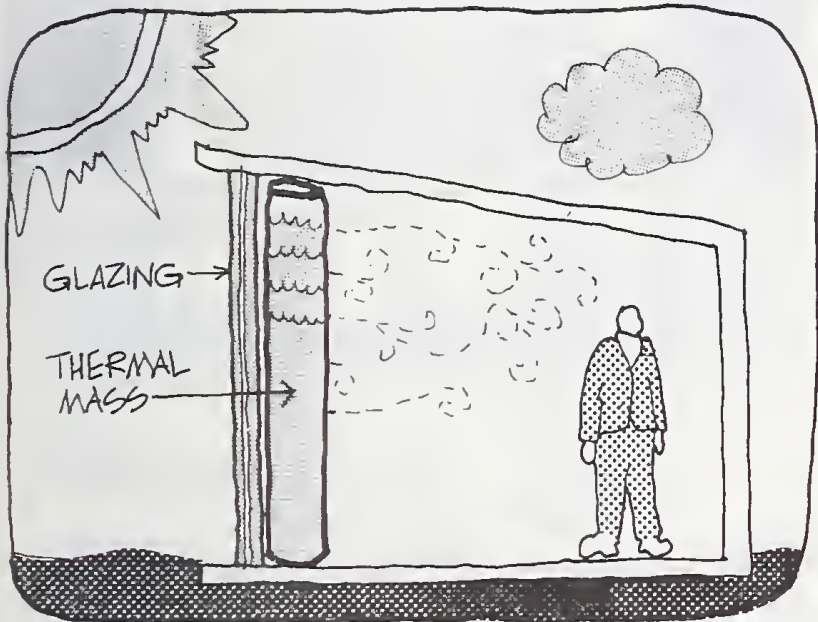

PASSIVE SOLAR SYS'TEM

HEATING HOUSE FROM COLLECTOR Solar radiation captured by the collectors and conver ted to thermal energy can be used to directly heat the house.

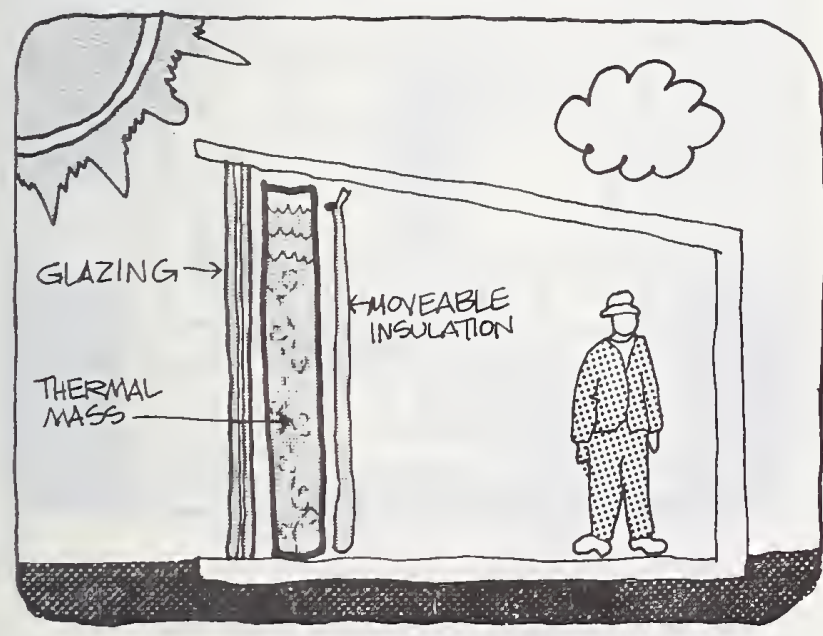

HEATING STORAGE FROM COLLECTOR If the house does not require heat, the captured (collected) thermal energy can be placed in storage for later use. designed to operate in four basic modes. In a very simplistic inanner, the four modes of solar system operation for both active and passive systems are described and illustrated below.

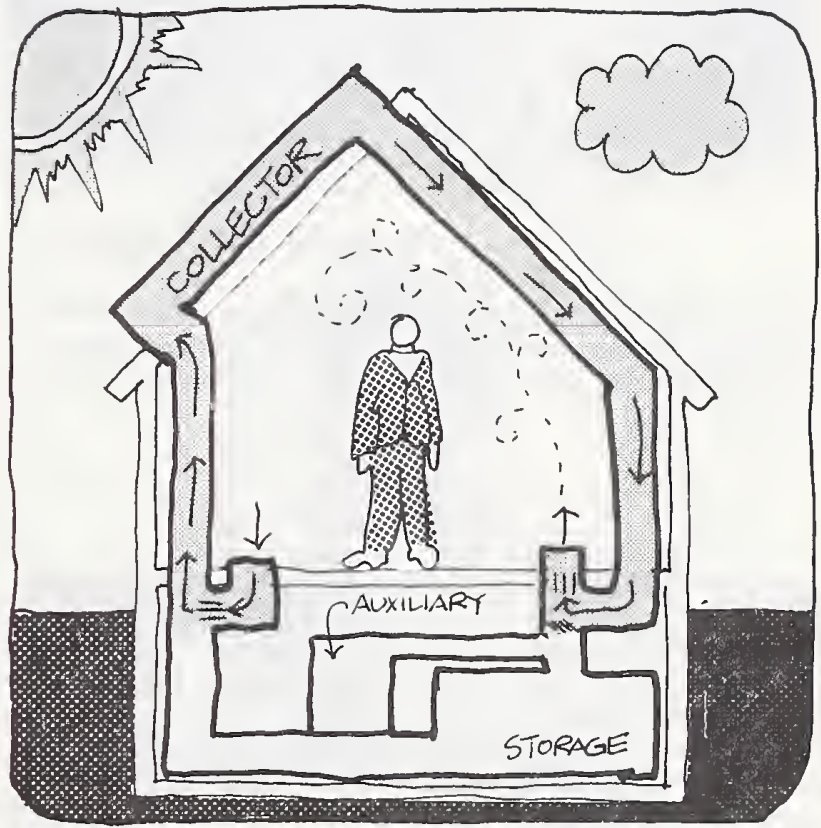

ACTIVE SOLAR SYSTEM

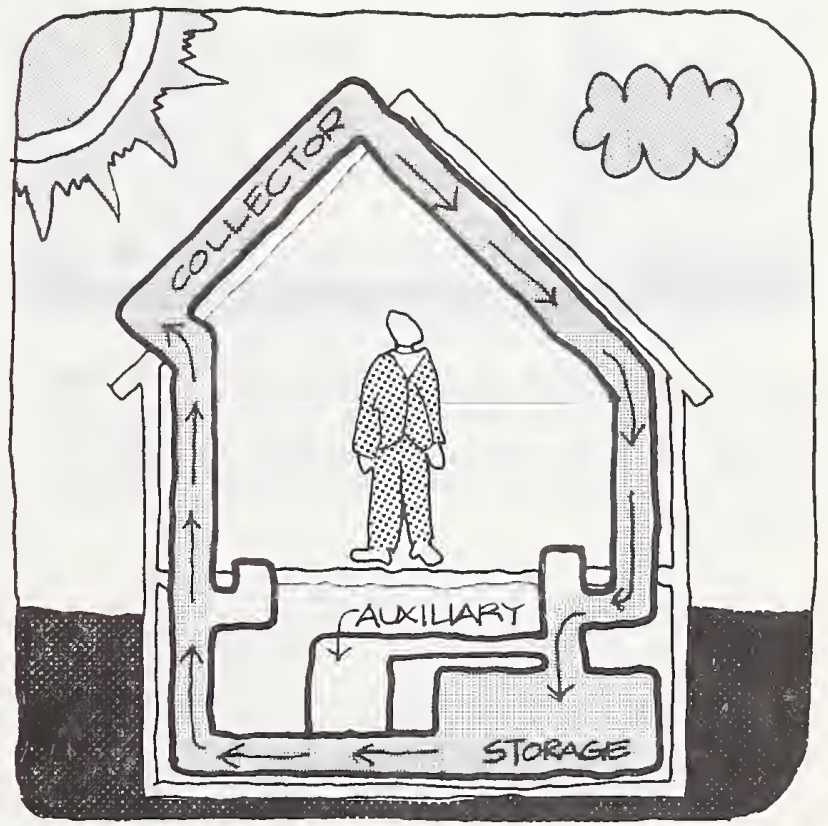




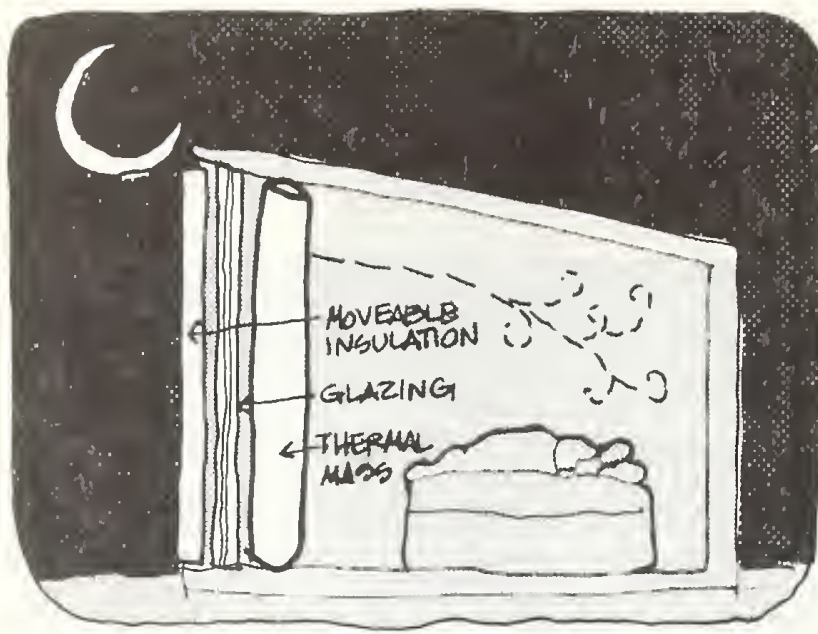

PASSIVE SOLAR SYSTEM

HEATING HOUSE FROM STORAGE Heat from storage can be removed to heat the house when the sun is not shining--at night or on consecutive sunless days.

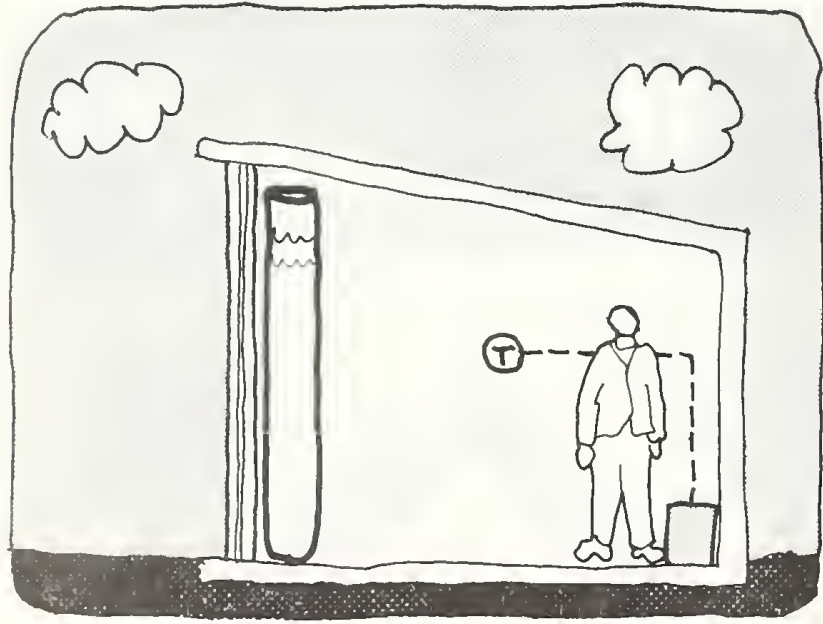

HEATING HOUSE FROM AUXILIARY If heat from the collector and storage is not sufficient to totally heat the house, an auxiliary system supplies all or part of the house's heating requirement.

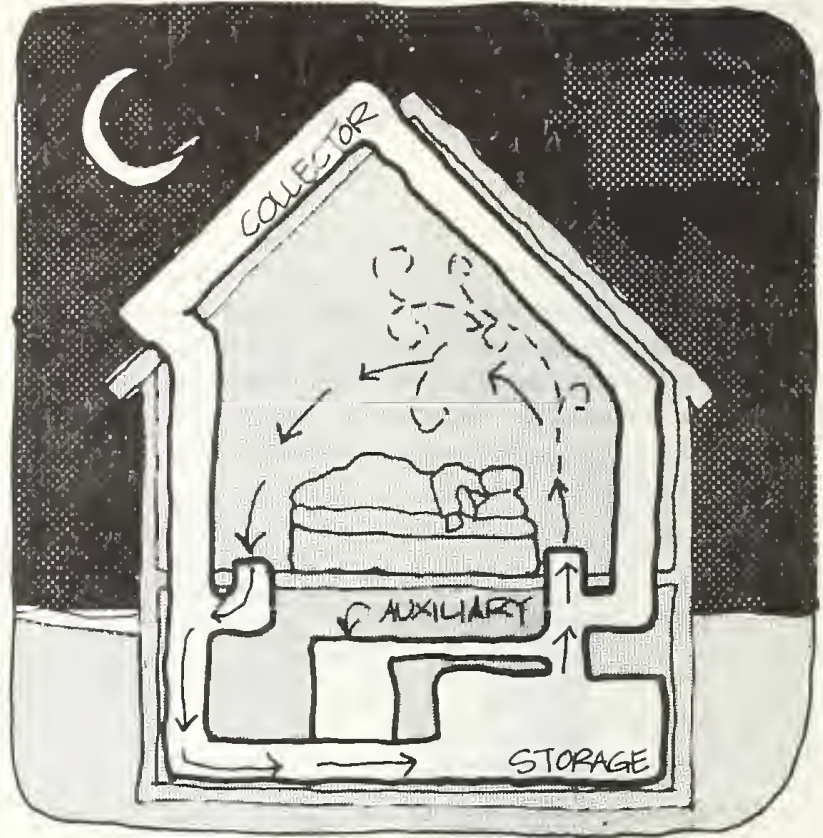

ACTIVE SOLAR SYSTEM

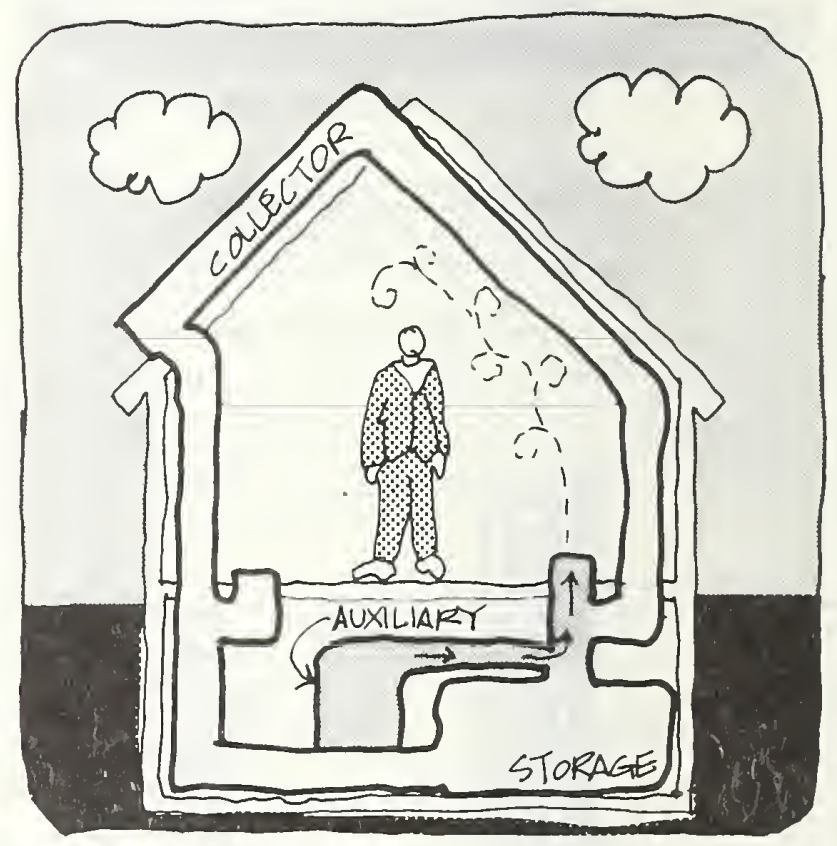


The solar system riay alsw ise designed to preheat water from the incuning water supply prior to passage through a conventional water heater. The domestic hot water preheat system can be com-

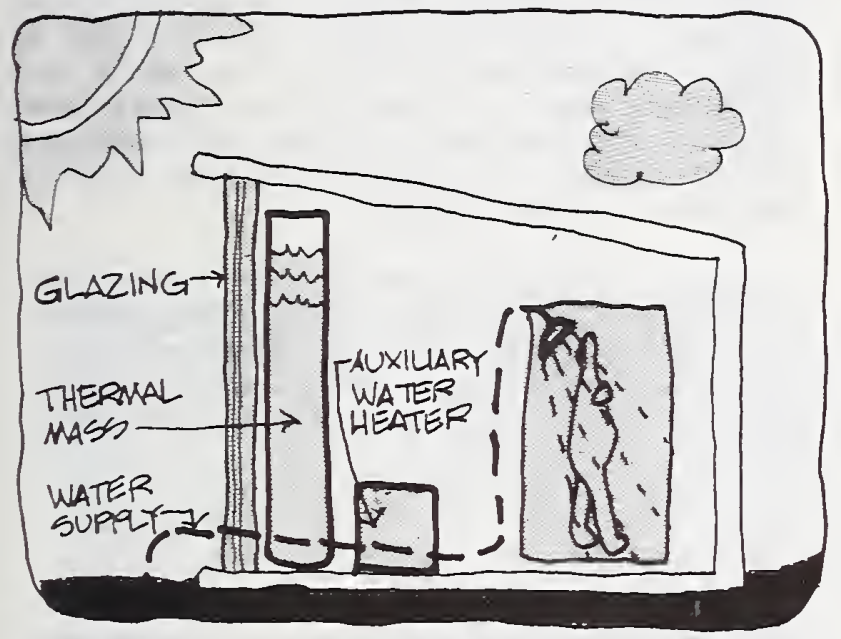

PASSIVE SOLAR SYSTEM

$\begin{array}{lcc}\text { DOMESTIC HOT WATER PREHEATING - } & - \\ \text { COMBINED SYSTEM } & \text { Domestic hot water is }\end{array}$ preheated as it passes through heat storage enroute to the conventional water heater.

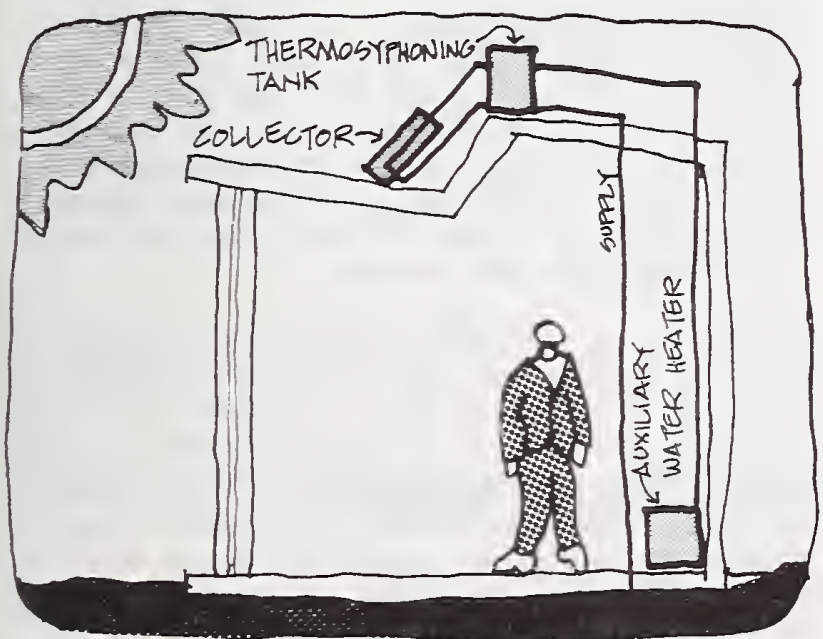

DOMESTIC HOT WATER PREHEATING SEPARATE SYSTEM Domestic hot water preheating may be the only solar system included in some designs. A passive thermosyphoning arrangement is shown above. bined with the solar heating system or designed as a separate system. Both situations are illustrated below.

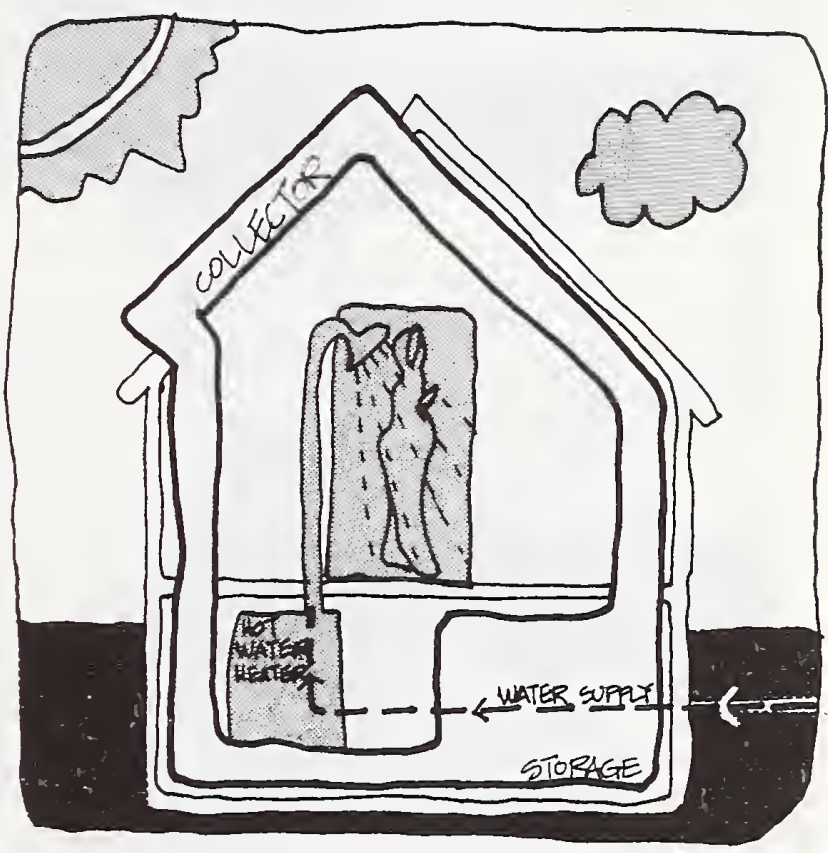

ACTIVE SOLAR SYSTEM 


\section{Solar Heating and Domestic Hot Water Systems: Basics of Solar Energy Utilization}

CLIMATE Sun, wind, temperature, humidity and inany other factors shape the climate of the United States. Basic to using solar energy for heating and domestic hot water is understanding the relationship of sun, climate and dwelling design.

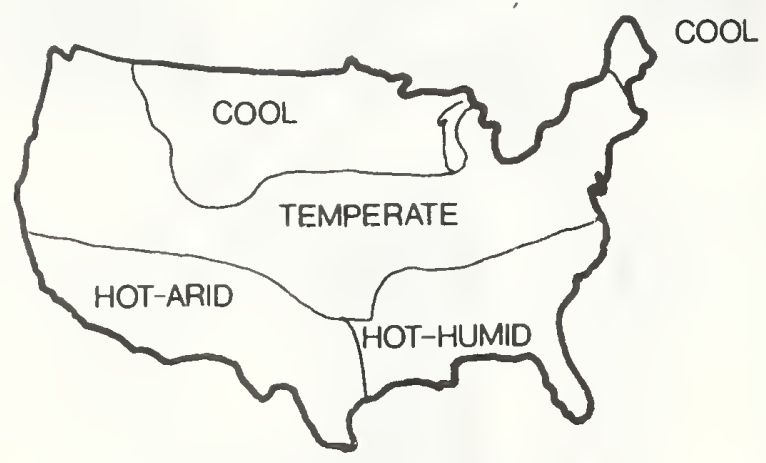

SOLAR RADIATION The sun provides the earth with almost all of its energy in the form of radiation. Solar energy, also known as solar radiation reaches the earth's surface in two ways: by direct (parallel) rays; and by diffuse (nonparallel) sky radiation. The solar radiation reach-
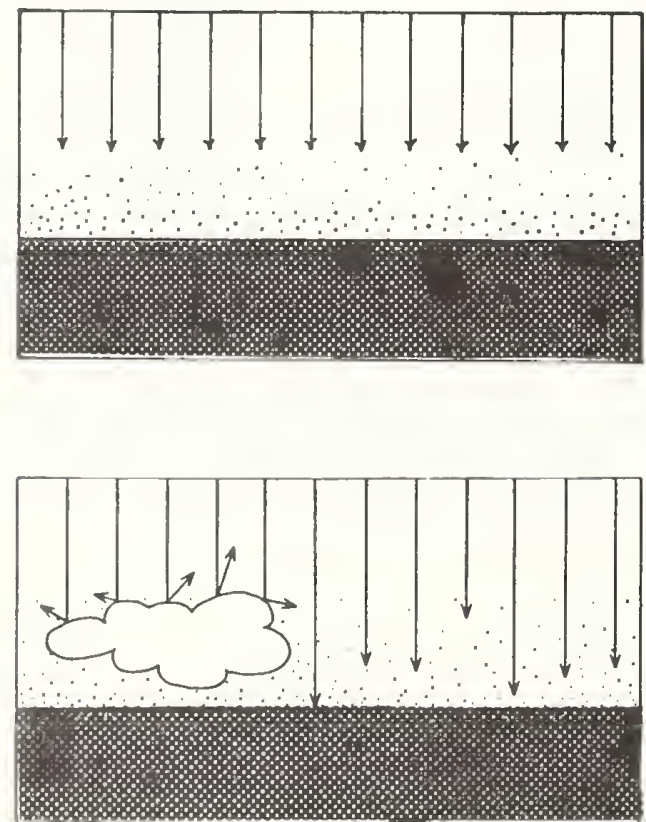

The amount and type of solar radiation varies between and within climatic regions: from hot-dry climates where clear skies enable a large percentage of direct radiation to reach the ground, to temperate and humid climates where up to 40 percent of the total radiation received may be diffuse sky radiation, reflected from clouds and atmospheric dust, to cool climates where snow reflection from the low winter sun may result in a greater amount of incident radiation than in warmer but cloudier climates.

As a result of these differences in the amount and type of radiation reaching a building site, as well as in climate, season and application--heating or domestic hot water--the need for and the design of solar system components will vary in each locale.

ing a building includes not only direct and diffuse but also radiation reflected from adjacent ground and building surfaces. It is these three sources of solar radiation that may be used for space and domestic hot water heating.

THE SOLAR CONSTANT A nearly constant amount of solar energy strikes the outer atmosphere-427 Btu per square foot per hour. This quantity is known as the solar constant. A large amount of this energy is lost in the atmosphere before it can be collected. No collector design can increase the amount of solar energy striking it, by focussing or other means.

ABSORPTION AND REFLECTION Nearly half the solar radiation reaching the earth's outer atmosphere is lost by absorption in the atmosphere and by reflection from clouds as it passes through the atmosphere to the earth's surface. 
AIR MASS More solar radiation is lost by absorption at low sun angles than at high angles because the length of travel through the atmosphere is greatly increased. The relative amount of atmosphere through which solar radiation passes is called the "air mass."

DIFFUSE-RADIATION Clouds and particles in the atmosphere not only reflect and absorb solar energy, but scatter it in all directions. Because of this, solar energy is received from all parts of the sky-more so on hazy days than on clear days. This type of radiation is called diffuse, as opposed to direct radiation. At most, diffuse radiation can only be about one-fourth of the solar constant or about $100 \mathrm{Btu} / \mathrm{hr} . / \mathrm{sq}$. ft.

DIRECT SOLAR RADIATION ON A HORIZONTAL SURFACE Less solar radiation strikes a given horizontal area as the sun gets lower in the sky. The amount changes by the cosine of the angle, measured from the vertical.

DIRECT SOLAR RADIATION ON A TILTED SURFACE The same principle applies to a tilted surface, such as a solar collector. By tilting the collector so that it is nearly perpendicular to the sun, more energy strikes its surface.
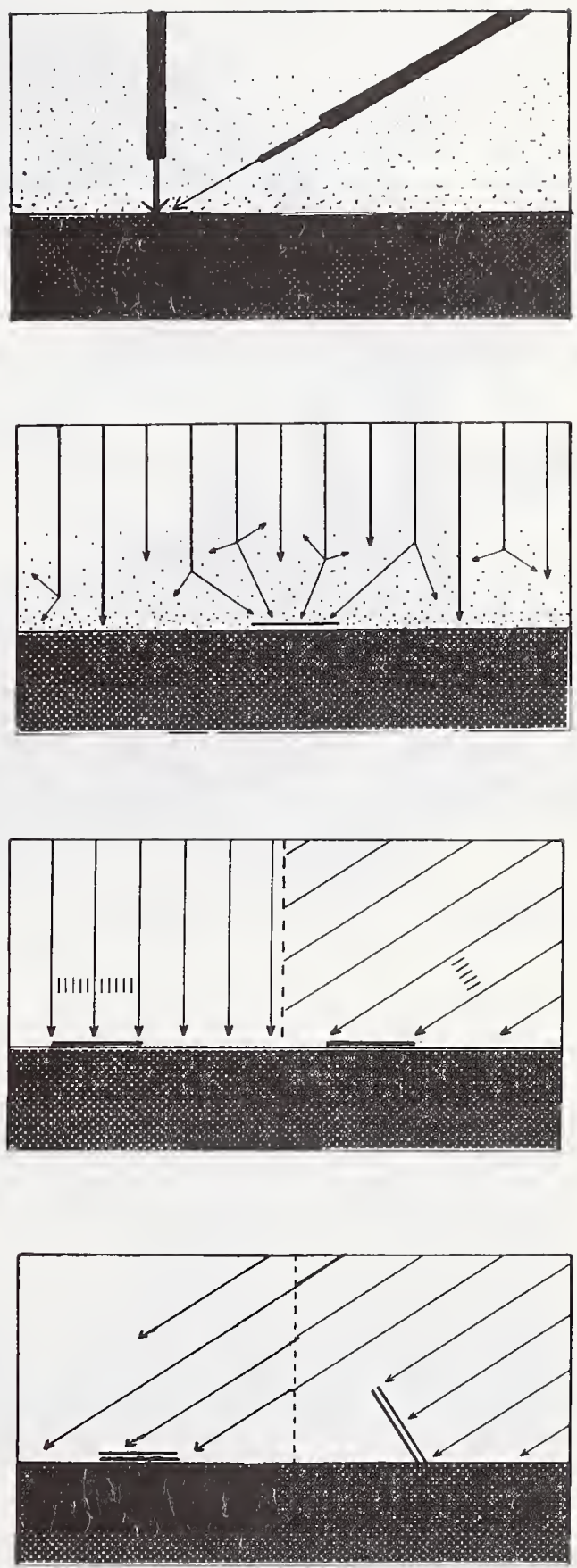


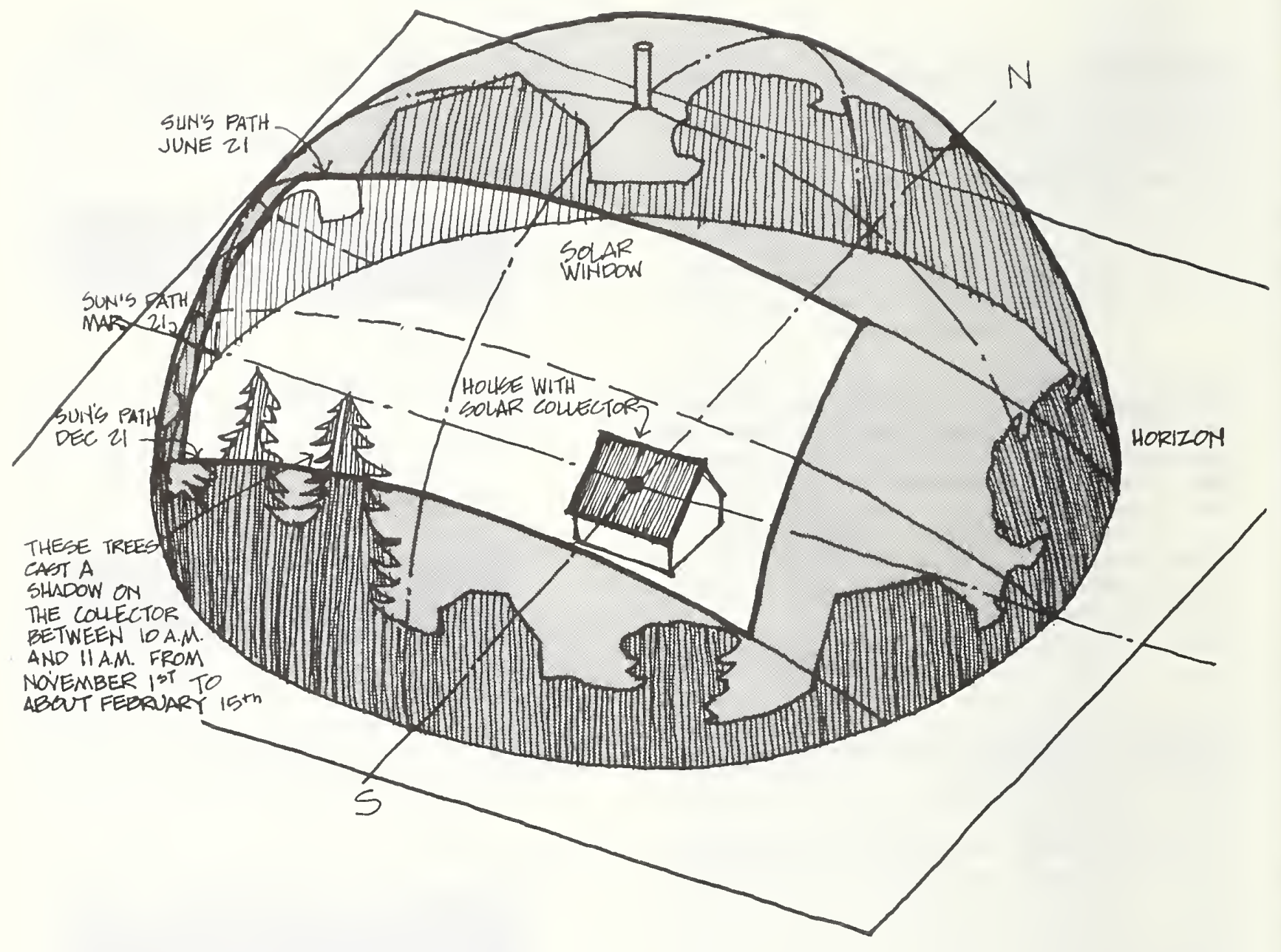

THE SOLAR WINDOW Imagine the sky as a transparent dome with its center at the solar collector or a house. The path of the sun can be painted (projected) onto the dome, as can be the outline of surrounding houses and trees. The morning and afternoon limits of useful solar collection (roughly 9 A.M. and 3 P.M.) and the sun's path between those hours throughout the year scribes a "solar window" on the dome. All of the useful sun that reaches the collector must come through this window. If any of the surrounding houses, trees, etc., intrude into this "solar window," the intrusion will cast a shadow on the collector. The isometric drawing above illustrates the "solar window" for a latitude $40^{\circ} \mathrm{N}$. The solar window will change for different latitudes. 
SIDE VIEW OF SKY DOME WITH "SOLAR WINDOW" A side view of the sky dome from the east illustrates the relative position and angle of the sun throughout the year that defines the boundaries of the "solar window."

PLAN VIEW OF SKY DOME WITH "SOLAR WINDOW" Viewed from above the sky dome, the seasonal path of the sun can be plotted thus defining the boundaries of the "solar window." This is easily accomplished by the use of a standard sun path diagram for the proper latitude. Sun path diagrams are widely reproduced and used for determining the azimuth and altitude of the sun at any time during the year; but can also be used to define the "solar window" and surrounding intrusions.
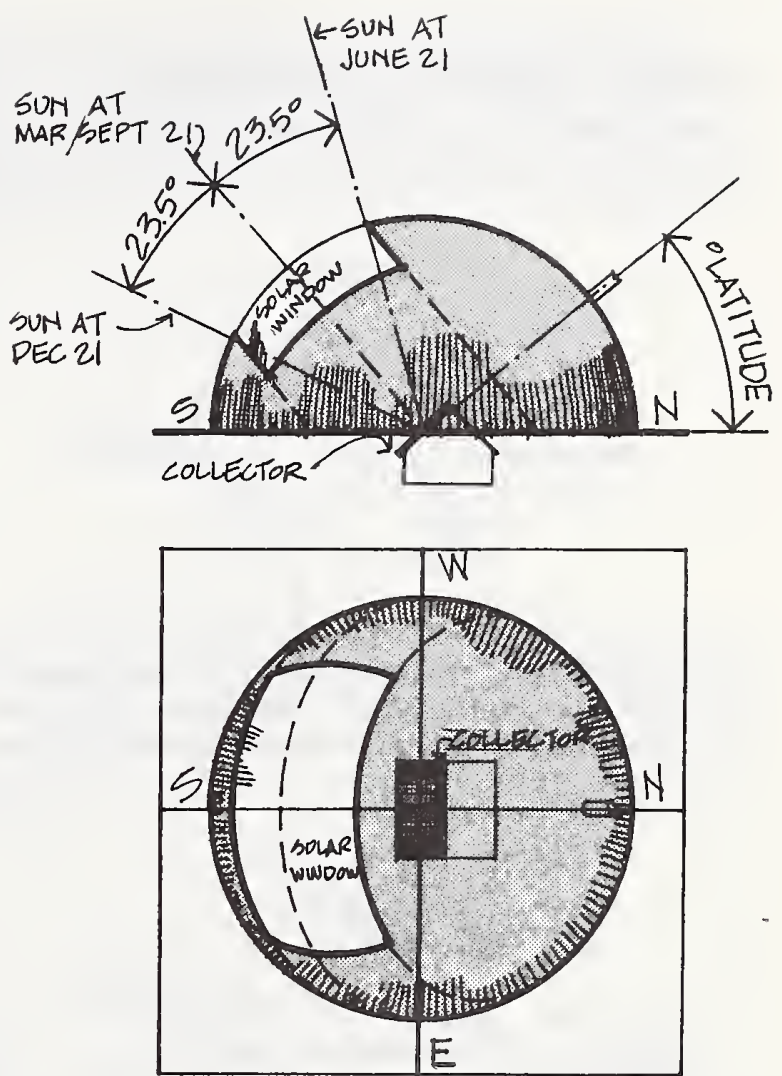

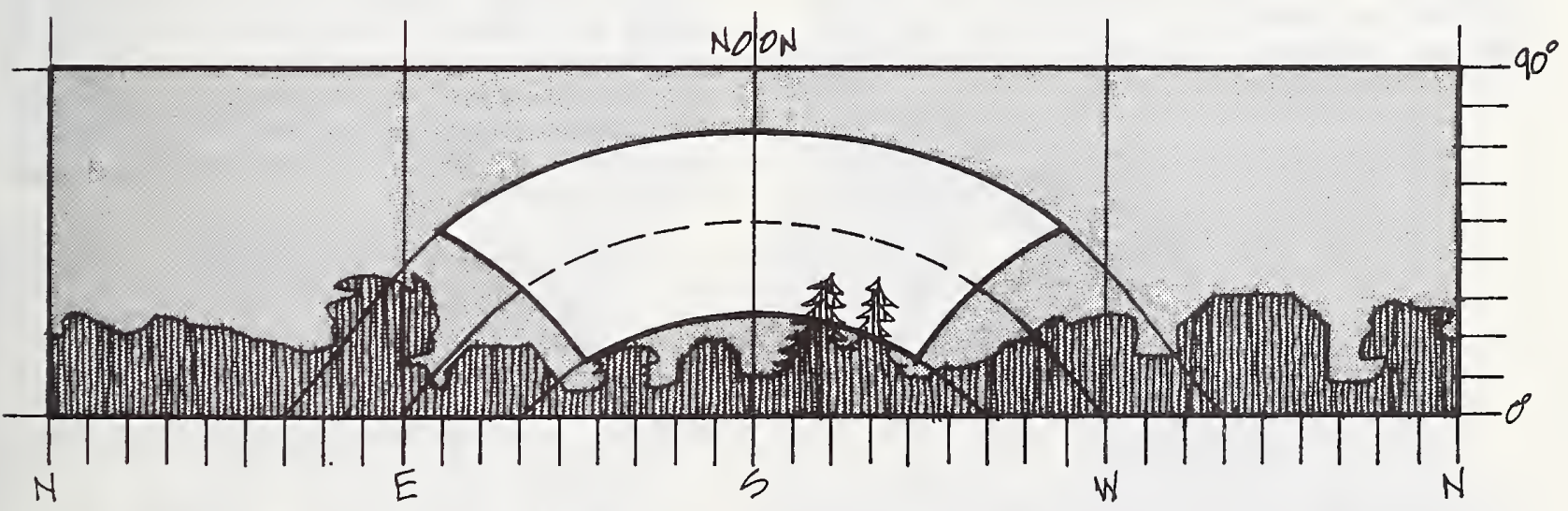

PANORAMA OF THE SKY DOME As with the spherical earth, the spherical sky dome with its "solar window" can be mapped using a mercator projection, in which all latitude and longitude lines are straight lines. Such a map is very useful for comparing the site surroundings with the "solar window" outline, since both can be easily plotted on the map. Any elements surrounding the site that intrude into the "solar window" will cast shadows on the collector. 
COLLECTION ORIENTATION AND TILT Solar collectors must be oriented and tilted within prescribed limits to receive the necessary level of solar radiation for optimum system operation and performance.

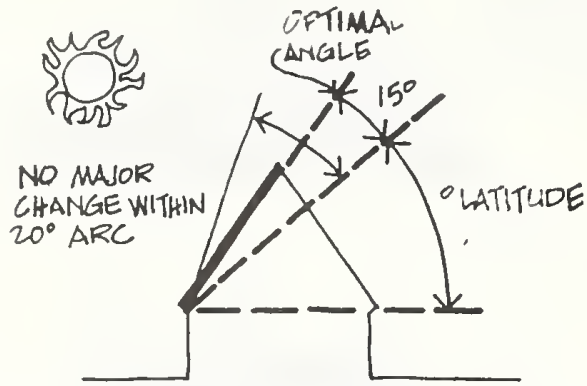

COLLECTOR TILT FOR HEATING The optimal collector tilt for heating is usually equal to the site latitude plus 10 degrees either side of the optimal are acceptable.

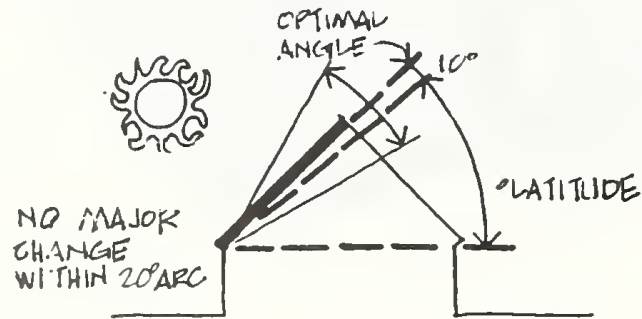

COLLECTOR TILT FOR HEATING AND COOLING The optimal collector tilt for heating and cooling usually is site latitude plus five degrees. Variations 10 degrees either side of the optimal are acceptable.

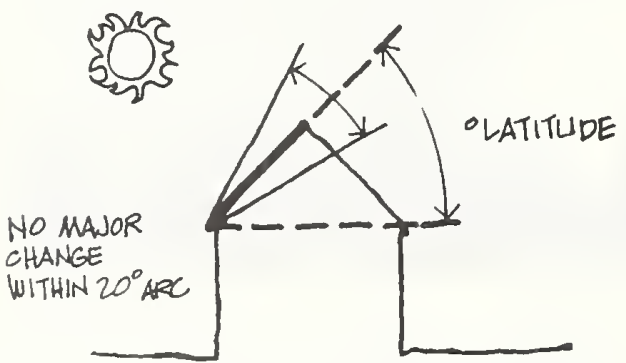

UOLLECTOR TILT FOR DOMESTIC HOT WATER The optimal collector tilt for domestic water heating is usually the site latitude. Variations 10 degrees either side of the optinal are acceptable.

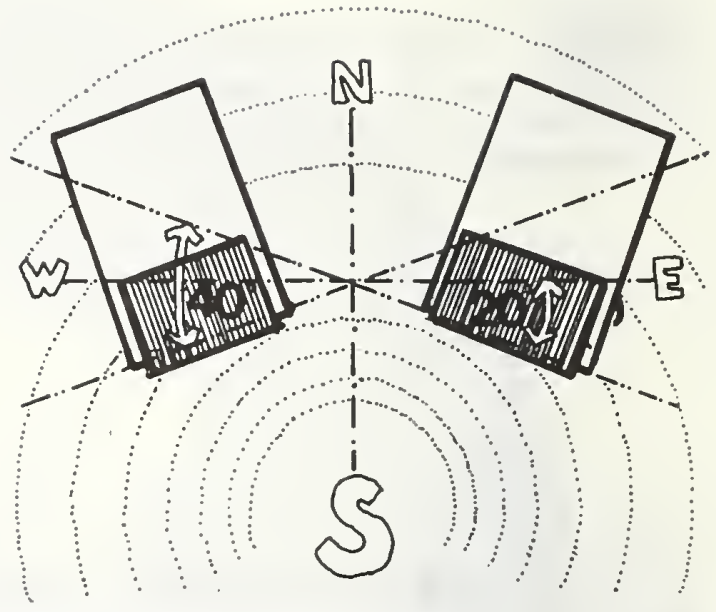

COLLECTOR ORIENTATION

A collector orientation of 20 degrees either side of true south is acceptable. However, an orientation west of true south is considered best in most situations.

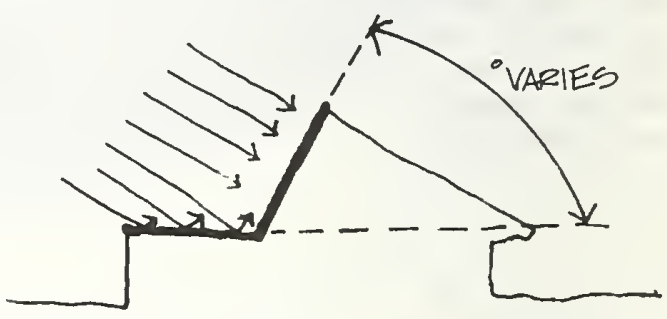

MODIFICATION OF OPTIMAL COLLECTOR TILT A gain in solar radiation may be achieved by tilting the collector away from the optimal to capture radiation reflected from adjacent ground or building surfaces. The corresponding reduction of radiation directly striking the collector due to non-optimal tilt should also be recognized when considering this option.

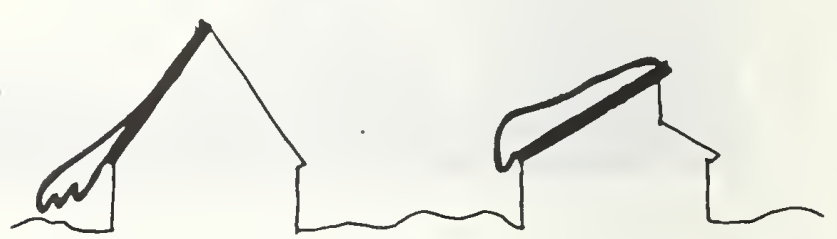

SNOWFALL CONSIDERATION

The snowfall characteristics of an area may influence the appropriateness of an optimal collector tilt. Snow build-up on the collector or drifting infront of the collector should be avoided. 
SHADING OF COLLECTOR BY BUILDING ELEMENTS Another issue related to both collector orientation and tilt is shading. Solar collectors should be located on the building or site so that unwanted shading of the collectors by adjacent buildings, landscaping, building elements, or other collectors does not occur. Collector shading by elements surrounding the site has been addressed by considering the "solar window" concept. Several considerations for avoiding unwanted shading of the collector by building elements or collector arrangements are presented below.

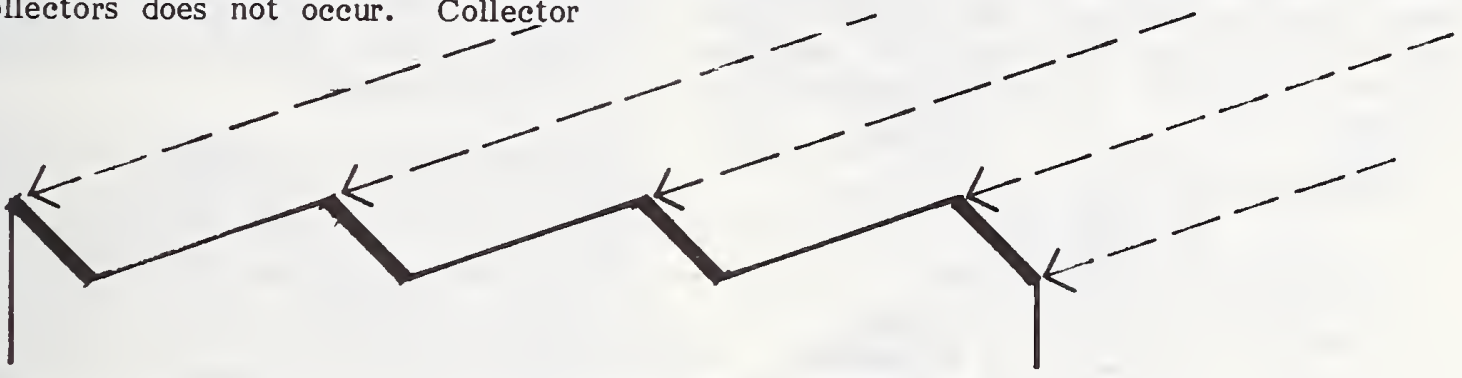

SELF-SHADING OF COLLECTOR Avoiding all self-shading for a bank of parallel collectors during useful collection hours (9 A.M. and 3 P.M.) can result in large spaces between collectors, as shown above. It may be desirable to allow some self-shading in order to optimize collection during peak heating load, which may not occur at the
SHADING OF COLLECTOR BY BUILDING ELEMENTS Chimneys, parapets, fire walls, dormers, and other building elements can cast shadows on adjacent roof-mounted solar collectors. The drawing to the right shows a house with a $45^{\mathrm{C}}$ south-facing collector at latitude $40^{\circ} \mathrm{N}$. By mid-afternoon portions of the collector are shaded by the chimney, dormer, and the offset between the collector on the house and the collector on the garage. A careful attention to the placement of building elements and to floor plan arrangement is required to assure that unwanted collector shading does not occur. lowest sun angie (December 21). This may allow a closer spacing of collectors, as shown below, thus increasing solar collection area. Also, by making the collector's back slope reflective can increase the amount of solar radiation striking the adjacent collector.
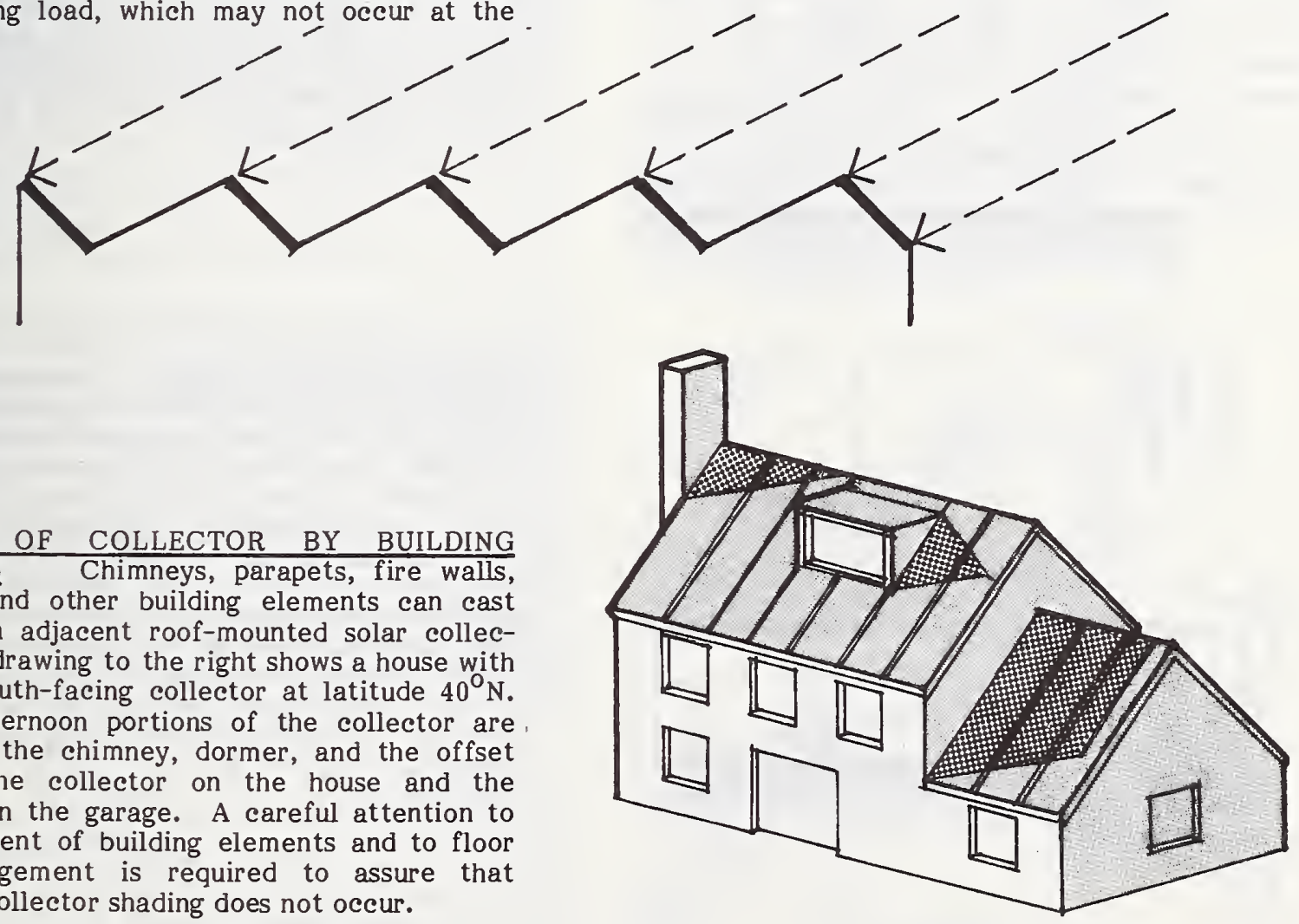
THE GREENHOUSE EFFECT Basic to the utilization of solar energy for space and domestic hot water heating is understanding the process by which solar radiation is converted to thermal energy. This conversion process is the basic link between the energy source--the sun--and the energy load-the dwelling. The process is best understood by briefly explaining solar radiation and then discussing the characteristics of a greenhouse.

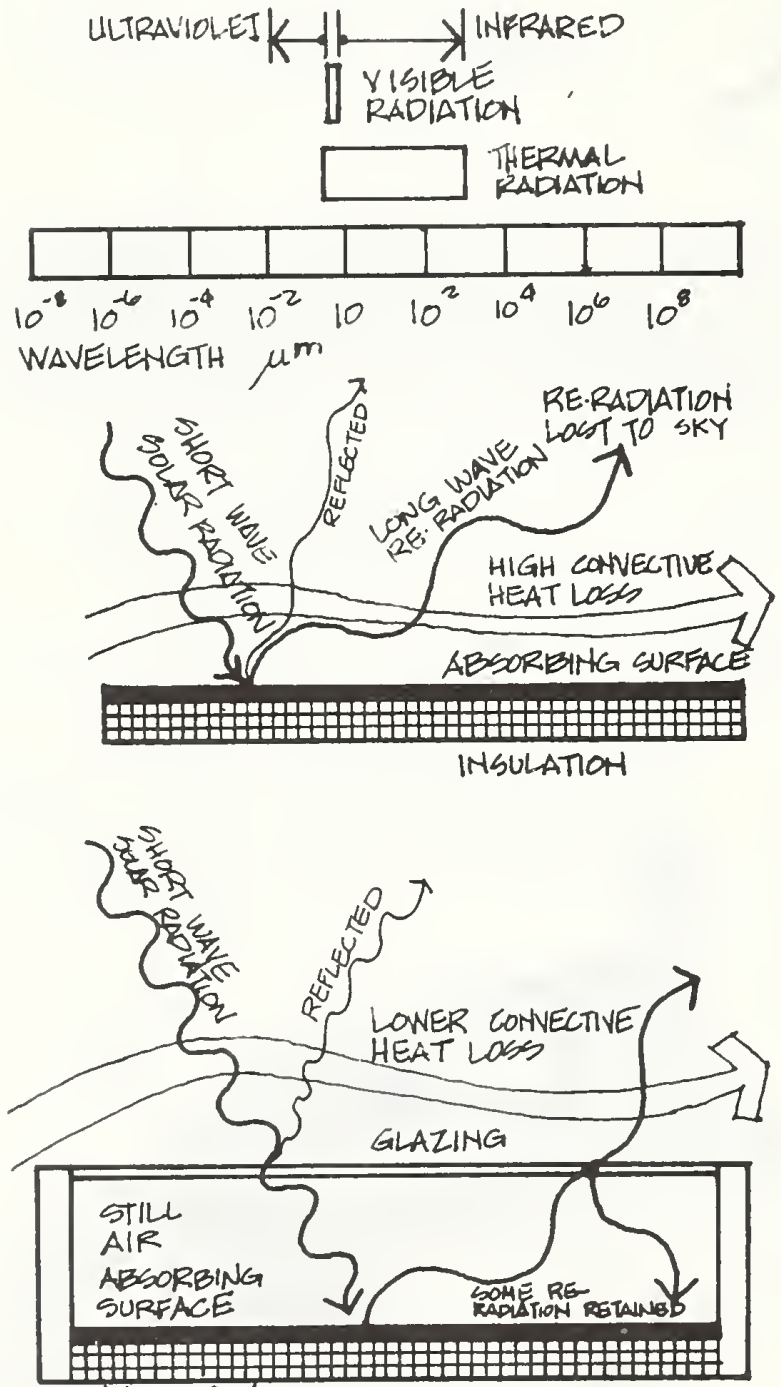

InSULATION
SOLAR RADIATION Solar radiation is electromagnetic radiation generated by the sun, which reaches the earth's surface with a wavelength distribution of .3 to $2.4 \mathrm{micrometers}$. Radiation is perceived as visible light between ultraviolet and infrared, specifically between .36 and .76 micrometers. For most solar applications, solar radiation in the visible and near-infrared range is the most important.

The drawings to the left show the principle of solar energy collection and conversion. When incoming solar radiation impinges on the surface of a body, it is partially absorbed, partially reflected, and, if the body is transparent, partially transmitted. The relative magnitude of each varies with the surface characteristics, body geometry, material composition, and wavelength.

For solar applications, energy must be absorbed, converted into useful thermal energy and removed by a heat transfer mechanism to be useful. Absorbed radiation heats up the absorbing body, which re-emits energy in the form of thermal radiation in the infrared part of the spectrum. If the absorbing surface is exposed to the atmosphere, part of the absorbed energy will be lost by convection or radiation.
THE GREENHOUSE EFFECT Many glasses and some plastics are transparent in the solar wavelength region and hence are used as windows. At the same time, these materials usually have low transmission values in the infrared region. By placing glass or plastic over the absorbing surface, energy is trapped in two ways. First, infrared radiation re-emitted by the absorbing surface is absorbed by the glazing, with a portion re-emitted again back toward the absorber and thereby trapped. Second, the glazing traps a layer of still air next to the absorber and reduces the convective heat loss. This behavior of glazing is called the "greenhouse effect" and is used in most solar collectors. 


\section{Solar Heating and Domestic Hot Water Systems: Active Systems}

Active solar systems are characterized by the use of energy-in addition to solar-for the transfer of thermal energy throughout the system. A variety of active concepts that have been constructed or proposed. The following discussion of active solar systems serves as an introduction to a range of active concepts.

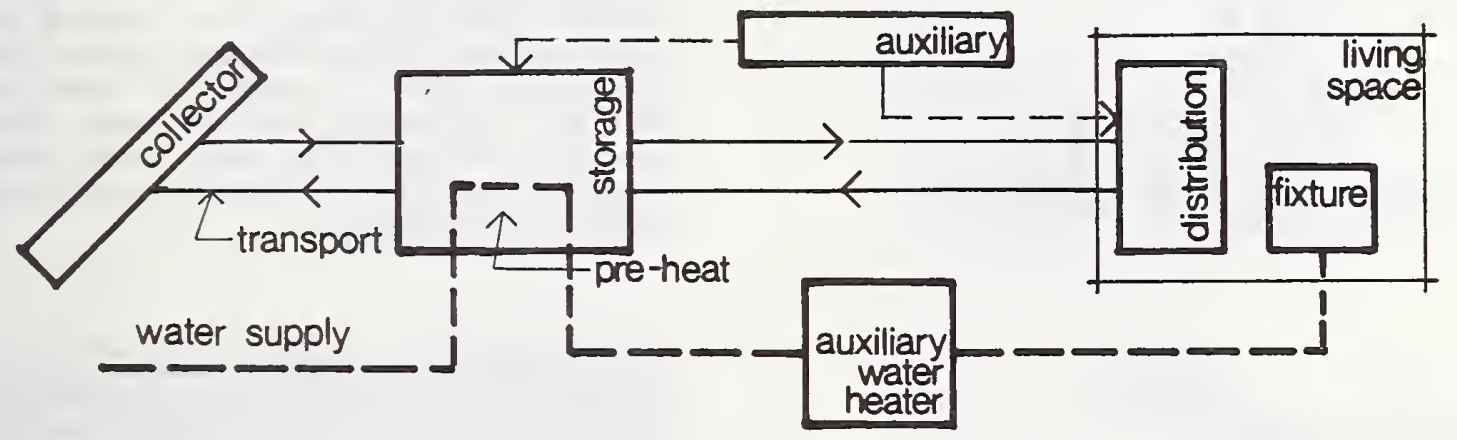

SOLAR HEATING AND DOMESTIC HOT WATER SYSTEMS: PROCESS DIAGRAM The most common solar system in use today is a combined solar heating and domestic hot water system. The system operates as follows. Solar radiation is absorbed by a collector and removed by a heat transfer (transport) medium to storage. Heat is removed from storage and distributed to the living spaces by a heat transfer medium (may or may not be same medium flowing through the collector). Circulation throughout the system is by pumps,

SOLAR HEATING SYSTEM: PROCESS DIAGRAM A solar heating only system can be developed by simply removing domestic hot water preheating from the combined system diagram. The operation of the solar heating system is the same as described above.

\section{SOLAR DOMESTIC HOT WATER SYSTEM;} PROCESS DIAGRAM The combined system diagram can be modified into a domestic hot water only system by eliminating the heating distribution and auxiliary component. The domestic water supply would pass through heat storage enroute to the conventional water heater thus preheating the hot water supply.

\section{SOLAR DOMESTIC HOT WATER SYSTEM:} PROCESS DIAGRAM Another method of preheating domestic hot water is by passing the potable water supply through the collectors. The heated water is placed in storage until a demand is initiated. The preheated water is then pumped from storage or flows by supply pressure to a conventional water heater. blowers, or other heat transfer medium moving devices. An auxiliary energy system is available both to supplement the output supplied by the solar system and to provide for the total energy demand should the solar system become inoperable. Manual or automatic controls maintain and monitor the system operation. Domestic hot water is preheated by passing the water supply through heat storage prior to passage through a conventional water heater.
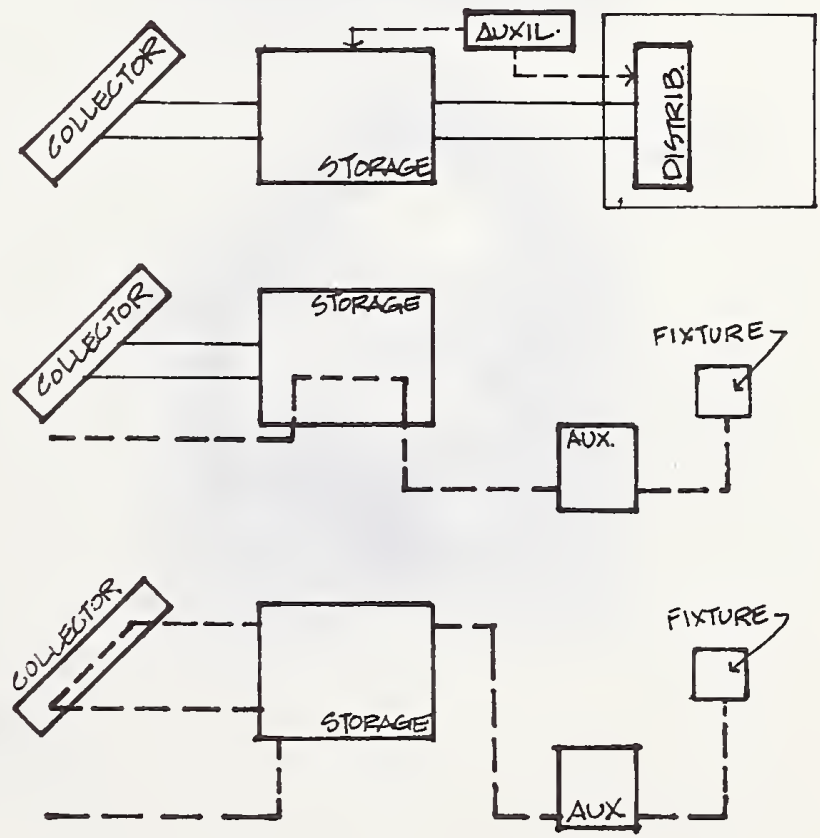
COLLECTOR - STORAGE DIAGRAMS

The removal of heat from the collector and its placement in storage involves a heat transfer medium
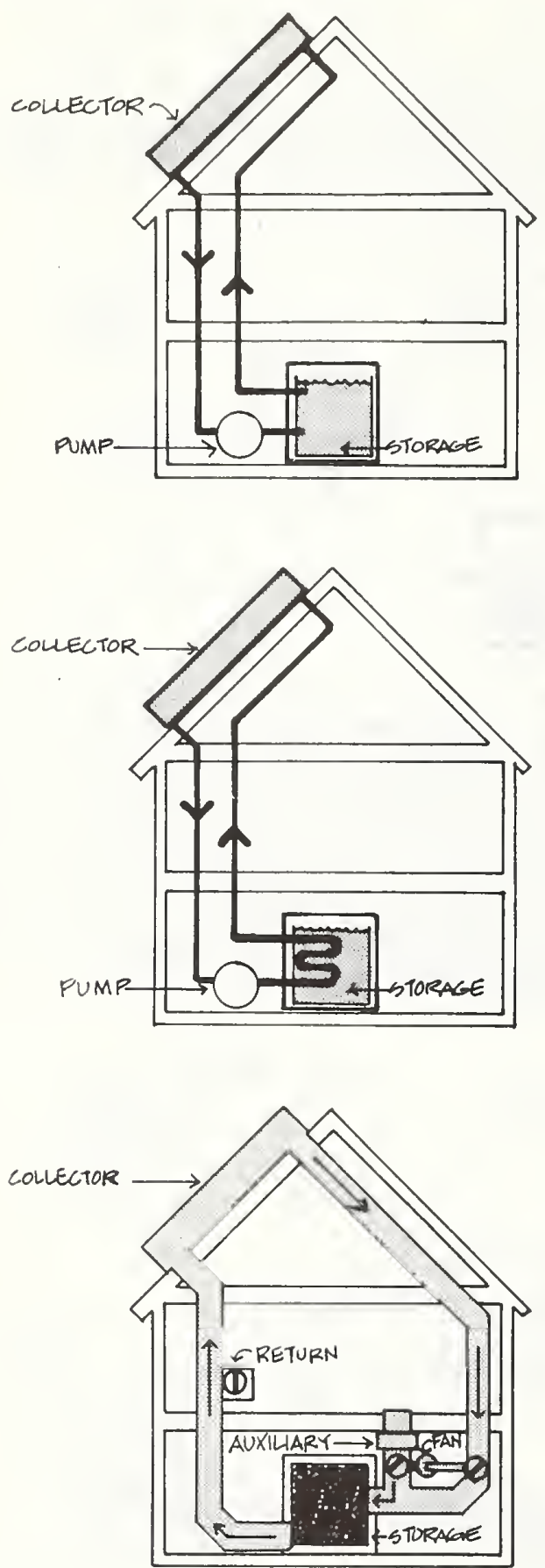

circulating in a transport loop. Several collectorstorage conditions are shown below.

OPEN CIRCUIT LIQUID COLLECTOR Storage water, treated as necessary to pervent corrosion, is drawn from the bottom of storage and, pumped through the collector and then returned to the top of storage. The circulating water, that can run through, on top or under the absorber plate, is distributed to the absorber by a manifold at the top of the collector; or it can be pumped up from below through tubes attached to or integral with the absorber plate. When the system is not running, air or an inert gas is allowed to enter into the collector and piping, and the water drains into storage. - Storage is at atmospheric pressure, a condition that should be considered in the design of the distribution system.

CLOSED CIRCUI'T LIQUID COLLECTOR A heat transfer liquid- - treated water, anti-freeze solution or other liquid-is pumped through the collector and then through a heat exchange in storage and back to the collector, in a closed loop. The loop is always filled with fluid, and therefore must be protected from freezing.

AIR COLLECTOR Although many arrangements of air collector-rock storage- warm-air distribution systems are possible, the one diagrammed is typical of the most popular systems in use. Air from the cold end of the rock storage bin is pumped through the collector and returned to the hot end of storage. The process is modified when air is circulating through the collectors and the house requires heat. In this case, the dampers must be adjusted to supply heat directly to the house. 
STORAGE - DISTRIBU'TION DIAGRAMS Heat is removed from storage and circulated to the house by the distribution component. There are

WARM-AIR DIS'TRIBUTION - HOT WATER COIL IN DUCT A warm-air disturibution system can be used with liquid storage by pumping the storage medium through a suitably sized heat exchange coil in the main supply duct of the distribution system. numerous ways this can be performed. Six

HYDRONIC DISTRIBUTION Liquid from storage is pumped directly through standard baseboard convector units, despite the relatively low temperatures that usually occur in solar systems during winter conditions. The size of baseboard units, and possibly the circuiting may change from ordinary hydronic systems.

INDIVIDUAL FAN-COIL UNIT DISTRIBUTION Liquid from storage is pumped to individual fancoil units located throughout the dwelling from distribution. The design and sizing considerations are similar to those for hydronic distribution.
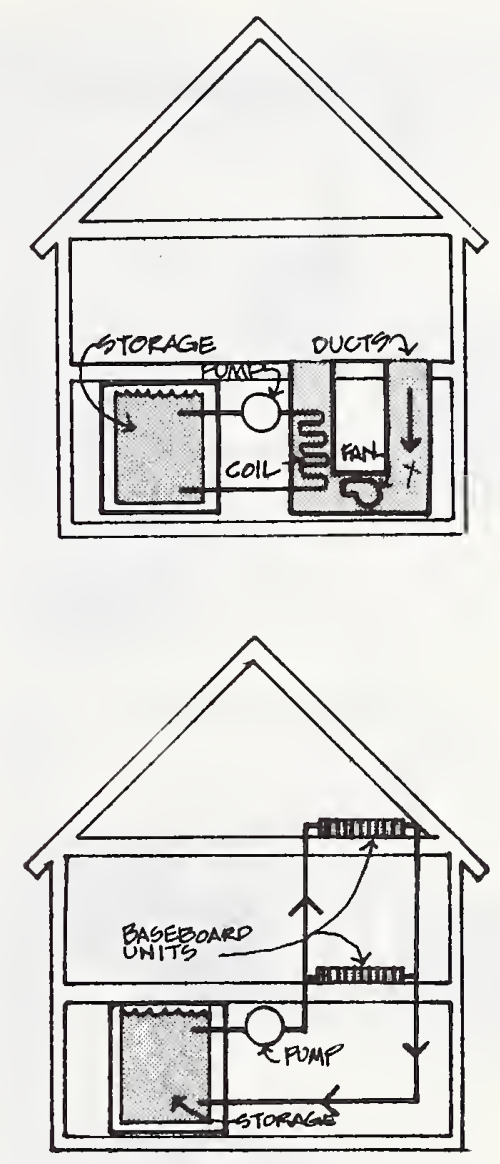

\section{methods are diagrammed below.}

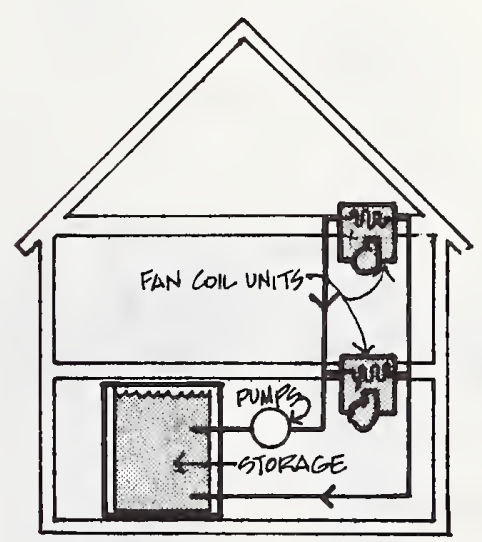



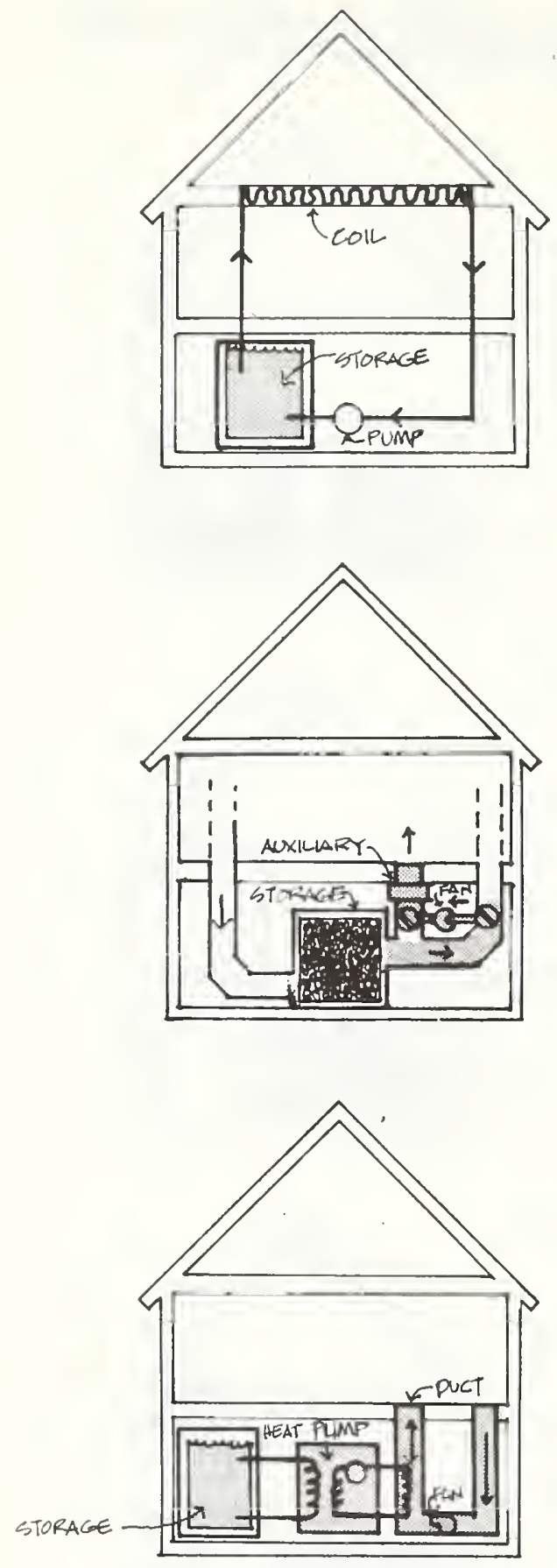

RADIANT COIL DISTRIBUTION Liquid from storage is circulated through coils located in the floor, walls and/or ceiling of the living space. Besides the water temperature the size and spacing of the coils is critical for effective radiant heat distribution.

WARM-AIR DISTRIBUTION FROM ROCK STORAGE For an air collector system employing rock storage, it is advantageous to distribute air to the living space from the hottest section of storage. As diagrammed, this will require reversing the flow of air through storage relative to the collection cycle. This can be done in several ways, the most common is diagrammed, using the same fan that supplies the collector along with two automatic dampers to control the direction of air flow.

WARM-AIR DISTRIBUTION - HEAT PUMP Either air or liquid can be used as the source of thermal energy for a heat pump distribution system. As diagrammed, liquid from storage is circulated through a heat exchanger in the heat pump unit. Where heat is transferred to the heat pump working fluid the compression cycle of the heat pump elevates the working fluid temperature and this high temperature heat is transferred to air through a heat exchanger to heat the space. 
PREHEAT COIL IN STORAGE A suitably sized coil passed through storage enroute to the conventional water heater. Unless the preheat coil has double-wall construction, this method can only be used for solar systems employing non-toxic storage media.
DOMESTIC HOT WATER PREHEATING Domestic hot water can be preheated either by circulating the potable water supply through the collectors or by passing the supply line through storage. Three storage related preheat systems are shown below.

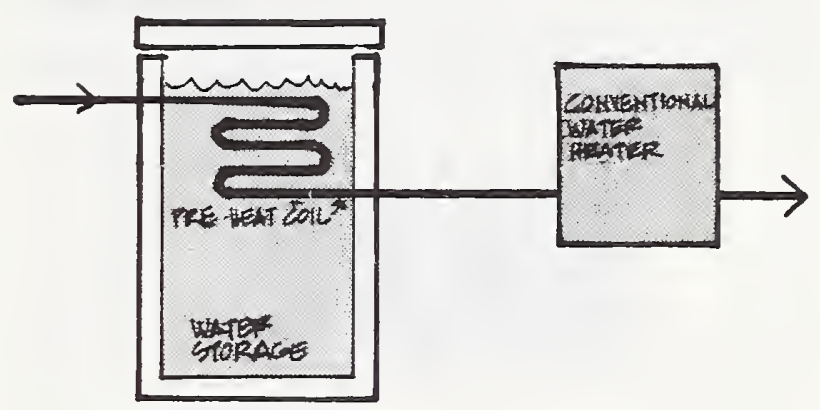

PREHEAT TANK IN STORAGE The domestic hot water storage tank is located within the space heating storage tank. The water supply passes through storage to the preheat tank where it is heated, stored, and piped to a conventional or tankless water heater prior to distribution. Double wall construction again will be necessary unless a non toxic storage media is used.

PREHEAT COIL OR TANK OUTSIDE OF STORAGE Liquid from storage is pumped to a heat exchanger-coil or tank-for domestic hot water preheating. If liquid from storage is toxic, the required separation is achieved by two separate heat exchange coils within a preheat tank or, as diagrammed, by the use of a double. wall exchanger.
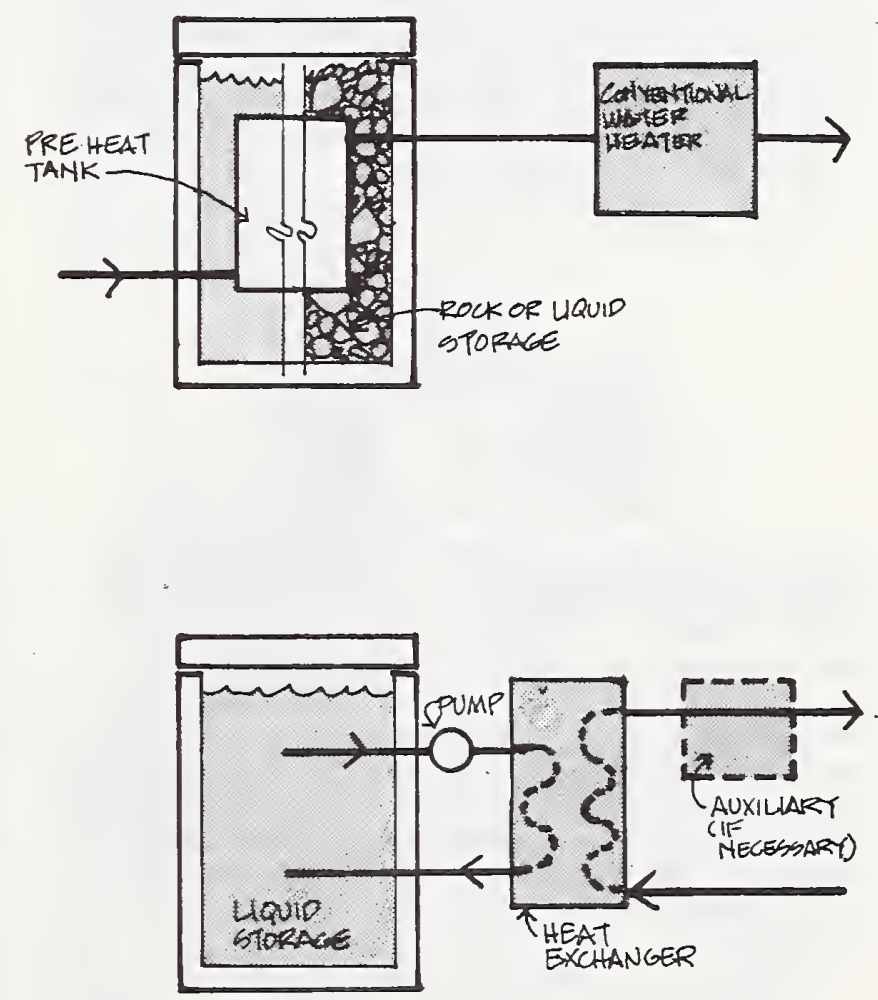
STORAGE - DISTRIBUTION - AUXILIARY ENERGY DIAGRAMS The provision of auxiliary energy to the dwelling, should the solar heating system not meet the dwelling's total energy demand or become inoperable, can be accomplished in numerous ways in combination with storage ano distribution. The auxiliary energy component may

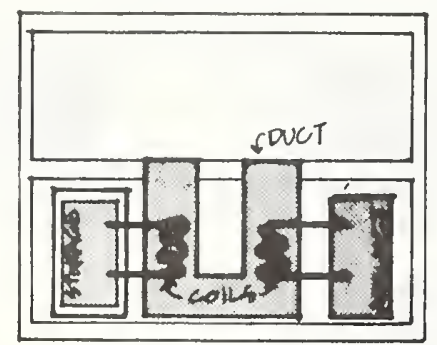

\section{AUXILIARY HEAT COILS IN AIR DISTRIBUTION} SUPPLY DUCT Two heat exchange coils--one from solar storage and one from the auxiliary unit-are located in the primary distribution supply duct. Depending on the temperature in storage, the auxiliary energy system may provide a full or partial boost to the supply air. The need for auxiliary energy is determined by the control component that maintains and monitors both the solar system and auxiliary system.

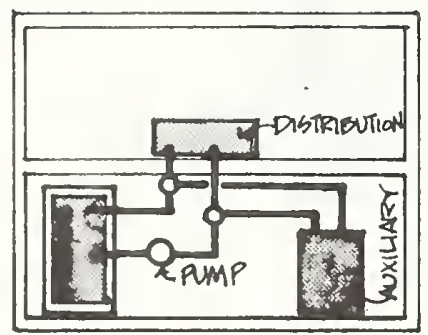

AUXILIARY HEATING STORAGE TRANSPORT LOOP TO DISTRIBUTION The auxiliary energy system is located between the storage and distribution component to permit a full or partial operation. The auxiliary system uses the same distribution network as the solar system. Valves at the connection between systems regulates auxiliary energy supply and prevents auxiliary from heating storage. Solar and auxiliary system operation is maintained and monitored by an integrated control component. operate independent of or in conjunction with the solar system. The control of solar and auxiliary system operation becomes an important consideration for the effective utilization of both. Four possible combinations are shown below.

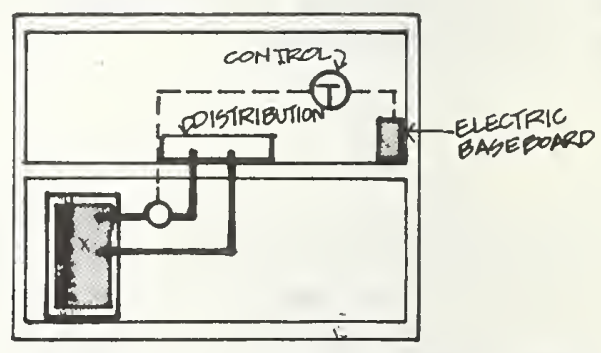

AUXILIARY WITH SEPARATE DISTRIBUTION The auxiliary energy system may be a totally seperate component not integrated with solar storage or distribution. This may involve a totally separate distribution network or, as diagrammed, individual electric baseboard units placed in the dwelling in locations and numbers as required. The two separate heating systems, however, are linked by the control component that regulates the systems operation.

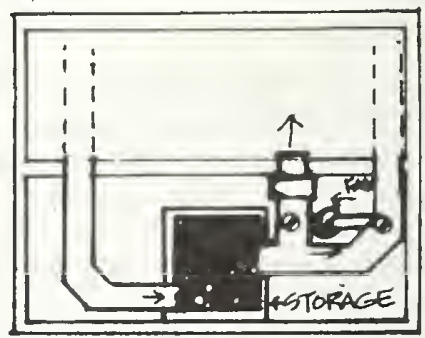

AUXILIARY WITH AIR COLLECTOR The auxiliary is located between the storage and the distribution compenent. The auxiliary stystem may be operated in two modes: 1) in conjunction with house heating, from the collector and 2) in conjunction with house heating from storage. In the first mode, the house is being heated directly from the collector. The auxiliary may provide an energy boost as the air from the collector circulates through the in-line auxiliary compenent. In the second mode, the house is being heated from stroage. Again, as the air circulates from storage through the auxiliary an energy boost may be supplied. The auxiliary and solar syste $m$ operation is maintained and monitored by an integrated control component. 


\section{Solar Heating and Domestic Hot Water Systems: Passive Systems}

Passive solar systems are characterized by the use of solar energy alone for the transfer of thermal energy throughout the system. Four passive systems are discussed below-three space heating

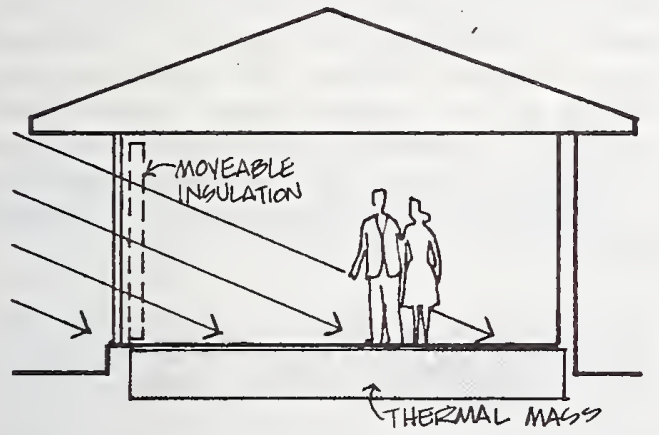

SOUTH-FACING TRANSPARENT BUILDING SURFACES This concept relies on the southern exposure of large transparent building surfaces to increase heat gain directly into the building--thus heating the space. To avoid overheating and space collecting energy, an adequate quantity and coverage of thermal mass such as masonry surfaces on the floor or walls should be used to absorb heat during the day and radiate it to the space after passage of the sun. Insulating devices should be available to minimize nighttime heat loss and to regulate daytime solar exposure.

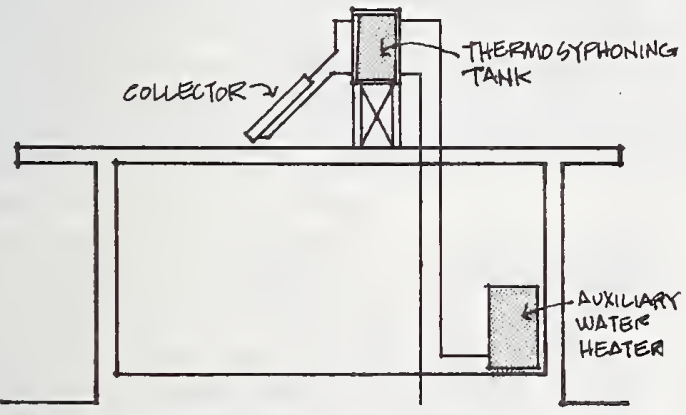

THERMOSYPHONING DOMESTIC HOT WATER PREHEATING This passive concept utilizes the natural rise of heated fluids for the collection and storage of domestic hot water. Domestic cold water supply is fed to the bottom of the storage tank that is located above the solar collector. Exposure of the collector to solar radiation causes the cold water to circulate by convection-through the collector--from bottom to top--and back into storage. The heated water is stored in the tank until a demand is initiated; then water is drawn of $f$ the top and fed by gravity to the dwelling or a conventional water heater. and one domestic hot water preheating system. There are innumerable other concepts, but the following will serve as an introduction to passive solar systems.

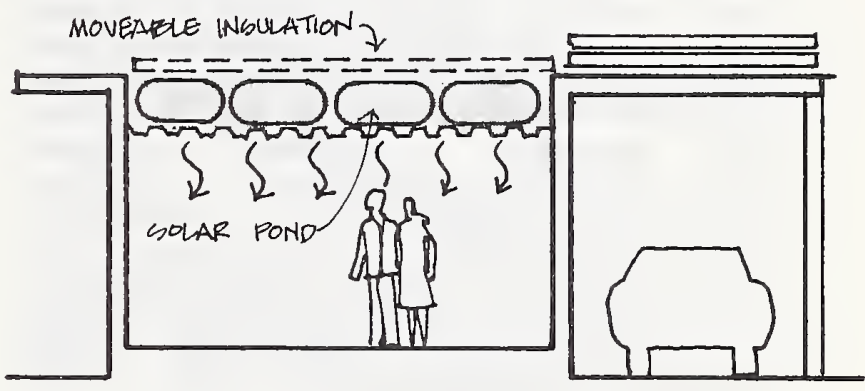

SOLAR POND This concept is similar to the previous passive system except that the thermal mass--water--is now located in a roof pond above the living space. In some climates, both heating and cooling can be provided by the system. Like the previous concept, proper control must be maintained over the heat exchange process. This can be accomplished by the use of movable insulating panels to expose or cover the pond, by filling and draining the pond according to the heating or cooling demand or by covering the pond with a transparent roof structure.

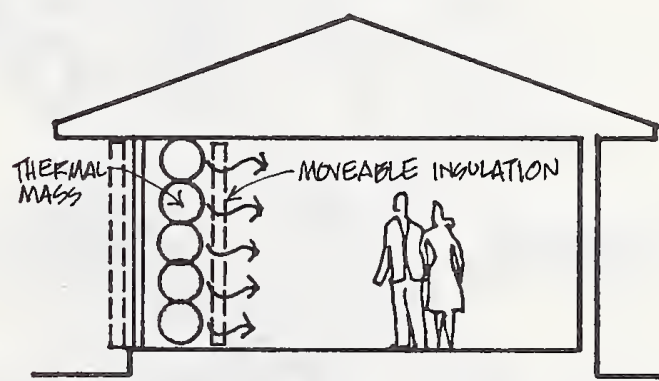

COMBINED WALL COLLECTOR-STORAGEDISTRIBUTION This passive concept relies on the exposure of a south-facing thermal mass (containerized water, masonry or concrete), located behind a transparent surface and separated from the surface by an air space, to solar radiation. The thermal mass acts as the collector, storage and distribution component. Solar radiation collected and stored in the thermal mass is distributed to the space by convection, conduction, and radiation. When collection ceases, it is advantageous to prevent heat loss through the transparent surface by an insulating device. 


\section{Solar Heating and Domestic Hot Water Systems: Component Descriptions}

A solar heating and domestic hot water system is composed of numerous individual parts and pieces including collectors, storage, a distribution network, ducts and/or pipes pumps and/or blowers, valves and/or dampers, fixed or movable insulation, a system of manual or automatic controls, gaskets, hoses and with some systems one or more heat exchangers, an expansion tank, and filters. These parts are assembled in a variety of combinations depending on function, component compatibility, climatic conditions, required performance, site characteristic and architectural requirements to form a solar heating and/or domestic hot water system. Those components that are unique to a solar system or that are used in an unconventional manner are briefly illustrated and discussed below.

\section{FLAT-PLATE COLLECTOR: AN EXPLODED} VIEW The flat-plate collector is the most common solar collection device for space heating and domestic water heating in use today. The collector may be designed to use either gas (generally air) or liquid (usually treated water) as the heat transfer medium. Regardless of the medium used, most flat plate collectors consist of the same general components as illustrated below.

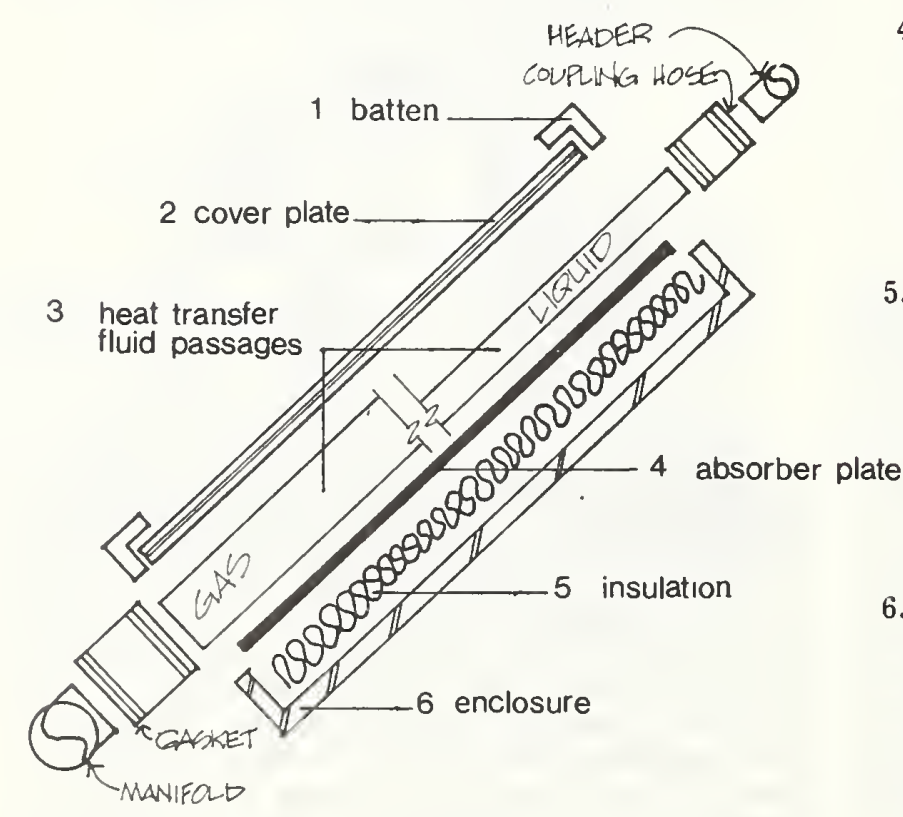

1. BATTEN Battens serve to hold down the cover plate(s) and provide a weather tight seal between the enclosure and the cover.

2. COVER PLATE The cover usually consists of one or more layers of glass or plastic film or sheet or combinations thereof. The cover plate is separated from the absorber plate to create an air space which traps heat by reducing re-radiation and convective losses. The space between the cover and absorber can be evacuated to further reduce convective losses.

3. HEAT TRANSFER MEDIUM PASSAGE Tubes or fins are attached to the absorber plate to facilitate transfer of thermal energy from the absorber plate to the heat transfer medium. The largest variation in flat-plate collector design occurs with this component. Tube on plate, integral tube and sheet, open channel flow, corrugated sheets, deformed sheets, extruded sheets and finned tubes are some of the techniques used for liquid collectors. Air collectors employ such configurations as gauze or screens, overlapping plates, corrugated sheets, and finned plates. The heat transfer passage must be affixed to the absorber plate so that a good thermal bond is assured.

4. ABSORBER PLATE The absorber plate is usually metallic and may contain integral heat transfer media passages. The surface is normally treated with a surface coating which improves absorptivity. Black or dark paints or selective coatings are used for this purpose.

5. INSULATION Insulation is employed to reduce heat loss through the back of the collector. The insulation must be suitable for the high temperature that may occur under normal operation; no flow and dry plate conditions. Thermal decomposition and outgassing of the insulating may significantly affect collector performance.

6. ENCLOSURE The enclosure is a container for all the above components. The assembly is usually weatherproof. Preventing dust, wind and water from coming in contact with the cover plate and insulation is essential to maintaining collector performance. 
CLOSED FLAT-PLATE LIQUID COLLECTOR Most flat-plate collectors in use today employ water, oil or an antifreeze solution as the heat transfer medium. The liquid circulates through passage ways attached to or integral with the absorber plate where it is heated before being pumped to storage or to the load. Freeze protection and prevention of corrosion and leaks require special consideration in transfer media, material and control selection.

OPEN FLAT-PLATE LIQUID COLLECTOR This type of collector uses corrugated metal panels or integral passage panels covered with a transparent cover plate for the circulation of the heat transfer medium. In the first instance, the transfer medium circulates--"trickles"-down the corrugated channels from a manifold at the top to a trough or gutter at the bottom of the collector. The heated water then flows by gravity to the storage tank. In the second case, the transfer medium is pumped from a manifold at the bottom through the collector where it is returned by gravity to storage. When collection is not occurring the transfer medium drains back into storage.

FLAT-PLATE AIR COLLECTOR Air collectors circulate air or other gases through or near the absorber plate to ducts that return the heated air to storage or the living space. Compared with liquid collectors, leakage, maintenance, and freeze protection problems are minimal. However, air collectors do require relatively large ducts for the heat transfer medium and more energy for medium transport.

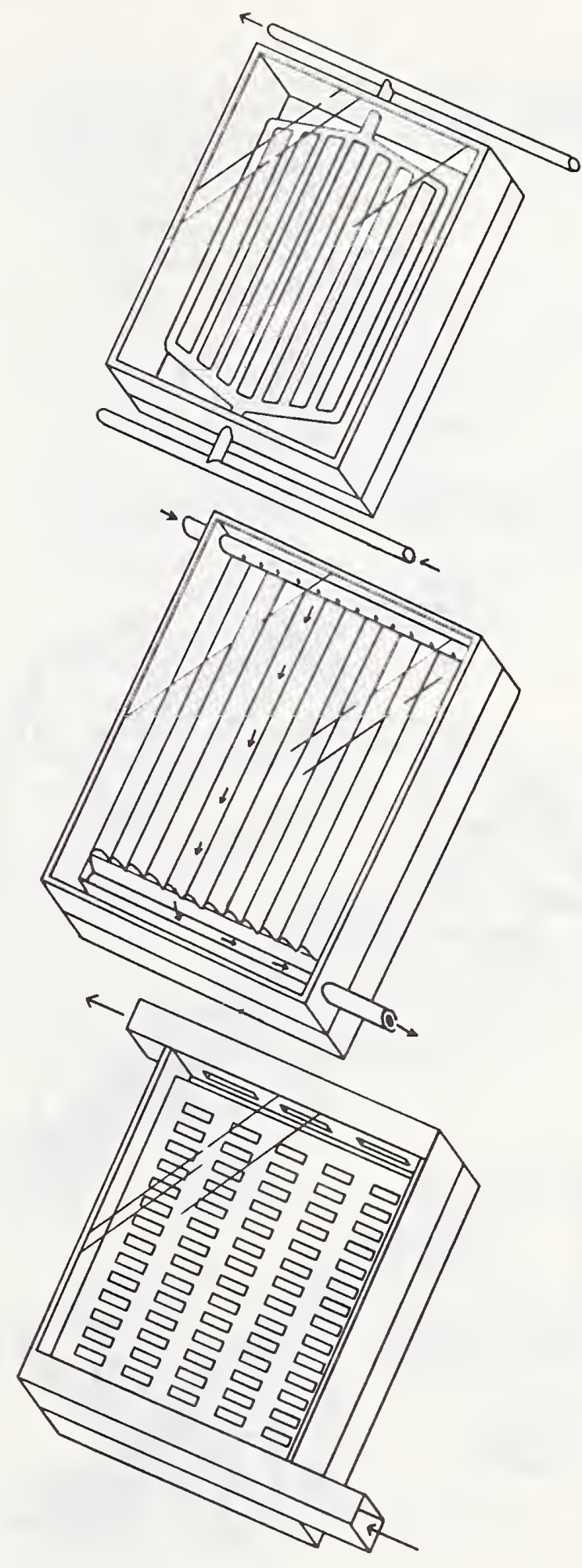

C -21 

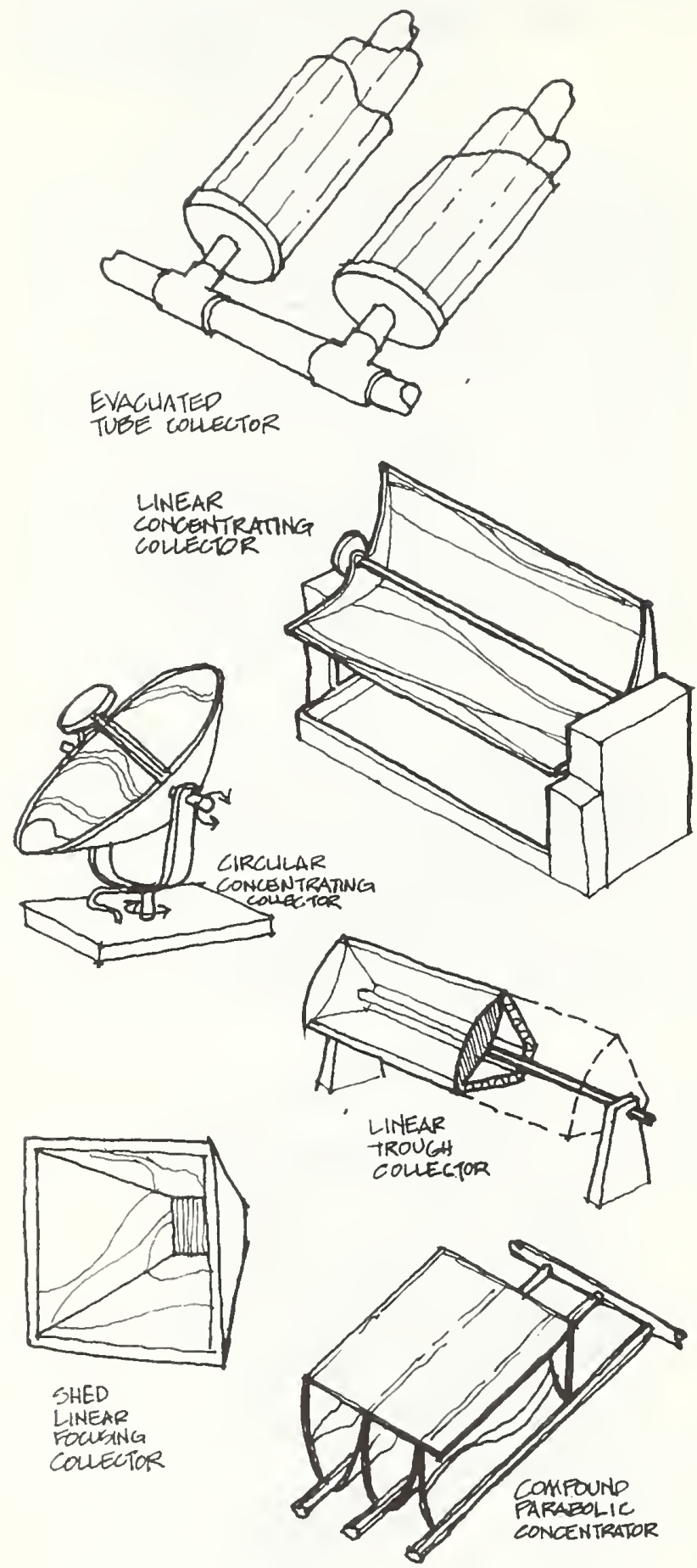

EVACUATED TUBE COLLECTOR These collectors employ a vacuum tube containing an absorber. The vacuum serves to reduce convective heat losses allowing higher working temperatures and efficiencies. The absorber consists of metal or glass tubes or tubes with fins where the captured thermal energy is transferred to the heat transfer medium which may be a liquid or gas. The basic modes of heat transfer within the collector are analogous to those illustrated for flat-plate collection. No insulation is required for the tubular collector itself, however, the manifold and connecting piping require insulation similar to flat-plate units. Both direct and diffuse radiation can be collected.

CONCENTRATING COLLECTORS Concentrating collectors (also known as focussing collectors) employ curved and multiple point target reflectors or lenses to increase radiation on a small area. The area where solar radiation is absorbed can be a point--the focal point--or a line-the focal axis.

A concentrating collector consists of three basic components: the reflector and/or lense, the absorber, and the housing which maintains alignment and contains insulation for the absorber and connecting piping. Often a mechanism is employed to allow the collector/reflector or the absorber to follow or track the sun's movement across the sky. Maintenance of the reflective surface, particularly in dusty or air polluted areas, and of the tracking mechanism are important considerations for collector performance.

Concentrating collectors are best suited for areas with clear skies where most solar radiation is direct. Their inability to function on cloudy or overcast days is a disadvantage when compared to flat-plate collectors. However, the high temperatures generated may make concentrating collectors particularly viable with solar cooling systems.

As with flat-plate collectors, numerous configurations and arrangements of concentrating collectors have been developed including linear and circular concentrators, lens focussing collectors, collectors with directional and nondirectional focussing and tube concentrators. A number of concentrating configurations are shown to the left. 
FLAT-PLATE COLLECTOR MOUNTING Flatplate collectors are generally mounted on the ground or on a building in a fixed position at prescribed angles of solar exposure--which vary

RACK MOUNTING Collectors can be mounted at the prescribed angle on a structural frame located on the site or attached to the building. The structural connection between the collector and the frame and the frame and the building or site must be adequate to resist any loads such as wind that may impact on it.

STAND-OFF MOUNTING Elements that separate the collector from the finished roof surface are known as stand-offs. They allow air and rain water to circulate under the collector thus minimizing problems of mildew and leakage. The stand-offs must have adequate structural properties to assure the maintenance of a fixed collector mounting. Stand-offs are often used to support collectors at an angle other than that of the roof to optimize collector tilt.

DIRECT MOUNTING Collectors can be mounted directly on the roof surface. Generally, the collectors are placed on a water-proof membrane on top of the roof sheathing. The finished roof surface together with the necessary collector structural attachments and flashing are built up around the collector. A weatherproof seal between the collector and the roof must be achieved or leakage, mildew, and rotting may occur.

INTEGRAL MOUNTING Integral mounting places the collector within spaces between structural roof members. The collector is attached to and supported by the structural framing members. The top of the collector is located almost flush with the finished roof surface. Weather tightness is again crucial to avoid problems of water damage and mildew. This method of mounting is frequently used for on-site built collectors. according to the geographic location, collector type, and the use of the absorbed heat. Flat-plate collectors may be mounted in four general ways as illustrated below.
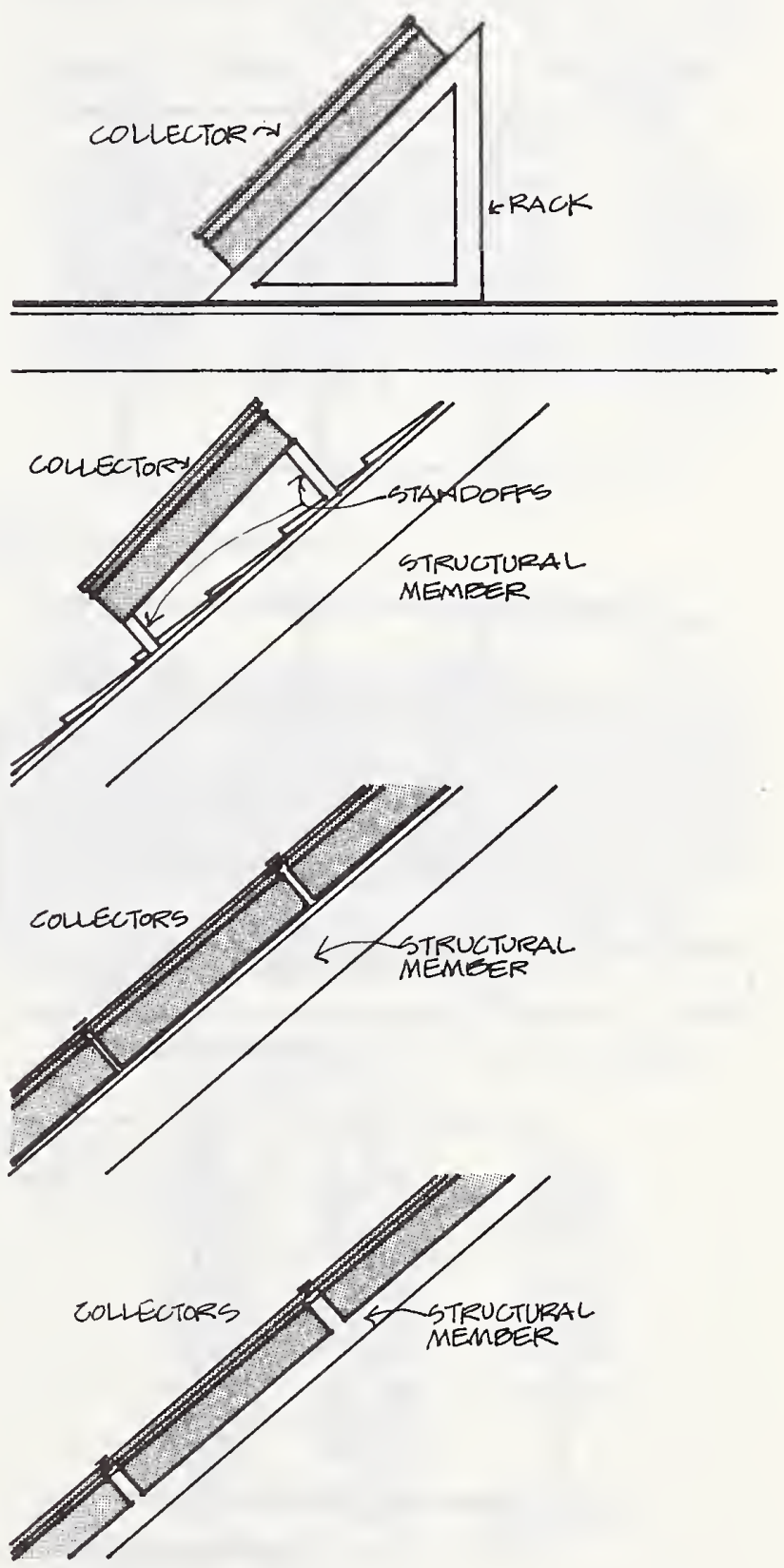
COLLECTOR GANGING

A building's solar collector is generally composed of individual collection units or panels arranged to operate as a single system. The arrangement and relationship of one collector unit to another is extremely important for effective solar collection and efficient system operation. Three basic multiple collector arrangeinents are shown below.
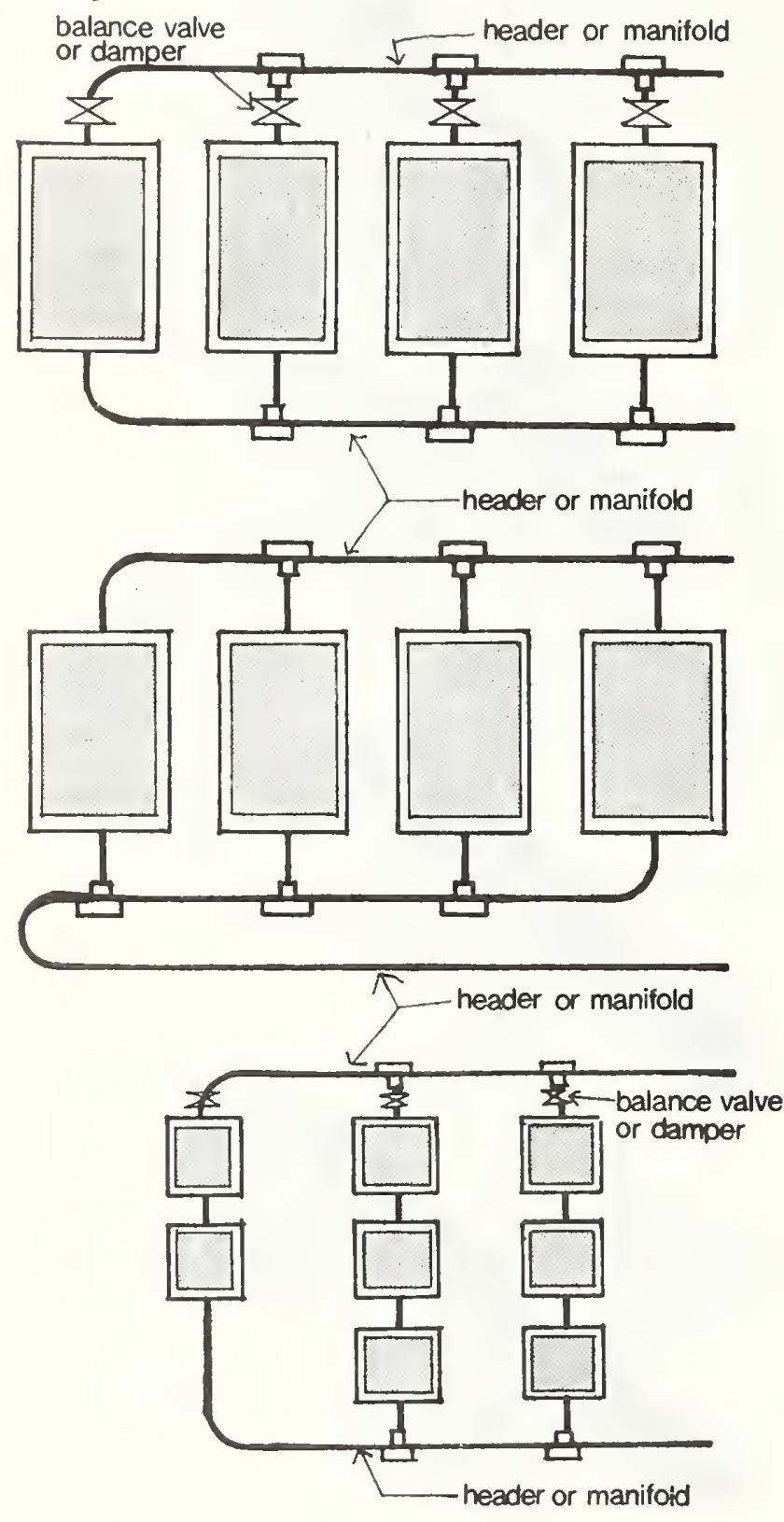

COLLECTOR GANGING: PARALLEL FLOW DIRECT RETURN A direct return distribution circuit circulates the transfer medium from the top of the collector to a return header or manifold at the bottom. This arrangement may cause severe operating problems by allowing wide temperature variations from collector to collector due to flow imbalance. Although the pressure drops across each collector will be essentially the same for the same flow rate, high pressure drops occurring along the supply/return header or manifold will cause flow imbalance, especially if no flow balance device is used. This problem can be reduced by sizing the header for minimum pressure drop, although this may be prohibitive because of economic and space limitations. Even manual balancing valves may be difficult to adjust and automatic devices or orifices may be required for efficient system performance. Provisions must also be made to measure the pressure drop in order to adjust the flow rate to prevent collectors closer to the circulating pump from exceeding design flow rates and those farther away from receiving less.

\section{COLLECTOR GANGING: PARALLEL FLOW -} REVERSE RETURN Reverse return piping systems are considered preferable to direct return for their ease of balancing. Because the total length of supply piping and return piping serving each collector is the same and the pressure drop across each collector is equal, the pressure drops are theoretically equal. The major advantage of reverse return piping is that balancing is seldom required since flow through each collector is theoretically the same. Provisions for flow balancing may still be required in some reverse return piping systems depending on overall size of the collector array and type of collector.

COLLECTOR GANGING: SERIES FLOW Series flow is often used in large planar arrays to reduce the amount of piping required by allowing several collector assemblies to be served by the same supply and return headers or manifolds. Series flow can also be employed to increase the output temperature of the collector system or to allow the placement of collectors on non-rectangular surfaces. Either direct or reverse return distribution circuits can be employed, but unless each collector branch has the same number of collectors, the reverse return system has no advantage over direct return--each would require flow balancing for this situation. 
HEAT EXCHANGERS A heat exchanger is a device for transferring thermal energy from one fluid to another. In some solar systems, a heat exchanger may be required between the transfer medium circulated through the collector and the

SHELL AND TUBE This type of heat exchanger is used to transfer heat from a transfer medium containing antifreeze to water used for storage. Shell and tube heat exchangers consist of an outer casing or shell surrounding a bundle of tubes. The water to be heated is normally circulated in the tubes and the hot liquid is circulated in the shell. Tubes are usually metal such as steel, copper or stainless steel and the shell is often steel for solar applications. A single shell and tube heat exchanger cannot be used for heat transfer from the toxic liquid to potable water because double separation is not provided and the toxic liquid may enter the potable water supply.

SHELL AND DOUBLE TUBE This type of heat exchanger is similar to the previous one except that a secondary tube is located in the shell. The heated liquid circulates between the shell and the second tube. An intermediary non-toxic heat transfer liquid is located between the two tube circuits. As the heated liquid circulates through the tube, the intermediary is heated which in turn heats the potable water supply. The heat exchanger can be equipped with a sight glass to detect leaks - toxic liquid often contains a dye-or to increase the liquid level in the intermediary chamber.

DOUBLE WALL Another method of providing a double separation between the transfer medium and the potable water supply consists of tubing or a plate coil wrapped around and bonded to a tank. The potable water is heated as it circulates through the coil. When this method is used the tubing or coil must be adequately insulated to reduce heat losses. storage medium or between storage and the distribution component. Three types of heat exchangers that are most commonly used for these purposes are illustrated below.
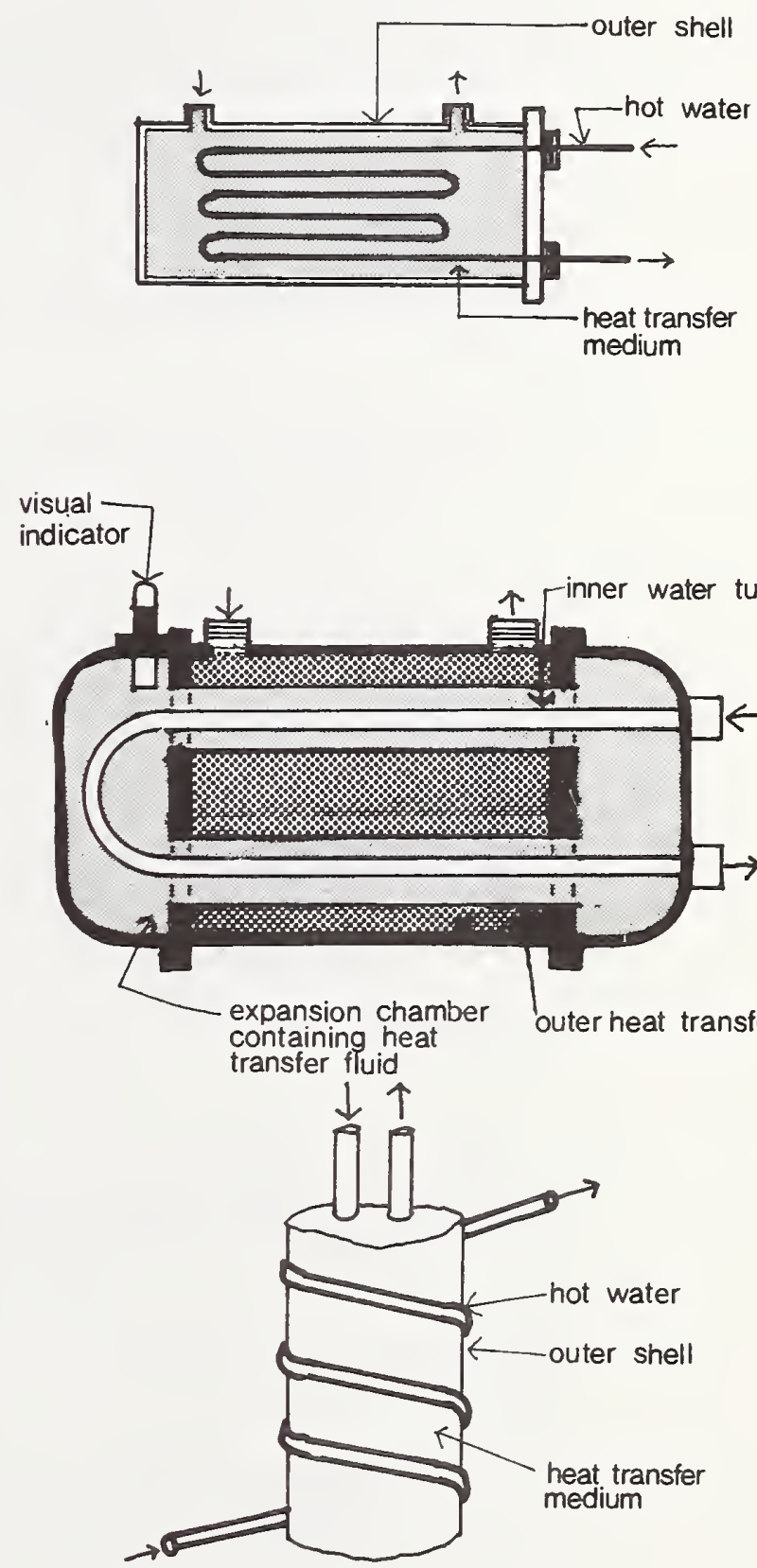



\section{DEFINITIONS}

General: Abbreviations, terms, phrases, and words and their derivatives used in these Intermediate Standards for Solar Application shall have the meanings given in this Appendix. The terms defined herein apply only for The Department of Housing and Urban Development (HUD) purposes and may differ in some respects from definitions prepared for building codes or other purposes. Wherever possible, the meaning in common use in the residential construction field is used.

Active Solar System: An assembly of collectors, thermal storage device(s), and transfer media which converts solar energy into thermal energy, and in which energy in addition to solar is used to accomplish the transfer of thermal energy.

Air Gap: An air gap in a potable water distribution system is the unobstructed vertical distance through the free atmosphere between the lowest opening from any pipe or faucet supplying water to a tank, plumbing fixture or other device and the flood level rim of the receptacle. (NSPC)*

Auxiliary energy subsystem: Equipment utilizing conventional energy sources both to supplement the output provided by the solar energy system as required by the design conditions, and to provide full energy backup requirements during periods when the solar $\mathrm{H}$, or DHW systems are inoperable.

Backflow: The unintentional reversal of flow in a potable water distribution system which may result in the transport of foreign materials or substances into the other branches of the distribution system. (NBS)

Backflow Preventer: A device or means to prevent backflow.

Back Pressure: Pressure created by any means in the water distribution system on the premises, which by being in excess of the pressure in the water supply main could cause backflow. (NBS)

Back-Siphonage: The backflow of possibly contaminated water into the potable water supply system as a result of the pressure in the potable water system becoming unintentionally less than the atmospheric pressure in the plumbing fixtures, pools, tanks or vats that may be connected to the potable water distribution piping. (NBS)

Biochemical Oxygen Demand: The quantity of oxygen used in the biochemical oxidation of organic matter in a specified time, at a specified temperature, and under specified conditions.

Chemical Compatibility: The ability of materials and components in contact with each other to resist mutual chemical degradation, such as that caused by electrolytic action.

* Abbreviations in parentheses indicate the sources of the definitions used here. (See Appendices $\mathrm{E}$ and F) 
Collectors, combined: The collector and storage are constructed and operated such that they functionally perform as one unit and the thermal performance of the individual components cannot be meaningfully measured.

Collectors, component: Collector that is not structurally integrated with the storage or bullding. The collector performance can be thermally characterized as an individual component with an active heat transfer fluid.

Collectors, integrated: The collector is constructed and operated as part of the building structure and heating system. The thermal performance is considered a part of the building heating load and solar energy provides a significant fraction of the building heat requirements.

Components: The smallest identifiable elements of a solar heating subsystem, such as valves, piping, controls, and containers, etc.

Contaminants: Materials (solids or liquids or gases) which when added unintentionally (or intentionally) to the potable water supply and cause it to be unfit for human or animal consumption. (ASSE 1013)

Creep: A time-dependent deformation resulting from sustained loads which can be influenced by local environmental factors such as, thermal atmosphere and/or cycling, and solar radiation.

Cross Connection: Any physical connection or arrangement between two otherwise separate piping systems, one of which contains potable water and the other either water of unknown or questionable safety or steam, gas, chemicals or other substances whereby there may be a flow from one system to the other, the direction of flow depending on the pressure differential between the two systems.

Design life: The period of time during which an $\mathrm{H}$, and DHW system is expected to perform its intended function without requiring major maintenance or replacement.

DHW: Domestic hot water system.

DWV: Drain, Waste, Vent

Energy transport subsystem: A portion of the $\mathrm{H}$, and DHW systems which transports energy throughout the system.

Failure (structura1): Faflure of a structure or any structural element is defined as one of the following

(a) Sudden, locally-increased curvature, major spalling, or structural collapse.

(b) The inability of the structure to resist a further increase in load.

(c) Structural deflections under design loads that cause significant thermal performance degradation of the component or subsystem.

Flow Condition: The condition obtained when the heat transfer fluid is flowing through the collector array under normal operating conditions. 
Forced-Circulation Air Coil: A coil for use in an air stream whose circulation is caused by a difference in pressure produced by a fan or blower.

Forced-Circulation Air Heating Coil: A heat exchanger, with or without extended surfaces, through which either hot water or steam is circulated for the purposes of sensible heating of a forced-circulation air stream.

H: Heating system.

Heat Transfer Medium: A medium, either fluid or air, which is used to transport thermal energy.

Laminated glass: Consists of two or more sheets of glass held together by an intervening layer or layers of plastic material.

Lethal Concentration (LC): Any concentration of a substance in air to which man has been reported to have been exposed for any given time that has been reported to have caused death in man or any concentration to which animals have been exposed for eight hours or less and that has been reported to have caused death in animals.

Lethal Dose (LD): Any dose of a substance introduced by any route other than inhalation over any given period of time and reported to have caused death in man or a single dose introduced in one or more divided portions and reported to have caused death in animals.

Load factors: Multipliers by which design loads are increased in order to obtain the loads to be used in ultimate strength design of structural elements.

Maximum "flow" temperature: The maximum temperature that will be obtained in a component when the heat transfer medium is flowing through the system.

Maximum "no-flow" temperature: The maximum temperature that will be obtained in a component when the heat transfer medium is not flowing through the system.

Maximum service temperature: The maximum temperature to which a component will be exposed in actual service, either with or without the flow of heat transfer medium.

\section{MPS 4900.1: FHA "Minimum Property Standards For One And Two Family Dwe11ings".}

MPS 4910.1: FHA "Minimum Property Standards For Multifamily Housing".

No-Flow Condition: The condition obtained when the heat transfer fluid is not flowing through the collector array due to shut-down or malfunction.

Outgassing: The emission of gases by materials and components, usually during exposure to elevated temperature, or reduced pressure.

Passive Solar System: An assembly of collectors, thermal storage device(s), and transfer medla which converts solar energy into thermal energy and in which no energy in addition to solar is used to accomplish the transfer of thermal energy. The prime element is a passive solar system is usually some form of thermal capacitance. 
Physical Compatibility: The ability of materials and components in contact with each other to resist degradation such as that caused by differential coefficients of thermal expansion.

pphm: Parts per hundred million

Safety glass: Glazing materials predominantly inorganic in character, which meets the appropriate requirements of this standard and includes laminated glass, tempered glass, and wired glass.

Safety glazing materials: Glazing materials so constructed, treated or combined with other materials as to minimize the likelihood of cutting and plercing injuries resulting from human contact with these glazing materials.

Service loads: Loads which are expected during the service life of a structure and upon which the design of the structure is based.

Solar Building: A building which utilizes solar energy by means of an active or passive solar system.

Solar degradation: The process by which exposure to sunlight deteriorates the properties of materials and components.

Solar energy: The photon energy originating from the sun's radiation in the wavelength region from 0.3 to 2.4 micrometers.

Solar Heating System: The complete assembly of subsystems and components necessary to convert solar energy into thermal energy for heating purposes, in combination with auxiliary energy when required.

Solar Time: The hours of the day as reckoned by the apparent position of the sun. Solar noon is that instant on any day at which the sun reaches its maximum altitude for that day.

Storage subsystem: The assembly used for storing thermal energy so that it can be used when required.

Subsystem: One of several major elements of a solar heating system, such as collectors, thermal storage device(s), heaters, etc.

System: The complete assembly necessary to supply heat to the dwelling in which it is installed.

Sustained load: A load that is considered to be applied to the structure over a projected period of time

Thermal Energy: Heat possessed by a material resulting from the motion of molecules and which can do work.

Toxic fluids: Gases or liquids which are poisonous, irritating and/or suffocating, as classified in the Hazardous Substances Act, Part 191, Chapter I. Title 21.

U1timate strength design: A method of proportioning structures or members for fallure at a specified multiple of working loads, and assuming nonlinear distribution of flexural stresses.

UV: Ultra-violet 
Water Hammer: The term used to identify the hammering noises and severe shocks that may occur in a pressurized water supply system when flow is halted abruptly by the rapid closure of a valve or faucet (NBS)

Water hammer arrester: A manufactured device, other than an air chamber, containing a permanently sealed cushion of gas or air, designed to provide protection against excessive shock pressure without maintenance.

Working stress design: A method of proportioning structures or members for prescribed working loads at stresses well below the ultimate, and assuming linear distribution of flexural stresses. 

AASHO H20-44 Standard Specification for Highway Bridges

ANSI A13.1 (1956) Scheme for the Identification of Piping Systems

ANSI A58.1 Building Code Requirements for Minimum Design Loads in Buildings and Other Structures

ANSI A112.1.1 (1971) Performance Requirements, Methods of Test for (ASSE 1001-1970) Pipe-Applied Atmospheric-Type Anti-Siphon Vacuum Breakers

ANSI A112.1.2 Air Gaps in Plumbing Systems (Reaffirmation and redesignation of $\mathrm{A} 40.4-1942$ )

ANSI B9.1 (1971) Safety Code for Mechanical Refrigeration

ANSI B15.1 (1972) Safety Standard for Mechanical Power Transmission Apparatus

ANSI B16.18 (1972) Cast Bronze Solder Joint Pressure Fittings

ANSI B31.1, Section I (1973) Power Piping

ANSI B96.1 (1973) Specification for Welded Aluminum-Alloy Field-Erected Storage Tanks

ANSI B124.1 (1971) Safety Standard for Air Filter Units (UL 900-Apri1 1971)

ANSI B137.1 (1971) Steel Underground Tanks for Flammable and Combustible Liquids (UL 58-July 1971)

ANSI S2.8 (1972) Guide for Describing the Characteristics of Resilient Mountings

ANSI Z95.1 (1974) Oil Burning Equipment (NFPA 31-1972)

ANSI 297.1 (1972) Performance Specifications and Methods of Test for Safety Glazing Material Used in Buildings

ARI Standard 260 (1967) Standard for Application, Installation, and Servicing of Unitary Systems

ARI Standard 410 Forced Circulation Air-Cooling and Air-Heating Coils

ARI Standard 610 Standard for Central Humidifiers (1974)

ARI Standard 620 Standard for Self-Contained Humidifiers (1974)

ARI Standard 760 Standard for Solenoid Valves for Use with Volatile Refrigerants and Water, 1975

ASHRAE 55-74 (1974) Thermal Environmental Conditions for Human Occupancy

ASHRAE 90-75 (1975) Energy Conservation in New Building Design 
ASHRAE Handbook of Fundamentals, Chapter 14

ASME SA-53, Section VIII Boller and Pressure Vessel Code

ASSE 1011 Performance Requirements for Hose Connection Vacuum Breakers

ASSE 1012 Performance Requirements for Backflow Preventers with Intermediate Atomospheric Vent

ASSE 1013 Performance Requirements for Reduced Pressure Principle Back Pressure Backflow Preventers

ASSE 1015 Performance Requirements for Double Check Valve Type Back Pressure Backflow Preventers

ASSE 1020 Performance Requirements for Vacuum Breakers, Ant1-Siphon, Pressure Type

ASTM A53-75 Specification for Welded and Seamless Stee1 Pipe

ASTM 739-73, Section 10.4 (1973) Flame Resistance Permanency

ASTM D660-44 (1970) Evaluating Degree of Resistance to Checking of Exterior Paints

ASTM D661-44 (1975) Evaluating Degree of Resistance to Cracking of Exterior Paints

ASTM D714-56 (1974) Evaluating Degree of Blistering of Paints

ASTM D750-68 (1974) Recommended Practice for Operating Light-and-Weather Exposure Apparatus (Carbon-Arc Type) for Artificial Weather Testing of Rubber Compounds

ASTM D772-47 (1975) Evaluating Degree of Flaking (Scaling) of Exterlor Paint

ASTM D822-60 (1973) Recommended Practice for Operating Light-and-Water-Exposure Apparatus (Carbon-Arc Type) for Testing Paint, Varnish, Lacquer, and Related Products

ASTM D1081-60 (1974) Test for Evaluating Pressure Sealing Properties of Rubber and Rubber-Like Materials

ASTM D1149-64 (1970) Test for Accelerated Ozone Cracking of Vulcanized Rubber ASTM D1308-57 (1973) Test for Effect of Household Chemical on Clear and Pigmented Organic Finishes

ASTM D1384-70 Corrosion Test for Engine Antifreeze in Glassware

ASTM D2247-68 (1973) Testing Coated Metal Specimens at 100 Percent Relative Humidity

ASTM D2570-73 Simulated Service Corrosion Testing of Engine Antifreeze

ASTM D2776-72 Tests for Corrosivity of Water in the Absence of Heat Transfer (Electrical Methods)

ASTM E72-74a Conducting Strength Tests of Panels for Building Construction ASTM E84-70 (1970) Surface Burning Characteristics of Building Materials 
ASTM E 108-75 (1975) Mothods of Fire Tests of Roof Coverings (NFPA 256-1970)

ASTM E154-68 Testing Materials for Use as Vapor Barriers Under Concrete Slabs and as Ground Cover in Crawl Spaces

ASTM E424-71 Test for Solar Energy Transmittance and Reflectance (Terrestrial) of Sheet Materials

ASTM F82-67 (1973) Recommended Practice for Fast Quality Check on Immersion for Nonmetallic Gasket Materials

AWWA C506-69 Backflow Prevention Devices-Reduced Pressure Principle and Double Check Valve Types

AWWA D100 (1967) Steel Tanks - Standpipes, Reservoirs and Elevated Tanks for Water Storage

AWWA D102 Painting and Repainting Steel Tanks, Standpipes, Reservoirs, and Elevated Tanks for Water Storage

BMC, Section M302 (1975) Specific Requirements for the Materials, Design and Fabrication of Ductwork.

CPSC 16 CFR, Part 1201 (1976) Architectural Glazing (Code of Federal Regulation)

Federal Hazardous Substances Labeling Act - Public Law 86-613, 12 July 1960

FCCCHR, Chapter 10 Manual of Cross-Connection Control (Foundation for Cross Connection Control Research)

FS-DD-G-451C (1972) Glass, Plate, Sheet, Figured (Float, Flat, for Glazing, Corrugated, Mirrors and Other Uses)

FS-TT-C-00598C(1) Caulking Compound, 0il and Resin Base Type (For Bullding Construction) (18 March 1971)

FS-TT-S-001543A Sealing Compound: Silicone Rubber Base (For Caulking, Sealing, and Glazing in Buildings and Other Structures) (9 June 1971)

FS-TT-S-001657 Sealing Compound: Single Component, Butyl Rubber Based, Solvent Release Type (for Buildings and Other Types of Construction) 8 October 1970

FS-TT-S-00227E(3) Sealing Compound Elastomeric Type, Multi-compound (For Caulking, Sealing and Glazing in Buildings and Other Structures)

9 October 1970

FS-TT-S-00230C(2) Sealing Compound: Elastomeric Type, Single Component (For Caulking, Sealing and Glazing in Buildings and Other Structures) 9 October 1970

FS-TT-P-95A(3) Paint, Rubber: For Swimming Pools and Other Concrete and Masonry Surfaces, 27 May 1966

FS-WW-U-516B Unions, Brass or Bronze, Threaded Pipe Connections and SolderJoint Tube Connections

FS-WW-U-531D Unions, Pipe, Steel or Malleable Iron; Threaded Connection, $150 \mathrm{lbs}$. and $250 \mathrm{lbs}$.

FS-WW-V-35B Ball Valve 
IAPMO PS 31-74 Specification for backflow Prevention Devices

IAPMO PSI Prefabircated Concrete Septic Tanks (1966)

NACE TM-01-69 (1972) Laboratory Corrosion Testing of Metals for the Process Industries

NACE TM-02-70 Method of Conducting Controlled Velocity Laboratory Corrosion Tests

NACE TM-01-71 Autoclave Corrosion Testing of Metals in High Temperature Water

NACE TM-02-74 Dymamic Corrosion Testing of Metals in High Temperature

National Primary Drinking Water Regulation - Federal Register, 24 December 1975

NEMA MG1-18.615 Hydraulic Institute Standards for Centrifugal, Rotary and Reciprocating Pumps

NFPA 26 (1958) Supervision of Valves

NFPA 30 (1973) Flammable and Combustible Liquids Code

NFPA 31 Standard for the Installation of oil Burning Equipment

NFPA 54 (1974) National Fuel Gas Code

NFPA 70, Section 240.24 Attachment Plugs

NFPA 72A (1974) Local Protective Signaling Systems

NFPA 89M-71 (1971) Heat Producing Appliance Clearances

NFPA 90B Standard for the Installation of Warm Air Heating and Air Conditioning Systems

NFPA 211 Standard for Chimneys, Fireplaces, and Vents

NFPA 321 (1973) Classification of Flammable Liquids

NFO 8 National Forest Products Association, The Wood Tank

NRCA - A Manual of Roofing Practice 1970 (71)

NSPC, Section 2.13 Ratproofing

MIL-T-52777 21 February 1974 Military Specifications for Tanks:

Storage, Underground, Glass Fiber Reinforced Plastic

MSS SP-73 Silver Brazing Joints for Cast and Wrought Solder Joint Fittings

SAE J447e(1964) Prevention of Corrosion of Metals

SAE J20e(1974) Coolant System Hoses

Threshold Limit Values for Chemical Substances and Physical Agents in the Workroom Environment with Intended Changes, 1975 - American Conference of Governmental Industrial Hygienists

UL 58 (1973) Standard for Steel Underground Tanks for Flammable and Combustible Liquids (ANSI B137.1-1971) 
UL 174 (1972) Standard for Household Electric Storage-Tank Water Heaters (ANSI C33.87-1972)

UL 181-74, Section 10 Factory-Made Air Duct Materials and Air Duct Connectors

UL 296 (1974) Standard for Oil Burners

UL 573 (1972) Standard for Electric Space-Heating Equipment (ANSI C33.12-1972)

UL 726 (1973) Standard for Oil-Fired Boiler Assemblies

UL 727 (1973) Standard for Oil-Fired Central Furnaces (ANSI Z96.1-1973)

UL 730 (1974) Standard for Oil-Fired Wall Furnaces

UL 732 (1974) Standard for Oil-Fired Water Heaters

UL 900 (1971) Safety Standard for Air Filter Units (ANSI B124.1-1971)

UL 1042 (1973) Standard for Electric Baseboard Heating Equipment (ANSI C33.951973)

Water Quality Criteria 1972, National Academy of Science and National Academy of Engineering 



\author{
ABBREVIATIONS \\ (Code Groups, Associations, and Gov't. Agencies)
}

\begin{tabular}{|c|c|}
\hline AASHO & American Association of State Highway Officials \\
\hline AGA & American Gas Association \\
\hline AMCA & Alr Moving and Conditioning Association, Inc. \\
\hline ANSI & American National Standards Institute \\
\hline ARI & Alr-Conditioning and Refrigeration Institute \\
\hline ASHRAE & $\begin{array}{l}\text { American Society of Heating, Refrigerating, and Air } \\
\text { Conditioning Engineers }\end{array}$ \\
\hline ASME & American Society of Mechanical Engineers \\
\hline ASSE & American Society of Sanitary Engineering \\
\hline ASTM & American Society for Testing and Materials \\
\hline AWWA & American Water Works Association, Inc. \\
\hline BMC & Basic Mechanical Code (Division of BOCA) \\
\hline BOCA & Building Officials and Code Administrators International, Inc. \\
\hline CISPI & Cast Iron Soil Pipe Institute \\
\hline CPSC & Consumer Product Safety Commission \\
\hline CS & Commercial Standard \\
\hline FCCCHR & Foundation for Cross-Connection Control and Hydraulic Research \\
\hline FHSLA-1960 & $\begin{array}{l}\text { Federal Hazardous Substances Labeling Act, Public Law 86-613 } \\
\text { July } 12,1960\end{array}$ \\
\hline FS & Federal Specifications \\
\hline HUD & Department of Housing and Urban Development \\
\hline HVI & Home Ventilating Institute \\
\hline IAPMO & International Association of Plumbing and Mechanical Officials \\
\hline IBR & Institute of Boiler and Radiator Manufacturers \\
\hline ICBO & International Conference of Building Officials \\
\hline IEC & International Electrotechnical Commission \\
\hline ISO & International Standards Organization \\
\hline MCA & Mechanical Contractor's Association \\
\hline MSS & $\begin{array}{l}\text { Manufacturer's Standardization Society of the Valve and } \\
\text { Fitting Industry }\end{array}$ \\
\hline NACE & National Association of Corrosion Engineers \\
\hline NAS/NRC & National Academy of Science/National Research Council \\
\hline NBS & The National Bureau of Standards \\
\hline NEMA & National Electrical Manufacturer's Association \\
\hline NESCA & National Environmental Systems Contractors Association \\
\hline NFO & National Forest Products Association \\
\hline NFPA & National Fire Protection Association \\
\hline NPC & Nationa1 Plumbing Code \\
\hline NRCA & National Roofing Contractor's Association \\
\hline NSF & National Sanitation Foundation Testing Laboratory, Inc. \\
\hline NSPC & National Standard Plumbing Code \\
\hline PL & Public Law \\
\hline SAE & Society for Automotive Engineers \\
\hline SBI & Steel Boiler Institute \\
\hline SPMA & Sump Pump Manufacturer's Association \\
\hline TEMA & Tubular Exchanger Manufacture's Association, Inc. \\
\hline UBC & Uniform Building Code \\
\hline UPC & Uniform Plumbing Code \\
\hline UMC & Uniform Mechanical Code \\
\hline UL & Underwriter's Laboratories, Inc. \\
\hline
\end{tabular}



NBS.114A (REV. 7.73)

\begin{tabular}{|c|c|c|c|}
\hline $\begin{array}{l}\text { U.S. DEPT. OF COMM. } \\
\text { BIBLIOGRAPHIC DATA } \\
\text { SHEET }\end{array}$ & $\begin{array}{l}\text { 1. PUIBLICATION OR REPORT NO. } \\
\text { NBSIR 76-1059 }\end{array}$ & $\begin{array}{l}\text { 2. Gov't Accession } \\
\text { No. }\end{array}$ & 3. Recipient's Accession No. \\
\hline \multicolumn{3}{|l|}{ 4. TITI.E: AND SUBTITLE } & 5. Publication Date \\
\hline \multirow{2}{*}{\multicolumn{3}{|c|}{$\begin{array}{l}\text { Intermediate Minimum Property Standards for Solar Heating } \\
\text { and Domestic Hot Water Systems }\end{array}$}} & April 1976 \\
\hline & & & $\begin{array}{l}\text { 6. Performing Organization Code } \\
\quad 460.03\end{array}$ \\
\hline \multicolumn{3}{|c|}{$\begin{array}{l}\text { 7. AUTHOR(S) } \\
\text { Solar Energy Program Team, Center for Building Technology }\end{array}$} & 8. Performing Organ. Report No. \\
\hline \multirow{2}{*}{\multicolumn{3}{|c|}{$\begin{array}{l}\text { 9. PERFORMING ORGANIZATION NAME AND ADDRESS } \\
\text { NATIONAL BUREAU OF STANDARDS } \\
\text { DEPARTMENT OF COMMERCE } \\
\text { WASHINGTON, D.C. } 20234\end{array}$}} & $\begin{array}{l}\text { 10. Project/Task/Work Unit No. } \\
4606500\end{array}$ \\
\hline & & & $\begin{array}{r}\text { 11. Contract/Grant No. } \\
\text { IAA-H-38-76 }\end{array}$ \\
\hline \multirow{2}{*}{\multicolumn{3}{|c|}{$\begin{array}{l}\text { 12. Sponsoring Organization Name and Complete Address (Street, City, State, ZIP) } \\
\text { Division of Energy, Building Technology \& Standards } \\
\text { Office of Policy Development and Research } \\
\text { Department of Housing and Urban Development } \\
\text { Washington, D.C. } 20410\end{array}$}} & $\begin{array}{l}\text { 13. Type of Report \& Period } \\
\text { Covered } \\
\text { Interim }\end{array}$ \\
\hline & & & 14. Sponsoring Agency Code \\
\hline
\end{tabular}

16. ABSTRACT (A 200-word or less factual summary of most significant information. If document includes a significant bibliography or literature survey, mention it here.)

This report presents standards for the use of solar heating and domestic hot water systems in residential applications. The standards have been developed for application in numerous housing programs of the Department of Housing and Urban Development and are a companion document to be used in conjunction with the HUD "Minimum Property Standards for One and Two Family Dwellings", 4900 and "Minimum Property Standards for Multifamily Housing", 4910. To the greatest extent possible, these standards are based on current state-of-the-art practice and on nationally recognized standards including the $M_{\infty}$ and - $^{-}$- Hi'l "interim Performance Criteria for Solar Heating and Combined Heatingivoling Systems and Dwellings".

17. KEY WORDS (six to twelve entries; alphabetical order; capitalize only the first letter of the first key word unless a proper name; separated by semicolons)

Solar buildings; solar collectors; solar domestic hot water systems; solar heating; standards; thermal storage;

\begin{tabular}{|l|c|}
\hline $\begin{array}{l}\text { 19. SECURITY CLASS } \\
\text { (THIS REPURT) }\end{array}$ & 171 \\
UNCL ASSIFIED & NO. OF PAGES \\
\hline $\begin{array}{l}\text { 20. SECURITY CLASS } \\
\text { (THIS PAGE) } \\
\text { UNCI.ASSIFIEN }\end{array}$ & 22. Price \\
\hline
\end{tabular}

$\square$ Order From National Technical Information Service (NTIS) Springfield, Virginia 22151 
